ROSALIA EDITH CAYA CARHUANINA

MODELAGEM DE UM COMPONENTE ADAPTATIVO PARA O GERENCIAMENTO DOS RECURSOS DE ACESSIBILIDADE DE UM SISTEMA COMPUTACIONAL DE USO GERAL 
ROSALIA EDITH CAYA CARHUANINA

MODELAGEM DE UM COMPONENTE ADAPTATIVO PARA O GERENCIAMENTO DOS RECURSOS DE ACESSIBILIDADE DE UM SISTEMA COMPUTACIONAL DE USO GERAL

Dissertação apresentada à Escola Politécnica da Universidade de São Paulo para obtenção do título de mestre em Ciências 
ROSALIA EDITH CAYA CARHUANINA

\section{MODELAGEM DE UM COMPONENTE ADAPTATIVO PARA O GERENCIAMENTO DOS RECURSOS DE ACESSIBILIDADE DE UM SISTEMA COMPUTACIONAL DE USO GERAL}

Dissertação apresentada à Escola Politécnica da Universidade de São Paulo para obtenção do título de mestre em Ciências

Área de concentração:

Engenharia de Computação

Orientador:

João José Neto

São Paulo 


\section{Catalogação-na-publicação}

\section{Caya Carhuanina, Rosalia Edith}

Modelagem de um componente adaptativo para o gerenciamento dos recursos de acessibilidade de um sistema computacional de uso geral / R. Caya -- São Paulo, 2016. $178 \mathrm{p}$.

Dissertação (Mestrado) - Escola Politécnica da Universidade de São Paulo. Departamento de Engenharia de Computação e Sistemas Digitais.

1. Acessibilidade 2. Interação Hómem-Máquina 3.

Middleware 4. Tecnologia Adaptativa 5. Recursos do Sistema I. Universidade de São Paulo. Escola Politécnica. Departamento de Engenharia de Computação e Sistemas Digitais II. t. 


\section{DEDICATÓRIA}

Dedico este trabalho aos meus anjos, meus

pais. 


\section{AGRADECIMENTOS}

Graças a Deus que me criou, que me deu tudo o que tenho, me fez tudo o que eu sou, porque vai comigo a cada passo do caminho, me protegendo, me guiando, me amando.

Aos meus pais porque não só me criaram com amor, mas porque com esse amor me deram asas para voar a novos horizontes com a certeza de que eles estão comigo onde seja que eu for, porque eles são parte de mim, e eu sou parte deles. Eles me deram coragem e força, amor e compreensão, céu e solo. Los amo.

Ao Professor João José Neto, por toda a orientação que me deu. Agradeço infinitamente cada um dos esclarecimentos, sugestões, conselhos e concertos que me deu na elaboração deste projeto, a sua contribuição foi certamente maiúscula no escopo acadêmico. No entanto, não tenho como agradecer tudo o que fez por mim como pessoa, seu apoio, exemplo e guia são um ganho incomensurável para mim. Estimo a sua amizade desde o fundo do meu coração.

Aos meus amigos, porque foram sempre essa torcida que não desiste. Aos que sempre estiveram, estão e estarão. Aos amigos de sempre, agradeço-lhes a força que me deram, porque ainda desde longe torceram incansavelmente pelo meu sucesso, e me lembram de onde eu venho. Aos amigos que o Brasil me deu, porque sem vocês os dias tivessem sido anos e a vida não tivesse sido vida, porque me ensinaram a crescer, e através de vocês aprendi muito mais sobre mim mesma, e assim descobri para onde eu vou.

Obrigada a todas as pessoas que me acolheram com os braços abertos desde que cheguei, porque na sua companhia nunca me senti uma estranha. Obrigada, mil vezes, pelos abraços, as risadas, por serem parte da minha vida, vocês são o meu Brasil.

"Estoy agradecida por noches que se hicieron mañanas, amigos que se hicieron familia y los sueños que se hicieron realidad."

"May the Spartans be with you" 
Any intelligent fool can make things bigger and complex... it takes a touch of genius -and a lot of courage- to move in the opposite direction.

(E.F. Schumager Small is Beautiful, 1973) 
Neste trabalho, é apresentada a modelagem de um componente que, através do uso de técnicas de tecnologia adaptativa, permite a reconfiguração da interface de usuário de um sistema legado de uso geral. A mencionada reconfiguração foca-se no gerenciamento adequado dos recursos do sistema para fornecer acessibilidade aos usuários com necessidades especiais no contexto corrente.

Nossa proposta procura responder à necessidade de colocar ao alcance das pessoas com deficiência os recursos tecnológicos presentes na sociedade da informação, assim como seus benefícios associados. Assim, o objetivo é diminuir a barreira criada pelo desenvolvimento de sistemas computacionais sob a conceição tradicional de um perfil de "usuário padrão", entre as tecnologias e os usuários com necessidades especiais. Ao respeito desse assunto, as propostas encontradas na literatura apresentam três abordagens: uma abordagem reativa ou tecnologias assistivas, uma abordagem proativa ou tecnologias inclusivas e uma abordagem dentro do marco legal. No entanto, no contexto de sistemas legados já imersos na sociedade, existe um problema em aberto. Nesse caso não é viável, logística e economicamente, a aplicação da abordagem reativa, já que significaria adicionar sistemas com tecnologias assistivas para as comunidades específicas, por exemplo: cegos, surdos, deficiência física, entre outros. Da mesma maneira, não é possível implementar a abordagem proativa pois ela só é aplicável para tecnologias em processo de desenvolvimento, e no nosso caso trata-se de sistema já em uso.

Nossa proposta é a modelagem de um componente que através de técnicas de tecnologia adaptativa possa assistir na reconfiguração dos recursos próprios do sistema em questão levando em conta tanto as informações de contexto corrente da interação (contexto do usuário, contexto do sistema, contexto do ambiente de execução) quanto as informações históricas da sua execução. Para atingir o nosso objetivo é especificada uma meta-arquitetura inspirada na programação orientada a componentes que permite flexibilidade, baixo acoplamento e mantém a integridade original do sistema.

Finalmente é realizada uma prova de conceito que permite confirmar a viabilidade técnica do modelo proposto.

Palavras-chave: Acessibilidade. Interação Hómem-Máquina. Middleware. Tecnologia Adaptativa. Recursos do Sistema. 


\section{ABSTRACT}

This work is presents the modeling of a component that, by Adaptive Technology's techniques, allows the reconfiguration of the user interface inside an inherited general use system. The mentioned reconfiguration focus in the adequate management of system resources in order to provide accessibility for users with special needs at real time.

Our propose intent to answer the need for putting at reach of people with disabilities the technological resources existing in the information society, as well as it corresponding benefits. Therefore, the objective is to decrement the barrier created by the developing of computational systems under the traditional conception of the "standard user" profile, between the technologies and the users with disabilities. About this matter, previous proposals found in literature classify them within three different approaches: a reactive approach or so called assistive technologies, a proactive approach or inclusive technologies, and a legal approach related to building an international legal framework. Nevertheless, in the context of inherited systems, which are already immerse in our society, a problem has kept underlying. In these cases, it is not affordable, from logistics as well as economics, the application of the reactive approach, because it will imply to add new versions of systems that implement assistive technologies at every spot and for every kind of specific community, for example: blind, deaf, motor impairment, and so on. In the same way, it is not possible apply the proactive approach because it can be only put into practice during the first phases of the development process of a software, and our case of interest is with already in use systems.

Our propose to help solving this problem is the modeling of a component which through the incorporation of Adaptive Technology's techniques can assist in the reconfiguration of the own resources inside an inherited system taking into account the current context information(user context, system context, and environmental context) as well as the historical information gather from previous executions. To achieve this goal a meta-architecture is specified taking the component oriented programming paradigm as inspiration to provide flexibility, loose coupling and keep the integrity of the original system.

Finally, a concept test is implemented to expose the viability of our propose from the technological perspective.

Keywords: Accessibility. Human-Computer Interaction. Middleware. Adaptive Technology. System Resources 


\section{LISTA DE ILUSTRAÇÕES}

Figura 1 Relação entre as diferentes formas de inclusão tecnológica de usuários com necessidades diferenciadas . . . . . . . . . . . . . . 20

Figura 2 Percentagem da População Mundial declarada com deficiência . . . . . 25

Figura 3 Percentagem da População Brasileira declarada com deficiência . . . . 25

Figura $4 \quad$ Percentagem de presença por tipo de deficiência dentro da população . 26

Figura 5 Porcentagem de presença de População com alguma deficiência por grupos de idade . . . . . . . . . . . . . . . . . . . . . . 27

Figura $6 \quad$ Telas de boas-vindas e configurações de usuário e preferências no sistema Web-4-All . . . . . . . . . . . . . . . . . . . . . . . . . . . . . 29

\begin{tabular}{lllll}
\hline Figura 7 & Arquitetura Geral do Sistema AVANTI & $\ldots$
\end{tabular} . . . . . . . . . . . . . . . . . 32

Figura 8 Comparação entre as ferramentas disponíveis que fornecem recursos de acessibilidade.

Figura 9 Principais Paradigmas de Interação Humano-Computador . . . . . . . 44

Figura 10 Diagrama básico do funcionamento de um dispositivo baseado em regras 52

Figura $11 \quad$ Diagrama básico do funcionamento de um sistema multimodal . . . . 54

Figura 12 Diagrama básico do funcionamento de SOA . . . . . . . . . . . . . . 57

Figura $13 \quad$ Esquema de macro estrutura de um dispositivo adaptativo . . . . . . . 59

Figura 14 Dinâmica de funcionamento de uma Tabela de Decisão convencional . 62

Figura 15 Dinâmica de funcionamento de uma Tabela de Decisão Adaptativa . . 64

Figura $16 \quad$ Ciclo clássico modelagem de usuário - adaptação nos sistemas adaptativos 66

Figura $17 \quad$ Elementos do sistema desde a perspectiva física ou de Hardware. . . . 76

Figura 18 Percepção do usuário da sua interação padrão com o sistema legado de uso geral . . . . . . . . . . . . . . . . . 76

Figura $19 \quad$ Percepção do usuário da sua interação com o sistema legado ao reconhecer a conexão de um dispositivo USB . . . . . . . . . . . . . 77

Figura $20 \quad$ Percepção do usuário da sua interação com o sistema ao iniciar o middleware . . . . . . . . . . . . . . . . . . . . . 77

Figura $21 \quad$ Percepção do usuário da sua interação com o sistema composto pelo middleware e o sistema legado. . . . . . . . . . . . . . . 78

Figura 22 Percepção do usuário da sua interação com o sistema ao concluir o uso do middleware . . . . . . . . . . . . . . . . . . . . . . . . . . . . . . . 78

Figura $23 \quad$ Percepção do usuário da sua interação com o sistema legado ao reconhecer a ejeção de um dispositivo USB . . . . . . . . . . . . . . . . 79 
Figura $24 \quad$ Elementos do sistema sob a perspectiva de Software . . . . . . . . . 79

Figura 25 Visão Geral da Aquitetura interna do Middleware. . . . . . . . . . . . . 81

Figura $26 \quad$ Arquitetura interna do Middleware- Componente de Comunicação . . . 82

Figura $27 \quad$ Arquitetura interna do Middleware- Componente de Gerenciamento . . 83

Figura $28 \quad$ Arquitetura interna do Middleware- Componente de Interação com o Sistema Operacional . . . . . . . . . . . . . . . . . . . . . . . . . . . . . . 84

Figura $29 \quad$ Arquitetura interna do Middleware- Componente de Interação com o Usuário . . . . . . . . . . . . . . . . . . . . . . . . . . . . . . . 86

Figura $30 \quad$ Arquitetura interna do Middleware- Componente de Extração de Informações do Entorno . . . . . . . . . . . . . . . . . . . . . . . . . . . 8

Figura $31 \quad$ Arquitetura interna do Middleware- Componente de Tomada de Decisão 88

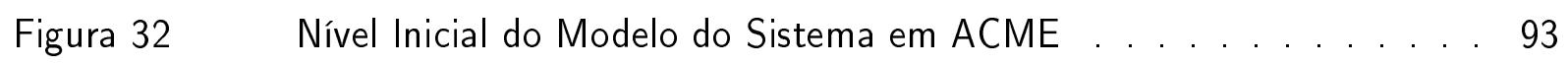

Figura 33 Nível 1 do Modelo do Adaptware em ACME . . . . . . . . . . . . . . . . 95

Figura $34 \quad$ Nível 2 do Modelo do Adaptware em ACME, subcomponente de interação com o sistema operacional . . . . . . . . . . . . . . . 97

Figura $35 \quad$ Nível 2 do Modelo do Adaptware em ACME, subcomponente de informações do usuário . . . . . . . . . . . . . . . . . . . . . . . . . . . 99

Figura $36 \quad$ Nível 2 do Modelo do Adaptware em ACME, subcomponente de extração de informações do entorno . . . . . . . . . . . . . . . . . 101

Figura 37 Nível 2 do Modelo do Adaptware em ACME, subcomponente de tomada de decisão . . . . . . . . . . . . . . . . . . . . . . 103

Figura $38 \quad$ Nível 3 do Modelo do Adaptware em ACME, subcomponente de formatação de informação . . . . . . . . . . . . . . . . . . 104

Figura $39 \quad$ Principais conceitos pesquisados na revisão da literatura . . . . . . . . 153

Figura $40 \quad$ Detalhe da revisão feita ao respeito de Acessibilidade. . . . . . . . . . . 154

Figura $41 \quad$ Detalhe da revisão feita ao respeito de Adaptatividade . . . . . . . . . 155

Figura 42 Detalhe da revisão feita ao respeito de Deficiência . . . . . . . . . . . 156

Figura $43 \quad$ Detalhe da revisão feita ao respeito de Interação Hómem-Máquina . . 157

Figura $44 \quad$ Detalhe da revisão feita ao respeito de Meta-arquitetura . . . . . . . . . 158

Figura 45 Detalhe da revisão feita ao respeito do desenvolvimento de Middlewares sob o paradigma de Programação orientada a componentes . . . . 159

Figura $46 \quad$ Detalhe da revisão feita ao respeito dos diferentes Paradigmas de Programação para suporte de Adaptatividade . . . . . . . . . . . . . 160

Figura 47 Detalhe da revisão feita ao respeito aos Perfis de Usuário . . . . . . 161

Figura $48 \quad$ Detalhe da revisão feita ao respeito dos Sistemas Multimodais . . . . 162 
Figura 49 Detalhe da revisão feita ao respeito do mecanismo de reconfiguração Plug-and-Play . . . . . . . . . . . . . . . . . . . . . . 163

Figura $50 \quad$ Detalhe da revisão feita ao respeito das Tecnologias sensíveis ao contexto164

Figura $51 \quad$ Detalhe da revisão feita ao respeito das Tecnologias Adaptativas . . . 165

Figura 52 Detalhe da revisão feita ao respeito da terminologia da área . . . . . . 166

\begin{tabular}{llll}
\hline Figura 53 & Comparação entre características dos termos adaptável e adaptativo & 169
\end{tabular}

Figura $54 \quad$ Relação entre Personalização, Adaptabilidade e Adaptatividade . . . . 170 


\section{LISTA DE TABELAS}

Tabela 1 Tabela de descrição do funcionamento dum dispositivo baseado em regras 52 


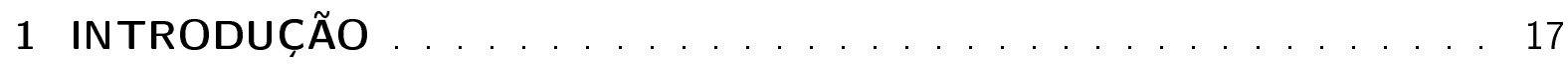

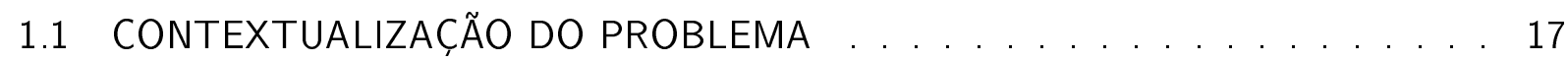

1.2 OBJETIVO DO TRABALHO $\ldots \ldots \ldots \ldots \ldots \ldots \ldots$

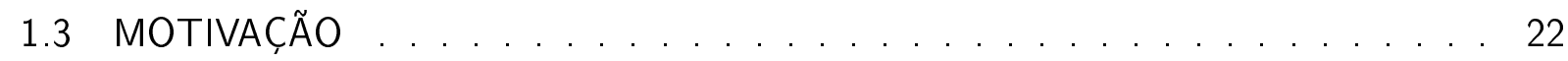

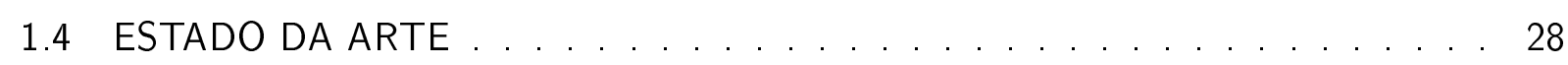

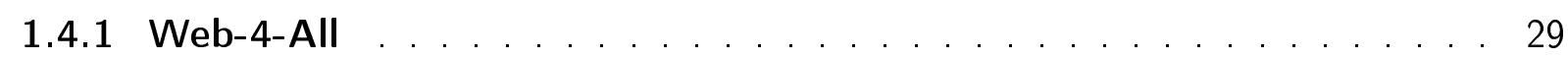

1.4 .2 AVANTI Web browser . . . . . . . . . . . . . . . . . . . 31

1.4 .3 Projeto INREDIS . . . . . . . . . . . . . . . . . . . 32

1.4 .4 Projeto EMBASSI $\ldots \ldots \ldots \ldots$

1.4 .5 Projeto Gaia . . . . . . . . . . . . . . . . . . . . . . . 34

1.4 .6 Google Accessibility . . . . . . . . . . . . . . . . . . 34

1.4 .7 Apple Inc. $\ldots \ldots \ldots \ldots \ldots \ldots$

1.4 .8 InfoVox . . . . . . . . . . . . . . . . . . . . . . 36

1.5 USO DA TECNOLOGIA ADAPTATIVA PARA RESOLVER PROBLEMAS DE

TOMADA DE DECISÕES . . . . . . . . . . . . . . . . . . . . . 39

1.6 TERMINOLOGIA UTILIZADA $\ldots \ldots \ldots \ldots \ldots$

1.6 .0 .1 "Customização" . . . . . . . . . . . . . . . . . . . . . . . . . . 40

1.6 .0 .2 Adaptabilidade. . . . . . . . . . . . . . . . . . 40

1.6 .0 .3 Personalização . . . . . . . . . . . . . . . . . . . . . 41

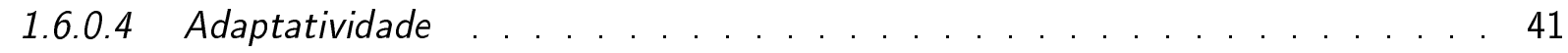

1.6 .0 .5 Middleware . . . . . . . . . . . . . . . . . . . . 41

1.6 .0 .6 Configuração de Sistema . . . . . . . . . . . . . . . . . . . 42

1.6 .0 .7 Componente Software . . . . . . . . . . . . . . . . . . . . 42

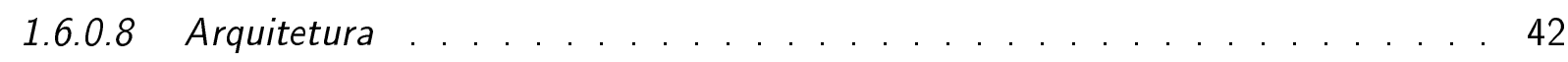

1.6 .0 .9 Contexto de execução . . . . . . . . . . . . . . . . . . . . . . 42

2 CONCEITOS E FUNDAMENTAÇÃO TEÓRICA . . . . . . . . . . . . 43

2.1 A ÁREA DE INTERAÇÃO HUMANO-COMPUTADOR E SEU COMPROMISSO COM O USUÁRIO . . . . . . . . . . . . . . . . . . . . . . 43

2.2 INDIVÍDUOS COM DEFICIÊNCIA NA SOCIEDADE DA INFORMAÇÃO . . . . . 44

2.3 ACESSIBILIDADE UNIVERSAL . . . . . . . . . . . . . . . . . 46

2.4 TECNOLOGIAS UTILIZADAS EM TRABALHOS RELACIONADOS COM FORNECER ACESSIBILIDADE. . . . . . . . . . . . . . . . . . . . . . . . 49

2.4 .1 Mecanismos baseados em regras . . . . . . . . . . . . . . . . . . . 50 
2.4 .2 Sistemas multimodais . . . . . . . . . . . . . . . . . . . . . 53

2.4 .3 Computação Orientada a Serviços . . . . . . . . . . . . . . . . 55

2.4 .4 Agentes Automáticos _. . . . . . . . . . . . . . . . . . 57

2.5 FUNDAMENTAÇÃO TEÓRICA DA PROPOSTA . . . . . . . . . . . 58

2.5 .1 Tecnologia Adaptativa . . . . . . . . . . . . . . . . 58

2.5.1.1 Tabelas de Decisão Adaptativas. . . . . . . . . . . . . . . . . . . 60

2.5 .2 Modelagem de perfil de usuário . . . . . . . . . . . . 65

2.5 .3 Contextualização da Tecnologia . . . . . . . . . . . . . . . 69

2.5.4 Meta-Modelo e Meta-Arquitetura . . . . . . . . . . . . . 71

2.5.4.1 Meta-Modelo . . . . . . . . . . . . . . . . . . . . 71

2.5 .4 .2 Meta-Arquitetura . . . . . . . . . . . . . . . . . 72

3 MODELO PROPOSTO . . . . . . . . . . . . . . . . . . . . . . . . . . 73

3.1 DELIMITAÇÃO DO TRABALHO DENTRO DO PANORAMA ANTERIOR . . . . 73

3.2 META-ARQUITETURA DA SOLUCุÃO . . . . . . . . . . . . . . . . . 74

3.2 .1 Componentes do Sistema . . . . . . . . . . . . . . . . . 75

3.2.1.1 Perspectiva física ou de Hardware. . . . . . . . . . . . . . . . . . . 75

3.2 .1 .2 Perspectiva de Usuário . . . . . . . . . . . . . . . . . . . . . 75

3.2 .1 .3 Perspectiva de Software . . . . . . . . . . . . . . . . . . . . . . 78

3.2 .2 Componentes do Middleware . . . . . . . . . . . . . . . . 81

3.2.2.1 Componente de Comunicação . . . . . . . . . . . . . . . . . . . . 82

3.2 .2 .2 Componente Geral de Gerenciamento . . . . . . . . . . . . . . . . . . 83

3.2.2.3 Componente de Interação com o Sistema Operacional . . . . . . . . . . . . 84

3.2.2.4 Componente de Interação com o Usuário . . . . . . . . . . . . . . . . 85

3.2.2.5 Componente de Extração de Informações do Ambiente de Execução . . . . 87

3.2.2.6 Componente de Tomada de Decisão . . . . . . . . . . . . . . . . . . 88

4 FORMALIZAÇÃO DA PROPOSTA $\ldots \ldots \ldots \ldots$

4.1 MODELAGEM FORMAL DA PROPOSTA . . . . . . . . . . . . . . . . 90

4.1 .1 ADLs $\ldots \ldots \ldots \ldots \ldots$

4.1 .2 A proposta . . . . . . . . . . . . . . . . . . . . . 91

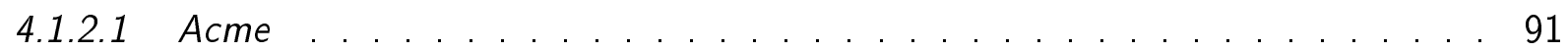

4.1 .2 .2 Os componentes. . . . . . . . . . . . . . . . . . . . . . . . . 92

4.1 .3 Funcionamento Padrão . . . . . . . . . . . . . . . . . . . . 104

4.1.3.1 Inicio da Interação . . . . . . . . . . . . . . . . . . . . . . . . . 105

4.1 .3 .2 Durante a interação . . . . . . . . . . . . . . . . . . . . . 110

4.1 .3 .3 Fim da interação . . . . . . . . . . . . . . . . . . . . . . . . . 113 
4.2 VIABILIDADE PARA A CONCRETIZAÇÃO DO MODELO . . . . . . . . . . 115

4.2 .1 Suporte Teórico . . . . . . . . . . . . . . . . . . . . . . . . 1115

4.2 .1 .1 Tecnologia Universal Serial Bus(USB) . . . . . . . . . . . . . . 115

4.2.1.2 Construção de Software Orientada a Componentes. . . . . . . . . . . . . 116

4.2 .1 .3 Padrões Internacionais . . . . . . . . . . . . . . . . . 116

4.2 .2 Suporte Tecnológico . . . . . . . . . . . . . . . . . . . . 117

4.2 .2 .1 Tecnologia Assistiva . . . . . . . . . . . . . . . . . . . . . . . 117

4.2 .2 .2 Recursos de Personalização . . . . . . . . . . . . . . . . . . . 118

4.2.2.3 Suporte dos Sistemas Operacionais para Tecnologia Assistiva . . . . . . . . . 119

4.2.2.4 Engenharia de Software baseada em Componentes . . . . . . . . . . . . . . 119

4.2 .2 .5 Tecnologia de acesso a recursos remotos . . . . . . . . . . . . . 120

4.2 .3 Suporte Social . . . . . . . . . . . . . . . . . . . . . . . . . . 121

4.2 .3 .1 Marco legal sobre pessoas com deficiências . . . . . . . . . . . . . 121

4.2.3.2 Referência do aporte de pessoas com deficiência viabilizado pelas tecnologias assistivas . . . . . . . . . . . . . . . . 122

4.2.3.3 Interesse tanto académico quanto comercial de investimento em pesquisas dirigidas à acessibilidade. . . . . . . . . . . . . . 123

4.3 VANTAGENS E NOVIDADES ASSOCIADAS AO MODELO . . . . . . . . . 124

4.3 .1 Adaptatividade . . . . . . . . . . . . . . . . . . . . . . . . . . . . 124

4.3 .2 Design Orientado a Componentes . . . . . . . . . . . . . . . 125

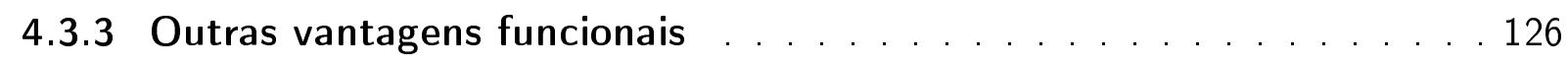

4.4 DIFICULDADES E LACUNAS ENCONTRADAS . . . . . . . . . . . . . 126

5 CONCLUSÕES, CONTRIBUIÇÕES E TRABALHOS FUTUROS . . . . 128

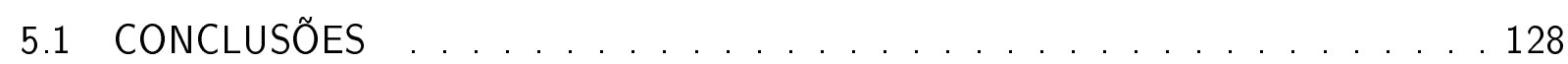

5.2 CONTRIBUIC Õ̃ES . . . . . . . . . . . . . . . . . . . . . . . . . . 132

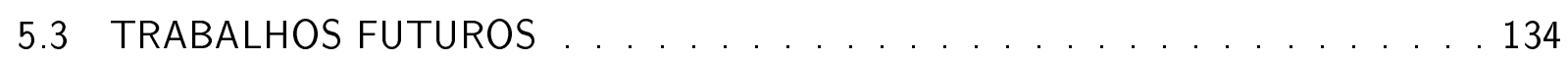

5.3 .1 Trabalhos como continuação deste projeto . . . . . . . . . . . 134

5.3 .2 Trabalhos alinhados com o assunto de acessibilidade. . . . . . . . 135

5.3 .3 Trabalhos alinhados com as tecnologias utilizadas . . . . . . . . 136

5.3 .4 Trabalhos alinhados com as ferramentas utilizadas . . . . . . . . 137

5.3 .5 Trabalhos derivados do próprio exercício da pesquisa . . . . . . . . . 137

Referências . . . . . . . . . . . . . . . . . . . . . . . . . . 139

Apêndice A - Mapa Conceitual da Revisão da Literatura . . . . . . . . . . . 152

Apêndice B - Personalização, Adaptabilidade e Adaptatividade . . . . . . . . 167 
Apêndice C - O Mecanismo PnP

Apêndice D - Exemplo dos arquivos XML relacionados ao Componente de interação com o Usuário

Apêndice E - Exemplo dos arquivos XML relacionados ao Componente de interação com o Sistema Operacional . . . . . . . . . . . . . . . 177

Apêndice $F$ - Exemplo dos arquivos $X M L$ relacionados ao Componente de interação com o entorno 178 
1 INTRODUÇÃO

Neste capítulo detalha-se o problema de acessibilidade experimentado pelos usuários com necessidades diferenciadas, de maneira particular as pessoas com algum tipo de deficiência, os quais têm restrita a sua interação com os diferentes sistemas computacionais existentes e ativos na nossa sociedade. Assim mesmo, apontam as consequências que geram a falta de acesso aos recursos tecnológicos para essa comunidade de usuários especialmente na era da denominada sociedade da informação. São enunciados tanto o objetivo principal do trabalho quanto a motivação que promove seu desenvolvimento. Em seguida, apresenta o estado da arte referente às diferentes pesquisas desenvolvidas pela comunidade científica na tentativa de fornecer uma solução para este problema, e os maiores desafios que ainda prevalecem. Finalmente, apresenta a justificativa do uso de tecnologias adaptativas para elaborar uma solução que forneça ao mesmo tempo efetividade e expressividade na modelagem formal do problema.

\subsection{CONTEXTUALIZAÇÃO DO PROBLEMA}

No decorrer dos anos, a tecnologia, e em particular os sistemas computacionais, têm firmado cada vez mais o seu papel fundamental nas atividades diárias das pessoas (MALINOWSKY; NYGåRD; KOTTORP, 2011), sendo utilizados para fins tão diversos como ((LEBLOIS, 2013): educação, notícias, comércio, lazer, saúde, vida política, acesso a serviços de governo, emprego, entre outros. Assim, ditos sistemas tem-se tornado o maior facilitador do desenvolvimento da sociedade da informação desde o final do século XX (LEBLOIS, 2013).

$\mathrm{Na}$ atualidade, como afirmado por Weiser (1999), as pessoas utilizam o computador de maneira quase mecânica, para realizar tarefas do seu dia-a-dia, tais como: procurar informação na Internet, consultar o email, organizar e fazer o agendamento das atividades do dia, redigir documentos e realizar compras (Bureau of Labor Statistics, 2005). Foi-se a época em que o computador estava exclusivamente dedicado para trabalhos de caráter científico e especializado (STEPHANIDIS; EMILIANI, 1999, NIELSEN, 1993) ou dedicado para indústria . Ao contrário, hoje existem sistemas computacionais de atuação muito mais abrangente, que têm atingido níveis de desempenho e eficiência que no século passado só podiam ter sido imaginados na ficção científica.

Assim, na atualidade uma pessoa encontra-se exposta aos diferentes sistemas computacionais numa diversidade de ambientes, tanto públicos quanto privados. Por exemplo, é possível interagir com esses sistemas em: aeroportos, terminais de ônibus, estações de trem, livrarias, bancos, bibliotecas e outros locais públicos e privados. Alguns deles estão configurados como 
quiosques interativos de modo que disponibilizam informações especializadas, e outros, como terminais de uso geral para acesso à internet, conforme descrito em Barfield e Caudell (2001) e Dourish e Bell (2013). Como consequência, a capacidade de interagir com esses sistemas tem se convertido em um pré-requisito para a participação de qualquer pessoa dentro da chamada sociedade da informação, sob o risco de ficarem excluídos (MALINOWSKY; NYGåRD; KOTTORP, 2011: LEBLOIS, 2013) dos benefícios que ela traz.

Da mesma maneira, o crescimento e assimilação na sociedade de novas tendências tecnológicas como Mobile, Ubiquitous e Wearable Computing manifestam duas necessidades: a necessidade do usuário por conectividade e a necessidade dos sistemas de incorporar numa etapa posterior ao seu desenvolvimento. No primeiro caso, existe uma preocupação do cidadão global por manter seu acesso à informação e aos serviços ativos a maior parte do tempo. Trata-se de um requerimento tão real e formal que é conhecido como Triple A Connectivity, conectividade em qualquer lugar, em qualquer momento, e desde qualquer dispositivo (anywhere, anytime, Any-device) e que pouco a pouco vai-se estendendo de maneira que não só é atribuída ao usuário, mas também as coisas, como bem o demonstra a chamada Internet das coisas, ou loT pelas suas siglas no inglês(Internet of Things) (KRUPITZER et al., 2015). No entanto, existem situações particularmente sensíveis nas quais ter acesso à informação não é uma tarefa que possa ser desenvolvida com facilidade, e esse é o caso das pessoas que apresentam necessidades diferenciadas devido a algum tipo de deficiência física ou mental, temporária ou permanente. Elas já enfrentam restrições nas suas atividades diárias dentro da sociedade (LEBLOIS, 2013), as quais são extrapoladas para a área tecnológica devido a que a maioria de sistemas não costumam ser projetados para atender as necessidades desse tipo de usuário. No caso do requerimento dos sistemas para admitir mudanças nas suas configurações numa etapa posterior ao seu desenvolvimento, como mencionado em Persson (2009) existe uma necessidade tanto da indústria quando do campo acadêmico, pelo desenvolvimento de sistemas acessíveis para efetuar mudanças neles após do desenvolvimento dos mesmos, e não só isso, mas que possuam interoperabilidade para trabalhar com outros dispositivos, os quais podem não ter sido vislumbrados no momento de desenvolvimento do sistema inicial. Este tipo de sistema, deve oferecer as condições ideais para o reajuste necessário para estabelecer uma interação adequada com diferentes tipos de usuário, por exemplo com usuários com necessidades diferenciadas.

Nos últimos anos foram formuladas propostas de diferente abrangência para fornecer alternativas de solução ao isolamento tecnológico que atinge este tipo de comunidades de usuários, e assim facilitar a inclusão de pessoas com necessidades diferenciadas, por exemplo: pessoas com algum tipo de deficiência, idosos, crianças ou algum tipo de população em desvantagem, dentro das atividades da sociedade. Através de essas alternativas procura-se garantir a partici- 
pação de tais cidadãos nas atividades necessárias para a evolução da sociedade e o seu próprio desenvolvimento.

De acordo com Stephanidis e Emiliani (1999) as três principais formas de inclusão de pessoas com deficiência na sociedade são:

- Reativa: na qual procura-se realizar ajustes "a posteriori" nas tecnologias disponíveis no mercado incorporando nelas os mecanismos necessários para fornecer acessibilidade aos membros de uma comunidade.

- Pro-ativa: na qual procura-se incorporar a preocupação ao respeito da inclusão de diferentes tipos de usuários no próprio processo de desenvolvimento do software. Assim, novas tecnologias adotam as diretrizes dadas pelo Design Universal (AKOUMIANAKIS; STEPHANIDIS, 2001) e Acessibilidade Universal. Assim, o objetivo é a criação de tecnologias que possuam mecanismos para atender as necessidades dos diferentes tipos de usuários sem fazer alterações maiores.

- Políticas: as quais propõem a criação, revisão e promoção de leis, normas e padrões que estabelecem um marco legal dentro do qual sejam esclarecidos os procedimentos, direitos e deveres da sociedade em relação ás pessoas com alguma deficiência.

Dessas formas de tratamento, a proposta reativa, também conhecida como tradicional, é a que mais tem sido implementada. A razão principal é disso é que ela foi a primeira tentativa para adequar os sistemas computacionais já existentes às necessidades de uma comunidade não considerada de antemão. Assim, ela procurava diminuir as restrições impostas pela abordagem contemporânea de "usuário padrão"no processo de construção de software, mais especificamente dentro da caracterização dos usuários finais do sistema ou ferramenta tecnológica em desenvolvimento. O conceito de "usuário padrão"pressupõe a seleção de um conjunto fixo de características (funcionalidades, capacidades, recursos e cenários) sob as quais o usuário pode experimentar uma interação eficiente com o sistema. É por meio de tais características que são especificadas as diretrizes para gerenciar tanto o processo quanto os recursos participantes da interação entre usuário e computador, por exemplo: meios de comunicação, canais, códigos e tecnologias. Como consequência disso, os usuários que não estão totalmente alinhados com dita padronização não têm garantida uma interação eficiente com o sistema sem a participação ativa de dispositivos ou mecanismos de apoio externos.

Na Figura1 é possível identificar a relação entre as três formas de inclusão tecnológica que os usuários com necessidades diferenciadas têm a disposição. A secção numerada com 1 corresponde às tecnologias desenvolvidas seguindo o conceito de usuário padrão, e que em consequência, não fornecem mecanismos de acessibilidade. A secção identificada com o número 
20

Figura 1 - Relação entre as diferentes formas de inclusão tecnológica de usuários com necessidades diferenciadas

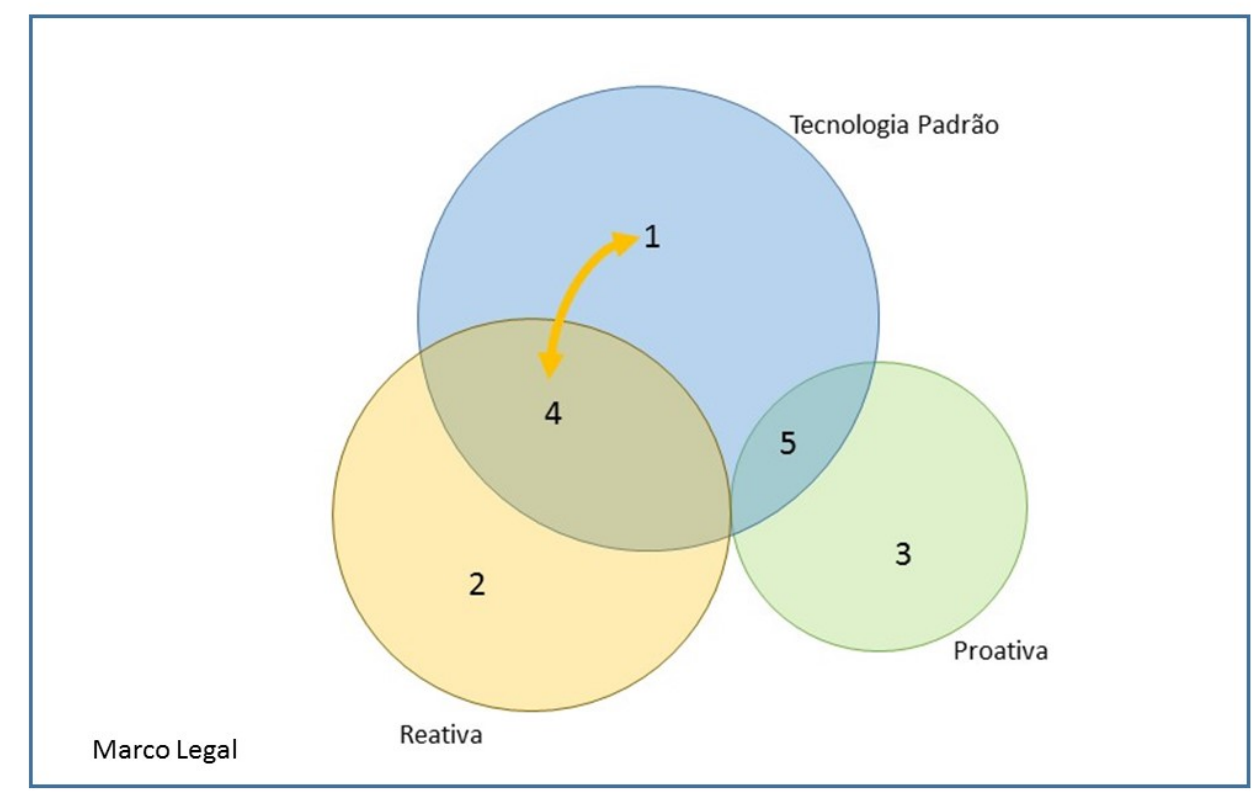

Fonte: Autora

2 corresponde às tecnologias criadas especificamente para atender as necessidades de usuários com algum tipo particular de deficiência referente ao uso de alguma tecnologia. Assim, por exemplo, uma impressora(uma tecnologia de uso geral) com saída de documentos em formato braille(especificamente orientado para fornecer acessibilidade para pessoas cegas) encontra-se nesta secção. A seção 3 identifica às tecnologias que já nascem (são projetadas) incluindo mecanismos que permitem implementar acessibilidade para usuários com necessidades diferenciadas caso seja preciso. A secção 4 descreve as tecnologias que tendo sido implementadas segundo o conceito de usuário padrão foram ajustadas para permitir a interação com usuários com necessidades inicialmente não contempladas. Assim, por exemplo as tecnologias que incorporam a posteriori elementos para fornecer acessibilidade como recursos adicionais ao software original (e disponíveis sob demanda) pertencem a esta secção.Por último, a secção 5 inclui as tecnologias que de maneira incremental tem incorporado mecanismos para fornecer acessibilidade como recursos nativos nas novas versões do software.Por exemplo, os novos aplicativos leitores de formato PDF incluem um leitor de tela nativo para facilitar o acesso à informação de pessoas impossibilitadas da interação por médio visual.

Assim, na atualidade, existem muitos computadores de uso geral cuja interface foi desenvolvida utilizando o conceito de "usuário padrão"e que, portanto, não possuem mecanismos internos que lhes permita fazer reconfigurações para se adaptar dinamicamente às necessidades dos diferentes usuários. Isso significa que muitas vezes, ainda quando a tecnologia (filtros, ferramentas, aplicações) para fornecer uma melhor interação com o usuário está disponível 
dentro do sistema, ela não pode ser utilizada no seu máximo potencial devido à falta de um componente de software que automatize a reconfiguração do sistema, é dizer que viabilize o caminho entre as secções 1 e 4 da Figura 1 .

\subsection{OBJETIVO DO TRABALHO}

O objetivo principal do projeto de pesquisa é propor um modelo que permita assistir um sistema computacional, legado e de propósito geral, na tarefa do gerenciamento dos recursos da interface de interação do usuário que ele possui. A finalidade desse gerenciamento é melhorar a experiência de interação entre humano e computador em termos de acessibilidade. De maneira particular, este trabalho foca-se em fornecer alternativas de acesso ao uso de tecnologias para usuários com deficiência visual e auditiva, mas procura estabelecer um marco("framework") tecnológico o suficientemente geral que permita abranger outros tipos de usuários com necessidades diferenciadas.

O seguintes objetivos parciais têm sido identificados:

- Obter um levantamento de informação do estado da arte corrente nas áreas de interfaces de usuários para usuários com necessidades diferenciadas, acessibilidade, programação orientada a componentes, middleware e tecnologias adaptativas colocando especial ênfase nas pesquisas que respondem a mais de um critérios.

- Elaborar um quadro comparativo das alternativas de solução aos problemas existentes, colocando especial ênfase em indicar as características que compartilham ditas soluções e as suas principais diferenças.

- Desenvolver um modelo de middleware que permita assistir um sistema subjacente de uso geral na reconfiguração dos seus próprios recursos de interação com o usuário. Dito modelo deve ser apresentado através duma linguagem formal que permita ao mesmo tempo a descrição das características de flexibilidade e baixo acoplamento dos componentes do sistema.

- Elaborar uma análise dos requerimentos necessários para futuras ferramentas e metodologias no trabalho de desenvolvimento de tecnologias semelhantes assim como as principais dificuldades encontradas durante este trabalho.

Para atingir esse objetivo o modelo incorpora técnicas de tecnologia adaptativa para permitir o sistema subjacente se ajuste, na medida do possível, às diferentes necessidades dos usuários finais que interatuam com o ele na medida que elas são manifestadas e tendo em conta o cenário de execução. 
Desde a perspetiva técnica o modelo propõe a criação de uma peça de software de interface portável, a qual estabelece comunicação com um sistema hospedeiro para agir como intermediário e dar suporte ao gerenciamento dos diferentes recursos de interação disponíveis nele, com a finalidade de reconfigurá-lo enquadrando-o ao cenário correspondente. Dito software faz uso de técnicas e tecnologias orientadas às tarefas de "coleta e extração de informações" (características do usuário, condições ambientais, e estados do sistema Weiser (1999)), formatação, flexibilidade e prolongação da vida útil do software na corrida tecnológica atual.

\subsection{MOTIVACุÃO}

Este trabalho tem motivação direta da perceção da importância que tem o acesso à informação para os participantes da sociedade no século XXI, do impacto que tem ser impedido de dito acesso, e da responsabilidade que isso implica para os criadores, projetistas e desenvolvedores de software como agentes fornecedores de tecnologias de acesso à informação. A motivação pessoal para o desenvolvimento deste projeto tem origem na experiência próxima que desde criança tive com pessoas com deficiência. A escola onde estude foi projetada como escola piloto, com foco principal na participação ativa dos estudantes na sua educação, em assuntos sociais através de atividades de projeção social e em diversidade como base para o desenvolvimento da tolerância. Nas salas de estudo tive a oportunidade de compartilhar experiências com colegas com problemas de aprendizagem, retardo mental e dificuldades motoras. A inclusão de pessoas com deficiência dentro das salas de aulas em uma idade tão nova permitiu que o conceito de igualdade de direitos fosse natural e necessário no meu conceito de sociedade. Assim mesmo, a escola organizava todos os anos uma atividade de projeção social na qual as alunas eram responsáveis pelo cuidado e bom funcionamento de uma casa de infantes em um bairro de baixas condições económicas, chamado "Hacentamiento Humano"no Peru. Essa atividade apresento-me novas necessidades de inclusão e diferentes tipos de deficiência, e além de tudo permitiu humanizar ditas necessidades através de um rostro humano. Ao ingressar na universidade comecei participar de um projeto de áudio-livros que permitia colocar documentos de engenharia e ciências ao alcance de pessoas cegas membros da comunidade universitária. É durante esse último projeto que identifico as dificuldades que as pessoas com deficiência enfrentam ao interatuar com sistemas computacionais de uso geral que estão dispostos nos mais diversos ambientes da nossa sociedade.

De maneira específica, a realização deste trabalho está suportada por três argumentos:

A. O acesso à informação é um Direito de todo membro da Sociedade da Informação, assim, os diferentes mecanismos que fornecem acessibilidade são os canais necessários para efetivar esse direito. 
A Declaração Universal dos Direitos Humanos(Nations (1948)) adotada pela Organização das Nações Unidas(ONU) em 1948, tem seus fundamentos na justiça, na igualdade e na liberdade inerentes à própria natureza humana. Esses direitos procuram garantir o respeito à dignidade e liberdades fundamentais que cada pessoa tem para desenvolver seu potencial de forma livre, autónoma e plena dentro da sociedade. Esse documento estabelece as diretrizes para novos recursos legais que visam promover e proteger esses direitos, a vez que concretizam as ações a ser efetuadas para atingir esse objetivo tendo em conta as características filosóficas, sociais e culturais na sociedade. Assim, a Declaração dos Princípios para a Sociedade da Informação(Nations (2003)) elaborada também pela ONU em 2003, reafirma que todo cidadão tem o direito universal de participar das atividades nos diferentes aspectos da Sociedade da Informação, sem restrição ou discriminação. Especificamente, o ponto A4 dessa Declaração estabelece:

Everyone and everywhere should have the oppportunity to participate and no one should be excluded from the benefits the Information Society offers. (NATIONS, 2003)

Particularmente, na dinâmica instituída na Sociedade da Informação o acesso à informação é o recurso que introduz e viabiliza a participação de um individuo nas atividades que promovem seu desenvolvimento como cidadão. Assim, a falta deste recurso tem como consequencia não só o enfraquecimento do senso de pertença à sociedade mas impacta significativamente a qualidade de vida das pessoas que a sofrem.

Tal como mencionado em Nations (2006) é necessário o trabalho conjunto de instituições de diferentes áreas do conhecimento para oferecer às pessoas com deficiência os instrumentos que Ihes permitam desfrutar plenamente dos direitos que a elas correspondem como seres humanos e membros da sociedade.

No campo tecnológico, o acesso e uso eficiente das tecnologias permitem a criação, modificação, difusão, crítica, e obtenção de informação. Essas capacidades permitem o desenvolvimento dos participantes na sociedade assim como o exercício das suas liberdades como ser humano. Por essa razão, a Convenção das Nações Unidas sobre os direitos das pessoas com deficiência pede para todos seus assinantes colocarem ênfase e disponibilizar recursos para a promoção e desenvolvimento de tecnologias, na medida do possível economicamente viáveis, que se ajustem as necessidades de uma variedade de tipos de usuário. O documento da ONU foi assinado pelo governo brasileiro o que coloca em manifesto o compromisso nacional para fornecer as facilidades que possibilitem a inclusão das pessoas com deficiência na sociedade.

\section{B. A definição de Pessoa com deficiência ou com necessidades diferenciadas é mais abrangente do que tradicionalmente se pensa.}


Contrário ao pensamento tradicional, a definição de deficiência não engloba unicamente as pessoas cegas, surdas e com dificuldades motoras, pelo contrário existem muitas e diferentes formas de deficiência como mencionado em Vanderheiden e Treviranus (2011). No ano 2007, a World Health Organization(WHO) elaborou a Classificação Internacional de Funcionalidade, Incapacidade e Saúde (ORGANIZATION, 2007) com o objetivo de estabelecer um padrão internacional para a descrição do que é considerado uma deficiência. Assim, neste trabalho é adotada a definição dada no documento mencionado: uma deficiência, ou impairment em inglês, é qualquer defeito, perda ou anormalidade da estrutura ou função psicológica, fisiológica ou anatômica da pessoa. Além disso, uma deficiência pode ser temporária ou permanente, regressiva ou estática, intermitente ou contínua, leve ou severa, e inclusive pode flutuar ao longo do tempo. Assim, uma pessoa "normal"torna-se uma pessoa com deficiência ao, por exemplo, quebrar uma mão, ou fazer uma cirurgia, ou até quando torcer o pé, pois isso implica uma mudança nas funcionalidades que a pessoa pode desempenhar e os recursos disponíveis para sua interação com o mundo. Como menciona Nations (2006) dita restrição de recursos, no campo tecnológico, que as pessoas experimentam por possuir alguma deficiência tem impacto direto sobre as oportunidades, desenvolvimento e bem estar que elas podem alcançar, assim como também no grau de contribuição que elas podem fazer à comunidade a qual pertencem. Isso devido a que, como apontam Malinowsky, Nygård e Kottorp (2011)), Leblois (2013). na atualidade a capacidade de interagir de maneira eficiente com as tecnologias constitui um requisito para o desenvolvimento contínuo dos indivíduos na sociedade, e permite que eles atinjam o seu máximo potencial melhorando sua qualidade de vida.

No nível mundial, e de acordo com os dados coletados e publicados no Relatório Mundial sobre a Deficiência World Health Organization e World Bank (2011) pelo World Bank e a World Health Organization em 2011 existem mais de um bilhão de pessoas que se declaram portadores de algum tipo de deficiência. Isto é, como indica a Figura 2 que aproximadamente - $15 \%$ da população mundial sofre a perda de alguma funcionalidade, dos quais um estimado de 200 milhões estão submetidos a dificuldades funcionais consideráveis.

No nível nacional, e de acordo com as estatísticas do Censo Demográfico de 2010 (IBGE) (2010) conduzido pelo Instituto Brasileiro de Geografia e Estatística(IBGE) 45,6 milhões de pessoas participantes da pesquisa, aproximadamente um $24 \%$ da população como aparece na Figura 3, se declaram portadoras de pelo menos uma das deficiências investigadas em dito instrumento: deficiência auditiva, visual, motora e mental/intelectual. Sendo que um $84 \%$ da pessoas declaradas com deficiência residem em áreas urbanas e que, portanto, encontram-se em constante exposição à interação com tecnologias e sistemas computacionais.

De maneira complementar a Figura 4 fornece informações sobre a distribuição da população 
Figura 2 - Percentagem da População Mundial declarada com deficiência

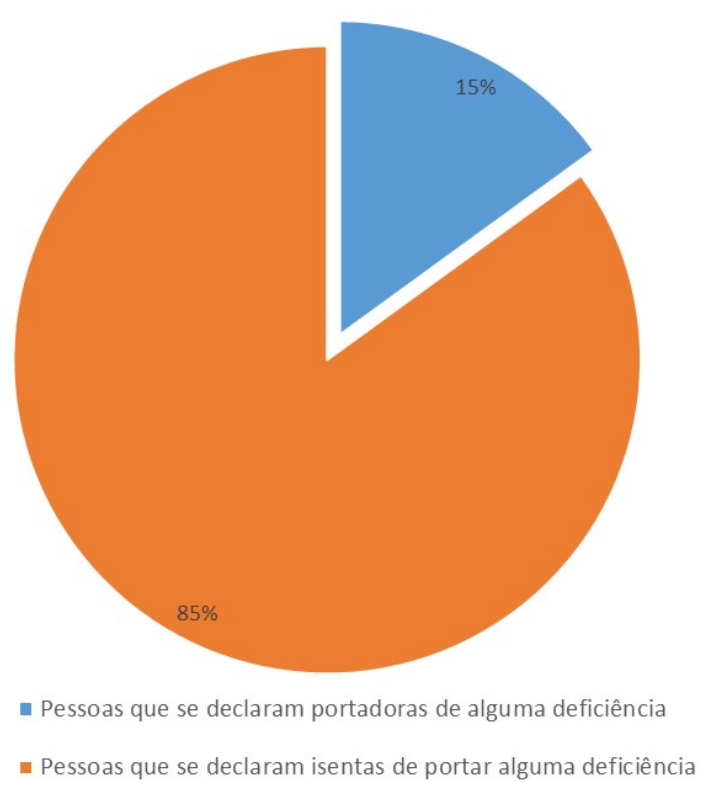

Fonte: (World Health Organization; World Bank, 2011)

Figura 3 - Percentagem da População Brasileira declarada com deficiência

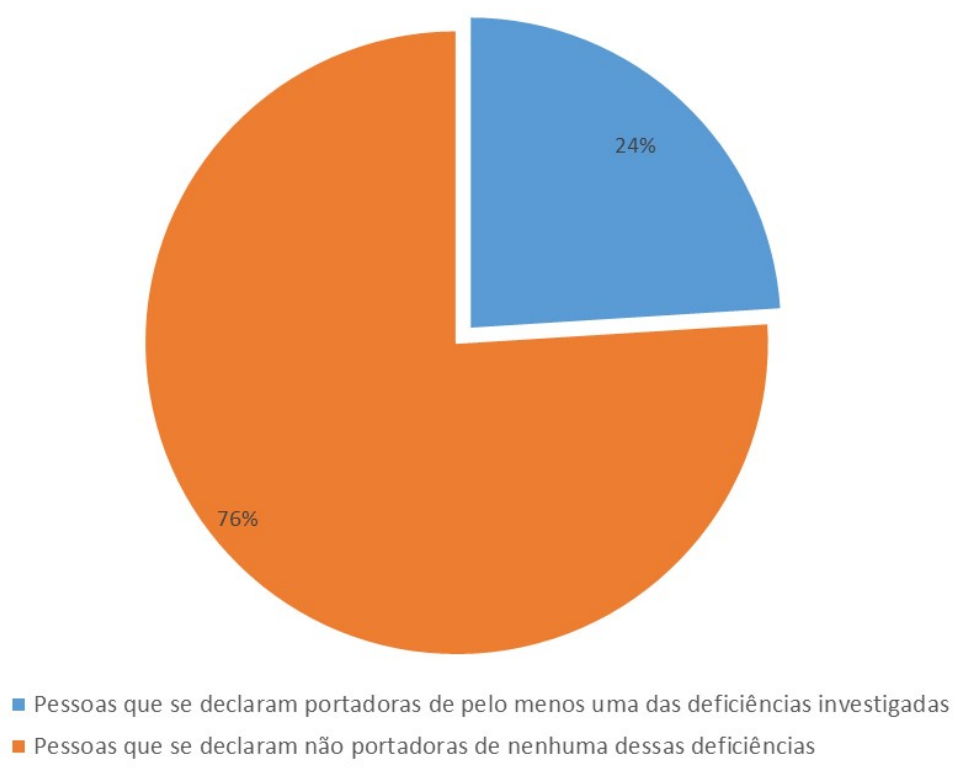

Fonte: ((IBGE), 2010)

por tipo de deficiência, de maneira que é possível concluir que a deficiência visual e motora são as que apresentam maior índice, representando o $80 \%$ de população declarada como deficiente. Adicionalmente, a Figura 5 apresenta o papel importante da passagem do tempo na aquisição 
Figura 4 - Percentagem de presença por tipo de deficiência dentro da população

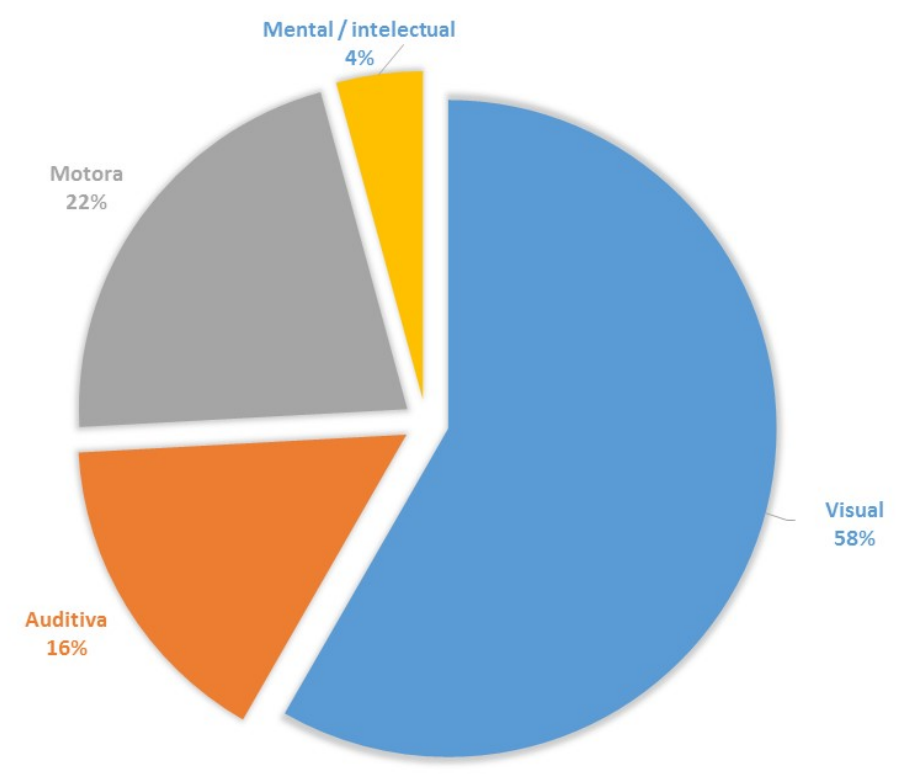

Fonte: ((IBGE), 2010)

de deficiências como parte do processo de envelhecimento das pessoas. Assim, a percentagem de pessoas com algum tipo de deficiência mantem-se inferior a $20 \%$ da população até os 40 anos, idade a partir da qual começa a ter um incremento considerável como consequência do desgaste físico produzido pela passagem do tempo.

C. Na atualidade existem recursos tecnológicos que viabilizam novas abordagens para resolver o problema de falta de inclusão tecnológica de usuários com necessidades diferenciadas.

A criação de novos elementos de hardware assim como o incremento no poder computacional que oferecem viabilizam a implementação de soluções tecnológicas que outrora eram tecnicamente impossíveis. Assim mesmo, a crescente preocupação, no nível mundial sobre a incorporação de pessoas com necessidades diferenciadas nas atividades da Sociedade da Informação tem motivado a criação de recursos e métricas que estão sendo progressivamente assimilados como padrões internacionais. Ditas tecnologias tem sido incorporadas de maneira "nativa"nas principais plataformas computacionais com a finalidade de facilitar a tarefa de personalização das ferramentas às necessidades do usuário. Consequentemente, a implementação de novas técnicas e mecanismos, ou mesmo a aplicação de tecnologias externas à área de Interação Humano-Computador, ou $\mathrm{HCl}$ pelas siglas em inglês (Human-Computer Interaction) tem sido facilitada pelo contexto tecnológico disponível no século XXI. 
Figura 5 - Porcentagem de presença de População com alguma deficiência por grupos de idade

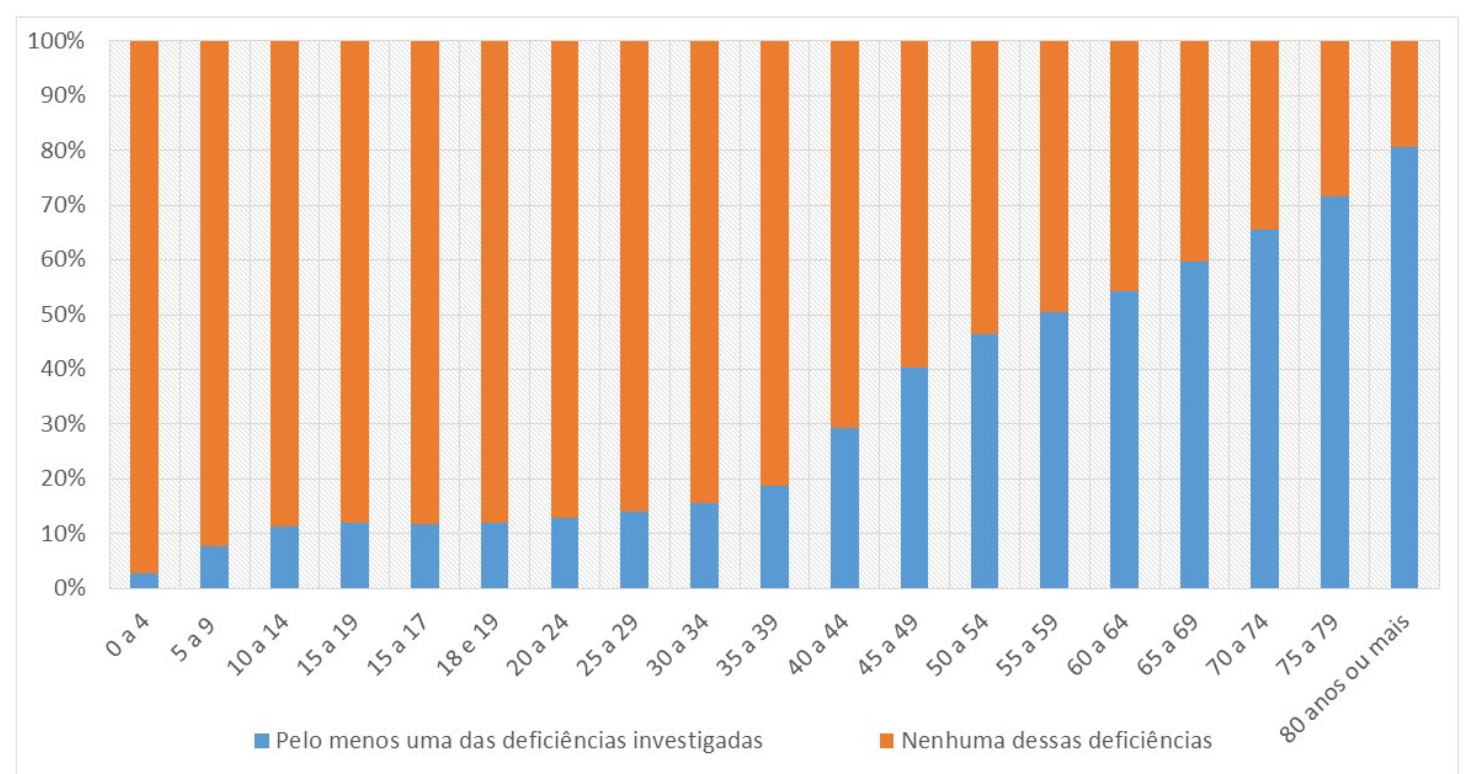

Fonte: ((IBGE), 2010)

O desenvolvimento de um mecanismo que permita que um sistema possa reconfigurar os recursos de interação com os usuários nele disponível significa ampliar seu alcance tornando-o acessível e enriquecendo-o com novas funcionalidades para interagir com uma comunidade de usuários mais abrangente do que a inicialmente considerada. Além disso, ao considerar as características do usuário o sistema torna-se personalizável, e isto, segundo Bagnara e Pozzi (2009), é desejável por todo usuário para qualquer sistema, pois o processo de interação é um fenómeno pessoal e ativo, que muda em várias dimensões: as habilidades do usuário, as condições ambientais, os recursos do sistema e até mesmo ao longo do tempo.

Tal como for mencionado anteriormente, todo usuário deseja ou precisa de algum nível de personalização ou ajuste na sua interação com um sistema, não é uma necessidade exclusiva das pessoas com de deficiência. Assim, é importante notar que o presente trabalho pretende propor um mecanismo para atender não só as necessidades das pessoas com alguma deficiência, mas também as necessidades de diferentes tipos de usuários de maneira geral.

Neste contexto, a Tecnologia Adaptativa fornece mecanismos para representar a diversidade dos sistemas interativos, explorar experiências passadas e permitir a reconfiguração do sistema de acordo com as informações obtidas Neto (2007). Particularmente, a incorporação de um recurso que permita algum nível de personalização dentro do processo de interação humanocomputador é necessária para permitir uma experiência eficiente e confortável para o usuário. Além disso, a preocupação pela consideração de mudanças no contexto das tecnologias e o 
estabelecimento de canais de interação adequadas tanto para as atividades entre humanocomputador quanto para as atividades entre tecnologias. Adicionalmente, este trabalho procura estabelecer um diferencial com outras possíveis abordagens de solução na medida que fornece uma alternativa portável, colaborativa em vez de invasiva para o sistema hospedeiro, trabalhando com os recursos disponíveis do sistema, mas sendo suficientemente configurável para que, de maneira fácil, seja possível colocá-lo em operação, de maneira que idealmente ele não fique obsoleto tão rapidamente como consequência natural da evolução tecnológica.

Como consequência, o desenvolvimento deste projeto tem como objetivo final proporcionar aos sistemas existentes uma implementação mais próxima do acesso universal, aportando adaptatividade como um elemento chave para trabalhar a diversidade na Interação HumanoComputador Stephanidis e Savidis (2001)), Coetzee e Barnard (2004)), Richter e Hellenschmidt (2004).

\subsection{ESTADO DA ARTE}

Na literatura existem diversos projetos de pesquisa que procuram oferecer uma solução para o problema de exclusão tecnológica que sofrem as pessoas com alguma deficiência. A maioria dessas propostas diferenciam-se fortemente nos seguintes pontos:

- Abordagem: Existem projetos concentrados em criar tecnologias reativas para oferecer acessibilidade aos sistemas computacionais legados, e existem projetos que procuram oferecer uma resposta que possa suportar as tendências emergentes na evolução tecnológica.

- Abrangência: De um lado existem projetos que se concentram em incorporar acessibilidade em determinados tipos de tecnologia, por exemplo, centrais de controle de dispositivos, sites web, quiosques de informação, entre outros. De outro lado, existem projetos que propõem seguir a tendência de criação de ambientes ubíquos de uso geral, tendo em conta, não apenas computadores pessoais, mas telefones, tablets, cartões inteligentes, e outros dispositivos que possam armazenar informações em diferentes contextos.

- Arquitetura: A tecnologia e os métodos utilizados para a construção de diferentes plataformas que suportam o objetivo principal dos sistemas em questão podem variar muito entre uma proposta e outra. Em alguns dos casos são frameworks para a construção de sistemas mais acessíveis, em outros são técnicas de modelagem para processar a informação do usuário, ou middlewares que, articulados de uma maneira especializada, permitem atender as diferentes necessidades de certas classes de usuários.

Descrevem-se a seguir os diferentes projetos de pesquisa que possuem maior semelhança tanto com a proposta quanto com a finalidade do presente trabalho. Primeiro são apresentados 
os projetos de pesquisa desenvolvidos em contexto acadêmico, mencionando-se logo após os recursos comerciais existentes que de alguma maneira procuram resolver o problema de acessibilidade para as pessoas com alguma deficiência.

\subsubsection{Web-4-All}

O Web-4-All Centre (2014)), Vanderheiden e Treviranus (2011) é um sistema criado pelo Adaptive Technology Resource Centre(ATRC) da Universidade de Toronto em Canada, em parceria com o governo canadense, como parte do Programa de Acesso Comunitário que procura fornecer acesso tecnológico nos espaços públicos do país. O sistema Web-4-All compõe-se de duas partes: um elemento portátil de tipo smart-card e um elemento fixo, instalado localmente no sistema hospedeiro. Na parte portátil do sistema Web-4-All é possível salvar as preferências do usuário para permitir a reconfiguração de computadores multi-usuário de uso geral. As preferências do usuário podem ser de três tipos: preferências de configurações de sistema, preferências de configuração do navegador web, e preferências na configuração das ferramentas de tecnologia assistiva disponíveis. Essas informações são codificadas em uma representação XML, criada por meio de um assistente passo-a-passo, e que, como máximo, ocupa $2 \mathrm{~KB}$ de espaço no dispositivo portátil. O elemento fixo do sistema Web-4-All deve ser instalado no computador de uso geral, de maneira que ele efetua as configurações necessárias de acordo com o indicado no pen drive do usuário, e com os recursos disponíveis no computador. Ao finalizar a interação com o usuário o sistema retornará à configuração padrão do computador.

A Figura 6(a), (b) e (c) apresenta algumas das janelas do sistema Web-4-All com as quais o usuário interage para especificar as suas preferências no sistema.

Figura 6 - Telas de boas-vindas e configurações de usuário e preferências no sistema Web-4-All

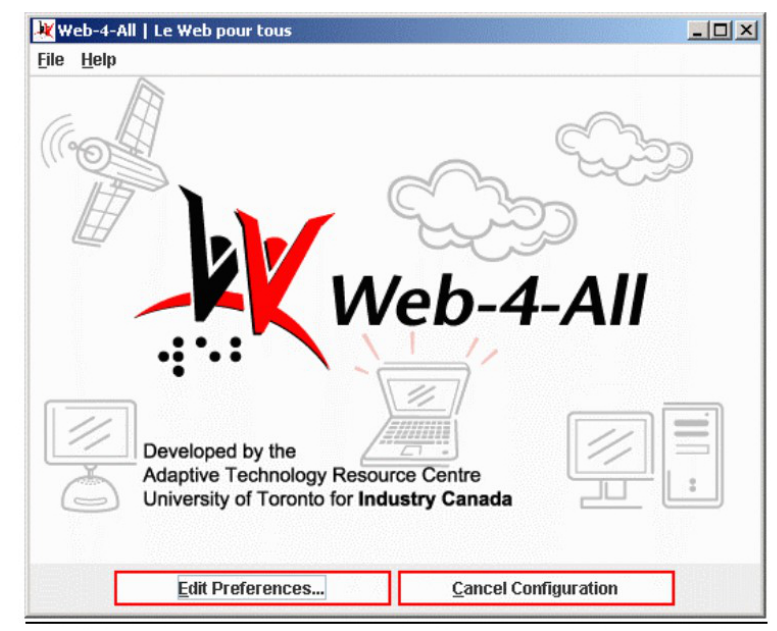

(a) 


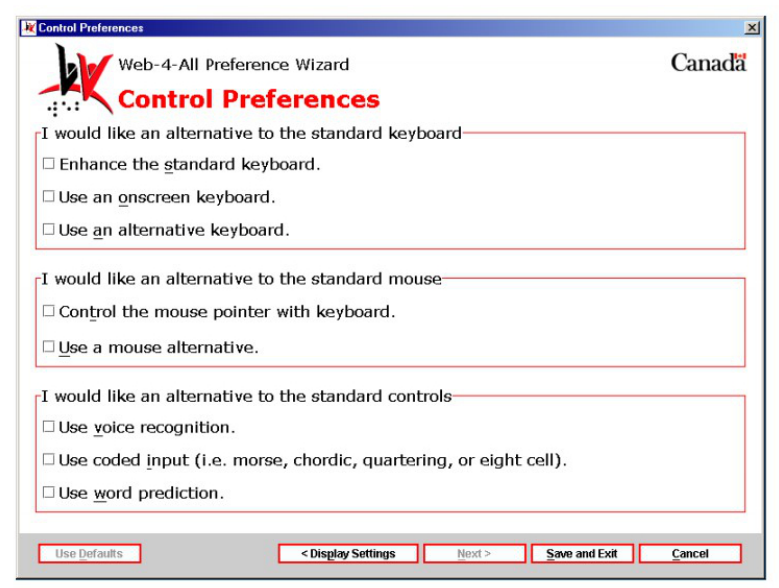

(b)

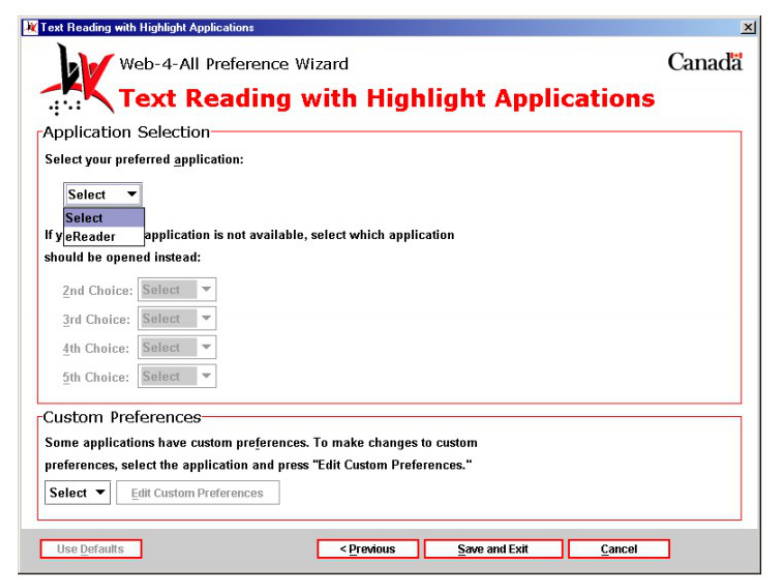

(c)

Fonte: (CENTRE, 2014)

Do ponto de vista arquitetônico, o Web-4-All compõe-se de módulos independentes, implementados em Java, responsáveis cada um deles por uma tarefa bem definida de maneira que um módulo só precisa se preocupar da existência dos outros no momento de interagir com algum deles.

As diferenças principais entre o projeto Web-4-All e a nossa proposta é que no nosso trabalho não será necessária a instalação de nenhum módulo como parte do sistema principal de maneira permanente. As informações contidas no modelo irão solicitar a reconfiguração do sistema principal por meio de funções próprias do sistema operacional que governa dito sistema, assim é possível utilizar a tecnologia em qualquer computador disponível. No caso do Web-4-All a solução é dependente da plataforma, tanto por questões de hardware, no caso da tecnologia smart card que utiliza, quanto por questões de software, na configuração das preferências da tecnologia assistiva própria do sistema operacional. No nosso caso, o modelo trabalha sobre uma meta-arquitetura o que permite que o sistema se adapte à plataforma em cada caso, em tempo de execução. 


\subsubsection{AVANTI Web browser}

O projeto do Sistema AVANTI Stephanidis e Savidis (2001)), Stephanidis et al. (1998) é uma iniciativa da Comissão Europeia por meio da qual é realizada a construção de um navegador Web que implementa o conceito de User Interfaces for All para oferecer acessibilidade aos usuários com deficiência visual e motora. O projeto propõe a criação de uma interface de usuário que ofereça tanto mecanismos de adaptabilidade e adaptatividade, quanto recursos de hardware que suportem a interação com usuários com necessidades diferenciadas. Para informações mais detalhadas sobre as definições e usos dos termos personalização, adaptabilidade e adaptatividade consultar o material trabalhado no Apêndice B: Personalização, Adaptabilidade e Adaptatividade. A arquitetura do sistema AVANTI, como representada na Figura 7 está dividida em três módulos principais:

- Módulo 1: Contém uma coleção de bases de dados multimídia as quais podem ser acessadas via HTTP e fornecem informações sobre a mobilidade necessária para pessoas com alguma deficiência.

- Módulo 2: O servidor AVANTI é responsável principalmente por três tarefas: (i) mantém a base de conhecimento correspondente ao usuário, (ii) salva as relações estabelecidas para as entidades na configuração do sistema, e (iii) adapta tanto o conteúdo quanto o formato de apresentação das informações de acordo com as características do usuário.

- Módulo 3: Uma interface unificada do navegador a qual pode se adaptar às características do usuário.

O funcionamento do sistema AVANTI baseia-se no trabalho coordenado de subcomponentes, os quais implementam, em conjunto, dispositivos baseados em regras sobre as quais podem ser aplicadas tomadas de decisão em busca da sua adaptação à situação corrente. Assim, existem componentes que exercem a tarefa de examinar as condições do sistema na procura de algum evento que possa influenciar a interface do usuário, outros cuja tarefa é gerenciar as regras que governam o dispositivo, outros que aplicam as regras correspondentes à situação presente, e outros que transformam essas diretivas em ações de mudança internas à interface do usuário.

As principais diferenças entre o projeto AVANTI e a proposta realizada neste trabalho são:

- Quanto aos recursos necessários: o projeto AVANTI incorpora previamente elementos de hardware e de software nos computadores destinados ao uso de pessoas com alguma deficiência, portanto, não é realizada uma busca dinâmica para conhecer os recursos do sistema. Essa informação é registrada e disponibilizada a priori e permanece estática 


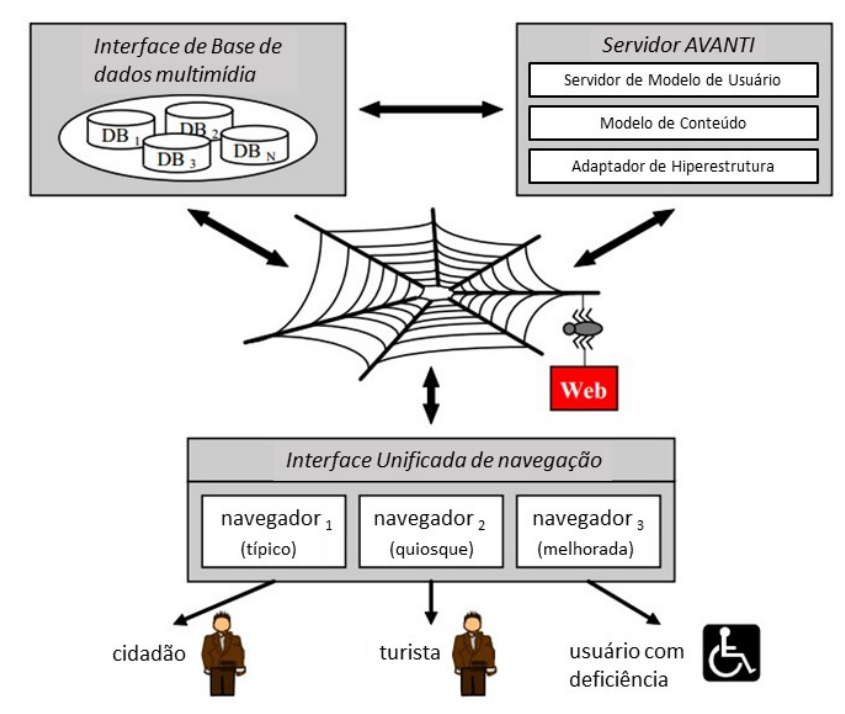

Fonte: Obtida e modificada de (STEPHANIDIS et al., 1997)

dentro do sistema, não permitindo mudanças a não ser por intermédio de uma alteração maior.

- Quanto ao escopo no projeto: A finalidade do projeto AVANTI é fornecer acessibilidade no contexto da navegação Web, portanto o escopo de ação se restringe ao suporte de àquela tarefa. Pelo contrário, a finalidade da proposta do presente trabalho é assistir o usuário no próprio processo de interação com um sistema legado de uso geral, de forma transparente. Isto é feito através da implementação de um mecanismo intermediário encarregado da reconfiguração do sistema hospedeiro levando em conta as preferências e necessidades do usuário. Assim, o usuário tem acesso a todos os recursos oferecidos no sistema, sem limitar ele à execução de uma tarefa específica, que no caso de AVANTI é a navegação Web.

\subsubsection{Projeto INREDIS}

O projeto INREDIS Pous e Ceccaroni (2010)), Pous et al. (Jan.)), INREDIS (2007), cujo nome provem do Espanhol Interfaces de Relación entre el Entorno y las personas con Discapacidad (Interfaces de Relacionamento entre o Entorno e as pessoas com deficiências) é uma iniciativa do governo espanhol, que promove a criação de tecnologias acessíveis e interoperáveis. O objetivo principal deste projeto é o desenvolvimento de tecnologias básicas que permitam criar canais de comunicação e interação entre as pessoas com algum tipo de 
deficiência e o seu entorno.

Particularmente, em Pous e Ceccaroni (2010), foi realizada a implementação de um display interativo de uso comunitário, ou ICD por ser as siglas em inglês de Interactive Community Display, que opera sob a diretriz de manter compatibilidade com dispositivos e tecnologias móveis já existentes e amplamente utilizadas. O projeto apresenta uma arquitetura baseada no trabalho em rede com implementação de Web Services e a construção de ambientes ubíquos e inteligentes.

A diferença entre nossa proposta e a implementação de INREDIS é que no segundo caso o sistema é totalmente dependente dos componentes, hardware e software, disponibilizados por meio dos dispositivos móveis de modo que o ICD é o agente intermediário responsável pela montagem de um sistema interativo. A nossa proposta parte da hipótese de contar com um sistema computacional do tipo tradicional e de uso geral, o qual sofre reconfigurações relativas à utilização de seus próprios recursos em benefício do usuário com o qual está interagindo. No entanto, a arquitetura da nossa proposta, deixa aberta a possibilidade de um modo de trabalho em rede com uso de Web services, sendo necessário realizar a especificação da interface que ditos componentes teriam. A implementação de dita interface não está inclusa no escopo deste trabalho.

\subsubsection{Projeto EMBASSI}

O projeto EMBASSI, como mencionado em Richter e Hellenschmidt (2004)), Richter e Enge (2003), é uma iniciativa patrocinada pelo governo Alemão para desenvolver soluções que permitam aos usuários interagir com os sistemas tecnológicos do futuro, especialmente quando se trata de sistemas de informação de uso público. O framework construído para o projeto EMBASSI utiliza um dispositivo móvel como assistente pessoal no processo de interação entre o usuário e os sistemas de informação presentes no entorno. O dispositivo móvel serve como fornecedor de hardware (dispositivos I/O) e software (serviços e aplicativos) e também como base de dados para armazenar as configurações e preferências do usuário. A arquitetura do sistema está baseada na implementação de agentes dedicados que processam, de maneira independente, a informação obtida nos diferentes canais disponibilizados para depois estabelecer uma rede de serviços que consumam tais informações para personalizar a interação com o usuário participante.

A maior diferença entre o projeto EMBASSI e a proposta deste trabalho é que no escopo de nosso trabalho os recursos disponíveis para melhorar a qualidade da interação entre usuário e computador são só aqueles que já estiverem instalados no momento de iniciar a interação. Todavia, caso na arquitetura proposta seja possível a incorporação de mecanismos que 
procurem novos recursos na rede, por exemplo serviços nos bancos de dados em nuvens, tal comportamento deverá ser expresso por meio de uma estratégia de configuração.

\subsubsection{Projeto Gaia}

Gaia é um framework desenvolvido pelo Laboratório de Computação Digital da Universidade de Illinois em Urbana-Champaign para a criação de ambientes inteligentes que sejam capazes de prestar ajuda às pessoas que realizam atividades em tais ambientes físicos. O objetivo principal do projeto é tornar os espaços físicos e os dispositivos eletrônicos neles contidos em sistemas computacionais programáveis de vanguarda a serviço do usuário. Em Ranganathan e Campbell (2003) é proposta a criação de um middleware que incorpore o uso de elementos sensíveis ao contexto como parte da informação processada pelos agentes em ambientes ubíquos. O sistema consiste em um grupo de diferentes agentes cada um deles desempenhando uma tarefa específica, alguns trabalhando no núcleo do sistema, outros na comunicação com os diferentes dispositivos que existem dentro do ambiente, outros realizando atividades diretamente relacionadas com os aplicativos, e outros ainda, dedicando-se ao gerenciamento da informação pessoal de cada usuário. A principal diferença entre Gaia e a nossa proposta é que Gaia é um sistema computacional novo, construído para manter vigência no tempo com as tecnologias de vanguarda, por meio da comunicação com dispositivos móveis para criar ambientes inteligentes que forneçam suporte para as atividades dos diferentes tipos de usuários. Por seu lado, a nossa proposta pretende resolver o problema presente nos computadores já disponíveis ao serviço do público em geral que inicialmente não fornecem suporte para facilitar a interação de usuários com deficiências, isto é os chamados sistemas legados.

A seguir as soluções no escopo comercial com maior semelhança com nossa proposta para fornecer acessibilidade as pessoas com alguma deficiência.

\subsubsection{Google Accessibility}

O compromisso de Google Google Inc. (2014) com os usuários é incorporar a preocupação pelo fornecimento de acessibilidade nos seus produtos ao longo do ciclo de vida do software, desde sua fase de concepção até sua manutenção e aperfeiçoamento. Seguindo essa diretriz a Google tem incorporado ferramentas e serviços nas suas diferentes plataformas tornando-a uma das maiores patrocinadoras de desenvolvimento de tecnologia assistiva na atualidade. No caso dos sistemas operacionais, Chrome OS e Android OS, são oferecidos recursos nativos dos sistemas operacionais que suportam a interação para usuários com baixa acuidade visual ou com cegueira por meio de legendas, gestos e ferramentas de ampliação, e contraste de imagem. Da 
mesma maneira, fornece suporte para interação com pessoas com alguma deficiência motora através de ferramentas com tecnologia de reconhecimento e síntese de fala. No caso dos serviços web, Google tem implementado recursos que permitem incorporar interpretação de linguagem de sinais, descrições automáticas baseadas em web semântica, entre outros ainda em versão beta ou em desenvolvimento. A proposta de inclusão de acessibilidade feita pela Google está alinhada com o núcleo de negócio da empresa: o desenvolvimento de serviços independentes que podem ser adicionados às plataformas web fornecidas por ela mesma. Dessa maneira, só no caso dos sistemas operacionais Android e Chrome é possível falar de um suporte geral para acesso às funcionalidades do sistema por meio de ferramentas nativas.

\subsubsection{Apple Inc.}

A Apple tem manifestado seu compromisso com a acessibilidade fornecida pelos seus produtos como um dos pilares que suportam a sua missão e visão Apple Inc. (s.d.)b), Apple Inc. (s.d.)a Assim tem padronizado interfaces para permitir que os recursos de acessibilidade sejam executados de maneira transparente em qualquer plataforma Apple, iOS ou OS X, transformando os seus dispositivos em tecnologia assistiva de "preços acessíveis". As ferramentas que são oferecidas pela Apple na plataforma OS X são: leitores de tela, ampliação de tela e de cursor, ferramenta de ditado, inversão de cores para maior contraste e a possibilidade de incorporar dispositivos de entrada e saída compatíveis como aparelhos de auxilio auditivo e Displays ou Linha Braille. No caso da plataforma móvel, iOS os serviços e aplicativos fornecidos como recursos para acessibilidade são: assistente inteligente Siri para permitir o gerenciamento dos diferentes serviços presentes no dispositivo por meio de fala, ferramentas de ditado, zoom, navegação, e alertas vibratórios. Da mesma maneira que no OS $X$ é fornecida a possibilidade de incorporar dispositivos de entrada e saída nas plataformas iOS, mas além disso também é permitido o gerenciamento de dispositivos de tecnologia assistiva diretamente pelos aplicativos da Apple. Exemplos desses últimos são: os dispositivos de auxílio para audição, os teclados personalizados, filtros de ruído, entre outros. Em ambos casos, as mudanças nas interfaces executadas para oferecer recursos de acessibilidade são, além de mudanças de tipos funcionais, mudanças estruturais no próprio sistema operacional do dispositivo.

A principal diferença entre ambas as abordagens comerciais mencionadas acima, Google Accessibility e Apple Accessibility, e a nossa proposta é, além do custo, que nossa proposta é um elemento tecnológico "transparente", no sentido de que ele apresenta potencial para ser utilizado em qualquer tipo de sistema hospedeiro, durante a interação só os recursos do middleware sofrem mudanças estruturais e sempre é respeitada a independência do sistema hospeidero, assim o controle interno sobre os elementos não se vê afetado ou transgredido. 
De acordo com a revisão feita das ferramentas de software no mercado o sistema comercial que apresenta maior semelhança com a solução proposta neste projeto é o InfoVox, detalhado a seguir.

\subsubsection{InfoVox}

O sistema InfoVox Acapela Group (2012) é uma solução de software desenvolvida pela empresa multinacional Acapela Group, descrita como um companheiro falante, um chamado all-in-one, com desempenho local e portátil especialmente desenvolvido para fornecer acessibilidade aos usuários com deficiência visual. O software é disponibilizado como um pen drive, e permite ser utilizado sem requerer instalação, pois contém um leitor de tela, um criador de arquivos MP3, um gerenciador de vozes para configurar algumas propriedades, um editor de pronúncia para tratar possíveis casos de exceção, e dois componentes responsáveis pela sincronização e atualização das partes do software: um gerenciador de Downloads e um gerenciador de atualizações de software. O software apresenta dois modos de trabalho: um modo portátil e um modo local. Por um lado, o modo portátil e efetuado por médio do pen drive, permitindo acesso a qualquer computador com os sistemas operacionais Windows $\mathrm{XP}$, Vista, 7,8 e 8.1 em qualquer das versões, 32 ou 64 bits. Por outro lado, o modo local permite ao usuário fazer a instalação, com ajuda do gerenciador de download, do leitor de tela e algumas das vozes disponíveis tanto no dispositivo como na loja da empresa. Numa segunda instância também foi lançada uma outra versão de InfoVox para uso com a plataforma iOS chamada de iVox, a qual pode interagir e disponibilizar novas vozes para a ferramenta de sínteses de fala padrão do sistema operacional. Lamentavelmente, por razões comerciais não é viável conhecer com certeza a arquitetura nem o mecanismo de implementação de InfoVox. Da mesma maneira, não se encontra disponível, dentro dos canais oficiais das empresas correspondentes, nenhuma referência sobre os detalhes de funcionamento sobre o preço do software. InfoVox, sendo uma solução de nicho, está comprometida só com disponibilizar recursos de síntese de fala. No entanto, ela é a ferramenta com maior semelhança do ponto de vista da facilidade de uso e transparência do lado do usuário, e na possível arquitetura desenvolvida para implementar o seu produto final. Já no caso da arquitetura do dispositivo adaptativo proposto no nosso projeto, detalhada no Capitulo 3, é possível identificar mais uma vantagem. No nosso trabalho os conceitos de adaptatividade são utilizados, tanto no nível de montagem da interface de interação com o usuário, quanto na própria configuração concreta do dispositivo segundo as condições e o tipo de sistema hospedeiro corrente de maneira que a flexibilidade da solução pode ser estendida.

A Figura 8 apresenta a maneira de resumo uma comparação rápida dos diferentes recursos 
e características oferecidas pelas diferentes ferramentas mencionadas nesta secção e a nossa proposta. 


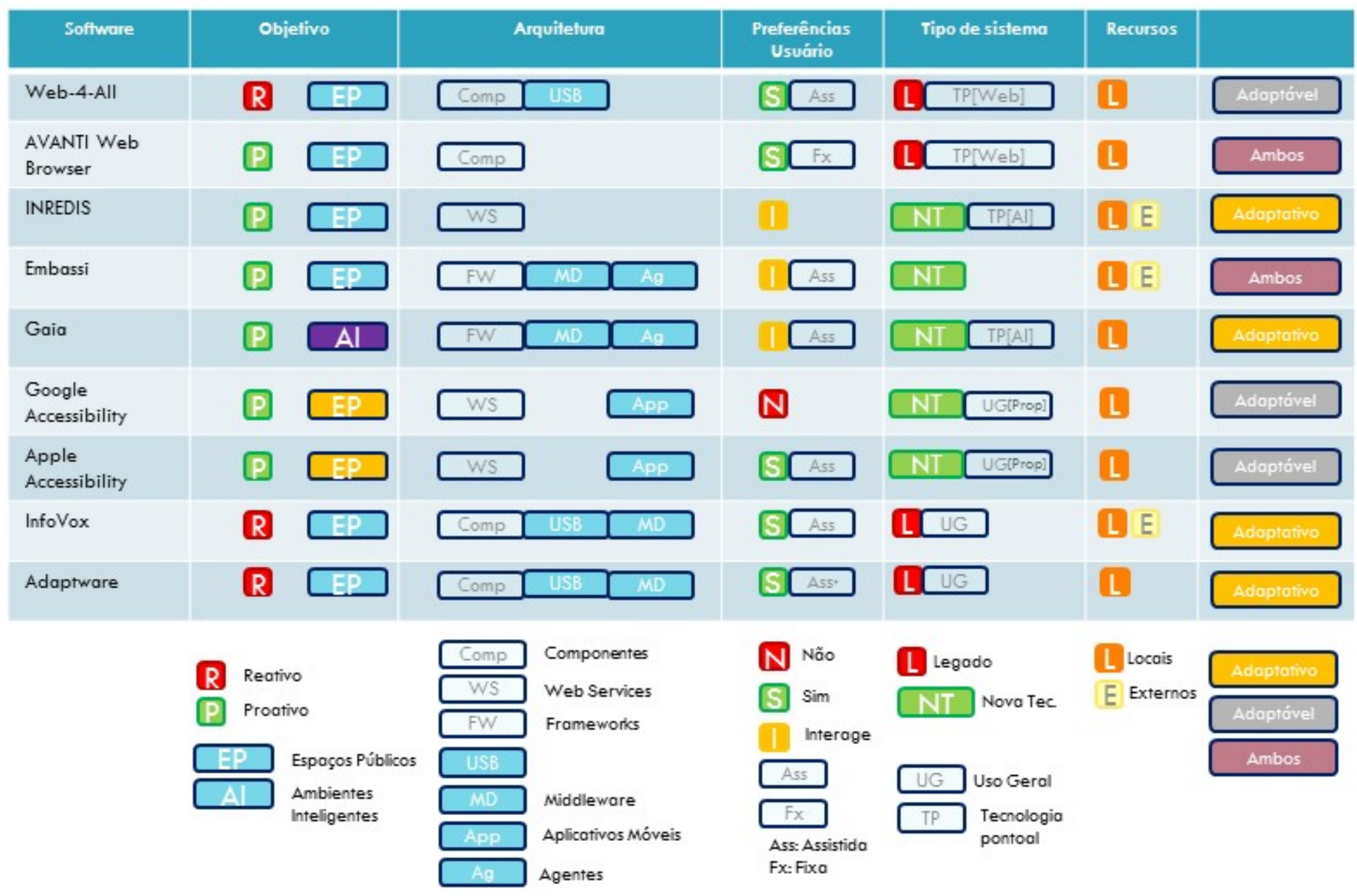




\subsection{USO DA TECNOLOGIA ADAPTATIVA PARA RESOLVER PROBLEMAS DE TOMADA DE DECISÕES}

Cada um dos projetos apresentados anteriormente propõe uma alternativa de solução para o problema de acessibilidade que experimentam as pessoas com alguma deficiência ao interagir com sistemas computacionais. No entanto, eles têm em comum o uso de tecnologias especializadas para realizar a tomada de decisões referente às ações a serem executadas de acordo com as informações obtidas. As diferentes técnicas variam desde o uso de agentes dedicados à tarefas específicas, técnicas de aprendizagem de máquina, ontologias, e até dispositivos regidos por regras. Em relação aos últimos, existe a dificuldade na especificação do comportamento do sistema frente a cada caso possível, por meio da criação de uma regra para cada um deles. Dado que não é econômico realizar esse processo exaustivamente, na maioria dos casos opta-se por limitar os casos a serem cobertos, restringindo-os àqueles com a maior probabilidade de ocorrência. No nosso trabalho é proposto o uso das técnicas de tecnologia adaptativa para a criação, modificação e eliminação das regras que especificam o comportamento do sistema frente às diferentes situações possíveis. Assim, as técnicas adaptativas apresentam um mecanismo formal, claro e, em vários dos casos, mais simples para gerar respostas aos diferentes estímulos contidos no contexto de alguma realidade. Além disso, as técnicas de tecnologia adaptativa permitem incorporar a informação das ações executadas no passado para auxiliar o processo de tomada de decisões. Dessa maneira, os dispositivos adaptativos atuam como instrumentos que viabilizam o uso de tecnologias legadas graças à incorporação de elementos encarregados de gerenciar ditas mudanças. Essas tecnologias legadas, na maioria dos casos, foram criadas sem mecanismos que lhes permitiam trabalhar com mudanças no contexto e que, portanto, são ferramentas fixas baseadas num padrão arbitrário. A evolução na área de tecnologias adaptativas apresenta uma variedade de dispositivos, assim, de acordo com o tipo de mecanismo subjacente, eles podem ser: estados, ações, funções, chamadas a função, entre outros. As incorporações desses elementos constituem a denominada camada adaptativa caraterística dos mecanismos de tecnologia adaptativa. Particularmente, no domínio do nosso trabalho as técnicas de tecnologia adaptativa oferecem uma ferramenta para a montagem de uma interface de interação com o usuário baseada nas informações dos diferentes contextos e a própria experiência de execução, esse mecanismo são as denominadas Tabelas de Decisão Adaptativas as quais são enunciadas no próximo capitulo. 


\subsection{TERMINOLOGIA UTILIZADA}

Nesta secção são apresentados e definidos os termos utilizados no contexto deste trabalho. O objetivo é colocar em evidência quais são as caraterísticas associadas com cada um deles e delimitar sua abrangência dentro da área de sistemas computacionais.

\subsubsection{1 "Customização"}

A palavra "customização" não é reconhecida como uma palavra formal dentro da Língua Portuguesa, no entanto, o seu uso tem sido aceito e generalizado não só no ambiente coloquial, mas também dentro das diferentes áreas acadêmicas relacionadas à tecnologia. Neste trabalho vamos utilizar o termo "customização" como um anglicismo do termo customization. Assim, o termo "customização" indica que as mudanças a serem efetuadas provêm de uma ordem expressa do usuário, o qual através de diretivas é capaz de escolher quais que são os novos valores que se adequam mais para suas necessidades. Existem duas maneiras de "customização" no entorno tecnológico, a primeira delas se refere à aplicação de mudanças dentro da mesma instância de dispositivo, e a segunda obedece à criação (entendido como planejamento, design ou desenvolvimento) de uma nova ferramenta tecnológica que é uma variação da primeira e incorpora as mudanças especificadas para satisfazer as necessidades do usuário, nesse último caso o termo ad hoc tem sido amplamente utilizado. Dentro desse contexto é importante notar que a "customização" pode ou não implementar adaptabilidade, termo que definiremos a seguir, para a incorporação de mudanças, consequentemente é teoricamente errado falar de adaptatividade como mecanismo para implementar "customização".

\subsubsection{Adaptabilidade}

O dicionário Aurélio define "adaptabilidade" de maneira geral como a qualidade ou capacidade de alguma entidade de ser mudada, em alguma das suas caraterísticas, com a finalidade de ajustá-la para um novo propósito ou uma nova situação. Assim, se uma entidade é adaptável significa que ela admite a possibilidade de aplicar de mudanças nas suas características padrões. É importante notar que em nenhum momento a definição de adaptabilidade faz menção sobre o agente executor da mudança, assim, uma entidade pode ser adaptada por um agente externo que tem o poder de decisão sobre as mudanças a serem feitas, as quais são aplicadas pela entidade a ser adaptada, ou, num caso particular, a própria entidade pode ser a responsável pela tomada de decisão e aplicação das mudanças na sua própria estrutura. Portanto, a adaptabilidade é caracterizada pela participação não ativa do sistema, e sim pela 
escolha por parte dum agente externo de alguma funcionalidade pré-existente que implemente o comportamento a alteração desejada.

\subsubsection{Personalização}

De maneira geral o termo "personalização" é definido como a capacidade que possui uma entidade para mudar alguma das suas próprias características, de aparência ou comportamentais, com o propósito de satisfazer as necessidades ou requerimentos de uma pessoa em particular. Assim, o poder de decisão sobre as mudanças a serem aplicadas (quais, quando e

como) está no próprio sistema e não num agente externo. Este termo é frequentemente utilizado no entorno de aplicações web e programação de aplicativos altamente responsivos. Neste entorno "personalização" significa que a ferramenta tecnológica conta com algum mecanismo que permite que ela mesma possa inferir algumas das preferências e necessidades do usuário à maneira de oferecer para ele as recomendações que melhor se ajustam com esses valores.

\subsubsection{Adaptatividade}

De maneira geral o termo "adaptatividade" é definido como a capacidade que possui alguma entidade para conseguir efetuar uma mudança nela mesma a fim de se adequar a uma nova situação. Esta palavra também expressa um estado, um grado ou medida da qualidade interna desta capacidade. Já na área tecnológica, o termo "adaptatividade" define a propriedade que apresenta um sistema, processo ou dispositivo computacional, que lhe permite, sem a interferência de agentes externos, tomar a decisão de executar alguma mudança, de maneira autônoma e dinâmica, no seu próprio comportamento como consequência de algum estímulo, entendido como alguma variação nas condições no seu ambiente de execução, e a sua configuração corrente.

\subsubsection{Middleware}

Dentro deste trabalho vamos adotar a definição de "middleware", enunciada em (SADJADI, 2003), como uma entidade de software para conectividade que encapsula um conjunto de serviços e que reside acima da camada do sistema operacional e abaixo da camada de aplicações de usuário. Um middleware facilita a comunicação e coordenação de componentes que, potencialmente, estão distribuídos através da rede do hóspede. Além disso, um middleware fornece aplicativos com abstrações de programação de alto nível. Assim,um middleware pode esconder processo de comunicação, mascarar a heterogeneidade dos sistemas subjacentes (dis- 
positivos hardware, sistemas operacionais, e protocolos de rede), e facilitar o uso de diferentes linguagens de programação no nível de aplicações.

\subsubsection{Configuração de Sistema}

Dentro do escopo deste trabalho entenderemos o termo configuração de sistema como a disposição particular e o estabelecimento de dados, funções, componentes de software, recursos de hardware, assim como também as relações entre eles, e as propriedades que cada um possui, de maneira que permite a operação correta do sistema de acordo com o definido pela sua arquitetura.

\subsubsection{Componente Software}

De acordo com Szyperski (2002) um componente de software é uma unidade de composição que estabelece um contrato especificando explicitamente só as interfaces e dependências de contexto. O Design baseado em componentes é um paradigma de design que tem sido utilizado para dar solução a diferentes problemas na área de engenharia de software. No entanto, considerando que existem diferentes tipos de componentes disponíveis, é muito complicado que todos eles ofereçam compatibilidade para se compor com qualquer outro. Normalmente, os componentes que oferecem esta compatibilidade de conexão estão baseados num mesmo marco de design, também chamado framework ou modelo de componentes, o qual garante essa compatibilidade através do estabelecimento de padrões e convenções.

\subsubsection{Arquitetura}

A Arquitetura dum sistema é, de acordo com Persson (2009), a organização fundamental dum sistema, encarnado em seus componentes, as relações ente eles, o ambiente de execução e o princípios que governam seu design e evolução.

\subsubsection{Contexto de execução}

De acordo com (DEY, 2001: DEY; ABOWD, 1999) um "contexto" está formado por quaisquer informações que possam ser utilizadas para caracterizar a situação na qual se encontra uma entidade. A sua vez, uma entidade é uma pessoa, lugar, ou objeto que é considerado relevante na interação entre o usuário e o aplicativo. 


\section{CONCEITOS E FUNDAMENTAÇÃO TEÓRICA}

Este capítulo faz uma revisão da teoria, define a terminologia utilizada ao longo deste trabalho e apresenta os conceitos necessários para a leitura e a compreensão do restante do texto. São apresentados, ou ao menos mencionados e comentados os conceitos, teorias e tecnologias relacionadas ao gerenciamento de recursos para a interação humano-computador e a evolução nessa área.

\subsection{A ÁREA DE INTERAÇÃO HUMANO-COMPUTADOR E SEU COMPROMISSO COM O USUÁRIO}

O desenvolvimento de um software que leve em conta as diferentes dimensões envolvidas na interação entre o usuário e o computador, proporcionando ao usuário uma experiência funcional e eficiente, ou seja de acordo com as suas necessidades e desejos, é um dos principais objetivos na área de Interação Humano-Computador, conhecida também como $\mathrm{HCl}$ pelas suas siglas em inglês (Human Computer Interaction). Tal foi justamente o objetivo que permitiu a evolução e a mudança no foco do projeto das interfaces da interação entre o homem e o computador. Inicialmente partiu-se da orientação às tarefas, segundo essa abordagem o importante era atingir a funcionalidade requerida sem prestar muita atenção às facilidades fornecidas para o usuário. Logo, o foco mudou para o usuário, assim a nova preocupação foi permitir um melhor intercâmbio de informações entre ele e o sistema, otimizando as entradas e saídas. Por último, a abordagem contemporânea foca-se no humano, isto é procura-se fornecer ao usuário do sistema uma experiência de uso satisfatória e adequada a suas diversas necessidades como individuo. Em Nielsen (1993) encontra-se uma ótima referência sobre as gerações de interfaces de usuário enquanto na Figura 9 são mostradas as principais tendências na área.

As mudanças ocorridas ao longo dos anos revelam a tendência de um atendimento crescente na evolução das tecnologias para a criação de sistemas que possam fornecer atenção das necessidades de usuários com perfis cada vez mais abrangentes. Em alguns casos, ter em consideração perfis de usuário diferentes é só uma característica desejável dos sistemas, em outros a necessidade de inclusão está sendo cada vez mais reclamada pelos próprios usuários Reinsberg (2014), e em outros é uma parte fundamental da tecnologia. Um exemplo do último caso é a computação ubíqua, sobre a qual, já em 1999 afirmou-se o seguinte:

Os sistemas operacionais e software em geral devem mudar de maneira substancial [...] eles devem ser capazes de se contrair e expandir automaticamente para atender as necessidades dinâmicas da computação ubíqua. (WEISER, 1999)

Da mesma forma, o crescimento das tecnologias móveis, computação vestível Wearable 
Figura 9 - Principais Paradigmas de Interação Humano-Computador

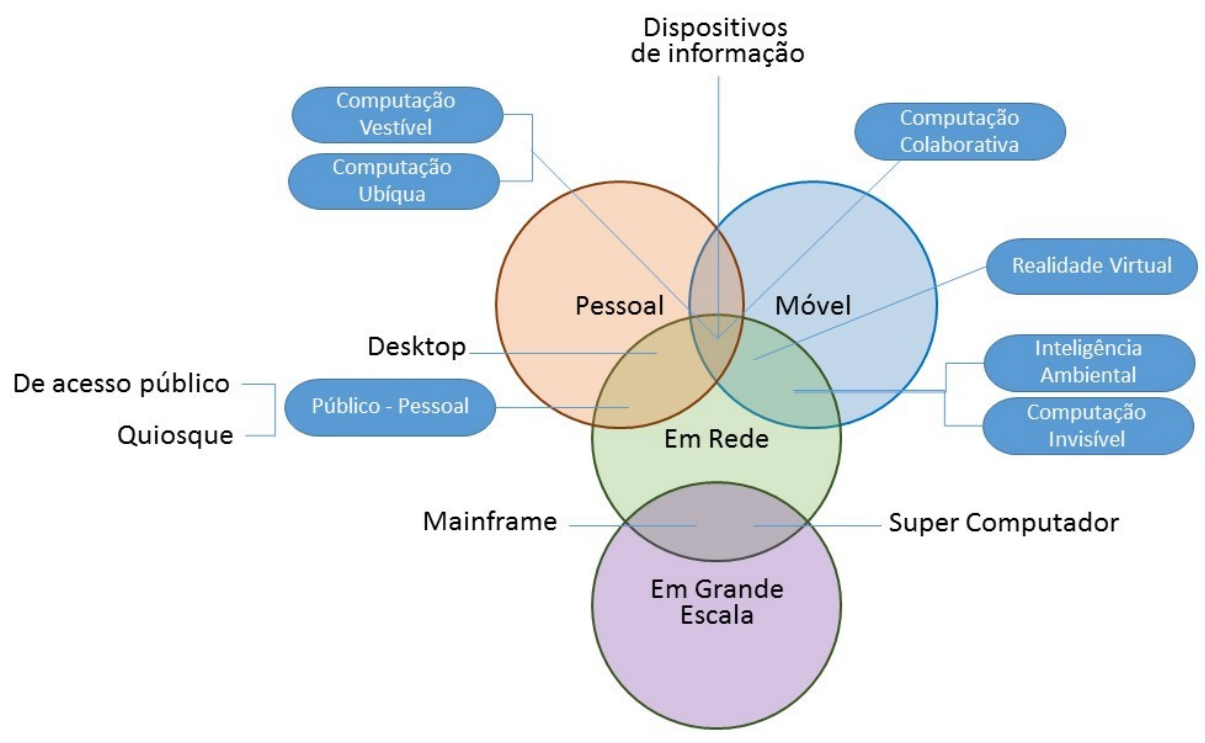

Fonte: Obtida e traduzida de (HEIM, 2007)

Computing Organization (s.d.), e a construção de entornos inteligentes, tem impulsionado o interesse pela inclusão de comunidades de usuários anteriormente desatendidos. Essas abordagens procuram trabalhar com metodologias que consideram perfis de usuário diferentes, e não só com daquele perfil de usuário "padrão"Akoumianakis e Stephanidis (2001), Bagnara e Pozzi (2009), pois reconhecem que ele restringe a população de possíveis usuários capazes de interagir com seus sistemas. Algumas das comunidades de usuários facilmente identificáveis como não alinhadas com o perfil de usuário padrão são as pessoas com alguma deficiência física ou mental, e idosos Hara, Naka e Harada (2009). Geralmente, eles precisam da intervenção da tecnologia de apoio para interagir com os sistemas computacionais mais simples e de propósito geral.

\subsection{INDIVÍDUOS COM DEFICIÊNCIA NA SOCIEDADE DA INFORMAÇÃO}

Como resultado da falta de inclusão nas tecnologias da informação as pessoas com alguma deficiência sofrem, em muitos casos, um isolamento na participação da realidade social, econômica, cultural e política das comunidades nas quais estão imersas. Nesses casos, a tecnologia não viabiliza para aquelas pessoas a execução dos seus direitos contidos nos Artigos 21,26 e 27 da Declaração Universal do Direitos Humanos (NATIONS, 1948). Assim, o fornecimento de mecanismos que permitam o acesso à informação por meio das Tecnologias de Informação e 
Comunicação implicam a remoção das barreiras tangíveis e intangíveis que até agora existem nas sociedades para o crescimento e desenvolvimento das pessoas com alguma deficiência, contribuindo assim para a criação de uma sociedade global e inclusiva. Neste contexto, várias iniciativas têm ocorrido a fim de incorporar uma diversidade de usuários na sociedade da informação. Algumas delas, as mais abrangentes, são o fruto do trabalho realizado e impulsionado pela UNESCO, por exemplo: World Summit on the Information Society (LEBLOIS, 2013)(WSIS), Action Plan (Genebra,2003) e o Tunis Commitment (Tunes, 2005), United Nations Standard Rules on the Equalization of Opportunities for Persons with Disabilities (1993), e o Worldwide Web Consortium Web Accessibility um manifesto da W3C em referência da acessibilidade. Da mesma forma, muitos países têm formulado políticas de inclusão no marco legal para proteger os direitos das pessoas com alguma deficiência, especialmente com a finalidade de garantir para elas um melhor acesso à informação, serviços públicos e empregos. Entre eles, de acordo com Leblois (2013), são: Estados Unidos, Austrália, Tailândia, a União Europeia, e também o Brasil com a Lei de Acessibilidade (Lei de Acessibilidade Nro. 10.098, Decretos Nro. 5.296 e Nro. 6.949) e a criação da Secretaria Nacional de Promoção dos Direitos da Pessoa com Deficiência (Secretaria Nacional de Promoção dos Direitos da Pessoa com Deficiência, 2015).

Na prática o cumprimento dessas disposições dentro no escopo tecnológico é evidenciado como a inclusão de medidas que permitam as pessoas com alguma deficiência interagirem com os diferentes dispositivos e tecnologias. Elas, são implementadas com base em duas ideias (STEPHANIDIS; EMILIANI, 2002): acessibilidade e usabilidade. De acordo com Leblois (2013) a acessibilidade refere-se à medida na qual um produto ou serviço está relacionado com as necessidades e capacidades de diversos grupos de usuários (no caso deste trabalho são os portadores de deficiências) de maneira que aquele produto ou serviço seja utilizado tão efetivamente por um usuário com deficiência quanto por um usuário que não possua deficiência nenhuma. Paralelamente o termo usabilidade, segundo Nielsen (1993) encontra-se relacionado com a questão de quão bem os usuários podem usar a funcionalidade fornecida por uma tecnologia ou sistema. Ela é uma propriedade multidimensional que procura analisar diferentes atributos da interação entre o usuário e o sistema ao desenvolver uma tarefa. Tradicionalmente, os atributos mais associados com usabilidade têm sido: capacidade de aprendizado, eficiência, facilidade para lembrar tarefas realizadas anteriormente, tolerância e recuperação de erros, e a satisfação experimentada pelo usuário. Todas essas características que, com o decorrer do tempo, ganharam importância para os usuários no momento de escolher entre uma tecnologia ou outra. 


\subsection{ACESSIBILIDADE UNIVERSAL}

O termo Acessibilidade Universal, ou Universal Accessibility (UA) em inglês, tem sido utilizado com diferentes conotações. Contrário ao que muitos supõem, ele não é novo nem é de exclusivo das tecnologias de informação, mas ele é um conceito sedimentado e utilizado há muito tempo em áreas como a engenharia civil e arquitetura Stephanidis e Savidis (2001). No entanto, este conceito não é estático, tendo evoluído junto com a sociedade em busca de satisfazer suas necessidades. Inicialmente, acessibilidade era utilizada para se referir à incorporação de características especiais em produtos, serviços e instalações para possibilitar que pessoas com alguma deficiência pudessem interagir com aqueles elementos.

Posteriormente, o florescimento das tecnologias e sistemas computacionais como parte fundamental das atividades diárias tornou evidente que era preciso criar mecanismos e ferramentas por meio dos quais as pessoas com alguma deficiência tivessem acesso e conseguissem utilizar adequadamente os recursos tecnológicos já disponíveis para a maioria dos membros da sociedade. Segundo essa tendência duas alternativas foram estabelecidas no campo das tecnologias de informação para incorporar usuários com necessidades especiais Stephanidis e Emiliani (1999).

a) Estratégias reativas e baseadas no reajuste e personalização, e;

b) Estratégias proativas e que procuram uma solução mais genérica e abrangente.

A primeira, também chamada abordagem tradicional, concentra-se em fazer reconfigurações ou adaptações de sistemas e produtos padronizados com a finalidade de atingir os requerimentos de acessibilidade para um determinado grupo de usuários. Historicamente, a maioria das soluções criadas sob esta abordagem tem sido utilizada para facilitar o acesso a tecnologias existentes (LEBLOIS, 2013) por parte de pessoas com algum tipo de deficiência. Assim, tais tecnologias são também chamadas como assistivas ou de apoio. Para atingir esse objetivo se tem seguido duas estratégias: as adaptações, a posteriori, de produtos padronizados e a elaboração de produtos especializados ou "ad hoc".

A primeira estratégia trabalha com produtos já existentes no mercado, produtos de uso geral, que foram criados segundo o conceito de usuário padrão e que por meio da incorporação de mecanismos especializados tanto no nível de software (por exemplo: filtros e técnicas dedicadas) quanto de hardware (por exemplo: dispositivos personalizados de entrada/saída) permitem atender as necessidades de usuários com deficiência. Na segunda estratégia, os produtos são projetados especificamente para atender as necessidades de uma comunidade particular dentre as pessoas com alguma deficiência, "ad hoc", por exemplo: cegos, surdos, pessoas portadoras de alguma deficiência física, entre outros. Dessa maneira trata-se do desenvolvimento de 
um produto tecnológico completamente diferente para disponibilizar funcionalidades padrão. No entanto, ainda quando esta abordagem desenvolve produtos que se ajustam melhor às necessidades especiais dos usuários, ela apresenta algumas desvantagens:

- Pouco difundidas: elas não são generalizadas nem muito difundidas (LEBLOIS, 2013), pelo contrário, são tecnologia de nicho, difíceis de se desenvolver e de se manter.

- Alto custo: o trabalho necessário para desenvolver o produto, a criação e suporte de mecanismos de acessibilidade, e a interação com dispositivos especializados de hardware fazem dos produtos ad hoc peças de software de custo elevado. Como consequência, só a população com capacidade aquisitiva suficiente tem acesso a essa tecnologia (STEPHANIDIS et al., 1997).

- Divisão das tecnologias: de acordo com o público-alvo com o qual interagem as tecnologias são divididas em: tecnologia para o público em geral, e tecnologia com finalidade assistiva.

- Latência tecnológica: entendida como o tempo que toma para una tecnologia estar disponível para usuários de necessidades especiais por meio de uma ferramenta "ad hoc" (STEPHANIDIS; EMILIANI, 1999, VANDERHEIDEN; TREVIRANUS, 2011), e a dessincronia que isso causa com a evolução tecnológica disponível para o usuário padrão. Isso quer dizer que no momento que é desenvolvida uma tecnologia que permite o acesso a ferramenta específica, por exemplo: processadores de texto, navegadores web, uma outra versão da ferramenta original já terá sido lançada.

Para fazer frente a tais problemas é proposta uma segunda abordagem com a incorporação da filosofia de Acessibilidade Universal (STEPHANIDIS; EMILIANI, 1999), mais abrangente que utiliza as diretrizes de Universal Design, ou UD, (AKOUMIANAKIS; STEPHANIDIS, 2001) e Design for All (DfA), já nas fases iniciais do desenvolvimento de software. Assim, Acessibilidade Universal passou para ser entendido como o esforço por projetar produtos e serviços levando em consideração as características dos possíveis usuários finais (STEPHANIDIS; SAVIDIS, 2001). Isto é, os projetistas de software que optarem por seguir os princípios da Acessibilidade Universal devem desenvolver produtos que, desde o início (STEPHANIDIS; EMILIANI, 1999), aceitem e considerem a possibilidade de interagir com usuários com necessidades especiais e não em um único padrão (FRIEDEWALD; COSTA, 2003). Por meio de esta abordagem procurase garantir o desenvolvimento de futuros sistemas que integrem a diversidade de usuários já presentes na sociedade global.

Com essa nova proposta a acessibilidade universal se concretiza, do ponto de vista tecnológico, como a capacidade de fornecer acesso a todos os cidadãos, por meio de mecanismos 
sistemáticos e rentáveis (tecnologias e ferramentas), aos recursos de informação da sociedade assim como às facilidades de comunicação interpessoais, de acordo com os diferentes contextos possíveis.

É importante notar que a ideia que permeia o conceito de acessibilidade universal não é a criação de uma tecnologia que a priori consiga cobrir as necessidades de todos os usuários, mas sim fornecer uma plataforma tecnológica preparada para atender mudanças nas necessidades dos usuários, sem que isso implique uma reengenharia. No entanto, esta abordagem é aplicável às tecnologias na fase de planejamento e desenho, porém, não representa uma resposta ao problema de acessibilidade nos sistemas atuais.

Contudo, um problema ainda fica em aberto: na atualidade existem muitos casos de sistemas legados que foram desenvolvidos com uma abordagem diferente do Design Universal (LEBLOIS, 2013), na maioria dos casos seguindo a filosofia de um usuário padrão (STEPHANIDIS; SAVIDIS, 2001) como base para definir a interação com o sistema. De maneira que o desafio é desenvolver tecnologia que permita integrar e gerenciar os recursos individuais contidos nos sistemas tradicionais imersos em nossas sociedades a fim de transformá-los em ferramentas verdadeiramente inclusivas, orientadas não apenas para interagir com um grupo particular de usuários (usuários tradicionais ou usuários com uma deficiência específica), mas para abranger diferentes perfis.

Nos últimos anos a pesquisa na procura de fornecer acessibilidade universal tem-se incrementado sob a consideração de que os problemas de acessibilidade não atingem somente pessoas com alguma deficiência de nascimento, mas também idosos, pessoas com doenças degenerativas, e outras deficiências funcionais (VANDERHEIDEN; TREVIRANUS, 2011) que são adquiridas ou que se manifestam ao longo da vida das pessoas.

Em Stephanidis e Savidis (2001) são indicadas três dimensões nas quais é necessário considerar a diversidade na construção de tecnologias de informação que implementam acessibilidade universal:

- Usuário: significa levar em consideração as possíveis características dos usuários finais de tais tecnologias.

- Escopo: dependendo da natureza e abrangência da tarefa principal do sistema é preciso incorporar tecnologias, métodos e até dispositivos de hardware que permitam suportá-la.

- Contextos: a especificação e caracterização dos contextos nos quais se desenvolve a interação permite a extração de informações que nutrem e ajudam para uma atividade mais eficiente.

É pertinente apontar que nessas três é possível identificar oportunidades de aplicação das técnicas de Tecnologia Adaptativa. 
No caso da modelagem de usuários, o processo mesmo de modelagem progressivo das características que descrevem e identificam um usuário é na sua própria natureza dinâmico. Isso, obedece não à tecnologia aplicada, mas ao sujeito sobre o qual é aplicada: o ser humano. Assim, na atualidade existem esforços (DíAZ; GERVáS, 2004 JANARTHANAM; LEMON, 2014 PAOLINO et al., 2009), para tornar os modelos clássicos de modelagem de usuário, modelos estáticos, em modelos dinâmicos, com o objetivo de refletir as mudanças nas caraterísticas do usuário. Para atingir esse objetivo têm sido misturadas e superpostas técnicas estatísticas de aprendizagem de máquinas aplicadas com certa periodicidade com os modelos subjacente. Nesse assunto as técnicas de Tecnologia Adaptativa encontram um cenário propício para trabalhar e atingir a dinamicidade requerida com três vantagens: independência entre o dispositivo subjacente e a camada adaptativa, clareza no modelo, e a possibilidade de acesso ao histórico de execução do modelo. No caso do escopo, na atualidade, com o surgimento das tecnologias móveis e computação ubíqua, a ideia de montagem de ambientes inteligentes está cada vez mais presente Sadri (2011). Nesses sistemas as tecnologias e dispositivos são conectados dinamicamente para atingir uma tarefa determinada, portanto, o sistema concreto como resultado dessa montagem muda de escopo de maneira dinâmica. Novamente, trata-se de um cenário favorável para a aplicação de técnicas adaptativas no aspecto da montagem de sistemas de ambientes inteligentes, especialmente incentivado pelo uso de arquiteturas subjacentes, na maioria dos casos modelo de agentes, as quais foram criadas para suportar esse tipo de comportamento.

No caso do contexto, a identificação de uma oportunidade para atuação da Tecnologia Adaptativa é direta. Ela pode ser aplicada com sucesso, porque considera desde o início a existência de diferentes cenários (AKOUMIANAKIS; STEPHANIDIS, 2001), e fornece a possibilidade de auto modificação para incorporar a diversidade que existe em termos de: habilidades humanas, proliferação tecnológica e variedade em contexto de uso dos sistemas de computador (AKOUMIANAKIS; STEPHANIDIS, 2001; BAGNARA; POZZI, 2009).

\subsection{TECNOLOGIAS UTILIZADAS EM TRABALHOS RELACIONADOS COM FORNECER ACESSIBILIDADE}

No escopo acadêmico encontra-se uma diversidade de projetos de pesquisa que, seguindo abordagens diversas, procuram desenvolver mecanismos, otimizar tecnologias, criar arquiteturas, e propor novos modelos para fornecer maior acessibilidade às ferramentas tecnológicas disponíveis para as pessoas com alguma deficiência.

Alguns exemplos de tal tipo de projetos são: AID Brown (1993), AIDA Cote-Munoz (1993). MIMUS Perez, Amores e Manchon (Dec.), The Mercator Environment Mynatt e Edwards 
Uma característica em comum das pesquisas acima indicadas é que elas estão orientadas para atender, de maneira isolada, algum dos aspectos que permitem acrescentar acessibilidade em diferentes sistemas, por exemplo:

- Algumas trabalham com diferentes perfis de usuários finais como: tetraplégicos Graça, Guerreiro e Jorge (2008), cegos Schloerb et al. (March), e pessoas com deficiência motora Turunen et al. (2010)), Karpov e Ronzhin (2007) Nesses trabalhos procura-se fornecer o suporte necessário para as diferentes modalidades de interação que os usuários podem utilizar.

- Outras pesquisas têm seu foco no estudo e análise das informações obtidas dos diferentes contextos de uso dos sistemas.

- Outras põem sua ênfase na investigação das oportunidades de acessibilidade que oferecem as diferentes plataformas tecnológicas de maneira que a acessibilidade esteja presente na maior parte delas Apple Inc. (s.d.)a), Nuance Communications (2014).

No entanto, todas elas indicam que a tecnologia que gerencia a interação com o usuário deve, idealmente conter um mecanismo que permita a reconfiguração da mesma, pois tal comportamento tem mostrado potencial para melhorar a experiência dos usuários em termos de acessibilidade. A seguir faz-se um breve resumo descritivo das tecnologias mais frequentemente utilizadas nas pesquisas da área.

\subsubsection{Mecanismos baseados em regras}

Um sistema computacional regido por um mecanismo baseado em regras é aquele cujo comportamento, total e inequivocamente, encontra-se explicitado em dito conjunto finito de regras, as quais chamaremos regras de produção.

Como mencionado em Neto (2001) um dispositivo baseado em regras é qualquer máquina de estados formal cujo comportamento depende unicamente de um conjunto finito de regras que para toda configuração possível no dispositivo mapeia uma próxima configuração. Uma configuração no nosso contexto é o conjunto de elementos que armazenam informações sobre o estado do dispositivo no momento corrente. No entanto é importante notar que a cada momento o desempenho do dispositivo está sendo determinado pelo histórico de execução, a sequência de entradas e as mudanças de estado correspondentes, até o momento corrente. Como enunciado em Ramos, Neto e Veja (2009) uma máquina de estados finita, ou autômato finito, pode ser determinística ou não determinística. Como determinístico se entende uma 
máquina de estados que para cada estímulo, ou símbolo de entrada, é possível determinar sempre um e só um estado seguinte para dito autômato. Quando um autômato apresenta mais de uma possibilidade de movimentação para o estado corrente e o estímulo ou símbolo fornecido se diz que ele é não determinístico.

A definição mais simples dum autômato finito determinístico está representada por uma quíntupla:

$$
M=\left(Q, \Sigma, \delta q_{0}, F\right)
$$

Sendo:

- $Q$ o conjunto finito de todos os estados que compõem o autômato;

- $\Sigma$ o alfabeto, finito e não vazio, dos símbolos de entrada;

- $\delta$ a função que define cada uma das transições de um estado corrente para outro, $\delta$ : $Q \times \Sigma \longrightarrow Q$

- $q_{0}$ o estado inicial, de maneira que $q_{0} \in Q$;

- $F$ o conjunto dos possíveis estados finais para o autômato, de maneira que $F \in Q$.

Um autômato finito opera realizando uma sequência de movimentos que o conduzem através dos seus estados partindo da configuração inicial representado por $q_{0}$. Para realizar uma transição são analisados tanto o estado corrente quanto o símbolo apontado pelo cursor da cadeia de entrada, com ambos dados é determinado por $\delta$ qual é o próximo estado. Ao executar a transição é atualizado o estado corrente e o cursor da cadeia de entrada aponta o seguinte símbolo. Esta dinâmica se repete até esgotar os símbolos da cadeia de entrada. Quando isto ocorre, dependendo do tipo de estado atingido, um estado final ou não, se diz que o autômato aceitou ou rejeitou a sequência de símbolos representados na cadeia de entrada.

A Figura 10 ilustra num nível macro o funcionamento básico deste tipo de dispositivo e a Tabela 1 especifica cada um dos elementos que conformam o formalismo.

O formalismo de máquinas de estado tem sido utilizado para modelagem matemático de processos computacionais, desde programas simples até sequências de circuitos lógicos ou sistemas especializados de controle de comportas de foguetes espaciais. Algumas das aplicações em diferentes áreas são:

- Implementação de Videogames: como em Mallouk e Clua (2006)), Lecky-Thompson (2008)), Warden (2012);

- Aplicações de Inteligência Artificial: sistemas especialistas, métodos de lógica difusa; 


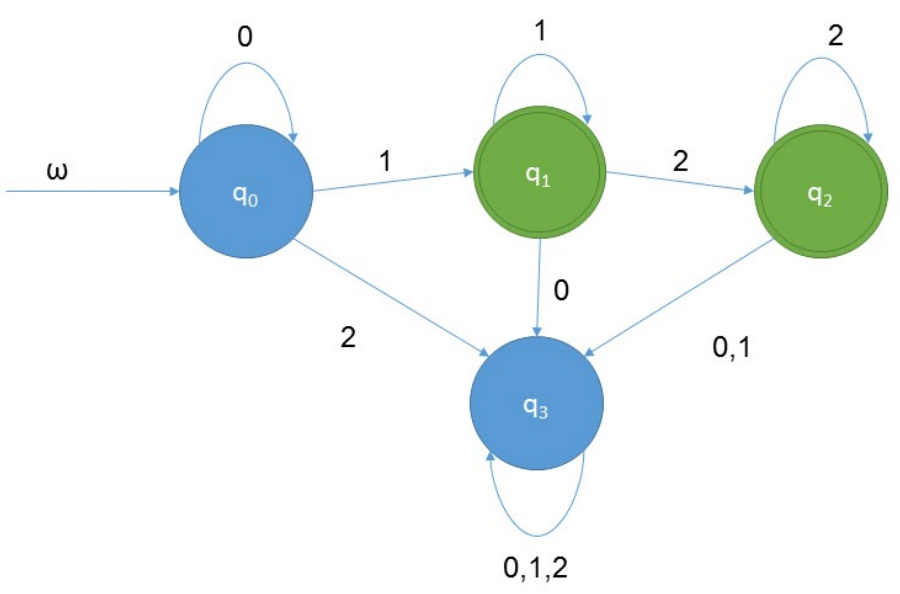

Fonte: Autora

Tabela 1 - Tabela de descrição do funcionamento dum dispositivo baseado em regras

\begin{tabular}{l||l}
\hline$Q$ & $\left\{q_{0}, q_{1}, q_{2}, q_{3}\right\}$ \\
\hline$\Sigma$ & $\{0,1,2\}$ \\
\hline$\delta$ & $\left\{\left(q_{0}, 0\right) \longrightarrow q_{0},\left(q_{0}, 1\right) \longrightarrow q_{1},\left(q_{0}, 2\right) \longrightarrow q_{3}\right.$ \\
& $\left(q_{1}, 0\right) \longrightarrow q_{3},\left(q_{1}, 1\right) \longrightarrow q_{1},\left(q_{1}, 2\right) \longrightarrow q_{2}$ \\
& $\left(q_{2}, 0\right) \longrightarrow q_{3},\left(q_{2}, 1\right) \longrightarrow q_{3},\left(q_{2}, 2\right) \longrightarrow q_{2}$ \\
& $\left.\left(q_{3}, 0\right) \longrightarrow q_{3},\left(q_{3}, 1\right) \longrightarrow q_{3},\left(q_{3}, 2\right) \longrightarrow q_{3}\right\}$ \\
\hline$q_{0}$ & $q_{0}$ \\
\hline$F$ & $\left\{q_{1}, q_{2}\right\}$ \\
\hline
\end{tabular}

- Simulações: Realidade Virtual como em Sarjoughian e Cellier (2013) Realidade Aumentada, como em Jun, Sung e Choi (2006); Programas de treino, como em Buzhinsky et al. (2014);

- Processamento de Linguagem Natural Roche e Schabes (1997) Análise de sintaxe, tradutores, fenomenos que envolvem dependencias de contexto, entre outras;

- Processo de Construção de Software: como em Lieberherr (1996)), Borger e Stark (2003).

- Modelagem de Arquitetura de Software: como em Carnegie Mellon University (2011). 
A variedade de aplicações possíveis é abrangente e como afirmado em Drumea e Popescu (2004)), Roche e Schabes (1997) corresponde com a flexibilidade que o modelo fornece para descrever a estrutura e o comportamento de sistemas complexos.

$\mathrm{Na}$ atualidade existem diferentes modelos tecnológicos contemporâneos e sofisticados que incorporam, de maneira subjacente e colaborativa, mecanismos baseados em regras, por exemplo:

- agentes: Holland e Miller (1991)), Wooldridge (1997)

- redes neurais: Haykin (1998)

- algoritmos genéticos: Ramirez et al. (2008);

- ontologias: Xiao-qin et al. (2009)), Matheus (2005)), Toninelli et al. (2005)), Zhong, Fu e Jiang (2010), entre outros.

Dentro do campo de pesquisa existem diferentes abordagens para a implementação de tecnologias orientadas a fornecer acessibilidade aos usuários com necessidades especiais. Alguns deles usam de mecanismos baseados em regras para a atingir o seu objetivo. Algumas das técnicas mais usadas são, por exemplo:

- Redes neurais para assistir usuários com deficiência física Adjouadi et al. (2008);

- Agentes Computacionais para criação de interfaces gráficas de usuário Jameson (2009)), López-Jaquero, Montero e González (2009)

- Agentes em sistemas multimodais para obter informações do contexto de usuário Hina et al. (2011).

- Reconhecimento de Linguagem de sinais Kim e Hong (June).

Finalmente, devemos apontar a afinidade estrutural entre a natureza do problema e esses mecanismos, as principais vantagens fornecidas pelos mesmos para a construção de interfaces de interação hómem-máquina, e a facilidade na conversão desse tipo de mecanismos para tecnologias adaptativas que oferecem uma alternativa de solução.

\subsubsection{Sistemas multimodais}

Uma das alternativas mais pesquisadas desde a década dos anos 90Stephanidis e Savidis (2001) é a implementação de sistemas multimodais como alternativa para o fornecimento de 
acessibilidade no escopo tecnológico. Com o decorrer dos anos não só têm sido criados diferentes modelagens para incorporação de modalidades, particularmente diferentes abordagens de implementação dos processos de fusão e fissão da informação recolhida pelos diferentes canais, mas também têm sido estudadas novas e mais complexas modalidades de interação com o computador. Partindo desse ponto, alguns projetos começaram pesquisar a potencialidade do uso de sistemas multimodais para fornecer acessibilidade aos usuários com deficiências. Assim, frente à ausência de alguma funcionalidade física por parte do usuário que impede a interação com o computador por meio da interface padrão outras modalidades poderiam ser disponibilizadas.

Na Figura 11 é apresentado o funcionamento básico de um sistema multimodal geral.

Figura 11 - Diagrama básico do funcionamento de um sistema multimodal

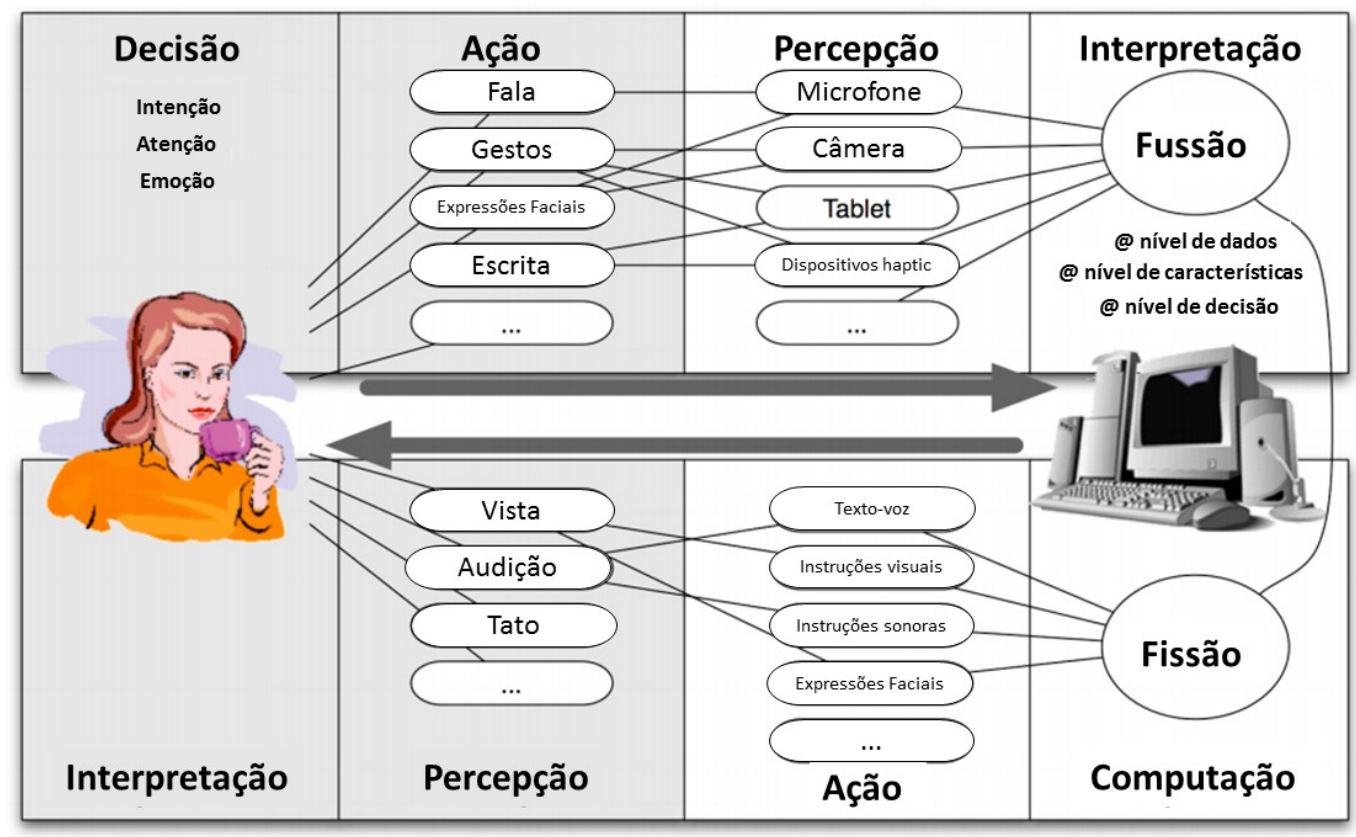

Fonte: Obtida e modificada de (DUMAS; LALANNE; OVIATT, 2009).

Alguns tipos de modelos mais específicos e sofisticados que têm sido utilizados para o desenvolvimento de sistema multimodais são mencionados de maneira mais detalhada em Jaimes e Sebe (2007)), Dumas, Lalanne e Oviatt (2009)), Wei e Hu (2011)

No contexto acadêmico, a maioria de projetos utilizam a multimodalidade para fornecer novas funcionalidades em aplicações de uso geral, mas alguns dos trabalhos estão orientados especificamente a oferecer acessibilidade para pessoas com deficiências por médio da incorporação e processamento de diferentes modalidades. Alguns exemplos desses tipos de projeto são:

- Assistive Smartphone for People with Special Needs: the Personal Social Assistant Vers- 
tockt et al. (May)

- Web-based Haptic Applications for Blind People to Create Virtual GraphsYu, Kangas e Brewster (March)

- Accessible speech-based and multimodal media center interface for users with physical disabilities Turunen et al. (2010)

- The Haptic Deictic System-HDS: Bringing Blind Students to Mainstream Classrooms Oliveira et al. (April-June).

- A Gesture Controlled User Interface for Inclusive Design and Evaluative Study of Its Usability Bhuiyan e Picking (s.d.).

- ICANDO - Low cost multimodal interface for hand disabled people Karpov e Ronzhin (2007);

- Multimodal system for hands-free PC control Karpov et al. (2005)

Assim também existem projetos nos quais a multimodalidade é utilizada como instrumento para a própria extração de informação sobre as condições do usuário como em Adjouadi et al. (2008) e a posterior construção dos perfis correspondentes e a personalização requerida.

Cabe mencionar que nos últimos anos o desenvolvimento de projetos de pesquisa dentro das áreas de tecnologia móvel e computação ubíqua tem se incrementado em grande forma, estando cada vez mais presente como track dentro de congressos e revistas de longa data, e inclusive suscitando a criação de instituições acadêmicas especializadas. Dessa maneira é colocado em evidência a potencialidade que os sistemas multimodais possuem para oferecer vantagens em diferentes assuntos e não só como solução para as pessoas com deficiência.

O caso particular da incorporação de tecnologias multimodais em sistemas legados apresenta, porém, um amplo campo de pesquisa não explorado, pois precisa enfrentar o problema de heterogeneidade de ditos sistemas.

\subsubsection{Computação Orientada a Serviços}

A computação orientada a serviços é, de acordo com Papazoglou (2003) o paradigma de desenvolvimento de software que utiliza os serviços como unidade fundamental dos sistemas. Os sistemas orientados a serviços são sistemas implementados segundo a ideia da conexão e colaboração de peças de software, já construídas, independentes e muitas vezes fornecidas por entidades externas. Assim, o conceito fundamental por trás dos sistemas orientados a serviços 
é o paradigma de programação orientada a componentes. Esse paradigma permite a construção de sistemas com base em componentes de software, blocos de código, já construídos os quais são funcionais, independentes, reusáveis e autocontidos Wang e Qian (2005). Um serviço pode executar diferentes tipos de tarefas, desde funções simples até processos de negócio complexos. Esses componentes podem ter diferentes formas, tamanhos e complexidades, mas devem satisfazer as condições enunciadas em Papazoglou (2003): tecnologicamente neutro, baixamente acoplado e transparência na sua localização. Um caso particular de serviços são os web services já que eles utilizam a Internet (e com ela seus padrões e protocolos) como meio de comunicação entre os serviços que compõem o sistema. Nesse caso as vantagens que oferecem os sistemas orientados a serviços são incrementadas pois um serviço pode ser procurado dentro do universo da internet, o qual amplia grandemente a possibilidade de "componentes"disponíveis. No entanto, assim como os sistemas orientados a serviços apresentam vantagens, eles também precisam fazer frente a outros problemas próprios da sua natureza, principalmente o trabalho sobre a rede e à dinâmica a que ela está sujeita.

A arquitetura mais utilizada para o desenvolvimento deste tipo de sistemas é SOA, pelas siglas em inglês de Service-Oriented Architecture.

Na Figura 12 é apresentada a dinâmica de funcionamento básico de um sistema orientado a serviços. Assim, SOA define a interação entre elementos de software como uma troca de informações entre o solicitador do serviço, também chamado cliente, e o fornecedor do serviço. Esta troca é possível graças a uma entidade chamada agência de descoberta. Desse modo, as operações principais dentro dessa dinâmica são a publicação, busca e enlace. No cenário típico, a dinâmica se apresenta dessa forma: o provedor do serviço desenvolve e publica o descritor do serviço para uma agência de descoberta, através dela o serviço é detectável. 0 cliente realiza uma operação de busca na agência de descoberta para obter o descritor do serviço que precisa. Uma vez que o cliente possua o descritor do serviço, ele pode interagir com as funcionalidades fornecidas sempre que cumpra com a interface estabelecida para cada caso (parâmetros, tipos de dados, entre outros).

Alguns projetos de pesquisa, implementaram acessibilidade para usuários com deficiência, através da criação de sistemas orientados a serviços. Esses sistemas são compostos por :

- Sistemas de E-learning e suporte para atividades de aprendizagem para pessoas com deficiência: RajKumar e Vinod (2015)), Douce, Porch e Cooper (2010).

- Interfaces de Controle através de expressões faciais: Costa-Pazo et al. (s.d.)

- Sistemas integrados para Ambientes de Assistência à vida de pessoas com deficiência: Abousharkh e Mouftah (2011)), Stav et al. (2013) 
Figura 12 - Diagrama básico do funcionamento de SOA

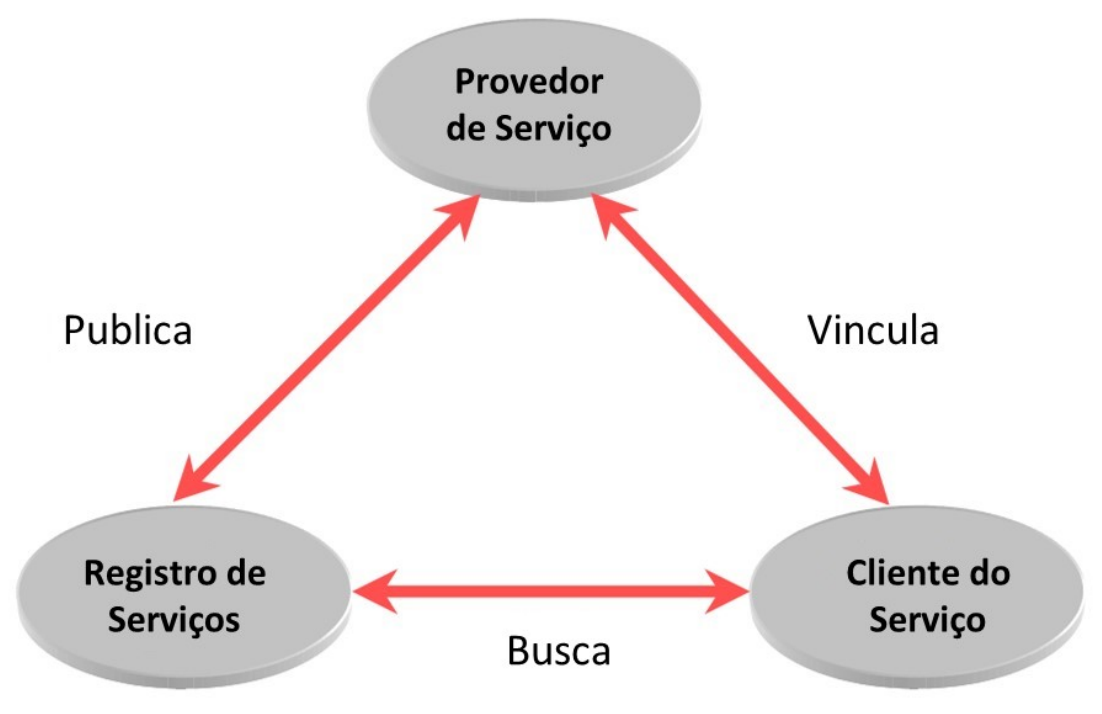

Fonte: Obtida e modificada de (PAPAZOGLOU, 2003)

Assim, existem implementações de tecnologias de vanguarda que propõem entender como serviços aquelas funcionalidades que atendem aos usuários com necessidades diferenciadas, de maneira que sejam reutilizáveis, eficientes a ganhem independência de plataforma. Uma razão que promove a criação de serviços como unidade básica dessas aplicações é o surgimento e desenvolvimento acelerado das tecnologias móveis, tais como smartphones e tablets, as quais possibilitam o desenvolvimento de novas tendências no conceito de sistemas, por exemplo: ambientes inteligentes, internet das coisas, computação ubíqua, entre outros.

\subsubsection{Agentes Automáticos}

De acordo com Djenidi et al. (2004) os agentes são entidades que podem interagir e colaborar dinamicamente produzindo sinergia nas funcionalidades do sistema. Assim, como afirma Ranganathan e Campbell (2003)), Nwana (1996) os agentes podem ser diferentes tipos de tecnologias, por exemplo: aplicativos, serviços, componentes, ou até dispositivos. Segundo esse raciocínio, o uso de agentes para a implementação de módulos que forneçam acessibilidade aproveita as vantagens da programação orientada a componentes e também alinha a solução tecnológica com as tendências dentro da área.

Os sistemas compostos por agentes normalmente estão organizados como uma coleção de agentes que interagem, de maneira colaborativa para uma finalidade em comum. Depen- 
dendo do critério aplicado, os agentes podem ser categorizados em diferentes tipologias, em (NWANA, 1996) é oferecida uma revisão detalhada das diversas categorias a que podem pertencer um agente. Em (GENESERETH; KETCHPEL, 1994) os agentes são analisados desde a perspectiva do mecanismo de comunicação que eles implementam para efetuar sua interação dentro do sistema.

Na área acadêmica, a tecnologia de agentes automáticos já tem sido utilizada como um conjunto de componentes dentro da arquitetura de um sistema, tipo middleware, para incorporar sensibilidade ao contexto. Um desses trabalhos é apresentado em (RANGANATHAN; CAMPBELL, 2003; LUCK; MCBURNEY; PREIST, 2003). Levando em conta este trabalho precedente é possível identificar diferentes pontos em comum entre os agentes automáticos e as técnicas de tecnologia adaptativa, que vão desde a aplicação de modelos semelhantes, tanto na própria configuração de ambas as tecnologias quanto nas técnicas quem propõem sua incorporação em sistemas maiores, até nas formas de implementação que usam paradigmas diretamente relacionados.

De maneira particular, a tecnologia de agentes tem sido utilizada para fornecer acessibilidade para pessoas com necessidades diferenciadas nos seguinte projetos de pesquisa:

- Projeto Gaia Ranganathan e Campbell (2003)

- Paradigma de agentes multimodais multimidia genericos Djenidi et al. (2004)

- AB-HCl López-Jaquero, Montero e González (2009)

- Travelling Actors Pinsdorf (2002)

\subsection{FUNDAMENTAÇÃO TEÓRICA DA PROPOSTA}

Nesta seção são apresentados os conceitos teóricos necessários para ilustrar o problema e a proposta de solução do projeto de pesquisa. Dessa maneira, se propõe adicionar acessibilidade aos sistemas de uso geral imersos na sociedade.

\subsubsection{Tecnologia Adaptativa}

As instituições fundamentais dos dispositivos de tecnologia adaptativas foram apresentadas em um primeiro modelo em Neto (1994) onde é realçada a diferença entre um dispositivo do tipo autômato de pilha estruturado e um autômato adaptativo. Nesta primeira abordagem foram utilizados recursos de notação para especificar as características dos autômatos adaptativos para a construção de reconhecedores dependentes de contexto. Uma evolução deste 
modelo é apresentada em Neto (2007) com a finalidade de fornecer uma formulação geral, para qualquer tipo de dispositivo adaptativo e não somente no caso de autômatos, e simplificar a notação, mas sem perder expressividade ou compatibilidade com a proposta original. De maneira geral, como descrito em Neto (2007)), Ramos, Neto e Veja (2009) a adaptatividade refere-se à capacidade que possui um sistema para reconfigurar o seu próprio comportamento em resposta espontânea aos dados fornecidos como entrada, e o histórico de operação. Assim, um dispositivo adaptativo permite representar e modelar de maneira formal e, em alguns casos, mais simples o comportamento de um sistema que sofre alterações na sua própria configuração como consequência das mudanças que acontecem dentro do seu contexto de execução ao longo da vida útil do mesmo sistema.

Figura 13 - Esquema de macro estrutura de um dispositivo adaptativo

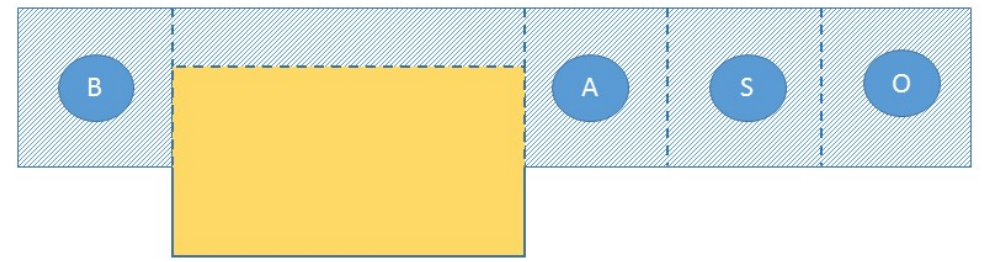

Camada Adaptativa

Dispositivo Subjacente
B: Ações Adaptativas do tipo "before"

A: Ações Adaptativas do tipo "after"

S: Ações Semânticas

O: Outro tipo de ações possíveis

Fonte: Autora

De acordo com Neto (2007), em um dispositivo adaptativo é possível distinguir, pelo menos dois componentes: um dispositivo subjacente e um mecanismo adaptativo. Normalmente, o dispositivo subjacente é não-adaptativo, e é responsável pela execução de diferentes funções dentro do sistema geral. Existem implementações de dispositivos adaptativos de naturezas diferentes. Dessa maneira, temos visto a aplicação de adaptatividade em forma de autômatos Neto (1994), gramáticas lwai e Neto (2001)), Pflücker e Neto (2007), tabelas e árvores de decisão Tchemra (2007), redes de Markov, statecharts Neto, Almeida e Santos (1998) entre outros Neto (2007). Isso permite aproveitar as potencialidades dos diferentes modelos nas diversas áreas, pois teoricamente não existe dependência direta entre algum formalismo 
60

particular e o mecanismo adaptativo.

De outro lado, o mecanismo adaptativo é totalmente dedicado à função de gerenciar as alterações do comportamento do dispositivo subjacente, ou seja, incorporar a adaptatividade, permitindo a aplicação de ações que incorporam, eliminam ou modificam a configuração do dispositivo de acordo com as condições presentes no contexto de execução.

Dessa maneira, como apresenta a figura 13, é possível Tchemra (2007), visualizar um dispositivo adaptativo como um dispositivo composto de um núcleo responsável pela execução das tarefas principais do sistema, e uma camada adaptativa que permite ao dispositivo subjacente reagir diante de mudanças no ambiente de execução. Com esta visualização fica evidente que a tecnologia adaptativa não tem efeito direto sobre o poder computacional do dispositivo subjacente, isto é, ela não fornece maiores capacidades na realização das suas funções. A vantagem proporcionada pela aplicação da camada adaptativa é justamente permitir a execução das funcionalidades do dispositivo subjacente em contextos mais abrangentes e considerando fatores, que na configuração original, não foram incorporados. A analogia para esse trabaIho, em específico, é direta: um dispositivo adaptativo é a "ferramenta"de gerenciamento dos recursos do computador que permitem aos usuários interagirem em diferentes modalidades, ou com diferentes recursos ou aplicativos, de acordo com a necessidade corrente. Assim, a natureza do problema traz de modo inerente a necessidade de reagir às mudanças no contexto da interação humano-computador, e portanto, estabelece um ambiente propício, no qual a aplicação das técnicas adaptativas podem trazer vantagens significativas.

A adaptatividade pode ser aplicada em dois níveis: no nível de usuário e no nível de sistema pois ambos experimentam mudanças ao longo do tempo. Além disso o mesmo sistema pode ser adaptativo para concretizar a sua própria estrutura dependendo dos recursos que ele pode utilizar (componentes, serviços, etc.)

\subsubsection{Tabelas de Decisão Adaptativas}

O problema da tomada de decisão não é um processo estranho ou exclusivo da área da computação, pelo contrário, continuamente as pessoas tomam decisões para dar solução a algum problema particular, com base nas informações e recursos disponíveis. As informações acessíveis para a tomada de decisão normalmente podem ser classificadas, de acordo com sua origem, em: informações adquiridas previamente e assimiladas pelo sistema, e informações novas, fornecidas como parte do processo corrente.

Tomar uma decisão é um processo complexo e dinâmico, no qual é escolhida uma opção dentre as possíveis de acordo com a aplicação de um critério específico. Normalmente, é procurada a alternativa de solução que proporcione maior benefício e o menor risco no momento. 
Com essa finalidade podem ser armazenadas e consultadas informações históricas sobre o comportamento do sistema e os efeitos das decisões tomadas. Em síntese, a tomada de decisão pode ser vista como um processo sofisticado, altamente complexo e de execução dinâmica, dependente das condições presentes e que pode fazer uso de informações históricas para a escolha de uma alternativa que satisfaça determinados critérios. As características enunciadas anteriormente manifestam uma estreita relação com as condições ideais para a aplicação de modelos de tecnologia adaptativa, particularmente a incorporação de camadas adaptativas em dispositivos subjacentes, conforme o trabalho apresentado por Tchemra (2007) usando tabelas de decisão adaptativas.

Um dos modelos adotados na resolução de problemas de tomada decisões é a chamada tabela de decisão. Uma tabela de decisão é, de acordo com Vanthienen e Dries (1992), uma representação precisa, compacta, e de fácil validação, em termos de completude e consistência, dos procedimentos que descrevem o comportamento de um sistema complexo. O uso do formato tabular permite visualizar as várias combinações possíveis dentro do sistema dependendo de suas ações correspondentes e das suas condições. Adicionalmente, o uso de tabelas de decisão oferece, em alguns casos, vantagens sobre outros mecanismos Vanthienen e Dries (1992): é conciso, de fácil verificação de completude, consistência, e "correctness"(a palavra utilizada em português nas áreas correlatas é corretude, embora o termo não esteja dicionarizado, portanto, o seu uso ainda gera controvérsia), flexibilidade, fácil visão global, leitura em duas direções (da perspectiva dos dados e da perspectiva dos objetivos), o rigor na sua definição faz dele um meio uniforme para a comunicação entre diferentes componentes de um sistema maior permitindo análises dos modelos de decisão e dos resultados obtidos.

Basicamente, como indicado em Neto (2001), uma tabela de decisão compõe-se de regras(colunas) que se referem ao cenário descrito pelas condições, pelas próprias condições existentes no problema que se quer resolver (fileiras de condições), e das ações que são possíveis de executar para cada regra (fileiras de ações). Em cada regra, as células correspondentes às fileiras de condições especificam se essa condição deve ser testada ou não. Assim são possíveis três valores: "true", quando a condição estiver presente na configuração corrente da tabela, "false" quando a condição não estiver presente, e "nil" (representada com um --") quando a condição não deve ser avaliada. Já as células de cada regra que correspondem às fileiras de ações indicam qual ação deve ser executada devido a que ela satisfaz as condições especificadas.

Assim, tal como é mostrado na Figura 14 o funcionamento do sistema começa pela extração das condições que descrevem o cenário corrente do problema a partir do evento. Logo, tendo as condições como dados de entrada, são testadas as regras da tabela na procura da existência de alguma regra ou algumas regras que satisfazem essas condições. Se somente uma regra 
62

satisfaz as condições dadas trata-se de um caso determinístico, e as ações a ela associadas são executadas sequencialmente. Se existe mais de uma regra que satisfaz o conjunto de condições presentes, trata-se de um caso não determinístico, então todo esse conjunto de regras é ativado e são executadas, em paralelo, as ações correspondentes. Finalmente, o processo de operação da tabela é reiniciado para uma nova consulta. Algumas variações do modelo básico de tabelas de decisões são mencionadas em (PEDRAZZI, 2007).

Figura 14 - Dinâmica de funcionamento de uma Tabela de Decisão convencional

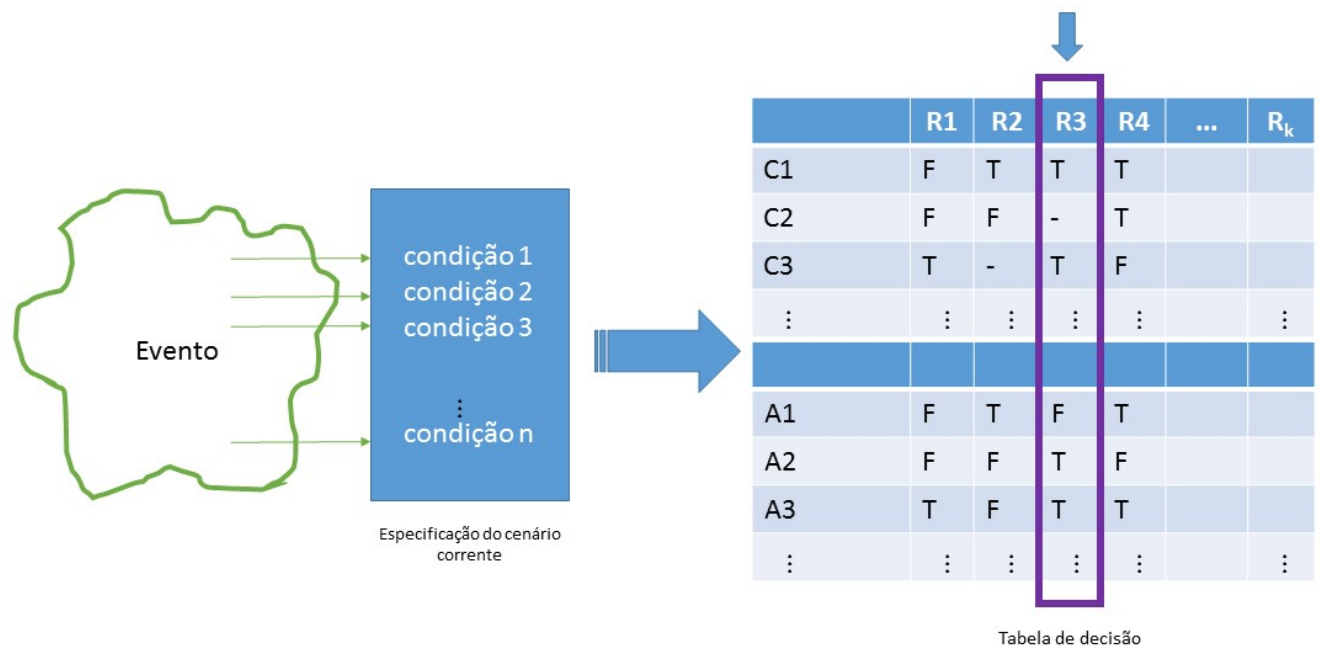

Fonte: Autora

O problema presente no formalismo de tabelas de decisão é que ele é um mecanismo estático, as regras que definem seu comportamento têm que ser definidas logo no início e não são permitidas mudanças ao longo da sua execução, limitando o domínio de sua aplicação. Com o objetivo de incorporar flexibilidade às tabelas de decisão foi proposta a inclusão de uma camada adaptativa, transformando-as em um novo formalismo: a Tabela de Decisão Adaptativa.

Uma Tabela de Decisão Adaptativa (TDA), é um formalismo que incorpora uma camada adaptativa sobre uma tabela de decisão convencional para possibilitar a dinâmica dentro do conjunto de regras que regem essa tabela. Assim, uma TDA é, como mencionado em Neto (2001) facilmente obtida de uma tabela de decisão convencional pela incorporação de fileiras que representam as ações adaptativas a serem executadas antes (ações adaptativas do tipo "before" e depois (ações adaptativas do tipo "after") da aplicação da regra. A TDA pode ser entendida, tal como apresentada em Tchemra (2007) da seguinte maneira:

$$
\mathrm{TDA}=(\mathrm{TDC}, \mathrm{CA})
$$


Onde TDC representa uma tabela de decisão convencional, e CA é a camada adaptativa incorporada no dispositivo subjacente. Uma configuração da TDC é entendida como os valores dos parâmetros que são extraídos do ambiente de execução e servem para calcular os valores das condições no momento analisado, e que serão mapeados para a regra ou regras correspondentes. Nesse contexto TDC é definida como:

$$
\mathrm{TDC}=\left(\mathrm{CT}, t_{0}, \mathrm{C}, \mathrm{R}, \mathrm{A}\right)
$$

Onde:

- CT representa todas as combinações possíveis para as condições e as ações presentes na tabela de decisão;

- $t_{0} \in \mathbf{C T}$, é a configuração inicial para a tabela de decisão;

- C é o conjunto finito das condições que caracterizam o problema: $C=\left\{c_{i} \mid\right.$ c representa o sujeito da condição e seu correspondente valor, $1 \leq i \leq n$ onde $\mathrm{n}$ é o número de condições possíveis do problema\}, de modo que o valor atribuído a cada $c_{i}$ descreve parcialmente o cenário corrente do problema;

- $\mathbf{R}$ é o conjunto de regras que regem a tabela de decisão: $\mathrm{R}=\left\{r_{k} \mid r\right.$ é uma relação que mapeia as condições do problema para as ações correspondentes. Assim, $r_{j}$ avalia se os valores das condições da tabela fornecidos como entrada coincidem com os valores indicados para testes na regra $\mathrm{k}$, com $1 \leq k \leq s$ onde s é o número total de regras especificadas na tabela de decisão para o tratamento do problema na configuração corrente \}; Adicionalmente, cada regra $r_{k}$ indica os valores atribuídos as ações correspondentes a serem executadas para o caso de satisfazer a regra.

- A é o conjunto de ações que podem ser executadas pelo sistema: $\mathrm{A}=\left\{a_{m} \mid\right.$ a representa uma possível ação no sistema, e tem especificado um sujeito da ação e o valor correspondente, $1 \leq j \leq m$, onde $\mathrm{m}$ é o número total de ações possíveis para o problema\}.

De forma análoga a camada adaptativa do dispositivo, CA, é definida pelo conjunto de ações adaptativas, do tipo "before" e "after", associadas às regras da tabela convencional. Assim, para cada regra $r_{j}$ se tem:

$\mathbf{A D}=\left\{\left(b a_{l} j, a a_{o} j\right) \mid b_{a} l \epsilon\right.$ conjunto de ações adaptativas do tipo "before" especificadas na tabela $1 \leq l \leq p$, e $b a_{l} j$ é o valor correspondente para a regra $r_{j}$, e $a a_{o} j \in$ conjunto de ações adaptativas do tipo "after" especificadas na tabela, sendo $a a_{o} j$ o valor correspondente para a regra $r_{j}, 1 \leq o \leq q$, onde $\mathrm{p}+\mathrm{q}$ é o número total de ações adaptativas definidas na configuração corrente da tabela $\}$ 
Por sua vez cada uma dessa ações adaptativas deve executar pelo menos uma das ações adaptativas elementares: (?) consulta às regras da tabela, (+) incorporação de novas regras dentro de $\mathrm{R}$, e (-) remoção de regras existentes em R. A Figura 15 permite identificar os elementos que compõem uma TDA distinguindo entre o dispositivo subjacente e a camada adaptativa.

Figura 15 - Dinâmica de funcionamento de uma Tabela de Decisão Adaptativa

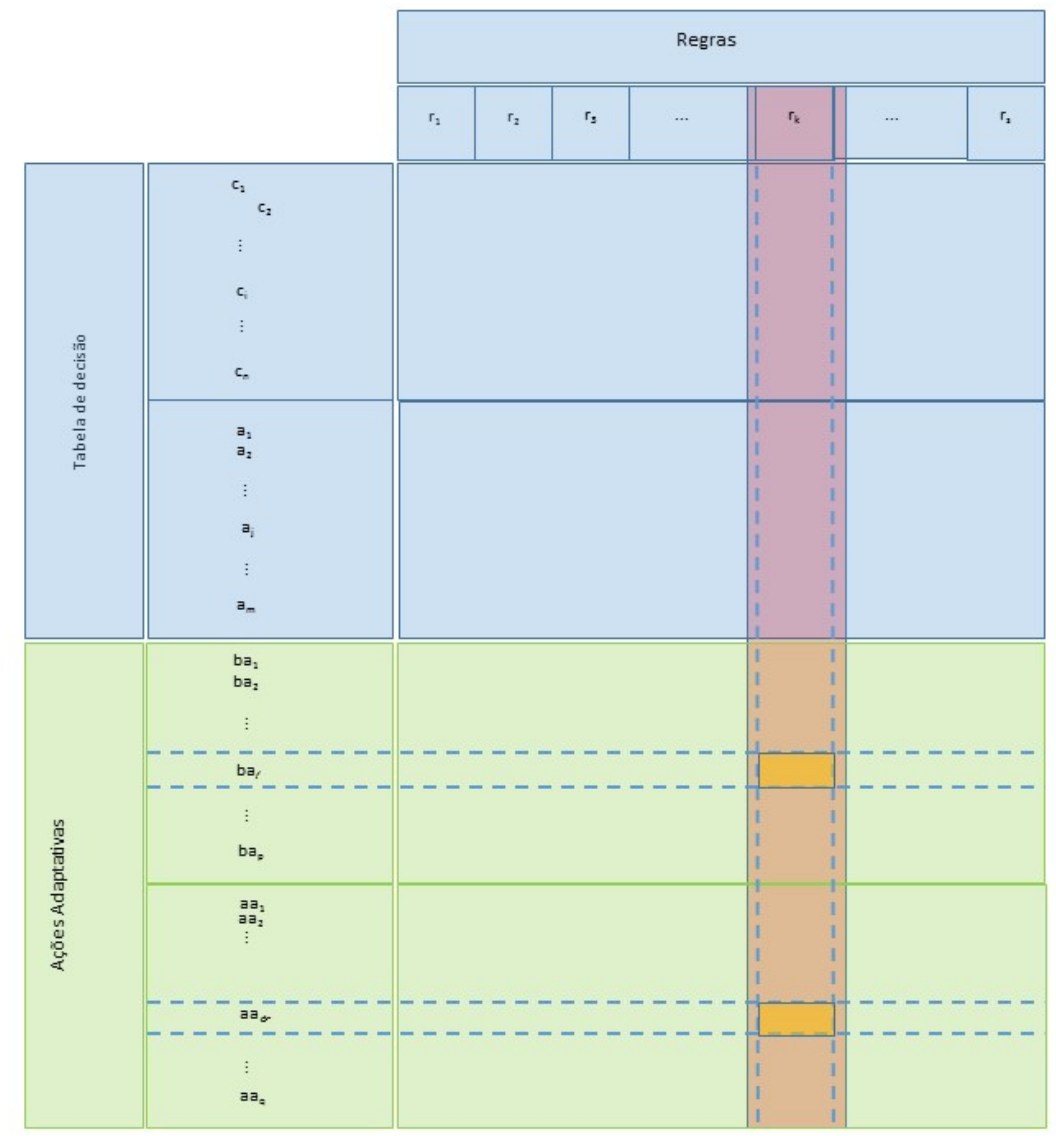

Fonte: Autora

Com a configuração especificada, o funcionamento de uma TDA segue o mesmo modelo que uma tabela de decisão convencional. Uma descrição geral do processo da tomada de decisão usando a TDA é dada a seguir. Para uma explicação mais detalhada do algoritmo pode-se encontrar em Neto (2001)), Tchemra (2007)), Pedrazzi (2007). são extraídas as condições que caracterizam o cenário corrente, depois são procuradas as regras que se referem a tais condições, e conforme se trata de um caso determinístico ou não determinístico, e em seguida se a regra a ser aplicada possui ações adaptativas associadas elas serão executadas: primeiro a ação adaptativa anterior à aplicação da regra $r_{j}$, em sequência se executará a regra $r_{j}$, e por fim, a ação adaptativa posterior à aplicação da regra convencional. Uma vez concluída a execução das ações correspondentes à regra que satisfaz as condições presentes é possível 
utilizar novamente a TDA, agora com a configuração resultante.

Para este trabalho foram escolhidas as TDA's por ser o instrumento recomendado (TCHEMRA, 2007)para o caso de problemas nos quais deve ser escolhida uma alternativa dentro de um grupo de possibilidades, tendo em consideração os recursos disponíveis, as consequências dessa decisão dentro do sistema e a aplicação de diferentes critérios ponderados para a avaliação das alternativas como, por exemplo, os sugeridos em Coetzee, Viviers e Barnard (2009)

\subsubsection{Modelagem de perfil de usuário}

A ideia de utilizar uma técnica que permita descrever as características e comportamentos dos objetos no mundo real não é uma novidade do século XXI e nem é exclusiva da área de sistemas computacionais. O próprio conceito de "modelo"está presente nas diferentes áreas do conhecimento, chamado na sua forma mais básica como modelo de conhecimento Biswas e Robinson (2010), e parte da necessidade de entender e definir o objeto de estudo e as interações que este tem com os outros elementos do domínio. Assim, de maneira geral, um modelo é utilizado como ferramenta para a representação de fenômenos complexos com uma abstração útil.

De acordo com VELSEN et al. (2008) um modelo de perfil de usuário contém as generalizações que descrevem um grupo de usuários, por exemplo suas caraterísticas, preferências e contextos. Essas características são as principais informações que permitem realizar os correspondentes ajustes num sistema computacional de maneira que ele possa fornecer um desempenho mais adequado para as condições (usuário e recursos) correntes.

Um perfil de usuário pode conter diferentes aspectos que permitem discriminar um tipo de usuário no sistema, por exemplo: tempo de experiência na área, objetivos, preferências, conhecimento. Da mesma maneira, a granularidade aplicada na construção do perfil permite identificar diferentes níveis de classificação. Assim, é possível modelar classes ou tipos de usuários, os quais representam grupos ou comunidades de usuários com características em comum, quanto um usuário particular, indivíduo específico, dependendo do nível de detalhe especificado.

Dependendo do objetivo da aplicação, a tarefa de modelagem de perfil de usuário pode ser mais abrangente ou não somente a especificidade de suas características. Em alguns casos as próprias características, e não só os valores, são desconhecidas, ou não se tem acesso a dados históricos que permitam a criação prévia de um perfil de usuário básico anterior à execução do sistema. Nesses casos a tarefa de modelagem de perfil de usuário inclui também a coleta e filtragem de dados para depois realizar a construção do modelo propriamente dito, seja este estático ou dinâmico. 
66

Como indicado em (BYUN; CHEVERST, 2001) os modelos de perfis de usuário tem sido utilizados para permitir o ajuste dos serviços ou informações disponibilizadas para os usuários. Assim, ditos modelos tem sido inseridos nos sistemas computacionais com diferentes finalidades sendo agrupadas em três grandes categorias: sistemas de recomendação, sistemas de recuperação de informações personalizados, e sistemas tipo coaching/teaching.

$\mathrm{Na}$ atualidade, os perfis de usuário são entendidos como a identidade digital de um usuário final do sistema e desempenham uma das tarefas mais importantes dentro de qualquer meio digital (BRUSILOVSKY, 1998), ja que são a ferramenta que dirige o desenvolvimento de sistemas computacionais. Esse conhecimento interno sobre o usuário é fundamental para possibilitar qualquer tipo de personalização no sistema, seja através de adaptabilidade ou adaptatividade. Um resumo prático das diferenças entre um sistema adaptativo e um adaptável dentro do contexto de modelagem de usuário é apresentado em Fischer (2001) A figura 16 apresenta o ciclo clássico que segue o processo de adaptação dos sistemas computacionais com base nas informações do usuário final.

Figura 16 - Ciclo clássico modelagem de usuário - adaptação nos sistemas adaptativos

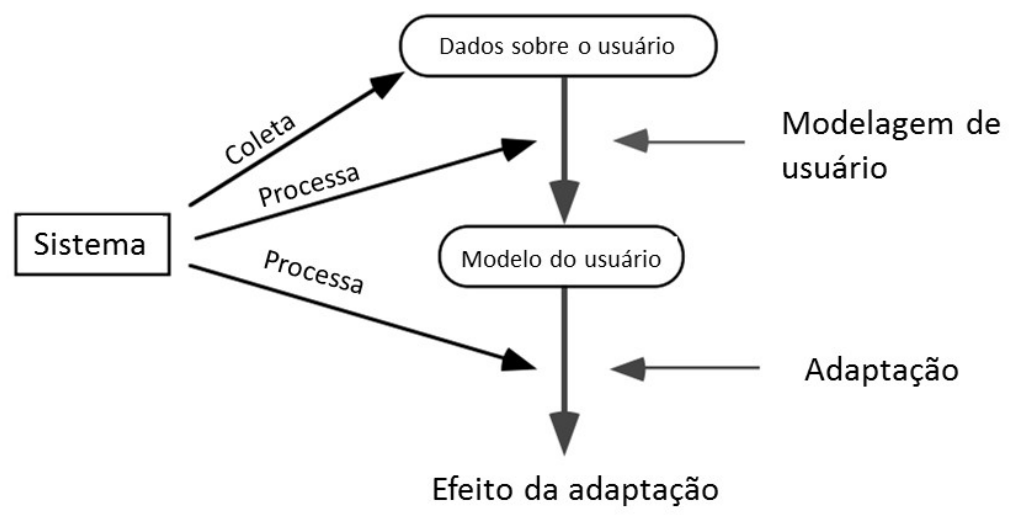

Fonte: Tomado e adaptado de Brusilovsky (1998)

Assim a existência dos perfis de usuário dentro do sistema viabilizam, não somente o uso, mas também a continua melhoria nas adaptações nesses sistemas com a finalidade de oferecer soluções que satisfaçam de maneira mais eficiente as necessidades particulares dos usuários finais.

Em Lee, Choi e Kim (2011) as caraterísticas que definem o contexto de usuário são: localização, condições meteorológicas, atividades, emoções, entre outros. 
Existem diferentes fatores que permitem diferenciar as técnicas de modelagem de usuário, alguns deles são: sensibilidade às mudanças, modelo subjacente e domínio de aplicação.

Historicamente, a modelagem de perfil do usuário tem sido caracterizada pela frequência com que que esses modelos são atualizados. Desse modo, existem modelos de perfis de usuários estáticos, modelos de perfis dinâmicos e modelos híbridos. As abordagens estáticas estabelecem um modelo de usuário fixo dentro do sistema computacional, que será utilizado desde a fase de projeção do software até o fim da sua vida útil. Essa abordagem foi o primeiro tipo de modelagem utilizado para representar o usuário dentro dos primeiros sistemas computacionais tanto na parte de design quanto na parte funcional.

A partir de 1996, o estudo e desenvolvimento das técnicas de modelagem de usuários dinâmicos foram impulsionados por razão do incremento no uso da WWW e a necessidade de personalização dos sistemas computacionais disseminados. A Modelagem dinâmica de usuário visa a construção de um modelo de perfil de usuário que possa ser atualizado de maneira incremental e mantenha ao longo do tempo um registo correspondente à situação do usuário final do sistema Janarthanam e Lemon (2014).

No início do século XXI o avanço nas tecnologias móveis propiciou um novo impulso nas pesquisas de modelagem de perfis de usuários, devido à disponibilidade de dispositivos de hardware e software que permitem o monitoramento das atividades dos usuários de uma maneira mais exaustiva, mas sem ser consideradas tecnologias invasivas. As tendências tecnológicas como wearable computing e ubiquous computing apresentam como parte da sua base funcional uma modelagem de perfis de usuários com alto nível de detalhe. Para fazer frente a esta nova demanda de personalização de conteúdo e funcionalidade foram criadas as técnicas de modelagem de perfis de usuários híbridas. Estas técnicas pretendem combinar as fortalezas de ambas as abordagens anteriores na procura de fornecer um modelo de conhecimento do usuário mais flexível.

Ao respeito dos modelos subjacentes, a maioria de trabalhos apresentam a criação de modelos com estimadores estatísticos e estereótipos para a seleção e criação dos atributos que compõem o perfil de usuário e nos casos de domínios mais específicos são selecionadas palavraschave, e hierarquias de interesses. Assim, diversas aplicações implementam variantes do "overlay model", também chamado "Student Model", para definir o conhecimento do usuário sobre um determinado domínio. Nesses casos, o conhecimento é armazenado na forma de um conjunto de tuplas "conceito-valor"para cada conceito presente na especificação do domínio. Na seleção dos conceitos relevantes para a definição do usuário assim como para o cálculo de valor associado a este são utilizadas técnicas probabilísticas, tais como: Redes neurais, estimadores de Bayes, modelo oculto de Markov, entre outros. Esta técnica é flexível e poderosa, e permite medir o conhecimento do usuário em diferentes tópicos. 
Uma outra técnica de modelagem utilizada com frequência é a criação de estereótipos como representação do conhecimento de um grupo de usuários que compartilham um conjunto de características de interesse, ou também chamado "rol" (JUNIOR; FILGUEIRAS, 2005). Nesse caso, o sistema define uma série de estereótipos, um conjunto para cada dimensão de interesse no sistema e o usuário é modelado de acordo com a propensão que ele tem para dito estereótipo. Essa propensão pode ser representada como um valor único, ou pertence ou não pertence, o como uma probabilidade de pertença.

Uma nova tendência na área de modelagem de perfis de usuário é o uso de arquétipos, no lugar de estereótipos. Esse é o caso da técnica denominada Personas. Essa técnica pode ser entendida como uma composição de arquétipos de usuário no sentido de que ela agrupa padrões de comportamento relacionados ao uso de um determinado produto (COOPER et al., 2014). Personas, como indicado em Cooper et al. (2014), tem como objetivo representar não só um conjunto de características, mas também descrever padrões de comportamento, motivações, atitudes, objetivos, capacidades, e o ambiente (etnográfico e social) que circundam as atividades de um usuário real. Goals são as motivações que regem o comportamento das Personas, e podem ser categorizados em diferentes dimensões e a seleção do "goal"específico determina em boa parte o benefício de adotar Personas como modelo de perfil de usuário.

A tarefa de construção de perfis de usuários dinâmicos normalmente pode ser dividida em três partes: a criação de um primeiro modelo de perfil de usuário, a obtenção de informações (feeback) que permitem considerar novas situações, eventos ou contextos de usuário, e a atualização do próprio modelo de usuário com base no feedback obtido. Para o modelo de usuário inicial é possível utilizar quaisquer das técnicas de modelagem de usuário estático para criar uma primeira versão de modelo de perfil de usuário, sempre que a estrutura de dito modelo corresponda com os objetivos e as capacidades tecnológicas presentes no sistema. Para a obtenção do feedback, algumas das técnicas para alcançar um modelo de usuário que considere as mudanças são: técnicas de aprendizagem por reforço Janarthanam e Lemon (2014)), Lee, Choi e Kim (2011), modelos probabilísticos e inferências: Díaz e Gervás (2004).

Como afirmado em Brusilovsky (1998) em muitos casos, os sistemas computacionais da atualidade utilizam uma técnica de modelagem híbrida que permite de maneira eficiente atingir o objetivo principal do sistema, levando em conta o domínio da aplicação, os recursos disponíveis e os requerimentos do usuário.

No nosso caso é fundamental a construção de um modelo de perfil de usuário dinâmico, simples, mas o suficientemente específico para descrever a aparição de necessidades especiais do usuário. O armazenamento dessa base de conhecimento sobre o usuário será externa à base de dados de recursos do sistema o que permite aproveitar o paradigma de programação orientada a componentes a ser descrito em seguida. 


\subsubsection{Contextualização da Tecnologia}

Uma das grandes qualidades dos seres humanos é a capacidade de transmitir ideias de uns para outros e reagir adequadamente à mensagem recebida. Isto deve-se em parte porque na interação entre humanos existe a transmissão de informações situacionais implícitas, o chamado contexto. Na interação entre humano e computador não existe a possibilidade de que cada um dos participantes tenha a capacidade de inferir automaticamente essas informações e portanto a qualidade da interação se vê empobrecida com à interação entre seres humanos. Para tentar fornecer uma melhor interação é preciso definir o que é o contexto e como pode ser usado dentro dos diferentes sistemas computacionais dependendo do objetivo deles. Em Dey e Abowd (1999) o contexto é definido como: "qualquer informação que possa ser utilizada para caracterizar a situação de uma entidade, sendo esta uma pessoa, lugar ou objeto que é relevante na interação entre um usuário e uma aplicação, inclusive os mesmos".

No presente texto, o conceito de contextualização de uma entidade, ou context awareness em inglês, é entendido como a tomada de consciência do contexto no qual atua dita entidade. De maneira geral, essa tomada de consciência inclui três componentes:

- Localização: O agente analisado reconhece que se encontra imerso em uma realidade pontual, um cenário particular limitado e definido por caraterísticas concretas.

- Percepção: O agente analisado é capaz de perceber os fenômenos ou eventos que acontecem em seu cenário através de mecanismos próprios. Por exemplo, no caso dos seres humanos os mecanismos que lhe permitem reconhecer as condições do ambiente no qual se encontram são os seus sentidos. Desta maneira é possível identificar e analisar as situaç̃̃es, condições, ou problemas existentes dentro do cenário de atuação do agente.

- Ação: O agente analisado é capaz de tomar ações possíveis dentro do seu cenário, isto é, ele é capaz de interagir com os elementos que compõem o ambiente. A tomada de decisão acerca das ações a serem executadas correspondem a um mecanismo próprio do agente, de maneira que se pode dizer que o agente passa a "conhecer"ou "entender"o que acontece ao seu redor.

Só depois de ter comprovado esses três componentes é possível dizer que uma entidade é consciente do contexto no qual vai desenvolver suas atividades.

De maneira particular, é possível delimitar e definir diferentes contextos dentro de uma mesma realidade. Por exemplo, em um diálogo entre duas pessoas é possível analisar:

- O contexto linguístico: que leva em conta as palavras utilizadas por ambos os agentes do diálogo. 
- O contexto de interação: que leva em conta não apenas as palavras, mas também as expressões corporais, entonação e outros elementos.

- O contexto psicológico: que leva em conta as palavras, expressões corporais, emoções, rapidez da resposta, em busca de um raciocínio que justifique a interação manifestada pelos agentes envolvidos.

Além dos contextos mencionados, nos quais o foco de análise é o diálogo, existem outros contextos relevantes para diferentes tipos de tarefas. Assim mesmo, cada um destes contextos está definido também pela seleção do agente principal que irá analisar o contexto, ou seja, não é a mesma coisa definir um contexto do ponto de vista de um agente observador do diálogo, ou do de um dos participantes do diálogo.

Já no campo tecnológico, o conceito de contextualização da tecnologia tem sido investigado por mais de 50 anos Schmidt, Beigl e Gellersen (1999), e tem ganhado importância na medida que ele ajuda na definição de contextos de interesse para o desempenho ideal de sistemas e ferramentas. Começou-se com a contextualização de peças de software com comportamento determinístico, as interações entre sistemas e bases de dados, até chegar à contextualização de interação com o usuário final. Em Ranganathan e Campbell (2003), por exemplo, é mencionado que os diferentes tipos de contextos que rodeiam as interações com os usuários são: contexto físico, ambiental, informacional, pessoal, social, de aplicativos, e de sistema Dey e Abowd (1999). A definição destes contextos permite a extração de informações que assistem aos sistemas na compreensão dos eventos, das reações do usuário a ditos eventos e, em alguns casos, das consequências das ações tomadas pelo sistema para responder as necessidades manifestadas.

Em Dey e Abowd (1999) é apresentada uma categorização dos diferentes tipos de sistemas que implementam contextualização, assim eles estão divididos em:

- Apresentação de informações e serviços ao usuário

- Execução automática de um serviço

- Etiquetagem de contexto às informações para uma recuperação posterior

Finalmente, na atualidade o conceito de contextualização está sendo aplicado para a construção de sistemas dinâmicos de grande complexidade, por exemplo na área de Ambient Intelligence e computação ubíqua. O objetivo nestas áreas é conseguir a montagem de sistemas com elementos que se anexam dinamicamente ao ambiente e que, por sua vez, são heterogêneos, de maneira que um diálogo e uma definição do contexto corrente torna-se um pilar fundamental para a construção do sistema global. 
Em seguida, são detalhadas as principais técnicas utilizadas no campo tecnológico para a modelagem de contextos tanto de sistema quanto de usuário final assim como as recomendações da literatura para a descrição adequada de um contexto corrente.

A seguir, serão expostos exemplos das principais tecnologias que analisam diferentes contextos para oferecer soluções aos usuários e os desafios encontrados, e é apresentada brevemente a tendência observada nos últimos anos para o desenvolvimento de tecnologias conscientes do contexto de acordo com a evolução esperada.

\subsubsection{Meta-Modelo e Meta-Arquitetura}

\subsubsection{Meta-Modelo}

O conceito de meta-modelagem tem sua origem na área de representação do conhecimento, na qual um meta-conhecimento é aquele que permite a descrição de um outro conhecimento de maneira geral e abstrata. Assim, pode-se dizer que um meta-modelo é, de maneira geral, o modelo de um modelo Smeda, Khammaci e Oussalah (2005). Ele define o marco, as regras, as restrições, técnicas e teorias aplicáveis para a modelagem de uma determinada família de problemas já definidos, representando, por isso, uma maneira geral de descrevê-los Ferber e Gutknecht (1998). Portanto, se um modelo representa a abstração de uma realidade definida, um meta-modelo representa mais um nível de abstração no qual são priorizadas as propriedades do próprio modelo. O conceito de meta-modelagem não é novo e tem sido utilizado com sucesso nas áreas da Matemática, Ciências da Computação e Engenharia de Software e Sistemas. Como indicado em Ferber e Gutknecht (1998) um meta-modelo permite dois níveis de análise: uma parte fixa (também chamada parte concreta) e uma parte dinâmica (também chamada de abstrata). A parte fixa contém todas aquelas propriedades invariantes que possuem os membros da família de problemas (ou sistemas, no nosso caso) a descrever. Eles são também conhecidos, na literatura, como núcleo do meta-modelo, pois são a mínima informação necessária para seu correto funcionamento. A parte dinâmica, por outro lado, está conformada pelas regras, restrições, técnicas e teorias que permitem a especificação das diferentes instâncias da classe de problemas que está sendo modelado. Assim, só no momento de conhecer a instância particular de problema a ser tratado é possível, por meio das especificações estabelecidas, converter o meta-modelo em um modelo específico que atende às necessidades do problema. 


\subsubsection{Meta-Arquitetura}

Como apontado em Smeda, Khammaci e Oussalah (2005) a aplicação de meta-modelos no contexto de arquitetura de software refere-se ao uso de uma linguagem de descrição de arquiteturas, ADL por suas siglas em inglês (Architecture Description Language), para estabelecer a descrição formal ou semi-formal da arquitetura de um sistema. Assim, uma meta-arquitetura define a estratégia sobre a qual será criado o sistema expondo claramente os objetivos, as restrições e os recursos do sistema. Ela tem como finalidade dar forma à arquitetura concreta do sistema para cada caso presente durante o tempo de vida do sistema. Para atingir esse objetivo, ela especifica uma série de "artifacts"que dão à montagem final da arquitetura, alguns deles são: orientações para as escolhas, padrões, especificação de estilos, documentações, e restrições. O desenvolvimento de uma meta-arquitetura é pertinente no caso do nosso trabalho pois permite estabelecer a arquitetura concreta adequada para cada instância de sistema com a qual o usuário estabeleça interação. 


\section{MODELO PROPOSTO}

Neste capítulo é detalhada uma proposta que, com ajuda da tecnologia adaptativa, procura proporcionar uma solução viável para melhorar a interação entre sistemas computacionais legados de uso geral e os usuários com deficiência. Assim, o capítulo três trata do problema do gerenciamento dos recursos do computador para fornecer uma interação humano-computador que atenda aos requisitos do usuário particular, facilitando, assim, a implementação da acessibilidade universal. São feitas as considerações principais sob as quais o trabalho é delimitado, assim como a metodologia que é utilizada para dar solução ao problema.

\subsection{DELIMITAÇÃO DO TRABALHO DENTRO DO PANORAMA ANTERIOR}

O principal objetivo do projeto é propor a modelagem de um componente tecnológico que permita gerenciar os recursos de interação com o usuário que possui um sistema legado de uso geral com o intuito de fornecer acessibilidade aos usuários com necessidades especiais. $O$ modelo proposto deve satisfazer algumas condições:

- Ser portável: de maneira que facilite sua aplicação em diferentes sistemas computacionais, sem que isso implique o transporte de elementos de hardware que possam limitar ainda mais a liberdade de movimentação, já restrita, que os usuários com necessidades especiais possuem.

- Ser "seamless": de maneira que o sistema subjacente não dependa da participação do componente para a execução de suas tarefas, mantendo estabilidade nas suas configurações antes e depois do uso de um componente que segue o modelo proposto. Nesse contexto, o componente deve agir como um elemento consultor e não como parte da arquitetura principal do sistema.

- Trabalhar prioritariamente com recursos locais: de maneira que sejam aproveitadas as tecnologias e recursos já presentes no sistema, evitando demoras associadas a procuras ou instalações de software externos que podem afetar a interação ou a configuração interna do sistema subjacente.

- Ser configurável: Sem dúvida a caraterística principal do componente. Dependendo do nível no qual é efetuada a configuração, a natureza desta pode ser entendida como uma personalização (uma ação iniciada pelo usuário) ou uma auto-modificação (uma ação adaptativa iniciada pelo próprio sistema). Além disso a arquitetura concreta do componente deve levar em conta as informações de usuário, ambiente e o sistema correntes, 
pelo qual é preciso contar com mecanismos internos que forneçam a flexibilidade requerida para favorecer uma interação eficiente com o usuário final baseada nas informações analisadas.

O modelo proposto integra o uso de técnicas adaptativas, análise de protocolos de comunicação entre componentes computacionais, e estratégias e metodologias de desenvolvimento de software. Além disso ele leva em conta a interação com componentes que implementam computação em nuvem, técnicas de modelagem de usuário para a gestão de tecnologias e técnicas da interação humano-computador. No entanto, é importante distinguir que não é finalidade deste trabalho propor melhorias nas técnicas independentes de criação de componentes, modelagem de bases de dados, modelagem de usuários, ou outras técnicas utilizadas na parte concreta dos subcomponentes da arquitetura, pois isso corresponde ao trabalho especializado em cada área. Nosso objetivo é propor a estrutura de um elemento de software que seja capaz de trabalhar de maneira eficiente com componentes heterogêneos, que implementem uma interface padrão estabelecida, para assistir ao sistema subjacente na concretização de uma interface de interação com o usuário.

Para atingir este objetivo principal foram estabelecidos os seguintes objetivos específicos:

(a) Especificação da meta-arquitetura que descreve o problema de gerenciamento de recursos.

(b) Especificação e criação de componentes e mecanismos de comunicação necessários para a montagem e concretização da meta-arquitetura.

(c) Modelagem e criação dos contextos utilizados para a adaptação do sistema: contexto de usuário, contexto de sistema e contexto de ambiente de execução.

(d) Modelagem e construção das bases de dados necessárias para o funcionamento do middleware: base de dados de usuário, diretório de serviços, base de dados de histórico de execução.

(e) Modelagem e construção do mecanismo de tabelas adaptativas.

(f) Configurar e aplicar os testes padronizados.

(g) Analisar os resultados dos testes.

\subsection{META-ARQUITETURA DA SOLUÇÃO}

A solução proposta neste trabalho segue o modelo de Middleware, entendido como "uma unidade de software(módulo, componente, agente, entre outros) que, sendo independente e 
externo a um sistema, pode ser incorporada nele para desempenhar uma tarefa de interlocução entre peças de software do mesmo sistema ou externas a este para a realização de um trabalho colaborativo". Assim, no nosso caso o Middleware é incorporado no sistema legado de propósito geral com a finalidade de assessorá-lo no gerenciamento dos recursos disponíveis para a reconfiguração da interface de interação humano-máquina. A finalidade de dita incorporação é fornecer uma interface alternativa à padrão que permita atender as necessidades particulares dos usuários no estado corrente do sistema. Nos parágrafos seguintes serão descritos os componentes do sistema e o funcionamento padrão dos mesmos. O modelo de middleware que propomos se encaixa como um Component-Middleware de acordo com a taxonomia proposta por Emmerich (2000), e um Domain-Middleware, especializado no trabalho de recursos de interface de usuário, de acordo com a taxonomia elaborada por Schmidt (2002).

\subsubsection{Componentes do Sistema}

O sistema, como objeto de estudo no nosso caso, está composto pelos elementos que intervêm no processo de interação entre humano e máquina: elementos físicos ou de hardware, elementos de software e o próprio usuário. Na continuação são detalhadas as perspectivas do sistema de acordo com os elementos do processo.

\subsubsection{Perspectiva física ou de Hardware}

De acordo com esta perspectiva o sistema em questão será formado por 3 elementos físicamente identificáveis: o sistema legado como o dispositivo computacional principal presente na interação, o Middleware associado com um dispositivo mobile, e o usuário. A Figura 17 ilustra esta perspectiva física.

\subsubsection{Perspectiva de Usuário}

Sob a perspectiva de um usuário final do sistema existem, durante o processo de interação, seis momentos diferenciados de intercâmbio de informações entre ele e o sistema. Esses seis momentos são:

(a) O usuário interage só com o Sistema Legado, não existe presença nem software nem hardware do Middleware.

(b) O Sistema Legado identifica a presença de um elemento hardware com conexão do tipo USB e notifica ao usuário. Nesse momento o usuário tem conhecimento da existência 


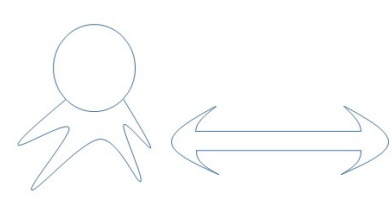

Usuário

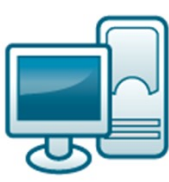

Sistema Legado

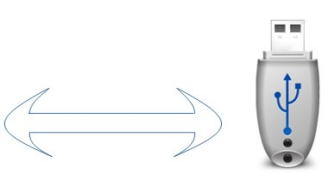

Middleware

Fonte: Autora

Figura 18 - Percepção do usuário da sua interação padrão com o sistema legado de uso geral

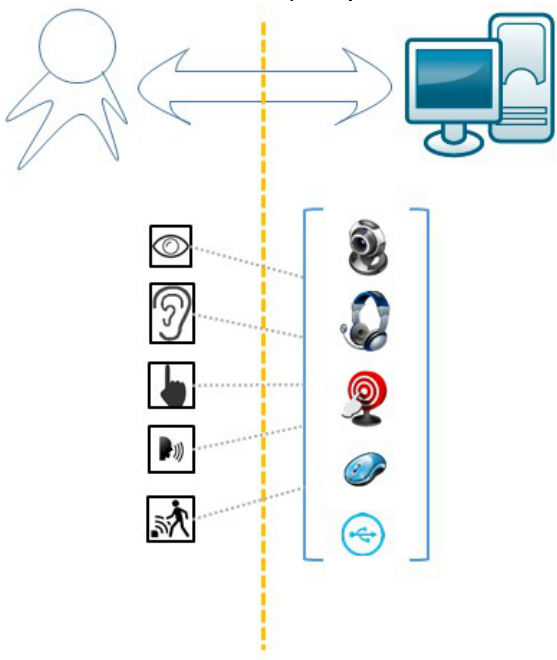

Fonte: Autora

de um elemento hardware, especificamente um dispositivo USB conectado ao Sistema Legado.

(c) O usuário interage diretamente com o Middleware, associado ao dispositivo USB, para ativar o seu funcionamento e fornecer alguma informação que define a configuração inicial.

(d) O usuário interage com o sistema, formado agora pela composição do sistema legado e o Middleware. Ele envia informações diretamente através da interface do Sistema Legado, e recebe o resultado das interações do Middleware com o Sistema Legado.

(e) O usuário manifesta a sua intenção de concluir com o uso do Middleware como assessor do Sistema Legado para a interação, então o Middleware evidencia sua existência e estabelece um canal de comunicação direta com o usuário para confirmar algumas informações a serem salvas como consequência da interação. O usuário rejeita ou confirma as informações a 
Figura 19 - Percepção do usuário da sua interação com o sistema legado ao reconhecer a conexão de um dispositivo USB
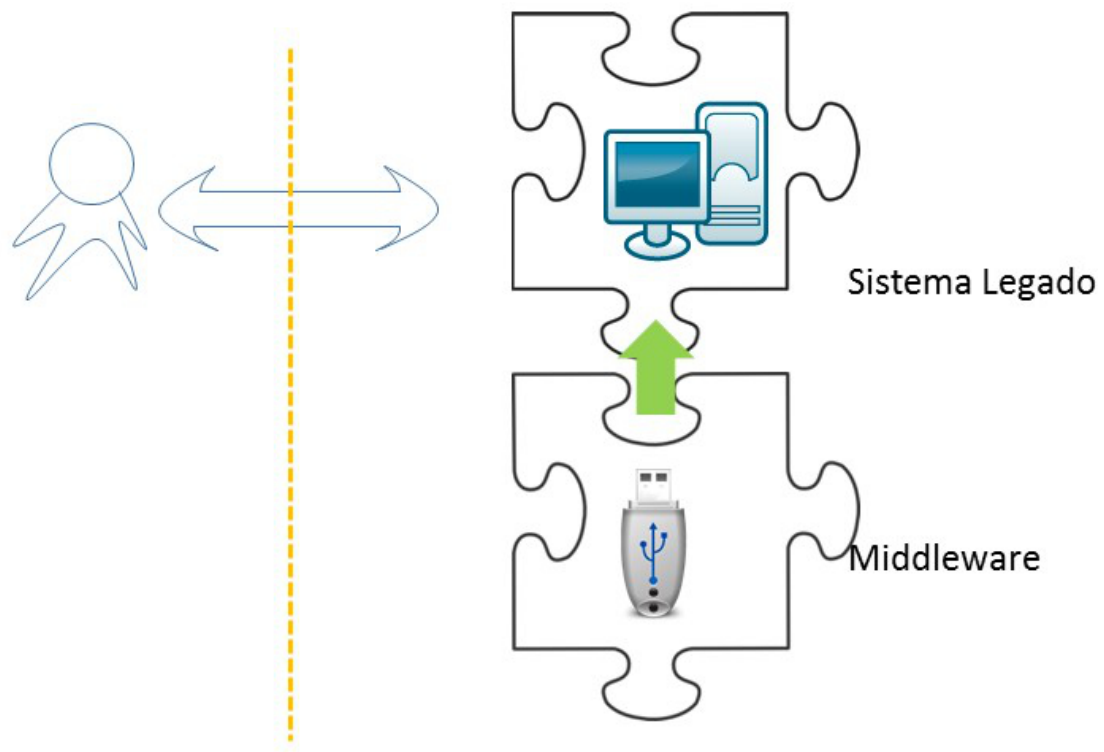

Fonte: Autora

Figura 20 - Percepção do usuário da sua interação com o sistema ao iniciar o middleware

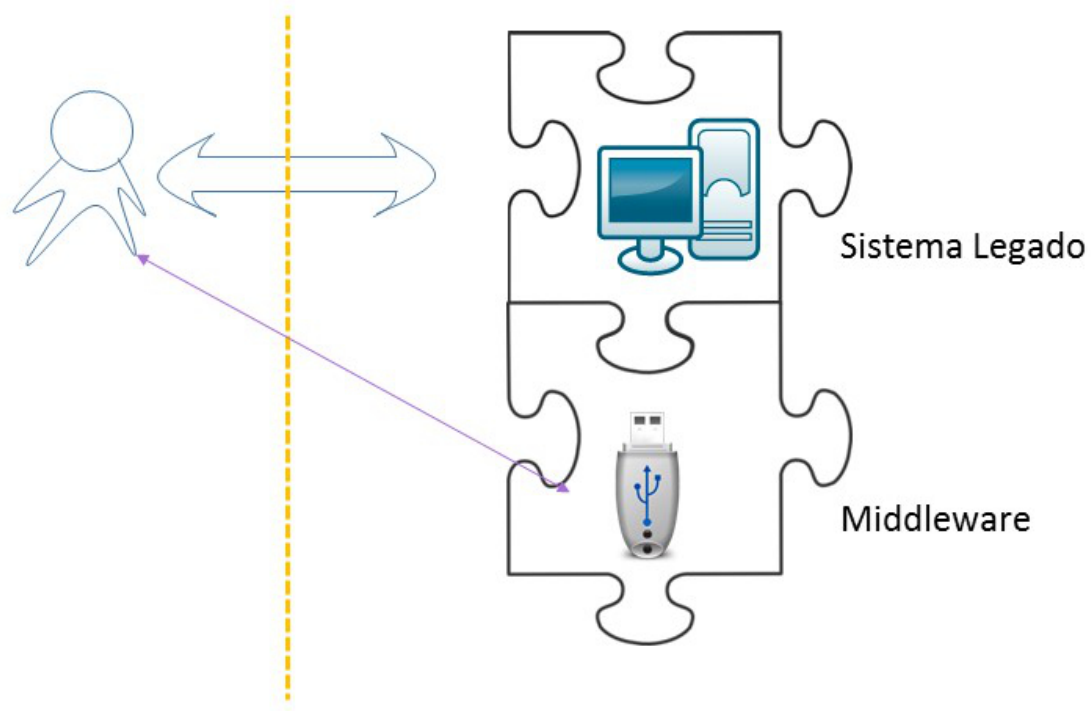

Fonte: Autora

serem salvas.

(f) O Sistema Legado identifica a solicitude de ejeção de um elemento hardware do tipo USB e notifica o usuário. Nesse momento o usuário tem conhecimento de que um elemento hardware, especificamente um dispositivo USB, foi desconectado do Sistema Legado.

Assim, o Middleware é uma peça de software, associada a um dispositivo hardware, que expõe sua existência ao usuário em dois momentos específicos: (1) para ativar a sua interação com o sistema hospedeiro e (2) para terminar dita interação. Para qualquer outro momento o usuário não percebe a existência do Middleware desde o ponto de vista funcional, pois não 
Figura 21 - Percepção do usuário da sua interação com o sistema composto pelo middleware e o sistema legado

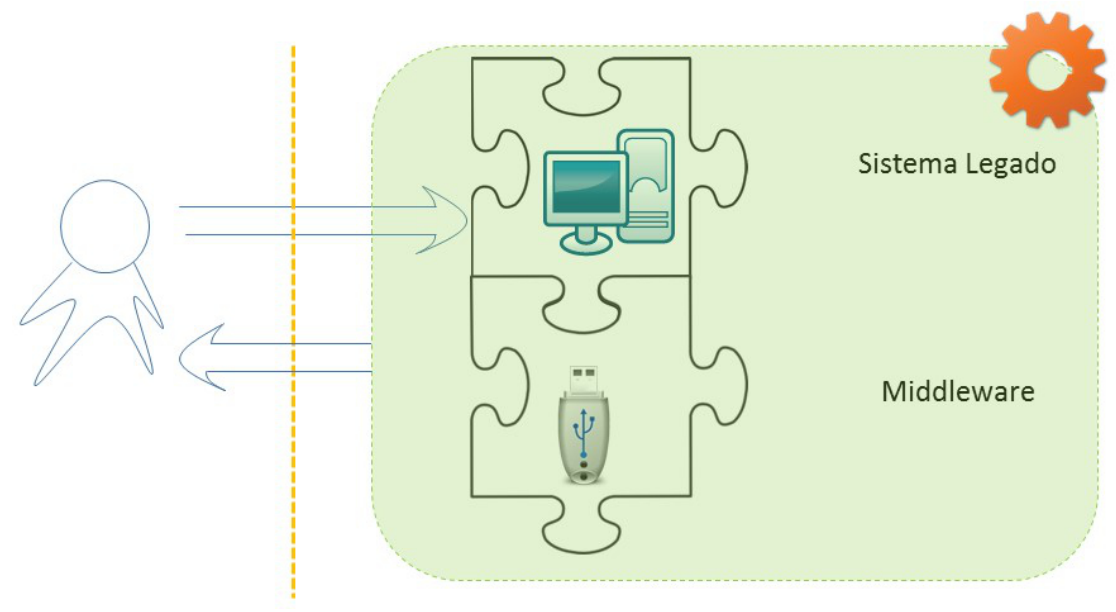

Fonte: Autora

Figura 22 - Percepção do usuário da sua interação com o sistema ao concluir o uso do middleware

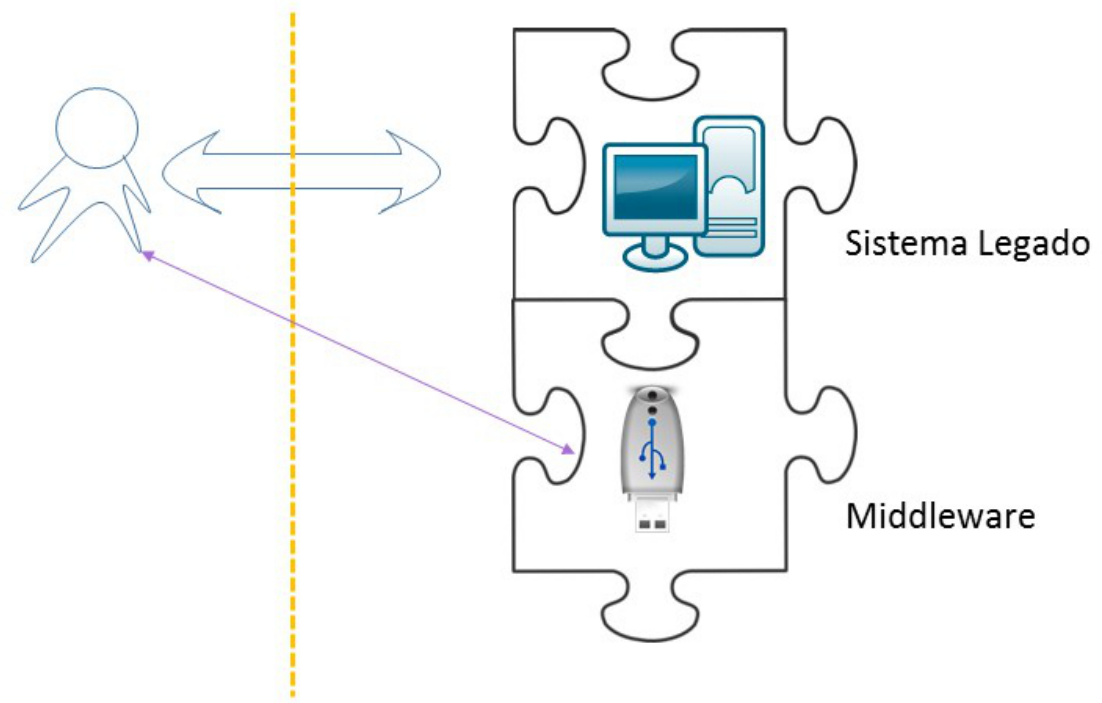

Fonte: Autora

é requerida sua participação direta nas atividades de reconfiguração da interface do sistema. Pelo contrário, uma das estratégias adotadas na elaboração do modelo é uma participação mínima do usuário, e quando necessária ela deve ser solicitada da forma e no tempo menos invasiva possível.

\subsubsection{Perspectiva de Software}

Do ponto de vista do sistema, entendido como o conjunto de elementos computacionais que participam das atividades envolvidas no processo da interação com o usuário, existem duas visões: a visão externa ao Middleware e a visão interna ao Middleware.

Sob uma perspectiva externa ao Middleware o sistema em questão está organizado em 4 
Figura 23 - Percepção do usuário da sua interação com o sistema legado ao reconhecer a ejeção de um dispositivo USB
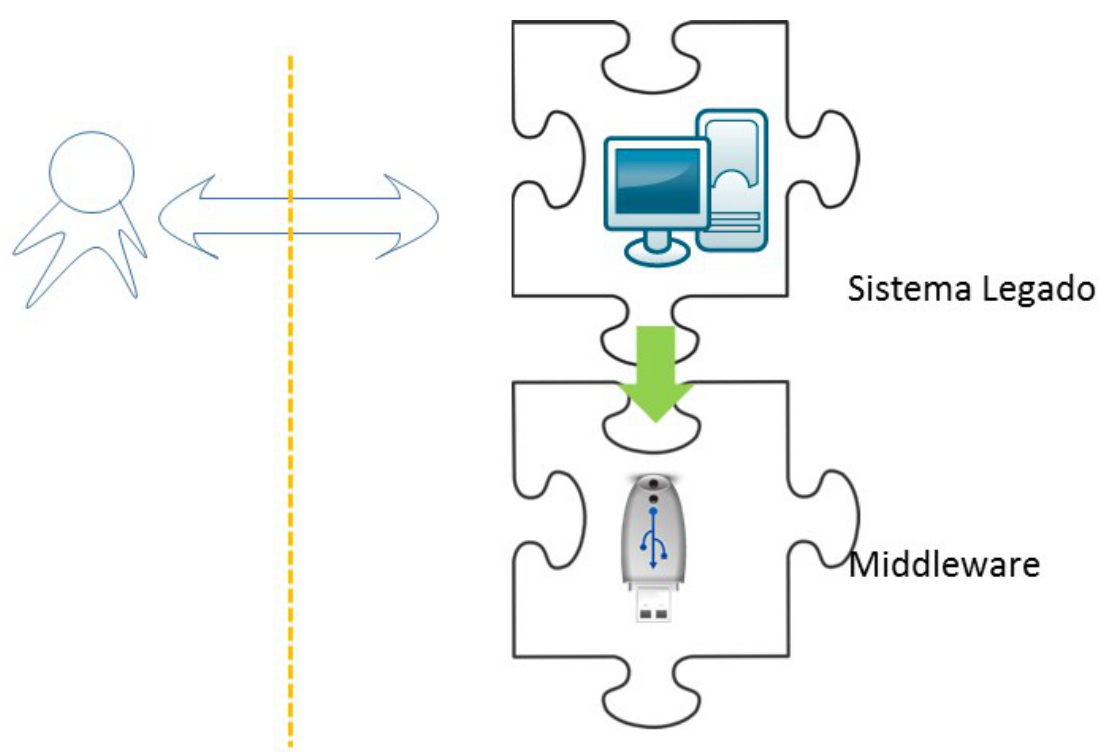

Fonte: Autora

camadas: a camada do sistema operacional, a camada de aplicações e recursos, a camada da meta-arquitetura e camada de componentes. A Figura 24 apresenta as ditas quatro camadas.

Figura 24 - Elementos do sistema sob a perspectiva de Software

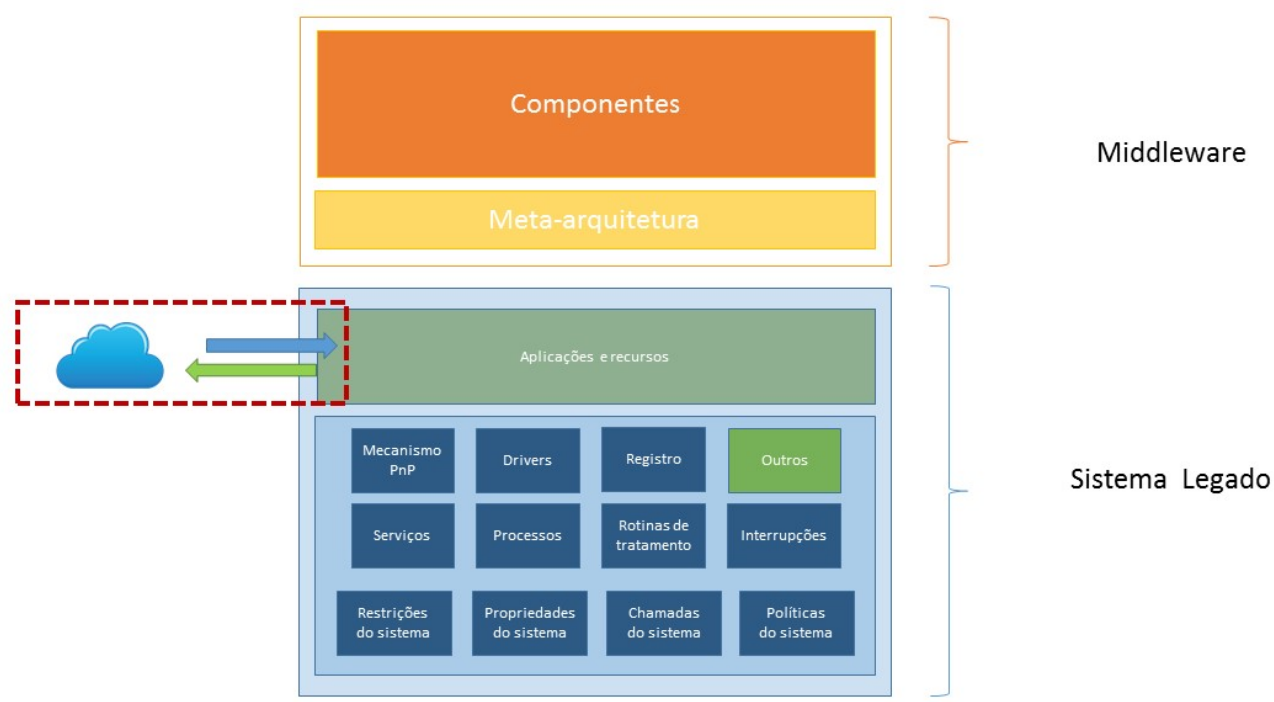

Fonte: Autora

A camada do Sistema operacional contém todas as informações e funcionalidades próprias do sistema operacional subjacente no sistema computacional legado. Algumas dessas informações são: o registo, as restrições, propriedades e políticas que regem o sistema, entre outras. Dentro das principais funcionalidades, de interesse para este trabalho, estão: o mecanismo $\mathrm{PnP}$, os 
drivers, os processos e serviços disponíveis no sistema, assim como as interrupções e as rotinas de tratamento correspondentes.

A camada de aplicações e recursos contém os elementos de software disponíveis para uso dentro do sistema legado. Dependendo da origem dos recursos existem dois casos bem diferenciados: acesso local, ou acesso remoto. Se o sistema não trabalha com uma estrutura de conexão à rede (hardware e software) então só é possível ter acesso aos recursos locais (instalados e disponíveis para uso do sistema operacional no computador). Se o sistema coloca em evidência a disponibilidade de uma conexão à internet pelo lado do do sistema legado, então é possível ter acesso a recursos remotos, por exemplo: web services, que implementam funcionalidades de interesse para a interação.

A camada de meta-arquitetura contém dois elementos principais: o componente de comunicação e o componente gerenciador do Middleware. O componente de comunicação é o encarregado de implementar o protocolo de comunicação entre o Middleware e o Sistema Legado, assim como de gerenciar os recursos associados com dita tarefa. O componente gerenciador do Middleware, ou Manager, é o encarregado de dirigir a concretização da meta-arquitetura para o trabalho com o sistema legado corrente, e para isso ele estabelece as conexões necessárias com os tipos de componentes requeridos e disponíveis.

A camada de Componentes contém as peças de software denominadas componentes que processarão as informações correspondentes com o problema. Cada um destes componentes desenvolve uma funcionalidade específica e expõe a interface correspondente a elas e as restrições para o seu uso.

É importante apontar neste estágio que em todos os casos, o Middleware é um elemento que trabalha à maneira de assessoria: ele solicita informações ao sistema hospedeiro e envia solicitações para serem atendidas por este, mas não atribui valores nem gerencia diretamente recursos que estão sob domínio do sistema operacional. Dessa maneira, no entanto, ambos os elementos são peças de software e hardware independentes, funcionalmente falando elas são conectáveis. O sistema é o encarregado do gerenciamento dos dispositivos de entrada e saída disponíveis no computador, assim como da montagem da interface de interação com o usuário. Por outro lado, o Middleware fica responsável pela configuração da interface baseado em informações correntes e históricas do contexto de execução.

Assim, do ponto de vista técnico o sistema hospedeiro possui, junto com outras informações, serviços, chamadas a sistema, as restrições aplicadas à configuração corrente, processos, políticas de segurança, propriedades e o acesso a serviços e recursos fornecidos pelos diferentes aplicativos a que têm acesso. São esses elementos que podem fornecer informações sobre o estado do sistema, e que também permitirão a concretização da montagem da interface com o usuário sugerida pelo Middleware. 
A visão interna ao Middleware apresenta informações técnicas agrupadas de acordo com a natureza das tarefas a serem desenvolvidas por seus componentes. Assim, apresentaremos esta visão na próxima seção seguindo uma estratégia de especialização, indo desde uma perspectiva mais geral até uma mais detalhada.

\subsubsection{Componentes do Middleware}

A estratégia escolhida para a modelagem do Middleware corresponde ao sugerido na literatura para a aplicação do paradigma de programação orientada a componentes: o agrupamento de funcionalidades em componentes de acordo com o tipo de informação que cada uma delas manipula, assim como a abrangência que essas funcionalidades têm dentro do sistema, de maneira que seja favorecido o baixo acoplamento entre os elementos do sistema. Assim, a Figura 25 mostra os 6 componentes do Middleware que compõem a meta-arquitetura: o componente de comunicação, o componente de gerenciamento de execução do Middleware, o componente de Interação com o Sistema Operacional, o componente de Extração de informações do entorno da interação, o componente de interação com o usuário, e o Componente de Tomada de Decisão. A seguir a descrição de cada um deles.

Figura 25 - Visão Geral da Aquitetura interna do Middleware

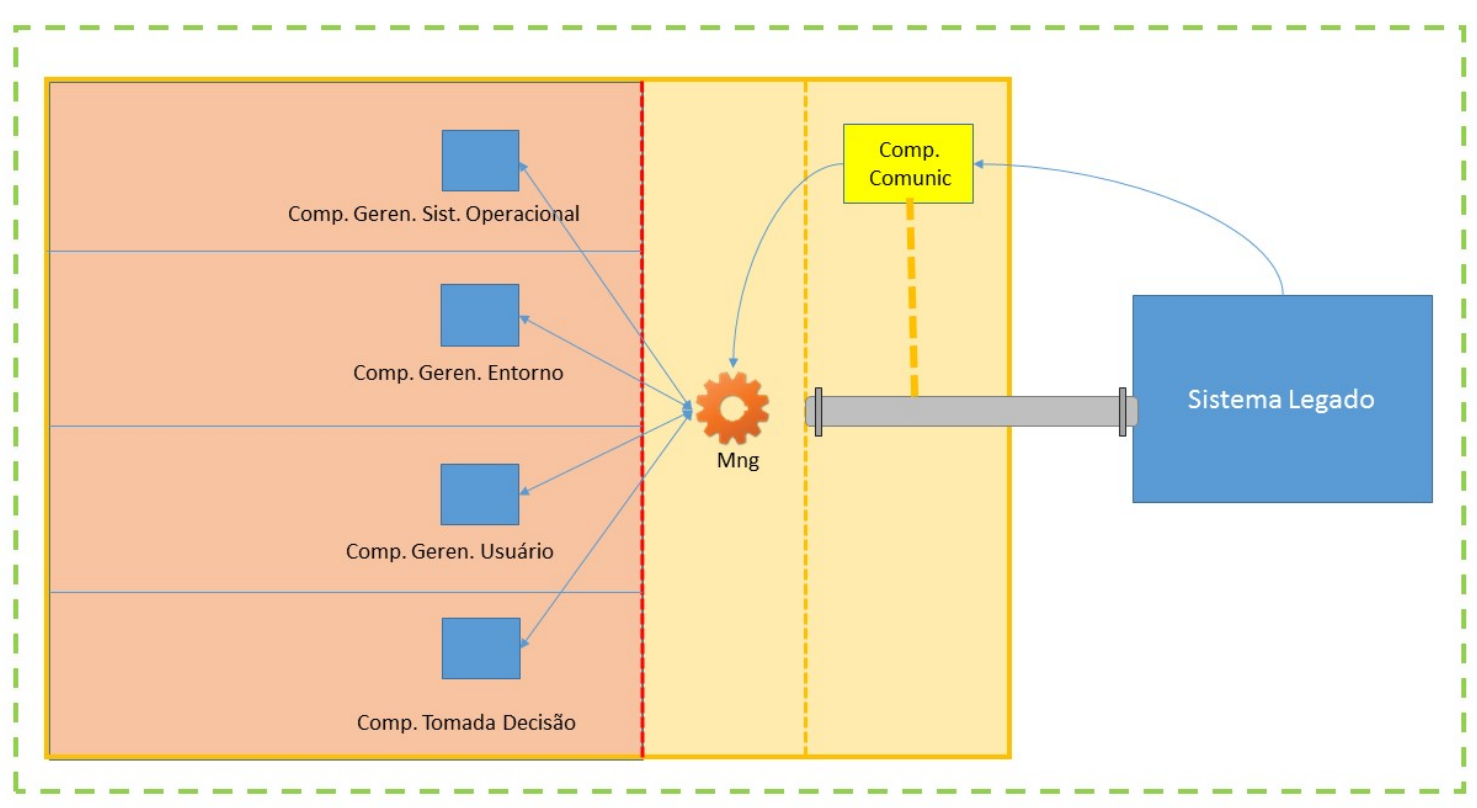

Fonte: Autora 


\subsubsection{Componente de Comunicação}

Este componente é o responsável pela configuração e o estabelecimento do canal para o intercâmbio de informações entre os outros componentes do Middleware e o Sistema legado. Este componente implementa um protocolo de comunicação entre componentes, e é responsável pela administração dos recursos designados para esta tarefa. Assim, ele é o primeiro e o último módulo a ser executado para cada ativação do Middleware. Este componente é uma peça de software concreta, isto é, ele implementa um protocolo concreto e não aceita mudanças na especificação de dito protocolo, a qual é fornecida sob o formato de arquivo XML. Da mesma maneira, ele tem a responsabilidade de salvar as notificações sobre o sucesso ou não da transmissão de informações, assim, ele mantém um arquivo log a ser consultado sob qualquer eventualidade. A Figura 26 mostra os elementos que participam neste componente.

Figura 26 - Arquitetura interna do Middleware- Componente de Comunicação

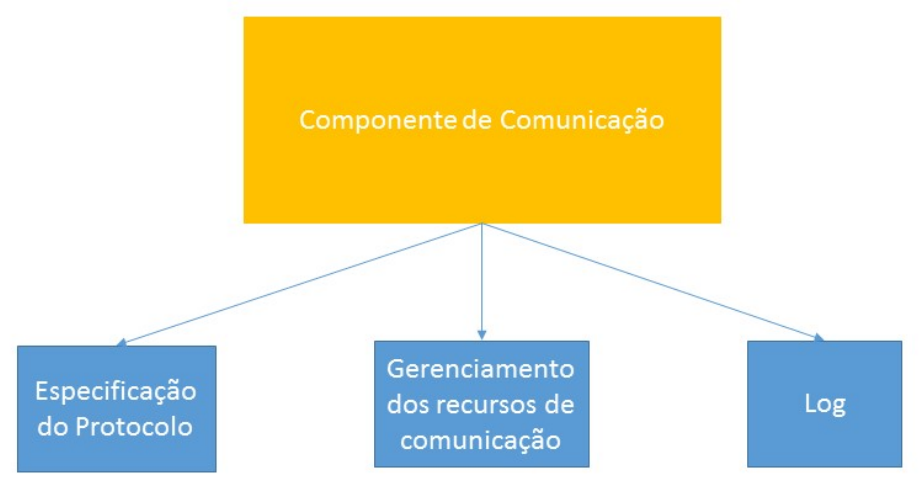

Fonte: Autora

No entanto, ele é um elemento concreto e pode ser trocado fora do tempo de execução e com mínimas considerações de configuração. Uma analogia de utilidade para caracterizar o comportamento deste componente é um driver de dispositivo, pois ele é responsável por estabelecer o entendimento e a troca de informações entre o sistema operacional e o software do fabricante para o dispositivo. Da mesma maneira, quando uma atualização de driver é disponibilizada, é necessário um processo de reconfiguração, mas depois de efetuá-lo, é possível utilizar o dispositivo como de costume. A Figura 26 mostra os elementos que participam neste 
componente.

Uma vez estabelecido o canal de comunicação entre o sistema legado e o Middleware o controle da execução passa para o Componente Geral de Gerenciamento, retornando a este componente só no processo de desativação do Middleware para liberar os recursos de sistema associados ao canal de comunicação.

\subsubsection{Componente Geral de Gerenciamento}

Este componente gerenciador do Middleware é o elemento responsável pela concretização do primeiro nível da arquitetura do Middleware. Ele recebe as informações de configuração através de um arquivo do tipo XML que contém os tipos de componente com os quais deve-se estabelecer uma comunicação, e as interfaces correspondentes para garantir a funcionalidade integral do sistema. Assim, em tempo de execução ele verifica ditas especificações com os componentes disponíveis no momento e logo inicia o funcionamento do Middleware.

Figura 27 - Arquitetura interna do Middleware- Componente de Gerenciamento

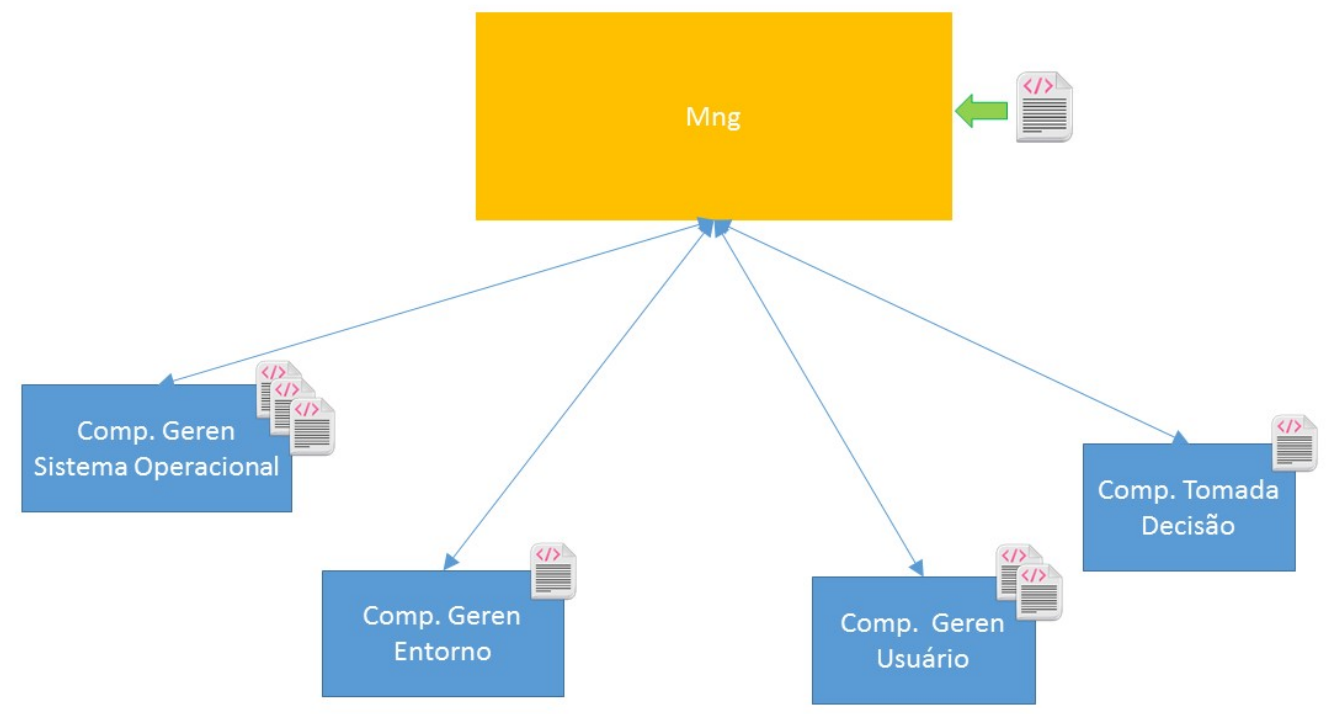

Fonte: Autora

A Figura 27 apresenta o Nivel 1 da hierarquia de componentes que formam a estrutura interna do Middleware e especificam a interação entre diferentes componentes, assim como a quantidade de saídas persistentes no formato XML que cada um deles produz.

Sendo o único componente no nível mais alto da hierarquia, todos os outros componentes remetem suas informações para este componente, que filtra e encaminha as informações obtidas para o subcomponente pertinente. Ele mantém também a sequência padrão de execução 
do Middleware: realizando as configurações iniciais, solicitando a construção dos contextos de sistema, entorno e usuário correntes e fornecendo estas informações para a tomada de decisão sobre a reconfiguração a ser aplicada ao sistema.

\subsubsection{Componente de Interação com o Sistema Operacional}

Este componente tem quatro tarefas principais que auxiliam o Middleware a lidar com as interações específicas necessárias entre ele e o sistema operacional do sistema em execução.

Figura 28 - Arquitetura interna do Middleware- Componente de Interação com o Sistema Operacional

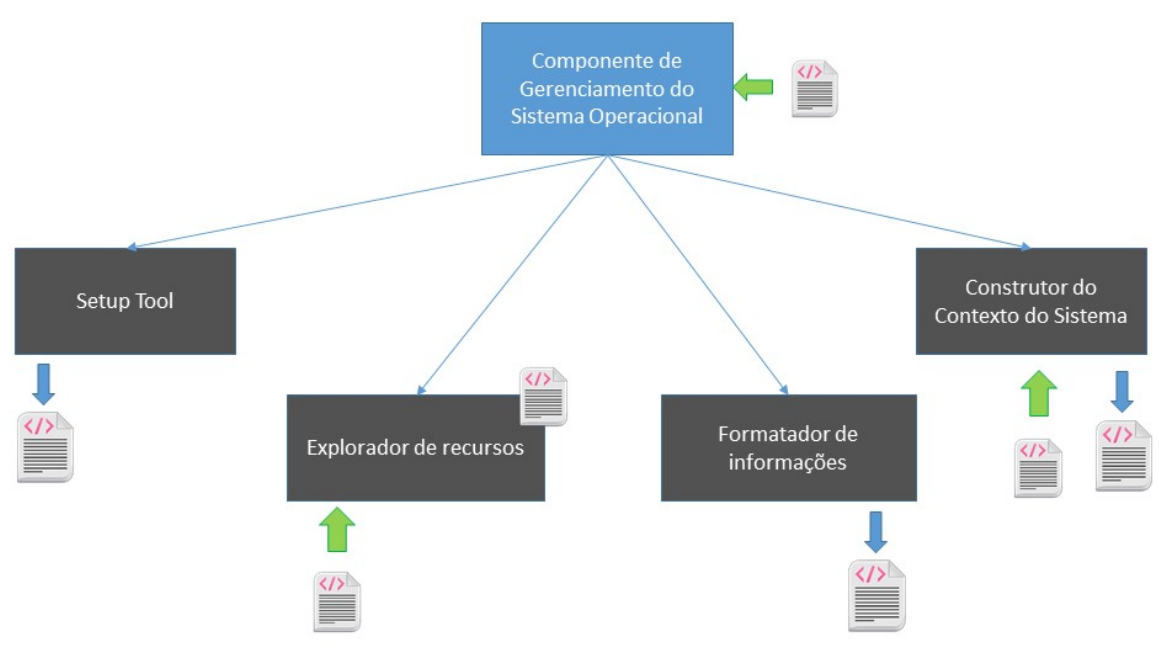

Fonte: Autora

Conforme ilustrado na Figura 28, existem quatro subcomponentes encarregados de tarefas específicas, a saber:

- Setup tool: Este subcomponente é o responsável pela identificação, afinação e sincronização com o sistema operacional corrente. Ele é também responsável por salvar as configurações iniciais do sistema legado em um arquivo do tipo XML para serem restituídas ao finalizar a interação com o Middleware.

- Explorador de Recursos: Este subcomponente está encarregado de examinar dentro do sistema operacional do sistema legado os tipos de recursos envolvidos na tarefa principal do Middleware: no caso deste trabalho, os recursos de interação entre humano e máquina, e retorná-los para seu uso na construção do contexto do sistema. A definição 
de quais são os tipos de recursos a serem procurados é fornecida como parâmetros da exploração através de um arquivo tipo XML. A finalidade deste componente é verificar se foi realizada alguma mudança em termos da quantidade ou tipo de recursos disponíveis, as características destes recursos e seus valores correspondentes. A ação deste subcomponente pode ser ativada através de ativação direta ou ativação indireta. A primeira modalidade de ativação corresponde com o conceito tecnológico conhecido como "daemon", que significa que o processo é lançado em execução a cada determinado intervalo de tempo (estabelecido como parâmetro dentro dos arquivos de configuração). A segunda modalidade de ativação, lança o processo de exploração como consequência da ocorrência de algum evento monitorado. A origem de dito evento pode vir tanto da ativação direta por ordem de algum outro programa dentro do sistema operacional ou acontecer como consequência da interação do usuário com o sistema. Em ambos os casos, o processamento deste evento é realizado de maneira assíncrona e segue as regras estabelecidas como parte das políticas do sistema operacional subjacente.

- Formatador das Informações: este subcomponente está encarregado da formatação das informações que vem do Sistema Operacional, no dispositivo subjacente, de acordo ao padrão adotado na comunicação dos módulos do Middleware e vice-versa. Dessa maneira, o trabalho dele é basicamente de traduzir, tanto no momento em que foram requeridas ou enviadas informações ao Sistema Operacional quanto no momento de serem recebidas as respostas correspondentes. No primeiro caso, as informações devem ser transformadas ao formato correspondente com o sistema operacional corrente. No segundo caso, as informações precisam estar de acordo com o formato padronizado usado na comunicação interna do Middleware para garantir independência do Sistema Operacional subjacente.

- Construtor do Contexto do Sistema: A tarefa principal deste subcomponente é a construção do contexto do sistema e exportá-lo para um arquivo XML. Ele tem como dados de entrada as informações colhidas por outro sub-modulo e as especificações correspondentes à construção de contextos.

Um exemplo do conteúdo esperado nos arquivos XML relacionados com este componente são apresentados no Apêndice $E$.

\subsubsection{Componente de Interação com o Usuário}

Este componente está encarregado de gerenciar o processamento das informações relacionadas ao usuário. Suas funções principais são: 
- Modelagem de usuário: fornece suporte para o acesso, atualização e recuperação das informações do usuário de acordo com a especificação do modelo de perfil de usuário utilizado, o qual é fornecido através de um arquivo XML, o Apêndice $D$ apresenta um exemplo pequeno do conteúdo esperado neste XML. Ele tem duas modalidades de trabaIho: (1)online, com acesso à base de dados do usuário, e (2)offline, com acesso à ultima sincronização das informações do usuário com uma cópia local das mesmas. O processo de sincronização das informações é explicito e controlado pelo usuário, podendo também ser automaticamente configurado.

- Feature Extractor: este subcomponente é o responsável por monitorar, examinar e avaliar as ações do usuário que podem ser incorporadas como novas características. Ele possui políticas e critérios, expressos dentro de um arquivo $\mathrm{XML}$, que regulam a incorporação destas características e as regras com as quais serão incorporadas dentro do Middleware.

- Construção do Contexto do usuário: este subcomponente é responsável pela construção do contexto de usuário, a aplicação do formato correspondente para o intercâmbio dessas informações no Middleware. Além disso, ele é responsável de solicitar as atualizações correspondentes na base de dados.

Figura 29 - Arquitetura interna do Middleware- Componente de Interação com o Usuário

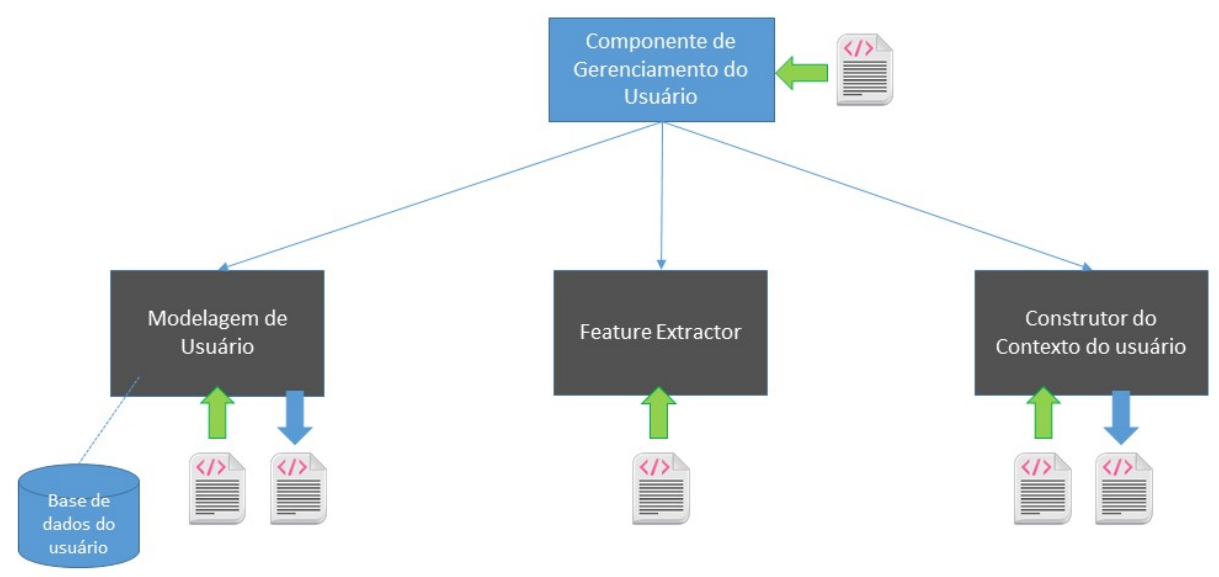

Fonte: Autora

Como apresenta a Figura 29 o componente de Modelagem de usuário gera uma cópia local do perfil do usuário para permitir o trabalho do Middleware em modo offline. 


\subsubsection{Componente de Extração de Informações do Ambiente de Execução}

Este componente está encarregado de gerenciar o processamento das informações relacionadas ao entorno no qual é executada a interação. Seus componentes principais, ilustrados na Figura 30 são descritos a seguir:

Figura 30 - Arquitetura interna do Middleware- Componente de Extração de Informações do Entorno

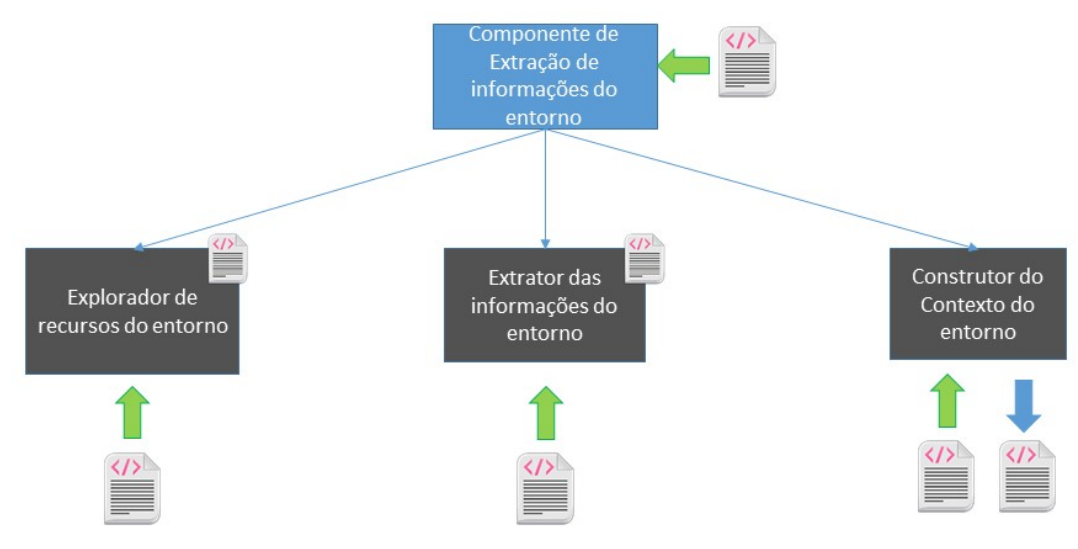

Fonte: Autora

- Explorador de recursos do ambiente: Este subcomponente explora os recursos tanto de software quanto de hardware que permitem obter informações sobre o estado do entorno no qual está tendo lugar a interação. Exemplos dos tipos de recursos que podem ser obtidos são: sensor de temperatura, sensor de luminosidade, microfone omnidirecional para ter uma medição da exposição ao barulho, ente outros. As informações colhidas são exportadas para um arquivo com formato $X M L$, para ser utilizadas em um processo seguinte.

- Extrator de Informações do ambiente: Com base nos recursos disponíveis no sistema, este subcomponente realiza a coleta das informações correspondentes em cada caso e associa com cada valor à característica que está sendo medida. Assim, por exemplo ele extrai os valores de luminosidade presentes no ambiente através do sensor correspondente, e os salva para a característica "luminosidade". Este componente tem acesso a um arquivo de parâmetros em XML para as características do ambiente, por exemplo, é possível transformar os valores extraídos para uma categoria, se for necessário. 
- Construção do Contexto do entorno: este subcomponente é responsável pela construção do contexto de entorno, com base no formato fornecido para o intercâmbio de informações dentro do Middleware.

Um exemplo do conteúdo esperado dos arquivos relacionados com este módulo são apresentados no Apêndice F.

\subsubsection{Componente de Tomada de Decisão}

Este componente é o encarregado do processamento das informações para efetuar a tomada de decisão sobre quais são as configurações pertinentes para a implementação de uma interface de usuário melhor ajustada às necessidades deste. Conforme é apresentado na Figura 31, os subcomponentes inclusos neste módulo são:

Figura 31 - Arquitetura interna do Middleware- Componente de Tomada de Decisão

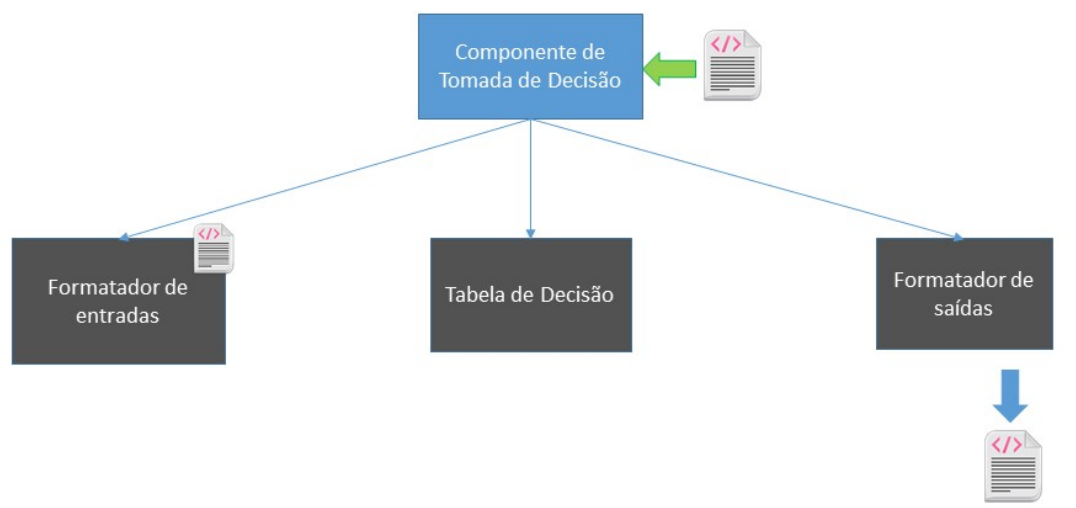

Fonte: Autora

- Formatador de Informações de entrada: Este componente está encarregado de realizar o pré-processamento dos dados de entrada, verificando a correspondência entre as características obtidas para cada um dos contextos que determinam o ambiente de execução, o perfil do usuário e os recursos do sistema e os valores associados a eles.

- Tabela de Decisão: Este componente está encarregado de testar as condições atuais no contexto da interação (sistema, entorno e usuário) e explorar quais das regras satisfazem 
as tais condições. Se existem duas regras que satisfazem as condições dadas tratase dum caso de não-determinismo que precisa ser resolvido com algumas das técnicas estudadas para ditos casos, como mencionado em Ramos, Neto e Veja (2009)), Neto (2001). Se, pelo contrário, trata-se de um caso determinístico então serão executadas as ações associadas com dita regra. A saída deste componente são as mudanças a serem executadas para fornecer uma interface de interação com o usuário que leve em conta as condições do contexto. Tais mudanças podem ativar e desativar recursos ou alterar os valores dos seus parâmetros de funcionamento.

- Formatador de Informações de saída: Este componente está encarregado de formatar as informações para a construção da nova interface de usuário de maneira que elas possam ser rápidas e inequivocamente traduzidas para as instruções necessárias no nível de sistema operacional.

Finalmente, a política de concretização do Middleware estabelece que se em algum momento existe mais do que um subcomponente no nível que expõe as funcionalidades e interface solicitada, o componente Mng do nível escolherá o mais atualizado, tendo como base a data de instalação no Middleware. Se não existe nenhum componente que expõe as funcionalidades e interface necessária o Middleware procurará nos registros locais o último "artifact"criado como output da execução de um componente do tipo solicitado, o "artifact"em questão será, na maioria dos casos um arquivo do tipo XML. 


\section{FORMALIZAÇÃO DA PROPOSTA}

Neste capítulo, é realizada a formalização do modelo proposto para um Middleware que auxilie um sistema legado na reconfiguração dos seus recursos de interação com o usuário. São brevemente descritas as técnicas e tecnologias utilizadas para esse fim e é elaborada uma análise de viabilidade de construção.

\subsection{MODELAGEM FORMAL DA PROPOSTA}

Para a modelagem da metarquitetura proposta para o middleware, é utilizada uma Linguagem de Descrição de Arquitetura, ou ADL (Architecture Description Language), com o objetivo de fornecer uma especificação formal que permita o entendimento e análise da mesma com o maior nível de detalhe possível para uma meta-arquitetura.

\subsubsection{ADLs}

ADLs são linguagems, notações formais, utilizadas para representar, definir e modelar a arquitetura de um sistema (CLEMENTS, 1996), tanto no nível dos elementos de software quanto hardware (BJöRNANDER; GRUNSKE, 2008), antes das fases de design detalhado e implementação.

Neste trabalho, vamos adotar a definição de arquitetura que diz:

"By architecture, we mean the components that comprise a system, the behavioral specifications for those components, and the patterns and mechanisms for interactions among them" (CLEMENTS, 1996).

Para atingir o objetivo de descrever a arquitetura de um sistema os ADLs oferecem representações gráficas e texto e, em vários casos são acompanhadas de ferramentas de software que assistem o arquiteto de software na elaboração do modelo.

ADLs disponíveis hoje variam grandemente dependendo da abordagem e do estilo de arquitetura que suportam, existindo alguns muito mais genéricos e outro mais especializados em um domínio específico. Como consequência, não é possível afirmar que existe uma única ADL que seja a melhor para todos os casos (KOGUT; CLEMENTS, 1994).

Sendo um conceito relativamente novo, não existe na literatura um consenso sobre quais são as características que definem uma ADL (MEDVIDOVIC; TAYLOR, 2000) mas, em alguns trabalhos, é possível ter uma visão e análise detalhadas sobre as características esperadas (KOGUT; CLEMENTS, 1994; BJöRNANDER; GRUNSKE, 2008), as diferenças que apresentam com as linguagens de programação (CLEMENTS, 1996), comparações entre as mais conhecidas (MEDVIDOVIC; TAYLOR, 2000) e as funcionalidades desenvolvidas em torno 
delas.

\subsubsection{A proposta}

O modelo proposto neste trabalho segue as diretrizes estabelecidas por três tecnologias:

- Programação Orientada a Componentes: na procura de baixo acoplamento entre peças de software para potencializar a reutilização dos mesmos e tentar incrementar a vida útil das tecnologias criadas.

- Mecanismo Plug and Play: a emulação desta tecnologia no nível de componentes procura fornecer flexibilidade para a identificação, registro e uso de peças de software em tempo de execução e possibilitar diferentes formas de concretizar um sistema com base num modelo estabelecido.

- Tecnologia Adaptativa: procura incorporar, de maneira evolutiva, a sensibilidade ao contexto dentro do sistema em questão.

Para a especificação do modelo da meta-arquitetura, foi favorecido o príncipio da simplicidade, de maneira que um equilíbrio entre expressividade e formalização seja atingido. Portanto, neste trabalho é utilizado a ADL ACME, a ser descrita brevemente na próxima seção, e os arquivos de configuração de parâmetros e de interfaces, importados e exportados através do padrão XML, amplamente utilizado e sedimentado na área tecnológica, fornecendo flexibilidade e simplicidade.

\subsubsection{Acme}

De acordo com o website oficial do projeto ACME:

Acme is a simple, generic software architecture description language (ADL) that can be used as a common interchange format for architecture design tools and/or as a foundation for developing new architectural design and analysis tools. (Carnegie Mellon University, 2011)

Acme é uma linguagem pequena e relativamente simples de aprender e utilizar para especificar uma arquitetura, sem comprometer, a flexibilidade e abrangência de sistemas que podem ser modelados. Acme está construida sobre a base de uma ontologia de sete elementos:sistema(system), componentes(components), conectores(connectors), potas(ports), funções(roles), representações (representations), e mapas de representações (rep-maps). Um sistema está composto por componentes que interagem entre eles através de conectores. Cada componente tem a sua interface definida segundo as portas que manifesta, e cada conector 
define cada participante da interação que ele descreve a través das funções. As representações constituem um mecanismo em Acme para dar suporte à decomposição hierárquica dos componentes e dos conectores em subsistemas. Assim mesmo, Acme Studio, a ferramenta de trabalho fornecida para especificações em Acme, incorpora testes de nível semântico que verificam a corretude da estrutura do modelo, a natureza dos componentes, e estabilidade das conexões e especificações adicionais incorporados nos componentes a maneira de regras. Segundo a política de Acme o sistema sendo modelado só pode ser salvo e exportado para XML se ele cobrir todas as especificações e condições carregadas em cada componente e passam os testes a nível hierárquico e de fluxo de informações.

Acme não fornece um modelo específico a ser seguido para descrever o comportamento de um sistema. Em vez disso, cada um dos elementos pode ser anotado com properties que representam tais informações.

Assim, as especificações geradas em Acme podem ser fornecidas para uma ferramenta de geração de código de modo a obter um protótipo base do funcionamento do modelo. Um exemplo deste tipo de integração é o ArchMapper(http://archmapper.sourceforge.net/), que permite a obtenção de código Java com base em modelo de Acme.

Para um maior detalhe sobre Acme pode-se consultar (Carnegie Mellon University, 2011. GARLAN; MONROE; WILE, 1997)

\subsubsection{Os componentes}

No nível inicial, o sistema pode ser descrito como a interação entre três elementos participantes: o usuário, o sistema legado e o Middleware, que é chamado daqui em adiante de Adaptware. A conexão entre o usuário e o sistema legado fica estabelecida através dos meios e canais presentes neste último; assim, se o sistema legado apresenta uma tela sensível ao toque, o usuário pode usar esse canal para interagir com ele. Caso o sistema não possuir outro canal além da tela convencional e o mouse, então a interação ficará delimitada por esses recursos. A conexão entre o sistema legado e o Adaptware é gerenciada a través de um conector, chamado em adiante componente de comunicação, que implementa um protocolo de comunicação para o Adaptware e o sistema legado. O protocolo em questão é especificado em um arquivo XML de configuração, e o implementador possui a liberdade para especificar qualquer protocolo sempre que a especificação do mesmo esteja complemente contida no XML que o componente de comunicação utiliza. Qualquer protocolo de intercâmbio de informações poderia ser especificado, de maneira particular, as especificações do UPnP(Universal Plug and Play) em (PERSSON, 2009) cobrem as condições necessárias para garantir a independência da linguagem de programação. Do ponto de vista da implementação, este conector poderia 
ser considerado como um componente; para todos os efeitos deste trabalho, ele é distinguido dos outros nesta categoria devido ao fato de que sua natureza corresponde a uma peça de conexão entre componentes de uma hierarquia e complexidade maior.

A Figura 32 apresenta o nível inicial da modelagem do sistema referido anteriormente.

Figura 32 - Nível Inicial do Modelo do Sistema em ACME

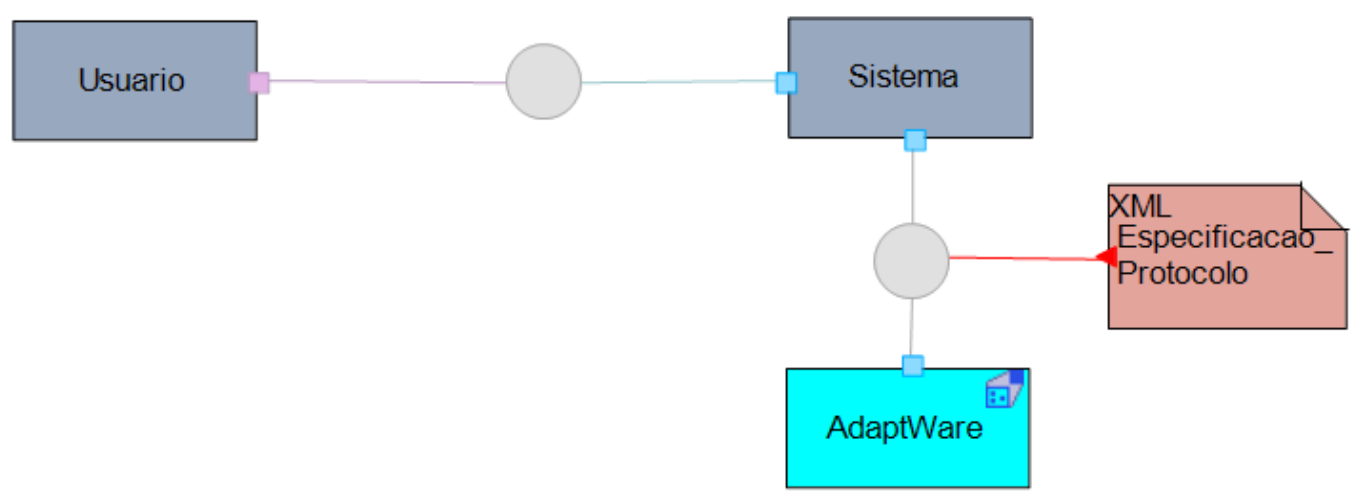

Fonte: Modelo desenvolvido com ACME

Dentro do Adaptware, cada um dos subcomponentes implementa a seguinte estratégia:

- Possui um subcomponente do tipo Mng, o qual é encarregado de concretizar tal componente, permitindo as conexões com os subcomponentes necessários para atingir seu objetivo. Este subcomponente também é o responsável de fazer o filtro das informações enviadas para cada subcomponente e a ordem de execução.

- O componente Mng recebe um arquivo do tipo XML que especifica quais são os tipos de subcomponentes necessários, assim como quais são as funcionalidades que cada um deles deve implementar. A especificação das funcionalidades é feita através das assinaturas que elas devem expor: parâmetros de entrada (quantidade, ordem e tipo) e valores de retorno.

A seguir é apresentada a especificação dos componentes que formam parte do Adaptware.

O Nível 1 do Adaptware é composto por cinco subcomponentes: o Mng, o subcomponente encarregado da interação com o sistema operacional, o subcomponente encarregado das informações do usuário, o subcomponente encarregado de obter as informações presentes no entorno da interação, e o subcomponente encarregado da tomada de decisão para implementar uma nova interface de interação com o usuário. A Figura 33 apresenta a especificação deste nível em ACME. As especificações das conexões em ACME são exclusivas, portanto, cada conector só pode ter 2 roles (um para os dados de entrada e outro para os dados de saída) e 
94

cada um deles deve estar associado com sua correspondente porta nos componentes de origem e destino. Assim, a função de entrada de um conector deve estar associada com a porta de saída do componente de origem, e a função de saída do conector deve estar associada com a porta de entrada do componente de destino. O tipo de função de cada um dos extremo de um conector é visualmente identificado pela cor: a função que identifica os dados de entrada é da cor vermelha, e a função que identifica os dados de saída é da cor azul. 
Figura 33 - Nível 1 do Modelo do Adaptware em ACME

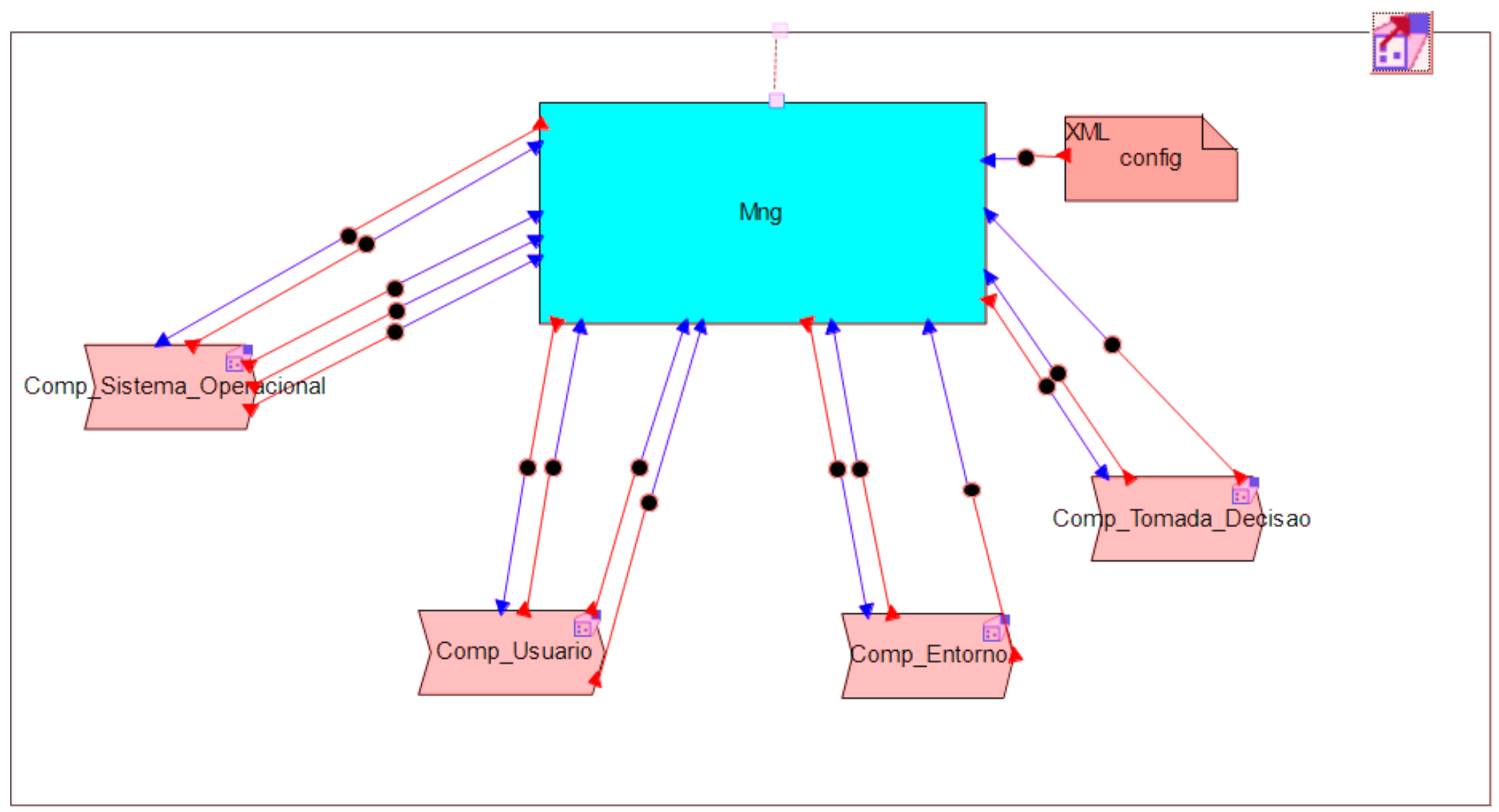

Fonte: Modelo desenvolvido com ACME 
No Nível dois de profundidade do modelo do Adaptware, está a especificação de cada um dos subcomponentes mencionados no parágrafo anterior.

O subcomponente encarregado do processamento das informações como resultado da interação com o sistema operacional do sistema legado está formado por quatro subcomponentes: o setup tool, o explorador de recursos, o construtor de contexto de sistema operacional, e o formatador de informações. O setup tool é o encarregado de procurar as informações que identificam o sistema operacional do sistema legado, assim como os atributos que definem a interface de usuário padrão que ele implementa e seus valores correspondentes. Tal informação é salva e disponibilizada para uso de outros subcomponentes dentro de Adaptware na forma de um arquivo do tipo XML. O subcomponente explorador de recursos está dedicado à procura dos recursos tecnológicos, disponíveis no sistema legado, que permitem definir a interface de interação entre humano e máquina. Para isso, ele recebe um arquivo XML que especifica os parâmetros da busca a ser efetuada, por exemplo, esse arquivo define que devem ser procurados elementos de software associados à tela como: leitor de tela, lupa, contraste, entre outros. Como consequência desta busca, é gerado um arquivo XML que contém as informações dos recursos correntes disponíveis desde o sistema legado. Se o sistema em questão tiver acesso à rede, esta capacidade também é notificada e salva no arquivo XML para conhecimento dos outros subcomponentes do Adaptware. O subcomponente construtor do contexto do sistema operacional recebe uma especificação XML do modelo de contexto que deve implementar, podendo conter informações diversas, como por exemplo as recomendadas em Byun e Cheverst (2001)), Hong, Suh e Kim (2009)), TalebiFard e Leung (2011). O contexto final do sistema é salvo e disponibilizado para o resto dos subcomponentes do Adaptware em um arquivo XML. Finalmente, o subcomponente de formatação da informação está encarregado de concretizar as interações entre o Middleware e o sistema operacional, a respeito de solicitação e leitura de informações. Por exemplo, ele traduz as solicitações para exploração dos recursos do sistema da linguagem utilizada no Adaptware para as correspondentes instruções (chamadas a sistema, solicitações de serviços, interrupções, entre outras) do sistema operacional do sistema legado. As informações traduzidas são salvas dentro de um arquivo XML que está disponível dentro do escopo do Adaptware. A Figura 34 apresenta a especificação deste subcomponente. 
Figura 34 - Nível 2 do Modelo do Adaptware em ACME, subcomponente de interação com o sistema operacional

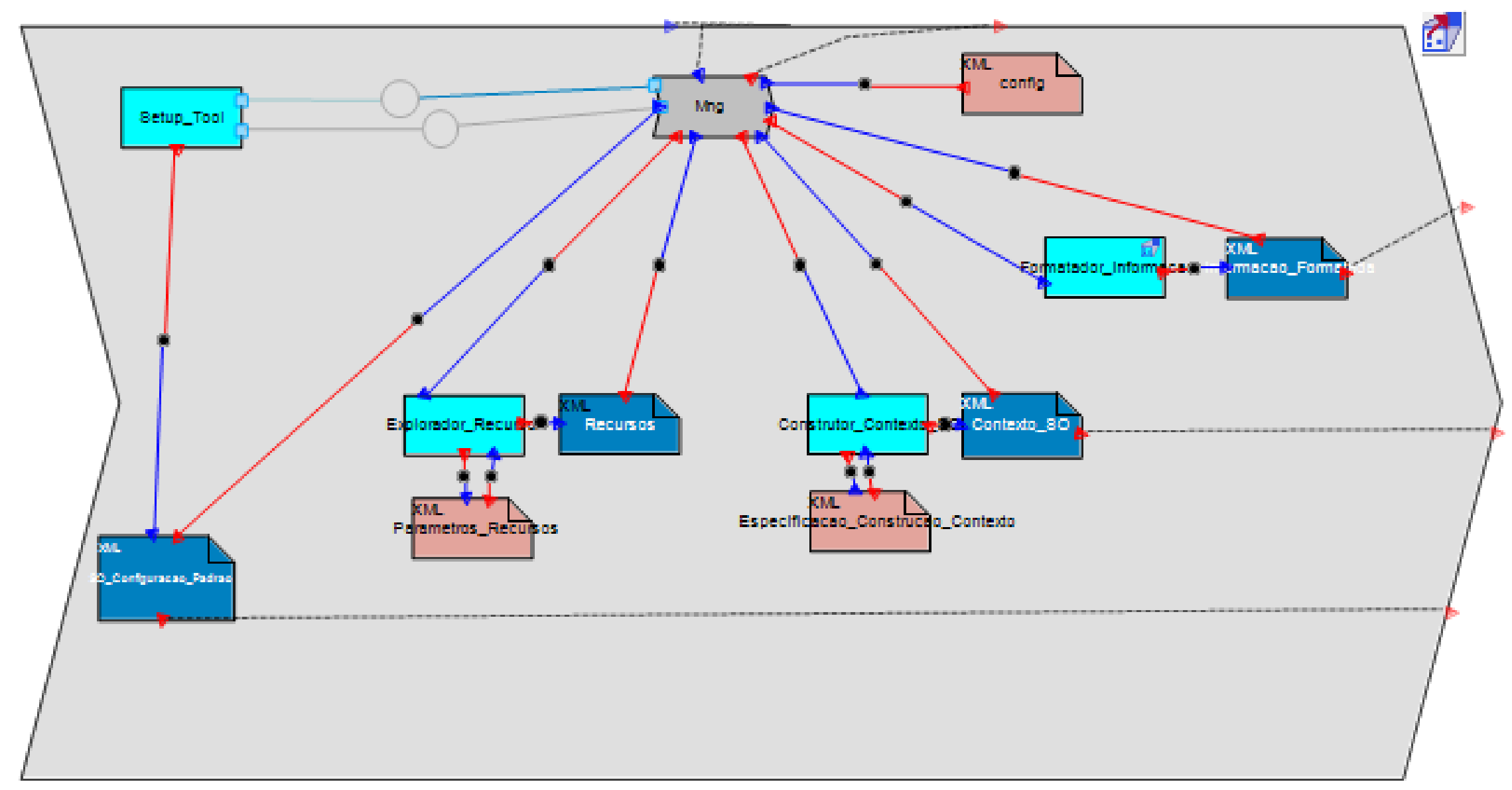

Fonte: Modelo desenvolvido com ACME 
O seguinte subcomponente especificado no nível dois é o subcomponente responsável do processamento das informações do usuário. Este subcomponente está formado por três subcomponentes: o componente responsável pela modelagem do usuário, o componente que é o feature extractor, e o construtor do contexto do usuário. O subcomponente encarregado da modelagem do usuário gerencia o acesso à base de dados do usuário, residente em um servidor de base de dados, que contém as informações que caracterizam a pessoa que participa na interação com o sistema. Para isso, ele recebe a especificação do perfil de usuário utilizado na base de dados ou, se for a primeira execução do Adaptware, descreve as informações a serem contidas dentro do modelo do usuário, assim eles são metadados que indicam como ler as informações salvas respeito do usuário, e a localização da base de dados. Este subcomponente exporta as informações recuperadas da base de dados do usuário, de acordo com o perfil fornecido, e o disponibiliza para os outros subcomponentes do Adaptware. O subcomponente Feature Extractor é responsável pela consulta das ações do usuário que podem incorporar informações para definir uma característica de interesse no contexto da interação humano-máquina. Assim, ele recebe um arquivo XML com a especificação dos critérios que ajudam na identificação desses potenciais características de usuário, e políticas que determinam quando uma mudança deve ser interpretada como uma nova característica do usuário a ser incorporado no modelo. Finalmente, o construtor de contexto do usuário, com base nas informações do perfil do usuário, gera o contexto do usuário baseado nas especificações que recebe como parâmetro na forma de um arquivo XML. Tais especificações, por exemplo, podem descrever o modelo de usuário utilizado em McTear (1993)), Brusilovsky (1998)), Byun e Cheverst (2001). A Figura 35 apresenta a descrição deste subcomponente. Assim, é importante lembrar que o Adaptware não substitui nenhuma atividade parte do processo de modelagem do usuário, mas sim utiliza a saída deste processo como parte das informações necessárias para o seu funcionamento. A especificação dos critérios utilizados para a criação do perfil de usuário, a incorporação de novas características, a substituição ou eliminação destas são responsabilidade do especialista encarregado da implementação de uma versão concreta do Adaptware. 
Figura 35 - Nível 2 do Modelo do Adaptware em ACME, subcomponente de informações do usuário

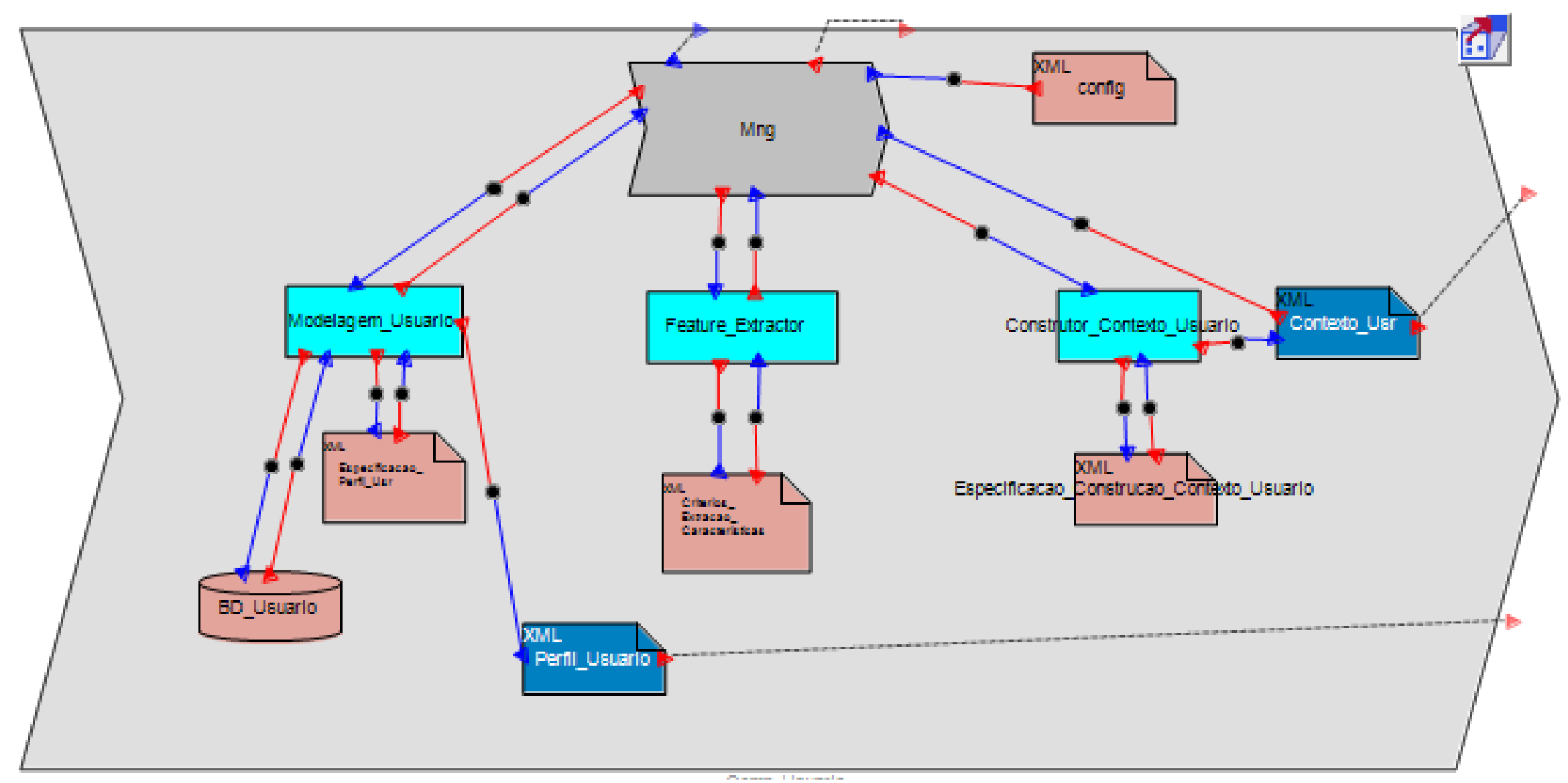

Fonte: Modelo desenvolvido com ACME 
100

Outro subcomponente no Nível dois do Adaptware é o subcomponente que permite a extração das informações que ajudam a caracterizar o entorno no qual é desenvolvida a interação. Este subcomponente está formado por três subcomponentes: o explorador de recursos que fornecem informação sobre o entorno, o extrator de informações, e o construtor do contexto do ambiente de execução. O subcomponente que explora os recursos que ajudam na descrição do entorno é uma peça de software dedicada à exploração de elementos de software e hardware que podem fornecer este tipo de informações. Por exemplo, um microfone para medir o nível de ruído, uma câmera web ou um sensor para medir o nível de luminosidade, ou a quantidade de trânsito de pessoas em um determinado lugar. Este subcomponente recebe como entrada um arquivo XML contendo os parâmetros para efetuar a busca, quais elementos para medir som, quais para medir luminosidade, quais para medir trânsito de pessoas, e assim por diante. Como resultado, ele gera um arquivo com os diferentes recursos presentes ou acessíveis no sistema legado. O subcomponente extrator das informações de ambiente de execução recebe esta lista de recursos e obtém os valores correntes em cada um desses recursos, logo com base em um arquivo XML de especificação, é capaz de transformar tais valores em informação útil para a descrição das características do entorno de interação. Estas informações são salvas em outro arquivo XML. Finalmente, o subcomponente de construção de contexto do entorno gera um arquivo XML que especifica as características do entorno de interação e os valores associados a elas no momento corrente. Para isso ele usa um arquivo XML que permite especificar o modelo a seguir para a construção do contexto. É importante ressaltar que o subcomponente de extração de informações de contexto gera dois arquivos XML de consumo interno: a lista de recursos para a extração de informações e as informações associadas a ditos recursos, isso deve-se ao fato de que é possível que não existam recursos acessíveis no sistema que sejam capazes de descrever o entorno da interação; neste caso, só o contexto do entorno estará disponível para os outros subcomponentes do Adaptware, e a possibilidade de ele estar vazio deve ser considerada. A Figura 36 apresenta a descrição deste subcomponente. 
Figura 36 - Nível 2 do Modelo do Adaptware em ACME, subcomponente de extração de informaç̃os do entorno

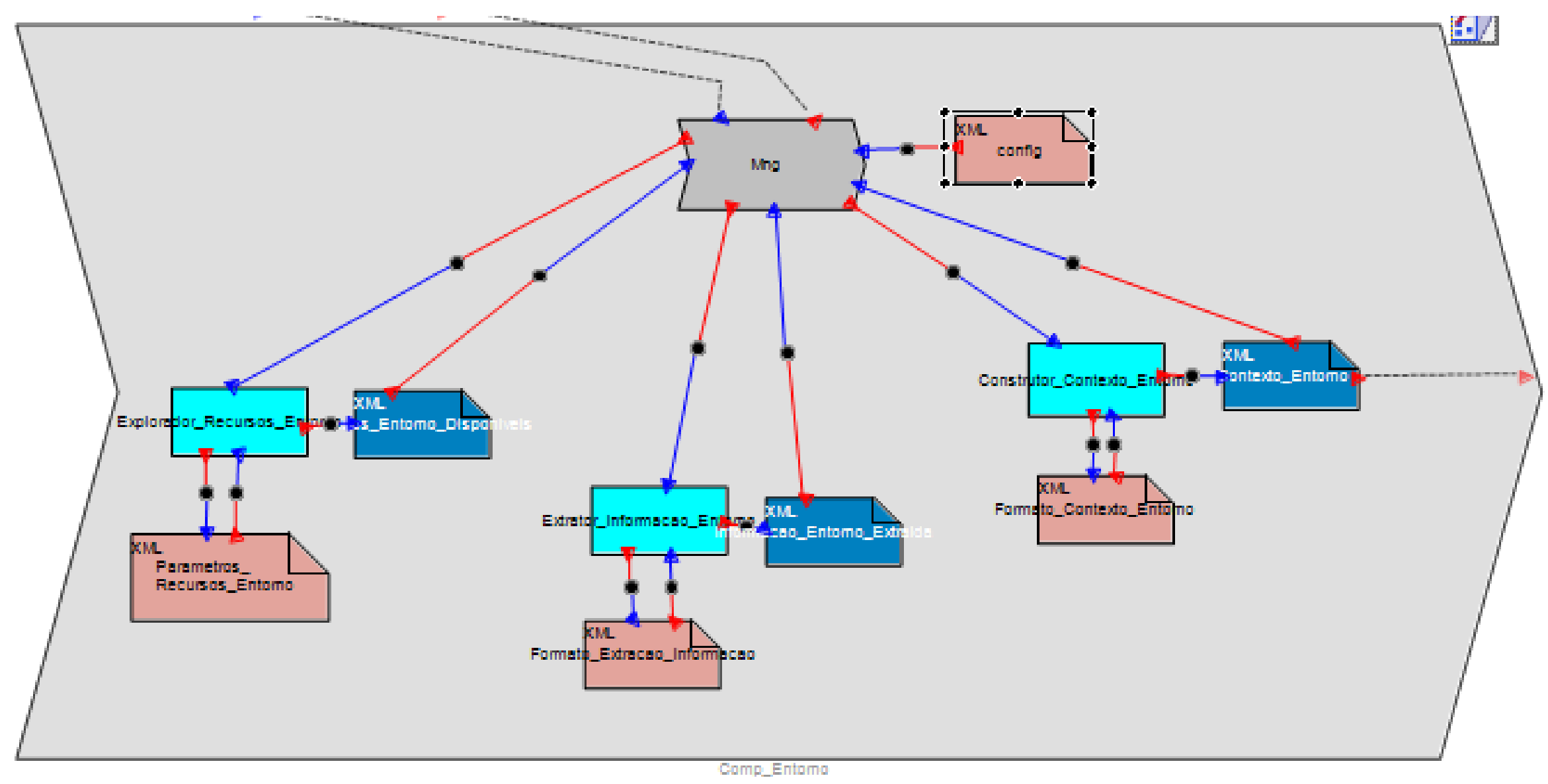

Fonte: Modelo desenvolvido com ACME 
102

O último subcomponente do Nível dois no Adaptware é o responsável pela tomada de decisão que definirá a reconfiguração da interface de usuário. Este subcomponente está formado por três subcomponentes: o formatador das informações que servem de entrada para a tomada de decisão, o responsável pela aplicação da técnica de tomada de decisão, e o responsável pela formatação das saídas obtidas após as tomada de decisão e que serão utilizadas para a solicitação das configurações no sistema operacional. O subcomponente encarregado de formatar as entradas para seu processamento depende do formato especificado em um arquivo de configuração XML que descreve a unidade a ser utilizada dentro da técnica específica de tomada de decisão a ser utilizada; se for uma tabela de decisão, por exemplo, ele estabelece como devem estar configuradas as condições para serem testadas na tabela. As informações formatadas são salvas em um arquivo do tipo XML para consumo dentro do escopo do subcomponente. O subcomponente responsável pela tomada de decisão é aquele que, tendo especificadas as informações correspondentes aos contextos de sistema, usuário e entorno no formato correspondente, testa as condições de interação para propor mudanças na configuração padrão da interface de usuário do sistema legado. Este subcomponente pode implementar uma entre diversas técnicas desenvolvidas para tratar este tipo de problema; neste caso específico, ele implementará uma tabela de decisão adaptativa para resolver o problema e propor uma reconfiguração. Como resultado da execução deste componente, procede-se a uma série de ações que serão traduzidas pelo próximo subcomponente. O componente de formatação das saídas da tomada de decisão é o encarregado de aplicar as ações indicadas pelo subcomponente anterior ao arquivo XML de entradas e obter, através desta ação, um arquivo de saídas que contém a nova configuração dos recursos da interface de interação no sistema legado. A Figura 37 apresenta a descrição deste componente. 
Figura 37 - Nível 2 do Modelo do Adaptware em ACME, subcomponente de tomada de decisão

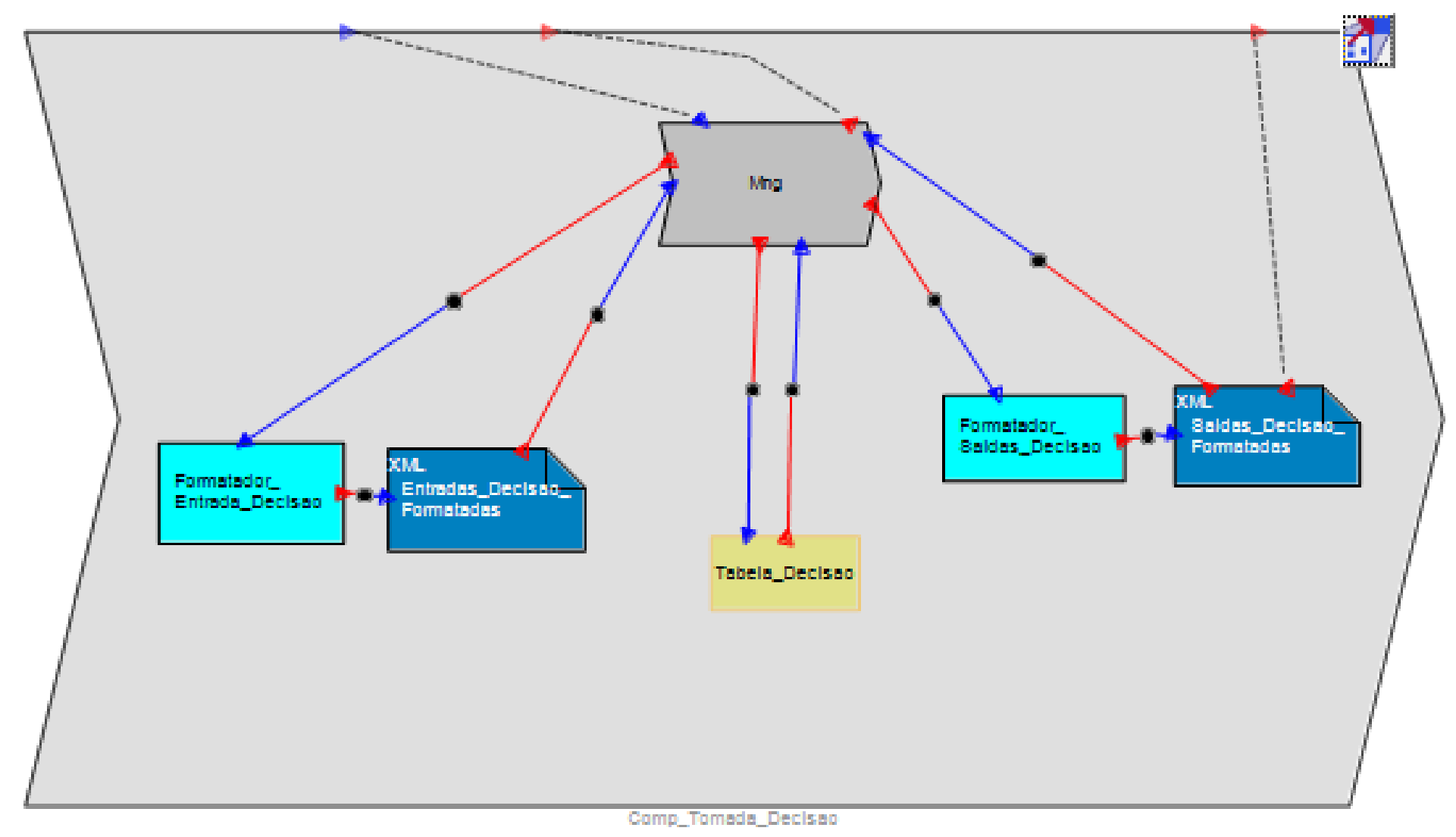

Fonte: Modelo desenvolvido com ACME 
Por fim, o nível três de profundidade do Adaptware contém a especificação do componente de Formatação das informações de acordo com o sistema operacional subjacente. Este subcomponente é o encarregado de reconhecer o sistema operacional concreto com o qual se está trabalhando e selecionar o subcomponente correspondente para realizar a tradução das instruções em diretivas próprias do sistema operacional. A Figura 38 apresenta a especificação deste subcomponente em ACME.

Figura 38 - Nível 3 do Modelo do Adaptware em ACME, subcomponente de formatação de informação

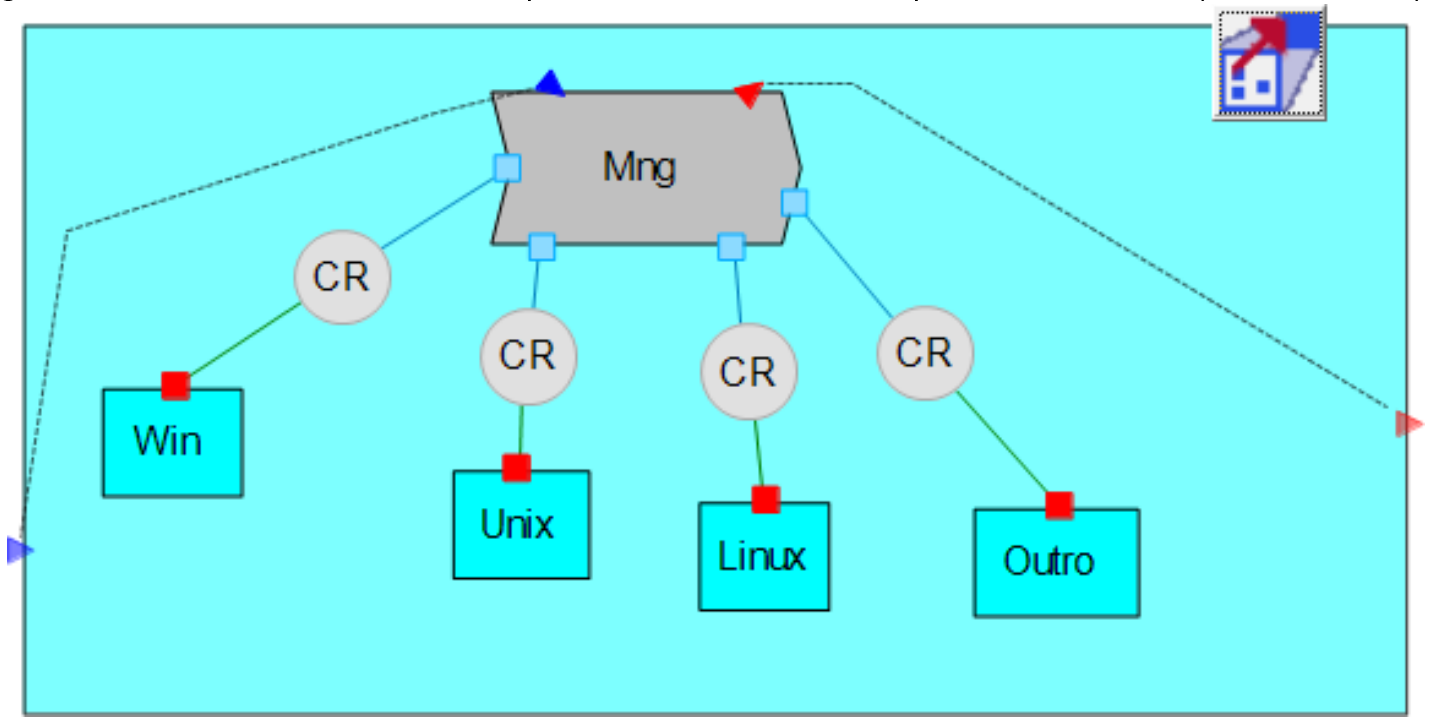

Fonte: Modelo desenvolvido com ACME

\subsubsection{Funcionamento Padrão}

Ainda quando o metamodelo é válido para diferentes tipos de conexão entre o Adaptware e o sistema subjacente nesta seção são explicitados o passos relacionados à implementação do Adaptware para conexão $\mathrm{PnP}$. Esta decisão corresponde ao fato de que na atualidade a maioria de computadores de uso geral possuem sistemas operacionais que implementam, como mínimo, o mecanismo PnP. Uma outra possível implementação do Adaptware é sugerida na seção de Trabalhos futuros, no Capítulo 5 deste documento, e responde à possibilidade de estabelecer conexões sobre a base de aplicativos em nuvem regidos pelos protocolos de SOA.

O funcionamento do Adaptware segue passos análogos aos implementados dentro do mecanismo PnP (Plug-and-Play Mechanism) para permitir a troca de informações entre um sistema arbitrário e um novo dispositivo sobre a base de uma interface padrão. A seguir são detalhados os passos do funcionamento padrão do Middleware nos três momentos que descrevem a interação entre humano e máquina. 


\subsubsection{Inicio da Interação}

No início da interação o funcionamento do Adaptware é descrito do seguinte modo:

1. O usuário conecta o dispositivo hardware, de tipo USB, que contém a implementação do Adaptware dentro do sistema legado.

2. O Adaptware é ativado. Tal procedimento pode ser automático sempre que as preferências do usuário ou as políticas de segurança do sistema o permitam. Entretanto, a ativação do Adaptware pode ser realizada com a intervenção expressa do usuário. Neste caso, o usuário deve selecionar o aplicativo Adaptware dentro do dispositivo reconhecido no sistema legado.

3. O conetor do Adaptware, responsável pela comunicação, é ativado e posto em funcionamento. Ele executa as ações especificadas do protocolo de comunicação que implementa e estabelece o canal para a troca de informações entre o sistema operacional subjacente e o componente de controle geral, ao qual chamaremos de Mng (sigla que advém do inglês Manager).

4. Logo que é estabelecido o canal para a comunicação o conetor passa o controle para o Mng.

5. O Mng concretiza o primeiro nível de subcomponentes da meta-arquitetura. Isto quer dizer que ele examina os elementos concretos presentes no Adaptware, na forma de arquivos dentro do nível de hierarquia de pasta no dispositivo, que cumprem com os meta dados para cada subcomponente, associando o dito componente ao processo corrente permitindo não só troca de informações, mas também garantindo os recursos que ele precisa. Neste ponto é de utilidade assinalar a analogia que existe com o processo de procura de drivers dentro do mecanismo $\mathrm{PnP}$.

6. O Mng ativa o subcomponente Mng_SO para gerenciar as atividades de interação com o sistema legado.

7. O Mng_SO carrega o arquivo de configurações do subcomponente e concretiza os componentes necessários para seu funcionamento.

8. O Mng_SO solicita, através de diretivas gerais, as credenciais do sistema operacional corrente. A dita solicitação é propagada para o Mng e até chegar no sistema operacional

9. O sistema legado atende à solicitação enviando suas credenciais. Dita resposta viaja através do Mng que direciona para o Mng_SO. 
10. O Mng_SO recebe as informações necessárias e concretiza os componentes do segundo nível da meta-arquitetura que são dependentes do tipo de sistema operacional. Se algum tipo de subcomponente não for encontrado a política de concretização da metaarquitetura para esse caso é aplicada.

11. O subcomponente Mng_SO ativa o subcomponente Setup tools é ativado.

12. O subcomponente Setup Tools solicita as informações correspondentes com a configuração inicial do sistema subjacente no momento de estabelecer a interação com o Adaptware para o Mng_SO.

13. O Mng_SO envia a solicitação do Setup Tools para o subcomponente formatador de informações para sua tradução em diretivas do sistema operacional correspondente, já identificado.

14. O subcomponente formatador de informações realiza a tradução e devolve as diretivas a serem enviadas para o Mng_SO.

15. O Mng_SO envia a solicitação para o Mng do Adaptware.

16. O Mng do Adaptware propaga a solicitação para o sistema legado.

17. O sistema legado responde ao pedido e informa a sua configuração inicial.

18. O Mng do Adaptware recebe a resposta do sistema legado e envia a informação para o subcomponente Mng_SO.

19. O Mng_SO envia a resposta para o subcomponente formatador de informações.

20. O subcomponente formatador de informações recebe a resposta do sistema legado e formata as informações para seu uso dentro do Adaptware.

21. O Mng_SO recebe as informações formatadas dos recursos acessíveis e envia para o subcomponente Setup Tools.

22. O subcomponente Setup Tools salva as informações recebidas sobre a configuração inicial do sistema legado.

23. O Mng_SO ativa o subcomponente de exploração de recursos e é acionado.

24. O subcomponente de exploração envia ao Mng_SO duas solicitações: uma para a procura de recursos acessíveis pelo sistema legado que satisfazem os parâmetros recebidos, e outra para a subscrição a eventos relacionados com este tipo de recurso, por exemplo: 
identificação de novo hardware especializado para braile, ou instalação de novos aplicativos relacionados ao suporte de acessibilidade.

25. O Mng_SO envia a solicitação do explorador de recursos para o subcomponente formatador de informações para sua tradução em diretivas do sistema operacional correspondente, já identificado.

26. O subcomponente formatador de informações realiza a tradução e devolve as diretivas a serem enviadas para o Mng_SO.

27. O Mng_SO envia a solicitação para o Mng do Adaptware.

28. O Mng do Adaptware propaga a solicitação para o sistema legado.

29. O sistema legado responde ao pedido e informa os recursos por ele acessíveis.

30. O Mng do Adaptware recebe a resposta do sistema legado e envia a informação para o subcomponente Mng_SO.

31. O Mng_SO envia a resposta para o subcomponente formatador de informações.

32. O subcomponente formatador de informações recebe a resposta do sistema legado e formata as informações para seu uso dentro do Adaptware.

33. O Mng_SO recebe as informações dos recursos formatadas e envia para o subcomponente explorador de recursos.

34. O explorador de recursos filtra as informações contidas na resposta do sistema legado e cria um XML correspondente à lista de recursos acessíveis.

35. O Mng_SO ativa o subcomponente construtor do contexto do sistema operacional.

36. O subcomponente construtor do contexto carrega a especificação fornecida para a construção do contexto e com base nas informações obtidas cria um XML com o contexto de sistema operacional.

37. O Mng_SO devolve o controle para o Mng do Adaptware.

38. O Mng do Adaptware ativa o seu subcomponente Mng_Usr para gerenciar as informações do usuário.

39. O Mng_Usr carrega o arquivo de configurações do subcomponente e concretiza os componentes necessários para seu funcionamento. 
40. O Mng_Usr ativa seu subcomponente para a interpretação do modelo de usuário.

41. O subcomponente encarregado de processar as informações do modelo de usuário carrega as especificações para identificar o tipo de modelo de usuário a ser utilizado e o acesso ao repositório, a base de dados, das informações do mesmo.

42. O subcomponente encarregado de processar o modelo de usuário obtém as informações correspondentes ao usuário no repositório e com base nas especificações cria um XML que corresponde com o perfil de usuário.

43. O Mng_Usr ativa seu subcomponente para construção de contexto do usuário.

44. O subcomponente de construção de contexto do usuário carrega as especificações para a construção do contexto e, com base nas informações obtidas, cria um XML que corresponde ao contexto do usuário.

45. O Mng_Usr devolve o controle para o Mng do Adaptware.

46. O Mng do Adaptware ativa o seu subcomponente Mng_En para gerenciar as informações do entorno no qual se desenvolve a interação.

47. O Mng_En carrega o arquivo de configurações do subcomponente e concretiza os componentes necessários para seu funcionamento.

48. O Mng_En ativa seu subcomponente explorador de recursos que permitem coletar informações sobre o entorno no qual se desenvolve a interação.

49. O subcomponente de exploração de recursos, com base nos parâmetros de busca fornecidos num XML, solicita ao Mng_En a busca de recursos que possam informar o estado do entorno da interação.

50. O Mng_En recebe a solicitação do explorador de recursos e a envia ela para o Mng do Adaptware.

51. O Mng do Adaptware identifica a solicitação do Mng_En e a envia ela para o subcomponente Mng_SO indicando que deve ser executada a tradução para diretivas do sistema operacional.

52. O Mng_SO identifica a solicitação do Mng do Adaptware formatador de informações.

53. O subcomponente formatador de informações realiza a tradução correspondente e retorna para o Mng_SO as diretivas concretas para a reconfiguração da interface do sistema operacional legado. 
54. O Mng_SO devolve as informações formatadas para o Mng do Adaptware que propaga a solicitação para o sistema legado.

55. O sistema legado processa a solicitação e envia as informações correspondentes para o Mng do Adaptware.

56. O Mng do Adaptware envia as informações para o Mng_En.

57. O Mng_En encaminha a resposta à solicitação para o subcomponente explorador de recursos de ambiente de operação.

58. O subcomponente explorador de recursos, com base nas informações obtidas, cria um XML com os recursos de ambiente de operação disponíveis no sistema legado.

59. O Mng_En ativa o subcomponente para extração das informações que permitam descrever o ambiente de operação do sistema.

60. O subcomponente extrator de informações aplica um filtro na lista de recursos disponíveis e formata as informações de acordo com a especificação carregada a partir um arquivo XML. Assim, baseado nas informações formatadas e na especificação para a construção do contexto de entorno, ele gera um XML com esses dados.

61. O Mng_En ativa o subcomponente de construção de contexto de ambiente de operação do sistema. Assim, baseado nas informações formatadas e na especificação para a construção do contexto de entorno ele gera um XML com esses dados.

62. O Mng_En devolve o controle para o Mng do Adaptware.

63. O Mng do Adaptware ativa o seu subcomponente Mng_En para gerenciar a funcionalidade de tomada de decisão.

64. O Mng_En carrega o arquivo de configurações do subcomponente e concretiza os componentes necessários para seu funcionamento.

65. O Mng_En ativa seu subcomponente formatador de informações de entrada.

66. O subcomponente formatador de informações de entrada realiza a verificação e formatação dos três contextos de acordo com o tipo de unidade de entrada que a tabela de decisão precisa. Ele gera um XML com as entradas preparadas para entrar na tabela de decisão.

67. O Mng_En ativa o seu subcomponente que implementa a Tabela de Decisão. 
68. O subcomponente que implementa a Tabela de Decisão realiza a tomada de decisão com base nas informações contidas nos dados de entrada. Como consequência, os valores são modificados nos dados das unidades e eventualmente são criadas novas unidades.

69. O subcomponente que implementa a Tabela de Decisão notifica ao Mng_En que concluiu com o processamento das informações.

70. O Mng_En ativa seu subcomponente formatador de informações de saída.

71. O subcomponente formatador de informações de saída realiza a verificação e formatação das mudanças a serem realizadas como consequência da tomada de decisão. Ele gera um XML com as novas configurações e envia para o Mng_En.

72. O Mng_En recebe as informações e envia para o Mng do Adaptware indicando que elas precisam ser traduzidas.

73. O Mng do Adaptware recebe as informações e encaminha para o Mng_SO indicando que uma tradução deve ser aplicada.

74. O MngSO recebe, identifica e encaminha o pedido para o subcomponente formatador de informações.

75. O subcomponente formatador de informações realiza a tradução correspondente e retorna ao Mng_SO as diretivas para o sistema operacional do sistema legado.

76. O Mng_SO devolve as informações formatadas para o Mng do Adaptware que propaga a solicitação para o sistema legado.

77. O sistema legado processa a solicitação e aplica as mudanças solicitadas.

\subsubsection{Durante a interação}

De maneira geral, durante a interação entre humano e máquina, a intervenção do Adaptware só estará presente quando alguma mudança no ambiente de execução acontecer. Assim, são identificados dois tipos de mudanças: mudança na configuração do sistema legado (software ou hardware) e mudança nos valores dos parâmetros que regem a interface de interação do sistema legado. A seguir, detalham-se os passos em cada um dos casos.

No caso de uma mudança na configuração do sistema legado

1. Novos hardware ou software podem ser instalados no sistema legado, ficando acessíveis. 
2. Um evento é gerado dentro do sistema legado associado com o registo dessa nova funcionalidade.

3. Os "listeners"que foram registrados pelo Adaptware para determinados eventos são acionados se a nova funcionalidade satisfaz os seus critérios.

4. As informações sobre o novo recurso são enviadas para o Mng do Adaptware.

5. O Mng envia as informações para o Mng_SO indicando tratar-se de uma atualização de recursos e que uma tradução deve ser aplicada.

6. O Mng_SO recebe, identifica e encaminha o pedido para o subcomponente formatador de informações.

7. O subcomponente formatador de informações realiza a tradução correspondente as informações sobre o novo recurso ao Mng_SO.

8. O Mng_SO envia uma solicitação de atualização para o subcomponente explorador de recursos.

9. O subcomponente explorador de recursos atualiza o arquivo XML dos recursos acessíveis a partir do sistema legado e comunica o final das operações de atualização para o Mng_SO.

10. O Mng_SO envia um pedido de execução para o subcomponente de construção de contexto de sistema.

11. O subcomponente construtor de contexto do sistema realiza a construção devida, atualiza o XML correspondente e envia o controle de volta para o Mng_SO.

12. O Mng_SO retorna o controle para o Mng do Adaptware.

13. O Mng do Adaptware pede a execução de todo o fluxo operacional do subcomponente encarregado de examinar as informações necessárias para a construção do contexto de entorno. É possível que nenhuma mudança seja necessária no contexto que descreve o entorno de execução do sistema.

Adicionalmente ao caso padrão existe o caso em que o usuário realize um ajuste, uma mudança direta ou assistida, nos valores dos recursos de interface de interação relacionadas a acessibilidade, por exemplo um ajuste manual do nível de contraste na tela, ou a ativação do leitor de tela. Neste caso adicionalmente aos passos anteriores são executados os seguintes passos: 
1. O Mng do Adaptware solicita ao subcomponente Mng_Usr a atualização das características do usuário e envia os parâmetros que sofreram alguma mudança e os seus valores correspondentes.

2. O Mng_Usr recebe a solicitação e solicita a execução do subcomponente construtor de contexto do usuário enviando as informações recebidas.

3. O subcomponente construtor de contexto recebe o pedido, e com ajuda das especificações realiza a atualização no contexto do usuário, alterando os valores das características já existentes ou adicionando temporáriamente novas características e os seus valores associados.

4. O subcomponente construtor do contexto de usuário devolve o controle das operações para o Mng_Usr.

5. O Mng_Usr devolve a sua vez o controle para o Mng do Adaptware.

Independentemente do tipo de evento que ativou o funcionamento do Adaptware os seguintes passos são executados como consequência de dita ativação:

1. O Mng do Adaptware ativa o seu subcomponente Mng_En para gerenciar a funcionalidade de tomada de decisão.

2. O Mng_En carrega o arquivo de configurações do subcomponente e concretiza os componentes necessários para seu funcionamento.

3. O Mng_En ativa seu subcomponente formatador de informações de entrada.

4. O subcomponente formatador de informações de entrada realiza a verificação e formatação dos três contextos de acordo com o tipo de unidade de entrada que a tabela de decisão precisa. Ele gera um XML com as entradas preparadas para entrar na tabela de decisão.

5. O Mng_En ativa o seu subcomponente que implementa Tabela de Decisão.

6. O subcomponente que implementa a Tabela de Decisão realiza a tomada de decisão com base nas informações contidas nos dados de entrada. Como consequência valores são modificados nos dados de ditas unidades e eventualmente são criadas novas unidades.

7. O subcomponente que implementa a Tabela de Decisão notifica ao Mng_En que concluiu com o processamento das informações.

8. O Mng_En ativa seu subcomponente formatador de informações de saída. 
9. O subcomponente formatador de informações de saída realiza a verificação e formatação das mudanças a serem realizadas como consequência da tomada de decisão. Ele gera um XML com as novas configurações e envia para o Mng_En.

10. O Mng_En recebe as informações e envia para o Mng do Adaptware indicando que elas precisam ser traduzidas.

11. O Mng do Adaptware recebe as informações e encaminha para o Mng_SO indicando que uma tradução deve ser aplicada.

12. O Mng_SO identifica recebe o pedido e encaminha para o subcomponente formatador de informações.

13. O subcomponente formatador de informações realiza a tradução correspondente e retorna ao Mng_SO as diretivas para o sistema operacional do sistema legado.

14. O Mng_SO devolve as informações formatadas para o Mng do Adaptware que progaga a solicitação para o sistema legado.

15. O sistema legado processa a solicitação e aplica as mudanças solicitadas.

\subsubsection{Fim da interação}

No momento final da interação é necessário executar algumas tarefa com a finalidade de manter a transparência do uso do Adaptware no sistema subjacente. As atividades a serem executadas são:

1. O Mng do Adaptware identifica o pedidodo usuário para a finalização de suas funções, como consequência o subcomponente Mng_SO é chamado.

2. O subcomponente Mng_SO identifica a ação de finalização da interação e chama ao subcomponente Setup Tools.

3. O subcomponente Setup Tools procura as informações salvas sobre a configuração original do sistema subjacente.

4. O subcomponente Setup Tools solicita as informações correspondentes com a configuração corrente do sistema subjacente no momento de estabelecer a interação com o Adaptware para o Mng_SO. 
5. O Mng_SO envia a solicitação do Setup Tools para o subcomponente formatador de informações para sua tradução em diretivas do sistema operacional correspondente, já identificado.

6. O subcomponente formatador de informações realiza a tradução e devolve as diretivas a serem enviadas para o Mng_SO.

7. O Mng_SO envia a solicitação para o Mng do Adaptware.

8. O Mng do Adaptware propaga a solicitação para o sistema legado.

9. O sistema legado responde ao pedido e informa a sua configuração corrente.

10. O Mng do Adaptware recebe a resposta do sistema legado e envia dita informação para o subcomponente Mng_SO.

11. O Mng_SO envia a resposta para o subcomponente formatador de informações.

12. O subcomponente formatador de informações recebe a resposta do sistema legado e formata as informações para seu uso dentro do Adaptware.

13. O Mng_SO recebe as informações dos recursos formatadas e envia para o subcomponente Setup Tools.

14. O subcomponente Setup tools faz as comparações necessárias para restaurar a configuração original do sistema legado.

15. O Setup Tools envia as mudanças a serem aplicadas para restaurar a configuração original do Sistema Legado para o Mng_SO.

16. O Mng_SO envia a solicitação do Setup Tools para o subcomponente formatador de informações para sua tradução em diretivas do sistema operacional correspondente, já identificado.

17. O subcomponente formatador de informações realiza a tradução e devolve as diretivas a serem enviadas para o Mng_SO.

18. O Mng_SO envia a solicitação para o Mng do Adaptware.

19. O Mng do Adaptware propaga a solicitação para o sistema legado.

20. O sistema Legado recebe essa mudanças e aplica as diretivas associadas a elas. 
21. O Mng do Adaptware indica para os subcomponentes Mng_SO, Mng_En, Mng_Usr e Mng_En para salvar as informações de configuração necessárias no histórico de funcionamento do Adaptware e eliminar as referências da arquitetura concreta para a execução.

22. O componente de Comunicação fecha a comunicação entre o Adaptware e o Sistema Legado, e procede de acordo com as especificações do protocolo para desmontar o canal de comunicação.

23. Finalmente, o componente de Comunicação do Middleware libera todos os recursos atribuídos à implementação do protocolo de comunicação.

No Apêndice G são apresentados os diagramas de atividades relacionados com o funcionamento padrão enunciado linhas acima.

\subsection{VIABILIDADE PARA A CONCRETIZAÇÃO DO MODELO}

Nesta seção é realizada uma avaliação do estado tanto no marco tecnológico como no marco social que definem o ambiente no qual será introduzida a nova tecnologia. Do lado tecnológico, são examinadas as formulações teóricas e a disponibilidade das ferramentas para a implementação da tecnologia. Do lado social, são analisadas as condições sociais presentes no momento do desenvolvimento da tecnologia que suportam seu uso. A seguir são indicadas as tecnologias a serem utilizadas para a construção do Middleware Adaptativo.

\subsubsection{Suporte Teórico}

Nesta secção são detalhadas as técnicas e modelos teóricos que fornecem a base científica para a proposta e desenho de seu modelo.

\subsubsection{Tecnologia Universal Serial Bus(USB)}

Desde o seu lançamento em 1996 o padrão USB tem facilitado não só a homogeneização das portas de conexão de dispositivos de entrada e saída, mas também gerou um impacto na maneira como esses dispositivos eram incorporados no sistema operacional. Assim, a tecnologia USB apresenta dois componentes igualmente importantes: o hardware identificado como a porta USB, e o software identificado como o mecanismo Plug-and-Play para a descoberta e instalação dos dispositivos periféricos conectados através desta porta. A criação da porta USB padronizou a interface pela qual os dispositivos periféricos podem ser conectados no sistema, assim, permitiu que o mesmo canal pudesse ser utilizado para transmitir informação, por 
exemplo, de uma câmera, um disco rígido portátil ou uma impressora. Do lado do software, o mecanismo Plug-and-Play permite que o sistema operacional detecte o dispositivo conectado a uma porta USB, instale do driver correspondente para seu gerenciamento e a sua desinstalação quando ocorrer uma posterior remoção deste dispositivo. É justamente este mecanismo o que permite uma independência entre o hardware do dispositivo periférico e o sistema operacional, e em consequência a incorporação e remoção de novos recursos anexos aos computadores. $\mathrm{Na}$ data em que esta dissertação foi elaborada, a tecnologia USB já é aceita como um padrão tecnológico internacional e é utilizada pela maioria das plataformas disponíveis ao público alvo desta proposta, que são, as pessoas com deficiência. Por essas razões a tecnologia USB foi escolhida como o elemento principal sobre o qual será realizada a implementação padrão do Middleware deste projeto. No entanto, cientes sobre o desenvolvimento tecnológico e o surgimento de tendências como mobile, sistemas embarcados e internet das coisas, descrevemos como um trabalho futuro a concretização de uma versão do Adaptware que implemente, no componente de comunicação, um protocolo para componentes orientados a serviço de maneira que a tecnologia possa ser utilizada em nuvem.

\subsubsection{Construção de Software Orientada a Componentes}

A construção de software orientada a componentes é uma metodologia na qual o sistema integral é formado por peças de software independentes que tem a capacidade de ser conectadas a outras peças através de uma interface pré-definida. Esta metodologia não estabelece a estrutura ou arquitetura do sistema em questão, ela fornece o suporte para o desenvolvimento, uso, evolução e troca de componentes com baixo acoplamento. O paradigma de programação orientado a componentes, enunciado com detalhe no Apêndice $C$, é uma abordagem de programação especificamente alinhada para o desenvolvimento de software deste tipo.

\subsubsection{Padrões Internacionais}

A seguir alguns dos padrões mais aceitos tanto na área comercial quanto na área acadêmica que estabelecem diretrices para o desenvolvimento de software.

Extensible Markup Language $(\mathrm{XML})$ // É uma linguagem de marcação estendida que permite criar documentos que especificam modelos de uma maneira flexível, eficiente, e satisfatoriamente inteligível, tanto para sua interpretação dentro dos sistemas computacionais quanto para os desenvolvedores de software World Wide Web Consortium (2015). Definida pelo World Wide Web Consortium (W3C) para a descrição de dados dentro da web, ela é autodescritiva e permite o uso de novos elementos dentro da estrutura do documento, respeitando 
os níveis de hierarquia estabelecidos dentro do mesmo. Além disso, fornece um conjunto de características que permitem interpretar suas informações e exportar para outros diferentes formatos. Dessa maneira, o XML oferece a possibilidade de atuar como um agente tradutor entre diferentes especificações tecnológicas. Na atualidade XML é um dos formatos mais utilizados para compartilhar informações estruturadas não só dentro da web, mas também em outros domínios, assim tem sido aplicado para facilitar a comunicação de dados entre programas computacionais, pessoas, e entre computadores e pessoas.

A International Organization for Standardization (ISO)// É uma organização mundial que tem desenvolvido uma série de padrões para o desenvolvimento de sistemas computacionais que consideram a acessibilidade como parte integral deles. Desta forma, existem documentos que regulamentam a terminologia a ser utilizada dentro destes sistemas, assim como as definições correspondentes dos tipos de deficiência, os tipos de resposta e registro do suporte que as ferramentas oferecem.

\subsubsection{Suporte Tecnológico}

Nesta seção são detalhadas os diferentes avanços tecnológicos que fornecem a base prática para a implementação do modelo proposto neste trabalho.

\subsubsection{Tecnologia Assistiva}

É entendida como os recursos, tanto de hardware quanto de software, que contribuem para proporcionar ou ampliar as habilidades funcionais de pessoas com deficiência, satisfazer as necessidades especiais que elas possam apresentar durante a execução de suas tarefas. Este tipo de tecnologia tem recebido, nos últimos anos, um impulso por parte das iniciativas de inclusão universal com patrocínios tanto da iniciativa privada quanto dos órgãos governamentais. Assim, na atualidade existem diferentes produtos e serviços que fornecem algum tipo de suporte assistivo, em alguns casos recursos simples e com funções bastante limitados, e em outros, elementos complexos que abrangem diferentes aspectos da deficiência à que procuram assistir. Dessa maneira, na tecnologia atual, a criação, uso e manutenção de produtos e serviços de tecnologia assistiva, da forma como é realçado em (AAAI - Association for the Advancement of Artificial Intelligence, 2014) e ( International Conference on Computers Helping People with Special Needs, 2014), constituem linhas de pesquisa e desenvolvimento em crescimento. Como conclusão, existem hoje recursos, no escopo das tecnologias assistivas, que permitem realizar escolhas sobre quais recursos de tecnologia assistiva poderiam ser utilizados, de acordo com as preferências do usuário. Alguns desses recursos são: as tabelas adaptativas e as árvores de 
decisão adaptativas. A escolha do dispositivo que melhor responda às condições do problema específico é responsabilidade do equipe de implementação da tecnologia particular.

\subsubsection{Recursos de Personalização}

O uso da tecnologia por parte de um usuário pode ser definido como uma atividade que tem como requisito a aplicação de algum tipo de personalização que estabeleça a relação entre tecnologia e usuário. Assim, todo usuário precisa de certo nível de "ajuste"para se sentir confortável com o desempenho da tecnologia que utiliza. Tal como foi mencionado em Weld et al. (2003) é possível subdividir o processo de personalização em duas categorias dependendo da origem do processo de reconfiguração: personalização e adaptação. No primeiro caso é o usuário quem através de diretivas explicitas indica ao sistema quais características modificar e com quais valores. No segundo caso, quando um software consegue se adaptar, a fonte da mudança na configuração do sistema tem origem no próprio sistema com apoio de mecanismos de previsão do comportamento do usuário, aprendizado ou outros métodos de indução. Na atualidade a maioria dos sistemas operacionais que regem os computadores destinados para uso geral fornecem um mecanismo de personalização que permite ao usuário ajustar, por exemplo, o tamanho de letra na tela, o contraste das cores, o uso de energia do equipamento, entre outros. No entanto, na última década tem-se incrementado o número de dispositivos que também incorporam mecanismos de adaptação baseados em novos usos dos dispositivos periféricos (sensores) e em informação histórica armazenada na conta do usuário. Alguns exemplos são: smart TV's e smartphones que pausam a reprodução corrente quando detectam que o usuário não está olhando para a tela (SmartPause) (CoolSmartPhone, 2011), ou que fazem ajustes no nível de volume e tamanho da tela de acordo com o a atividade ou modo de uso que está sendo dado para o dispositivo (Adapt Display e Adapt Sound) (Samsung, s.d.). O certo é que cada vez mais os dispositivos estão incluindo recursos que permitam utilizar o contexto do sistema, o perfil do usuário, e as condições do ambiente para fornecer uma experiência de usuário mais eficiente e confortável em comparação com os dispositivos tradicionais. No caso de pessoas com deficiência, a capacidade do software de se ajustar ao comportamento do usuário é um determinante poderoso para a realização das atividades do usuário, podendo facilitar o exercício da mesma ou impedir completamente seu desenvolvimento. É importante notar que a tendência mencionada acima não se refere ao desenvolvimento de tecnologia assistiva, mas concretamente, ao incremento em sistemas de uso geral de tecnologia que fornece recursos e mecanismos de auto reconfiguração dos sistemas com base em informações do contexto. Neste trabalho, uma solução assistiva é entendida como:

\footnotetext{
"a mix of mainstream and assistive technologies whose assembly is different from
} 
one individual and another, and from one context to another" ASSOCIATION FOR THE ADVANCEMENT OF ASSISTIVE TECHNOLOGY IN EUROPE (2003)

\subsubsection{Suporte dos Sistemas Operacionais para Tecnologia Assistiva}

Atualmente, os sistemas operacionais mais utilizados fornecem um conjunto de opções de serviços nativos que, por ordem direta e expressa do usuário, realizam mudanças na configuração do sistema para facilitar a interação com pessoas que portem algum tipo de deficiência. Exemplos deste tipo de serviços são: leitores de tela, amplificadores, reconhecedores de fala, ferramentas para a configuração de brilho e contraste na tela, entre outros. Diferente dos serviços externos, estes recursos nativos oferecem a vantagem de serem de rápido acesso para o sistema operacional, o qual gerencia seus atributos e valores de maneira mais eficiente, e que para o usuário se traduz em tempo reduzido de espera para a reconfiguração da interface de usuário. Felizmente, existe uma tendência tecnológica, manifestada em diferentes sistemas operacionais, de registrar de maneira explícita os recursos e aplicações que dão suporte para atender as necessidades de usuários com deficiências. Um exemplo é a iniciativa da Microsoft com a criação do mecanismo de Registro das Tecnologias Assistivas (Microsoft, 2014). Através desse mecanismo é possível indicar que aplicativos fornecem recursos para usuários com uma determinada deficiência. Esta inciativa também fez a escolha por um esquema do tipo XML para salvar as informações correspondentes com o registro de ditos aplicativos de maneira que, por exemplo, a comunicação do componente de exploração de recursos do nosso Middleware com este registro é viável e transparente. Da mesma maneira, a iniciativa ARIA(Accessible Rich Internet Applications) são as diretrizes desenvolvidas pela WAI( Web Accessibility Iniciative) da W3C que procura melhorar a experiência dos usuários com deficiências no uso das aplicações de internet que fornecem suporte para acessibilidade. Assim, os desenvolvedores de aplicativos podem implementar tais diretrizes e comunicar de maneira direta informações de utilidade para as tecnologias assistivas. A evolução tecnológica, e a mudança que ela gera no uso da tecnologia por parte dos cidadãos, tem incorporado a preocupação por fornecer este suporte nativo em plataformas recentes do tipo smartphones, tablets e dispositivos de "wearable computing" ou baseados na computação em nuvem.

\subsubsection{Engenharia de Software baseada em Componentes}

Permite definir um sistema em função de componentes funcionais e lógicos que implementam interfaces claramente definidas e que estabelecem uma comunicação por meio de troca de mensagens sempre que haja entre ambos uma interface compatível. Um componente é 
120

entendido no contexto deste trabalho como: uma peça de software pré-construída, reutilizável, autocontida que implementa padrões para definir uma interface e conexões (Wang and Qian, 2005). A Programação Orientada a Componentes foi escolhida como paradigma de programação pelas seguintes razões:

- Utiliza um nível de abstração maior: um componente pode ter qualquer forma, estar implementado sob qualquer paradigma de programação, ter qualquer tamanho ou nível de complexidade, portanto pode ser uma função simples, um web service, um agente, uma classe, sempre que ele defina claramente a interface que implementa os detalhes internos que possam ser desprezados. Assim a programação orientada-a-componentes permite a reutilização de peças de software já disponíveis, as que podem atender requisitos gerais ou ser extremadamente especializadas, uma vez que seja respeitada a implementação da interface. Assim a preocupação principal do desenvolvedor do sistema é definir e identificar primeiro as funcionalidades críticas ao nível do sistema e as formas de interação que existem entre elas, no lugar de começar pela definição e estruturação dos elementos menores.

- Gerenciamento de mudanças: Este paradigma está implementado sob a hipótese de baixo acoplamento de suas partes, o que permite atender duas condições presentes nos sistemas de hoje: (i) em alguns casos não é possível conhecer com antecedência o componente concreto que atenderá a solicitação disparada no sistema, nem como ele irá realizar tal atendimento em detalhe, por essa razão ele só depende da implementação de uma interface conhecida para realizar a troca de mensagens e o estabelecimento da comunicação propriamente dita, ou seja, que dois componentes diferentes possam atender o mesmo tipo de solicitação em duas instâncias de execução diferentes do mesmo sistema; (ii) em outros casos altera-se a própria solicitação do sistema, e portanto, é necessário especificar as novas condições. Nesse caso a mudança da interface tem como efeito a procura de componentes que satisfaçam as especificações correntes sem afetar o funcionamento interno dos componentes que o integram.

- Uma distribuição das tarefas de maneira ordenada e com baixo acoplamento permite que o produto seja flexível, ou seja, é possível trocar os componentes do sistema ou atualizá-los sem gerar um maior impacto no sistema.

\subsubsection{Tecnologia de acesso a recursos remotos}

Com a evolução tecnológica surgem com frequência cada vez maior novos dispositivos e tecnologias que permitem ter acesso a uma maior diversidade de recursos, tanto para recolher 
informações quanto para processá-las. Do ponto de vista do hardware, os exemplos desta tendência vão desde a incorporação de novos sensores nos smartphones (LANE et al., 2010) como acelerômetros, giroscópio, compasso digital, microfone, câmera, GPS, tátil entre outros, até a criação de novos dispositivos. Alguns desses novos dispositivos integram as iniciativas de wearable computing que procura criar peças de hardware que permitem acompanhar e monitorar as diferentes atividades dos usuários de maneira pouco invasiva, atingindo um nível quase imperceptível. Alguns exemplos são: os óculos inteligentes (Google Glass), relógios inteligentes (iWatch, Samsumg Gear, Moto 360 entre outros) e alguns rastreadores de atividades que medem: ritmo cardíaco, pressão sanguínea, temperatura corporal entre outros. Do ponto de vista do software, tem surgido uma grande variedade de aplicativos e serviços que permitem realizar a interpretação e análise dos dados colhidos pelos sensores incorporados nos dispositivos. Assim, por exemplo, é frequente encontrar a disponibilização de web services cada vez mais especializados na medição de características associadas ao nível de saúde das pessoas, ou aplicativos móveis nas lojas virtuais dos fornecedores mais conhecidos de tecnologia móvel que prometem recomendações personalizadas sob a base dos dados do próprio usuário. Esta disponibilidade de recursos que permitem obter informações sobre o contexto no qual o sistema está sendo executado possibilita a criação de perfis, de usuário, de condições físicas do ambiente de execução, e até das configurações do próprio sistema, que são utilizadas a posteriori para realizar sugestões, reconfigurações, previsões de comportamento e diversos outros tipos de análises.

É particularmente esta possibilidade, não invasiva para o usuário, de coleta, formatação, e análise das informações o que suporta a construção do modelo de Middleware baseado nas especificações do contexto corrente e o armazenamento das informações históricas.

\subsubsection{Suporte Social}

Nesta secção são detalhadas as condições socioculturais que permitem o desenvolvimento deste trabalho de pesquisa nas suas diferentes fases e que é de esperar constituam um cenário propicio para trabalhos futuros sobre acessibilidade.

\subsubsection{Marco legal sobre pessoas com deficiências}

$\mathrm{Na}$ atualidade existem diferentes iniciativas que procuram fornecer um marco legal que suporte os esforços para a inclusão das pessoas com deficiências, o que permite ter acesso aos instrumentos que regulam as necessidades básicas deste tipo de usuário.

Assim, a existência de projetos de lei e normas que buscam garantir a participação das pes- 
soas com deficiências nas diferentes atividades que se desenvolvem na nossa sociedade, tem como consequência uma maior exposição, em termos de visibilidade, das necessidades de dita comunidade. Da mesma maneira, tem sido elaboradas normas, acordos, declarações que procuram agir como diretrizes para o correto desenvolvimento de ferramentas e/ou incorporação de mudanças no entorno físico com a finalidade de atender as necessidades manifestas.

Em alguns dos casos estas iniciativas são lideradas pelos governos locais, por exemplo no caso do Brasil existe a Secretaria Nacional de Promoção dos Direitos da Pessoa com Deficiência, que desenvolve trabalhos no nível nacional, e a Secretaria dos Direitos da Pessoa com Deficiência do Estado de São Paulo Governo do Estado de São Paulo (2015) é o órgão governamental criado especialmente para garantir que as pessoas com deficiência tenham seus direitos assegurados, fornecer as informações legais a serem cumpridas no estado de São Paulo e garantir, quando possível, que as oportunidades para as pessoas com deficiência sejam ampliadas e a diversidade respeitada. Da mesma maneira, existem iniciativas desde o campo empresarial, e por parte de instituições não governamentais, todas elas no plano local. Mas existem iniciativas a nível global que procuram regular as medidas a serem tomadas pela sociedade para incorporar as pessoas com deficiência, algumas delas são: o Plano estadual de ação para a garantia de direitos das pessoas com deficiência, o Programa Estadual de Prevenção e Combate à Violência contra Pessoas com Deficiência, e o Observatório de Reabilitação e Tecnologia Assistiva.

Com esses instrumentos é possível desenvolver projetos de pesquisa e tecnologias que adotam essa base e só se preocupar por fazer as contribuições que caem na área de especialização e não em estabelecer ou colher, muitas vezes de maneira leiga e precária, as necessidades dos usuários com deficiência.

4.2.3.2 Referência do aporte de pessoas com deficiência viabilizado pelas tecnologias assistivas

A própria referência do potencial duma pessoa com alguma deficiência tem mudado com o passar do tempo. No século passado não era estranho pensar numa pessoa com deficiência como uma pessoa limitada, não só na capacidade funcional especifica, mas como individuo, como integrante de uma comunidade. Como evidência estão alguns dos termos oficiais que foram utilizados para designar-os: deficiente, incapacitado, e na língua espanhola até minusválido os quais assimilaram um referente negativo, e que atingia a pessoa na sua integridade como individuo e não era indicativo exclusivo de alguma perda de funcionalidade. No entanto, com o desenvolvimento de novas tecnologias, e o interesse particular de alguns pesquisadores, surgiram as tecnologias assistivas, com a finalidade de criar ferramentas que pudesse cobrir essas deficiências funcionais e permitir elas desenvolver seu verdadeiro potencial. 
As referências de grandes personalidades com alguma deficiência são amplas, tal como é por natureza o próprio termo deficiência, e vão desde desordenes cognitivos leves, controláveis e não visíveis, até paraplegia e tetraplegia.

Provavelmente um dos maiores referentes atuais duma pessoa com deficiência que integrou tecnologias assistivas para permitir-e mostrar o seu potencial como um dos melhores físicos do século é o Professor Stephen Hawking. No entanto, existem exemplos de artistas, ativistas, esportistas, escritores, entre outros que realizam grandes contribuições.

\subsubsection{Interesse tanto académico quanto comercial de investimento em pesquisas dirigidas à acessibilidade}

A incorporação das pessoas com deficiências como participantes ativos dentro da sociedade da informação significa que as tecnologias devem começar a considerar as necessidades destes usuários como parte dos seus projetos. Assim, dentro da área comercial emergem iniciativas que buscam promover o desenvolvimento de tecnologias assistivas que permitam satisfazer essas necessidades, muitas dessas iniciativas são lideradas por empresas reconhecidas que manifestam publicamente a importância deste tipo de tecnologias e o impacto na vida das pessoas com deficiência. Uma dessas iniciativas, provavelmente a mais antiga, foi a da IBM que incorporou dentro do seu próprio manual de treinamento a seguinte diretiva sobre tecnologias assistivas:

"For people without disabilities, technology makes things easier. For people with disabilities, technology makes things possible." (International Business Machine, IBM, 1991)

Continuando com esse interesse nos últimos anos tanto as mais importantes empresas quanto as mais prestigiosas universidades têm criado centros de pesquisa, projetos, associações, parcerias e conferências que buscam incentivar novas e melhores ferramentas para a integração das pessoas com deficiência nas atividades da sociedade. Algumas destas iniciativas são:

- Google Accessibility (Google Inc., 2014) na secção de Iniciativas e Pesquisa

- Microsoft Research and Development Projects Related to Accessibility (Microsoft Corporation, s.d.)

- AT and T Labs Research - Assistive Technology (AT\&T Lab Research, 2015)

- Facebook Accessibility (Facebook, Inc., 2015)

- AAATE:Association for the Advancement of Assistive Technology in Europe (AAATE, 2015) 
124

- RESNA:Rehabilitation Engineering and Assistive Technology Society of North America (Resna, 2015)

- ICCHP:International Conference on Computers Helping People with Special Needs (ICCHP, 2015)

- MIT Assistive Technology Club (MIT Assistive Technology Club, 2015)

\subsection{VANTAGENS E NOVIDADES ASSOCIADAS AO MODELO}

Na seguinte secção são descritas as principais vantagens identificadas para a solução proposta tanto no nível estrutural quanto funcional.

\subsubsection{Adaptatividade}

Adaptatividade em diferentes níveis: O sistema proposto incorpora conceitos de adaptatividade em diferentes aspectos que vão desde a criação do próprio produto até o mecanismo de tabelas de decisão adaptativas. A seguir, descrevem-se os diferentes pontos nos quais é utilizada a adaptatividade neste projeto.

- Metodologia de Construção de software: A própria construção do sistema é concebida como uma Máquina de Estados Adaptativa, a qual reflete a evolução do ciclo de vida do software partindo desde um estado inicial, a intenção da criação do sistema, e que por meio de chamadas de máquina e ações adaptativas vai mudando sua estrutura, criando ou removendo estados e realizando transições, até chegar na configuração final do sistema e, portanto, ao produto final. Assim a máquina de estados adaptativa representa um modelo de construção de software incremental semelhante ao detalhado em Lieberherr (1996) no qual o processo de desenvolvimento de software é entendido como uma sequência de ações, geradas a partir de uma determinada entrada e que em consequência fornecem saídas que vão mudando o panorama global. É importante notar que seguindo esta metodologia o sistema vai crescendo de maneira evolutiva, mantendo em cada fase um protótipo funcional.

- Concretização da arquitetura: toda vez que o sistema for ser executado ele deve concretizar a meta-arquitetura, seguindo o sugerido em Ferber e Gutknecht (1998), que possui para conseguir interagir eficientemente com os recursos que o cenário de execução fornece. Assim, as condições do cenário corrente, do ponto de vista de arquitetura: 
sistema operacional, condições de rede, políticas de segurança, entre outras, influem na configuração final da arquitetura do middleware.

- Tabela de Decisões Adaptativa: o componente do sistema que implementa um mecanismo de tecnologia adaptativa sobre a base de uma técnica de tomada de decisões já conhecida como são as tabelas de decisões. Maior compatibilidade com a evolução tecnológica: a inclusão de um mecanismo de adaptação dentro da própria estrutura do Middleware incrementa a esperança de vida útil da tecnologia, pois ela pode-se ajustar para permitir sua execução sobre diferentes plataformas, com novos recursos, e até para considerar novos cenários e contextos, se assim for especificado.

\subsubsection{Design Orientado a Componentes}

- O uso do mecanismo Plug-and-Play como inspiração para a montagem da arquitetura do middleware permite ao mecanismo de tomada de decisão trabalhar sobre um conjunto de recursos disponíveis diferente em cada situação, assim de maneira dinâmica, ele avalia qual é a melhor sugestão de interface para o estado corrente.

- Dado que um componente vem em diferentes "formas e sabores"ele pode ser concretizado na forma de um web service, ou de um agente, ou de um módulo, e assim por diante, em consequência a tecnologia proposta considera só as características mais gerais de um componente. Dessa maneira o software resultante é flexível ao respeito das tecnologias concretas que implementam os componentes que a integram. Isso tem como consequência imediata a possibilidade do software de manter vigência com o desenvolvimento de novas tecnologias sempre que elas cumpram com implementar a interface base. Por exemplo, o componente de comunicações implementa o protocolo especificado por XML o qual pode ser tanto $\mathrm{PnP}$ ou um protocolo orientado a serviços, permitindo neste último caso uma conexão no nível de aplicativos. Assim, trata-se de uma tecnologia que identifica o seu sistema hospedeiro, vincula o componente concreto que permite-lhe interagir com ele, e depois concretiza o restante da sua arquitetura sobre a base dos recursos que dito sistema tem.

- A capacidade de identificar o sistema hospedeiro em tempo real permite ao middleware ter acesso aos dispositivos identificados/conectados/registados nele e as suas funcionalidades. Assim, é possível, configurar uma rede de recursos de software e hardware maiores, mas que sempre cumprem com a condição de ser acessíveis desde o sistema hospedeiro.

- A possibilidade de especialização de um componente mediante a troca dele durante a 
etapa de inicial de descoberta. Assim, uma componente que desempenhava uma funcionalidade de maneira simples e básica pode ser trocado por outro que implementa a mesma funcionalidade mediante um processo bem mais sofisticado e complexo.

\subsubsection{Outras vantagens funcionais}

- O protocolo de conexão permite ter uma alta tolerança a falhas. Se um componente não é achado então o sistema procura os dados de saída que foram produzidos pela execução do mesmo tipo de componente, ou algum compatível, em outra instância.

- Mecanismos Adaptativos conversando com mecanismos que permitem adaptabilidade.

\subsection{DIFICULDADES E LACUNAS ENCONTRADAS}

Nesta secção são listadas as dificuldades e problemas encontrados durante o desenvolvimento do projeto. São especificados problemas tanto referentes com a própria natureza da pesquisa quanto no nível tecnológico, assim como também são apresentadas as soluções aplicadas em cada caso e as recomendações para trabalhos futuros. Até o momento de apresentação deste documento as seguintes dificuldades foram identificadas:

- Falta de uma plataforma para a construção de meta-arquiteturas

- Falta de acesso para as aplicações desenvolvidas anteriormente respeito do assunto

- Falta de mecanismos de avaliação de usabilidade e acessibilidade nos sistemas de uso geral

- Falta de metodologias e métricas para realizar análise das ferramentas atuais

- Falta de um repositório com tecnologias adaptativas a maneira de biblioteca para oferecer ferramentas de construção de software

- Falta de mecanismos nas metodologias e ferramentas atuais para o design de software que expõem claramente o comportamento adaptativo de um sistema.

- A maioria das ferramentas de modelagem gratuitas na atualidade carecem de flexibilidade, usabilidade, ou simplesmente não oferecem versões atualizadas e estáveis ou não tem documentação apropriada. 
- Falta de consenso nas diferentes áreas: desde as terminologias até o processo de construção de software o que dificulta a pesquisa em diferentes momentos, desde o levantamento das informações até as sugestões para trabalhos futuros.

- A maioria das ferramentas de software disponíveis nos sistemas de uso geral como recursos para fornecer acessibilidade são dependentes da plataforma, o que dificulta a reutilização de elementos terceirizados, e muitas vezes proprietários. Essa dificuldade para fazer que um recurso possa interagir com um outro fica mais clara no seguinte exemplo: o uso da funcionalidade de leitura de tela inclusa na maioria dos aplicativos para visualização de arquivos PDF não pode ser utilizada de maneira independente fora desse aplicativo, o que impossibilita seu aproveitamento como recurso para oferecer maior acessibilidade.

- Não existe consenso sobre como registar as informações sobre as ferramentas que oferecem alguma funcionalidade que pode ser aproveitada com finalidades de fornecer acessibilidade: Linux faz de uma maneira, Windows de outra, Macintosh de uma outra diferente. Esta heterogeneidade dificulta o desenvolvimento de tecnologias mais eficientes que possam focar o seu trabalho na área de acessibilidade no lugar de lidar com restrições de mercado. A iniciativa ARIA, é uma tentativa de estabelecer um padrão para este registo de informações relacionadas à acessibilidade, mas só no nível de aplicativos de internet, ficando pendente ainda uma proposta análoga no nível de sistemas operacionais. 


\section{CONCLUSÕES, CONTRIBUIÇÕES E TRABALHOS FUTUROS}

Neste capítulo são enunciadas as conclusões obtidas como produto deste trabalho de pesquisa. Da mesma maneira são detalhadas as contribuições feitas em diferentes pontos relacionados com o problema trabalhado. Por último, são descritos os trabalhos futuros que podem ser desenvolvidos como consequência deste trabalho.

\subsection{CONCLUSÕES}

Nesta seção são apresentadas as principais conclusões obtidas logo do desenvolvimento do projeto. As conclusões apresentadas correspondem tanto ao área tecnológica como ao assunto de acessibilidade e a própria execução da atividade de pesquisa.

- Analise crítico da literatura em diferentes momentos da pesquisa como fator fundamental para encaminhar o desenvolvimento do projeto.

É evidente para qualquer pesquisador na área acadêmica a importância de elaborar uma boa analise da literatura com a finalidade de conhecer a profundidade o problema a ser tratado e as soluções que já têm sido elaboradas até o momento. Esse levantamento bibliográfico é a atividade que permite gerar o estado da arte e o estado da prática do problema, além de dar uma ideia inicial de qual irá ser a diferenciação que a pesquisa sendo elaborada vai ter do lado das outras propostas de solução. No entanto, esse momento inicial não é o único que precisa de um levantamento de informação. Uma vez avançado o projeto é necessário fazer um levantamento bibliográfico para conferir se as hipóteses elaboradas para o projeto já foram avaliadas, parcial ou totalmente, em outras pesquisas, ou se consideram todos o fatores relacionados à problemática. Logo, é necessário recorrer à literatura para conferir se existe conflitos entre os trabalhos realizados até agora e a solução sendo proposta, assim como também como ela se enquadra dentro das categorizações (classificações e taxonomias) elaboradas pelos pesquisadores da área ao longo dos anos. Finalmente, é preciso uma revisão para identificar trabalhos futuros relacionados à pesquisa realizada e para identificar os desafios e as lacunas que ainda ficaram por cobrir. Esta revisão contínua da bibliografia permite ter acesso à informações que sustentam diferentes partes do trabalho de pesquisa no tempo adequado para tomar as medidas necessárias para encaminhar o projeto na direção mais conveniente. Contudo, é importante apontar que existe uma necessidade de contar com ferramentas de pesquisa que permitam a realização de este tipo de revisão sistemática de maneira semi-automática, de maneira que o trabalho meramente mecânico fique suportado por 
uma força computacional correspondente.

- A identificação da problemática central permite a exploração de outras áreas na procura de fenômenos semelhantes.

Acontece com certa frequência no ambiente acadêmico que a natureza de um problema, a parte central do mesmo, não é exclusivo de uma área só. Prova de isso são, por exemplo, as soluções para problemas de inteligência artificial que encontraram respostas no comportamento de insetos, o qual deu origem às áreas de computação bio-inspirada e, nos últimos tempos, computação orgânica. Dessa maneira, é importante identificar a parte essencial do problema e procurar, com mente aberta, problemáticas semelhantes em outras áreas. Para a elaboração da proposta deste trabalho foram exploradas problemáticas das áreas de: botânica, biologia, teoria da computação, psicologia, educação, neuro ciência, linguística, inteligência artificial, sociologia, design gráfico, medicina, astrologia, música, aprendizagem de línguas estrangeiras,e história. Ainda quando algumas ideias, em algum ponto, não foram consideradas ideais para dar solução ao problema de acessibilidade de maneira direta, mas todas elas aportaram para consideração de trabalhos futuros.

\section{- O conhecimento teórico prévio sobre os assuntos envolvidos na problemática} permite a consideração ou rejeição de diferentes elementos na proposta de solução.

A preparação teórica nos assuntos envolvidos dentro da problemática como atividade prévia à formulação de uma proposta de solução permite não só esclarecer as condições sob as quais é definido o problema, mas também verificar o cumprimento das hipóteses relacionadas. Assim mesmo, permite observar as restrições estabelecidas em estudos prévios que ajudam na seleção certa de métodos para a elaboração da proposta de solução. Esses elementos teóricos constituem uma base sólida sobre a qual é possível construir novos recursos que aproveitam as características e propriedades formais longamente aceitas e utilizadas dentro das áreas acadêmicas. A pouca aprofundação nos assuntos teóricos correspondentes significa o incremento do risco de cometer erros ou assumir condições inexistentes que decrementam a corretude da proposta de solução. Assim, dento do projeto de pesquisa realizado foi necessário fazer uma revisão básica dos conceitos relacionados aos mecanismos e técnicas participantes tanto em trabalhos anteriores quanto na solução final apresentada. Alguns conceitos parte dessa revisão são por exemplo: teoria de autômatas, dispositivos adaptativos e as suas formulações, engenharia de software orientada a componentes, sistema multimodais, teoria de agentes tecnológicos, modelagem de usuários, contextualização da tecnologia, entre outros. Dessa maneira, ficou claro, ao 
término desta pesquisa, que a aquisição dos conhecimentos teóricos dos assuntos envolvidos na problemática a ser tratada é uma parte fundamental do exercício da pesquisa científica, e deve ser abordada em um momento prévio ao trabalho de elaboração de uma proposta prática e concreta de solução.

- Importância de uma modelagem adequado, tanto do problema quanto da proposta de solução.

Modelar corretamente o problema permite ter em consideração todos os dados que carregam informações que podem ajudar no processos para oferecer uma solução. Assim, por exemplo, em Macías-Escrivá et al. (2013) é mencionado que parte importante do processo de criação de sistemas adaptativos é responder a seis perguntas, denominadas $5 W+1 H$, que ajudam a estabelecer o marco sob o qual será desenvolvido o dispositivo. Assim mesmo, escolher um modelo que represente de maneira adequada a solução proposta permite incorporar atributos adicionais à própria solução do problema, por exemplo permite incorporar estratégias que incrementam a vida útil do software, ou que fornecem funcionalidade multi-plataforma, ou que admite interagir com outros sistemas.

- Identificar as oportunidades para aplicar tecnologia adaptativa é uma parte crítica do desenvolvimento de sistemas.

Aprender a identificar momentos nos quais a tecnologia adaptativa traz potencial ganho é uma das partes essenciais do trabalho. Existem muitas ocasiões nas quais é difícil para o pesquisador abstrair a natureza dinâmica do problema, e pensar na solução de maneira independentemente dos recursos técnicos a serem utilizados. Não entanto, esta atividade significa uma grande vantagem: identificar as melhores técnicas, metodologias, teorias, modelos para resolver as diferentes partes que compõem o problema. Uma de essas técnicas é a tecnologia adaptativa, a qual a sua vez precisa da seleção de um formalismo subjacente correspondente com a natureza da problemática que irá ser enriquecido com uma camada adaptativa para permitir a sua auto-reconfiguração. Entender que o funcionamento da tecnologia adaptativa permite seu uso eficiente, primeiro para reconhecer qual irá ser o assunto a resolver, e segundo para identificar os elementos com os quais irá interagir. Assim, as vezes, a análise profunda do problema e a modelagem no nível macroscópico do sistema permite descobrir pontos potenciais para aplicação de adaptatividade que não tinham sido considerados na visão inicial da solução, esse foi o caso deste projeto.

- Modelagem híbridas para problemáticas complexas como alternativa que permite sinergia de recursos. 
Como mencionado no parágrafo anterior, o trabalho com elementos que proveem de outras áreas permite aproveitar o melhor de cada uma. Assim, se tem uma sinergia de conhecimentos que permite explorar fenômenos e possibilidades que de outra maneira passariam desapercebidos. Além disso, quando uma problemática é identificada em outra área, e a modelagem é a adequada é possível aproveitar todo o trabalho já realizado em dita área para enriquecer o tratamento da problemática tecnológica em particular, o qual se traduz em flexibilidade, expressividade e simplicidade no trabalho. No nosso caso, a proposta elaborada é uma modelagem que mistura a tecnologia implementada no mecanismo $\mathrm{PnP}$, a arquitetura orientada a componentes e a própria modelagem de dispositivos adaptativos.

- A adaptatividade permite fornecer mecanismos de gerenciamento de mudanças que preparam o sistema para possíveis eventos dos quais ainda não se têm suficiente informação.

Através da tecnologia adaptativa é possível estabelecer um mecanismo que permitirá executar as mudanças necessárias na configuração do sistema como consequência de determinados eventos. No entanto, no momento do desenvolvimento das tecnologias não é possível descrever todas os eventos a serem considerados, especialmente, porque em alguns dos casos são consequência de tecnologias que no momento são só projetos, ou interações que simplesmente não conseguimos imaginar. Dessa maneira, alguns eventos não são tratados na configuração original dos dispositivos adaptativos, mas a possibilidade de incorporá-los através da construção de um caminho em algum ponto do tempo de execução de software é uma grande vantagem frente a tecnologias convencionais.

- Aproveitamento das teorias, metodologias, instrumentos desenvolvidos em outras áreas do conhecimento.

A adaptatividade pode ser aproveitada em diversos níveis desde modelos matemáticos que descrevem dispositivos abstratos até o próprio comportamento da atividade de pesquisa. No caso deste trabalho aprendi que não são só os componentes tecnológicos os que podem ser heterogêneos na sua constituição interna, mas expor um conjunto de capacidades que encaixa à perfeição com as características do problema, são também as teorías, os conceitos, as abstrações, os modelos de diferentes áreas do conhecimento que podem, sob uma "welcoming interface"(chamada interação com mente aberta, e cafés com pesquisa), interagir a maneira de não só resolver problemas de modo eficaz e eficiente, mas também gerando sinergias que poucas vezes, ou quase nunca, somos capazes de imaginar.

- A maioria de ferramentas construídas segundo o paradigma orientado a com- 
ponentes estão associadas a tecnologias (arquiteturas, protocolos, modelos) fixadas pelos frameworks do mercado.

A maioria das ferramentas tecnológicas baseadas no paradigma de Engenharia de software orientadas a componentes apresentam implementações concretas de alguma tecnologia em particular (serviços, agentes, módulos, entre outras) esquecendo da modelagem de interfaces genéricas que depois possam ser aproveitadas em trabalhos com diferentes tecnologias. Muitas vezes esse costume está baseada no uso de frameworks associados com alguma tecnologia específica: arquiteturas, protocolos, modelos, e até outras ferramentas do mesmo fabricante. Ainda quando é necessário concretizar as tecnologias para realizar as implementações correspondentes, isso não significa que as tecnologias devem ser fixadas pelas ferramentas nas quais a solução vai ser implementada no lugar de ser uma decisão de modelagem e projeto de software. Assim, o trabalho com tecnologias que permitam a modelagem, descrição, implementação e implantação de ferramentas livres, no sentido de permitir ao desenvolvedor escolher as diferentes tecnologias que deseja aplicar nos diferentes estágios, foi estabelecido como uma prioridade dentro deste projeto. Por essa razão foram escolhidas tecnologias livres e apropriadas com dita flexibilidade: Latex na elaboração do documento, Acme na especificação do metamodelo, e padrão XML na exportação da arquitetura do Middleware.

- O trabalho de realizado com a finalidade de fornecer acessibilidade para pessoas com deficiência gera um beneficio muito mais abrangente do que o publico alvo.

Como já for mencionado na revisão da literatura a consideração de diferentes modelos de usuários além do "usuário padrão"permite a criação de entidades de software e hardware personalizáveis e reconfiguráveis. Muitas vezes, os usuários não possuidores de deficiência limitam suas exigências tecnológicas às possibilidades oferecidas pelas ferramentas, sistemas e dispositivos com os quais interage. Assim, a incorporação nos sistemas de mecanismos que admitam mudanças sobre a representação do usuário com o qual interagem permite a os diferentes usuários ter um aproveitamento personalizado das tecnologias disponíveis. De maneira que, tanto usuários portadores de deficiência quanto usuários isentos de deficiência conseguem se beneficiar dos recursos tecnológicos.

\subsection{CONTRIBUIÇÕES}

As principais contribuições inclusas como parte deste trabalho são:

1. Elaboração de um mapa das áreas e os conceitos pesquisados para o levantamento de 
informações como parte da revisão da literatura relacionada com o assunto principal deste trabalho apresentado no Apêndice $A$.

2. Revisão do estado da arte e estado da prática das soluções propostas para o problema de acessibilidade em sistemas legados de uso geral.

3. Uma revisão do desenvolvimento corrente nas áreas comerciais e acadêmica, apresentado como parte do Capitulo 1, com o foco nas características que as tecnologias assistivas procuram fornecer acessibilidade para pessoas com deficiência, e apresenta os potenciais aportes que a tecnologia adaptativa pode fazer na solução dessa problemática particular.

4. Um tabela comparativa das características dos principais projetos que apresentam semeIhanças com o presente trabalho. Os critérios de comparação dentro de dita tabela são: o tipo de solução que implementam (reativa ou proativa), a abrangência de uso, o tipo de arquitetura, se tratam as preferências do usuário, o tipo de sistema com o qual interagem, o tipo de recursos que utilizam, e se são soluções adaptáveis, adaptativas ou ambas. A tabela resultante é apresentada como parte do Capítulo 1.

5. As justificativas para a viabilidade da implementação do modelo proposto sob as perspectivas: teórica, tecnológicas e social são apresentadas no Capítulo 4.

6. As sugestões para dar solução ou melhorar algumas das principais dificuldades encontradas na elaboração deste trabalho, expostas no Capítulo, são apresentadas na seção de Trabalhos Futuros deste mesmo capítulo.

7. Descrição da meta-arquitetura de um software, de tipo middleware, para permitir o gerenciamento dos recursos de interação humano-computador orientados a fornecer acessibilidade. A descrição apresentada no Capítulo 3 especifica as perspetivas de hardware e software do sistema, assim como também a perceção do usuário nos diferentes momentos de interação com o sistema. Assim mesmo, são descritos os diferentes componentes contidos no middleware e as funcionalidades de cada um deles.

8. Um modelo formal da meta-arquitetura do software proposto segundo a abordagem de engenharia de software orientada a componentes para a assistência de um sistema legado de uso geral na reconfiguração dos seus recursos de interação Humanos-Computador com a finalidade de fornecer uma maior acessibilidade para usuários com deficiência. Dito modelo é apresentado no Capítulo 4, segundo as especificações do ADL Acme para permitir uma descrição independente de alguma linguagem particular. 
9. Detalhe do funcionamento padrão do modelo nos três momentos possíveis de interação com o usuário: configurações e procedimentos executados começo da interação, atividades e procedimentos durante a interação, e procedimentos e verificações no final da interação.

10. Relatório integrado do funcionamento do Mecanismo Plug-and-Play que se na maior parte das referências se encontra incompleto ou espalhado de maneira que seu entendimento é dificultado. Dito relatório é apresentado no Apêndice $C$.

11. Finalmente, a discussão e conclusões obtidas do trabalho e sugestões para trabalhos futuros são apresentadas no último capitulo.

12. A revisão da terminologia utilizada dentro da área tecnológica para descrever sistemas que possuem a capacidade de reconfiguração, de maneira autônoma, em tempo de execução, e dependendo unicamente dos estímulos recebidos e dos seu histórico de execução deu origem a um artigo submetido para evento aguardando avaliação no momento de apresentar este documento.

\subsection{TRABALHOS FUTUROS}

Nesta seção são apresentadas as propostas de trabalhos futuros que podem ser desenvolvidos como consequência do trabalho de pesquisa realizado.

\subsubsection{Trabalhos como continuação deste projeto}

- Estudo e seleção de testes formais para modelos de arquitetura de software.

- Configuração de testes com ênfase nas características do problema de acessibilidade para pessoas com deficiência.

- Aplicação dos testes e análise dos resultados obtidos.

- Implementação do modelo do Adaptware em alguma das ferramentas para desenvolvimento de middleware sob a abordagem de engenharia de software orientada a componentes como as citadas em (KRUPITZER et al., 2015).

- Teste do desempenho do Adaptware para diferentes casos: diferentes sistemas operacionais e diferente acesso a recursos (locais e em nuvem) assim como para usuários com deficiência visual ou auditiva. 
- Analise da satisfação do usuário ao respeito do desempenho do Adaptware de acordo com métricas de QoS(Quality of Software).

- Teste da reconfiguração dinâmica dos componentes do Adaptware: políticas de configuração, substituição de componentes e protocolos de comunicação.

- Avaliação de mudanças e teste básico do desempenho do Adaptware para diferentes plataformas: smartphone, tablet, ambientes inteligentes. Algumas métricas de interesse para este teste podem as relacionadas à quantidade de mudanças, ao nível de experiência necessário para realizar-as, e a robustez do Adaptware modificado na nova plataforma.

- Implementação de um aplicativo para automação da criação dos elementos necessários(arquivos de configuração, componentes, protocolos) para mudanças ou extensões do Adaptware. Este aplicativo deve considerar como prioridades a facilidade de uso por parte do usuário e simplicidade sem sacrificar clareza nas informações e funcionalidades que implementa. Assim mesmo, é interessante fornecer a possibilidade de incorporar novos templates.

- Uso de tabelas adaptativas para a própria seleção dos componentes que compõem o Adaptware no lugar de políticas de configuração. Neste caso as políticas podem ser mantidas como estratégia de segurança o só como base no primeiro uso de Adaptware.

- Desenvolvimento de uma versão em nuvem do Adaptware.

\subsubsection{Trabalhos alinhados com o assunto de acessibilidade}

- Automação para a exploração e categorização dos recursos orientados a acessibilidade dentro de um sistema computacional em tempo real. Este tipo de informações não é facilmente registrada, e muito menos de rápido acesso dentro dos sistemas legados. Ainda quando todas os aplicativos e serviços presentes no sistema estão indexados no registro interno, as funcionalidades que implementam para fornecer adaptatividade são anônimas, quer dizer, não é imediato obter, por exemplo, um listado dos recursos dirigidos à acessibilidade para pessoas com baixa visão. Adicionalmente, os recursos são diferentes em cada plataforma o que incrementa a dificuldade da busca com algum critério. Um iniciativa recente é a oferecida pela Microsoft como parte do Easy of Access Center com a criação de um processo de registro, tanto dos serviços quanto dos aplicativos, especificando suas funcionalidades com suporte para acessibilidade. 
- Montagem de um repositório de recursos de acessibilidade considerando Ambient Intelligence. O trabalho deve estar principalmente orientado a examinar os protocolos de comunicação para montagem de um ambiente inteligente, a interação entre seus componentes, e as políticas para compartilhar recursos dentro do ambiente.

- Automação da criação de modelos computáveis para diferentes deficiências com base nas informações disponíveis nas diferentes bases de dados institucionais com esse objetivo. As pesquisas sobre deficiências são extensas em outras áreas do conhecimento, especialmente as ciências humanas e a pedagogia têm se preocupado em realizar estudos sobre as necessidades das pessoas com deficiências e propostas para satisfazer ditas necessidades. O aproveitamento das pesquisas nessas áreas permite a elaboração de modelos mais exatos e especializados.

- Extender o trabalho para outros tipos de deficiência. Contando com modelos computáveis sobre outras deficiências é possível avaliar e implementar o ajustes que devem ser feitos no Adaptware para a incorporação desses novos modelos. De preferência essa incorporação deve ser dinâmica seguindo a filosofia adaptativa deste trabalho e a natureza do problema.

\subsubsection{Trabalhos alinhados com as tecnologias utilizadas}

- Incorporação de tecnologias adaptativas dentro da criação de perfis de usuário dinâmicos. A linha de pesquisa de modelagem de usuários tem se interessado cada vez mais nos últimos anos na busca de novas opções além da abordagem estática,assim, existem hoje metodologias e técnicas que permitem, por diferentes estratégias, fornecer algum mecanismo para processar mudanças dentro da representação do usuário. Particularmente, as estratégias híbridas prometem uma interessante proposta já que, por exemplo, permitem a mudança dos modelos considerando à sua vez fatores de eficiência e performance.

- Protocolo Plug-and-Play para recursos de software. A ideia central para o desenvolvimento desta proposta é a criação de um mecanismo de comunicações padronizado para elementos software, inspirado no mecanismo Plug-and-Play que nasceu com a mesma finalidade no nível de hardware. A implementação de um protocolo geral ia facilitar um intercâmbio de informações entre elementos de diferentes desenvolvedores, plataformas, locações, mas que podem ser reutilizados na construção de novos sistemas contando com a interface e o gerenciador apropriado.

- Testar o trabalho para outro tipo de objetivos diferente de acessibilidade aproveitando o conjunto de tecnologias interatuando no Adaptware. Nesta proposta a ideia é focar a 
pesquisa nas características macro do problema resolvido com o Adaptware: um software para assistir na tomada de decisão que possui uma arquitetura com baixo acoplamento. A identificação de outros problemas que estão alinhados com esta problemática, por exemplo E-learning, permite um aproveitamento interessante já seja da parte conceitual, de modelagem ou de arquitetura do trabalho realizado no Adaptware.

\subsubsection{Trabalhos alinhados com as ferramentas utilizadas}

- Criação de uma ferramenta que permita explorar o funcionamento de dispositivos adaptativos de maneira paralela a sua descrição em notação formal. Especificamente, existe a necessidade de ter uma ferramenta que permita ao usuário desmitificar o funcionamento dos dispositivos adaptativos, evidenciando claramente as partes que o compõem de maneira que seja simples para o usuário associar a formulação com a correspondente implementação.

- Criação de um simulador para dispositivos adaptativos, que permita verificar o correto design de um dispositivo com base na especificação formal do modelo.

- Framework para o desenvolvimento de dispositivos adaptativos: acessibilidade da própria tecnologia adaptativa. A existência e disponibilização de uma ferramenta que ajude no desenvolvimento de Autômatos Adaptativos e suas especializações, a ferramenta AdapTools, significa um valioso aporte para os trabalhos com tecnologias adaptativas que seguem esses modelos. Assim mesmo, a falta de essa ferramenta para outros formalismos constitui uma das maiores dificuldades para a incorporação de tecnologias adaptativas no desenvolvimento de software por parte da comunidade. Este trabalho propõe a construção de um Framework, no mínimo adaptável, que permita com base nos templates para diferentes formalismos a implementação de dispositivos adaptativos. Assim mesmo, o framework deve oferecer opções de diferentes vistas, representações e ações (depuração, simulação, treinamento, entre outras) para representação do dispositivo e do seu funcionamento.

\subsubsection{Trabalhos derivados do próprio exercício da pesquisa}

No desenvolvimento da pesquisa alguns assuntos foram explorados a maneira de procurar resposta a questões intermediarias. Alguns deles são totalmente distantes da problemática particular tratada neste trabalho, mas a consideração de alguns deles é no mínimo interessante para novas pesquisas. 
- Aprender a esquecer. A capacidade de aprendizagem e a capacidade de esquecer têm sido exploradas amplamente tanto na área da Psicologia quanto da área de Educação como parte principal na construção dos estruturas mentais que governam nosso comportamento, a nossa representação do mundo, e a nossa interação com o entorno. A área tecnológica pela sua parte, faz muitos anos, começou tentar traduzir a capacidade de aprendizagem para mecanismos computáveis, assim criaram-se a modelagem e representação do conhecimento, os mecanismos de inferência, sistemas especialistas, algoritmos bio-inspirados, entre outros. No entanto, a capacidade de esquecer careceu da mesma atenção, de maneira que esses algoritmos, técnicas, mecanismos, e modelos, precisam de novas capacidades para conseguir processar a quantidade de informações que armazenam. É interessante, por tanto, examinar e analisar um dos melhores mecanismos de otimização para bases de dados expostos na natureza.

- Modelagem de comportamento. A análise de modelos formais das ciências exatas para representar o conceito de comportamento. Identificar suas características em cada formalismo, e o significados dos atributos (propriedades, operações, operadores) que são ganhos como resultado da interação. Assim mesmo, analisar e identificar as diferenças necessárias para modelar o comportamento de diferentes tipos de indivíduos, especialmente na sua natureza unitária e coletiva.

- Gestão de dispositivos de hardware híbridos com controles adaptativos. Na atualidade, é cada vez mais comum que os dispositivos hardware possam ser componíveis, um exemplo desta tendência são as tabletes transformers as quais possuem teclado destacável, um outro exemplo é a iniciativa para smartphones chamada Phoneblocks (HAKKENS, 2013). Nesses casos a natureza do próprio dispositivo é adaptativa e os seus componentes podem ser trocados em tempo de execução, teoricamente, com total suporte. Assim, é interessante estudar o uso de tecnologia adaptativa a maneira de gestor de ditos recursos.

- Estudo das complicações e desafios dentro dos sistemas adaptativos, chamados SaS (Selfadaptive Systems), onde cada subsistema é um sistema adaptativo e possíveis conflitos entre políticas devem ser resolvidas em tempo de execução. 
Referências

ASSOCIATION FOR THE ADVANCEMENT OF ASSISTIVE TECHNOLOGY IN EUROPE. Site Oficial. Disnponível em: http://www. aaate.net/. Acessado em: 03/09/2015.

ABOUSHARKH, M.; MOUFTAH, H. A soa-based middleware for wban. Medical Measurements and Applications Proceedings (MeMeA), 2011 IEEE International Workshop on. p. 257-260, May 2011. DOI: 10.1109/MeMeA.2011.5966780.

ACAPELA GROUP. Infovox. Disponível Online em: http://www.acapela-group.com/ infovox/. Acessado em: 03/10/2014.

ADJOUADI, M. et al. Adaptive eye-gaze tracking using neural-network-based user profiles to assist people with motor disability. Journal of Rehabilitation Research and Development, v. 45, n. 6, p. $801-818,2008$.

AKOUMIANAKIS, D.; STEPHANIDIS, C. Universal design in hci: a critical review of current research and practice. Proceedings of the Workshop No. 14 "Universal design: Towards universal access in the info society", organised in the context of the ACM Conference on Human Factors in Computing Systems (CHI 2001). 2001.

APPLE INC. Accessibility. Site Oficial. Disponível Online em: http://www.apple.com/ support/accessibility/. Acessado em: 03/03/2013.

APPLE INC. Apple - Accessibility. Site Oficial. Disponível Online em: https://www.apple. com/accessibility/. Acessado em: 03/03/2013.

ASSOCIATION FOR THE ADVANCEMENT OF ASSISTIVE TECHNOLOGY IN EUROPE. A 2003 view on Technology and Disability. [S.I.]: AAATE, 2003. (AAATE Position Paper).

AT\&T Lab Research. Assistive Technology. Disponível Online em: http://www . research.att.com/projects/AssistiveTechnology/?fbid=ajYw6woyMI4 Acessado em: 03/10/2014.

BAGNARA, S.; POZZI, S. The continuity of disability, diversity and personalisation: an emerging challenge for hci. InTech, 2009. DOI: 10.5772/7722.

BARFIELD, W.; CAUDELL, T. Fundamentals of wearable computers and augmented reality. [S.I.]: CRC Press, 2001.

BHUIYAN, M.; PICKING, R. A gesture controlled user interface for inclusive design and evaluative study of its usability. The International Journal on Software Engineering and Applications, v. 4, n. 9, p. 513-521. 
BISWAS, P.; ROBINSON, P. A brief survey on user modelling in hci. Proc. of the International Conference on Intelligent Human Computer Interaction (IHCI) 2010. 2010.

BJöRNANDER, S.; GRUNSKE, L. C4-01 TR M49, Architecture Description Languages for Automotive Systems A Literature Review. [S.I.]: Faculty of Information and Communications Technologies, Swinburne University of Technology, Australia, July 2008.

BORGER, E.; STARK, R. F. Abstract State Machines: A Method for High-Level System Design and Analysis. Secaucus, NJ, USA: Springer-Verlag New York, Inc., 2003.

BROWN, D. P. Experiences from the aid project. In: Adaptive User Interfaces: Principles and Practice. Adaptive User Interfaces: Principles and Practice. Amsterdam: NorthHolland, 1993. p. 69-78.

BRUSILOVSKY, P. Methods and techniques of adaptive hypermedia. In: Adaptive hypertext and hypermedia. Adaptive hypertext and hypermedia. [S.I.]: Springer, 1998. p. $1-43$.

Bureau of Labor Statistics. Most common uses for computers at work. [S.I.]: U.S. Department of Labor, 2005. (The Editor's Desk).

BUZHINSKY, I. et al. Inducing finite state machines from training samples using ant colony optimization. Journal of Computer and Systems Sciences International, Springer, v. 53, n. 2, p. 256-266, 2014.

BYUN, H. E.; CHEVERST, K. Exploiting user models and context-awareness to support personal daily activities. Personal Daily Activities, Workshop in UM2001 on User Modelling for Context-Aware Applications. p. 13-16, 2001.

CARNEGIE MELLON UNIVERSITY. Acme - The Acme Architectural Description Language and Design Environment. Site Oficial. Disponível Online em: http://www.cs.cmu.edu/ racme//. Acessado em: 03/03/2015.

ADAPTIVE TECHNOLOGY RESOURCE CENTRE, UNIVERSITY OF TORONTO.Web-4All. Site Oficial. Disponível Online em: http://web4all.ca/html/english/w4a_home_e. html. Acessado em: 01/02/2014.

CLEMENTS, P. C. A survey of architecture description languages. Proceedings of the 8th International Workshop on Software Specification and Design. p. 16-, 1996.

COETZEE, L.; BARNARD, E. Pattern recognition in service of people with disabilities. PRASA 2004, 2004. 
COETZEE, L.; VIVIERS, I.; BARNARD, E. Model based estimation for multi-modal user interface component selection. Proceedings of the 20th Annual Symposium of the Pattern Recognition Association of South Africa (PRASA 2009). p. 1-6, 2009.

COOLSMARTPHONE. What is Samsung Smart Pause and Smart Scroll? Disponível Online em: http://www.coolsmartphone.com/2013/03/15/ what-is-samsung-smart-pause-and-smart-scroll/. Acessado em: 03/10/2013.

COOPER, A. et al. About Face: The essentials of interaction design. [S.I.]: John Wiley \& Sons, 2014.

COSTA-PAZO, A. et al. Gesture-controlled interfaces for people with disabilities.

COTE-MUNOZ, J. A. Aida: an adaptive system for interactive drafting and cad applications. In: Adaptive User Interfaces: Principles and Practice. Adaptive User Interfaces: Principles and Practice. Amsterdam: North-Holland, 1993. p. 225-240.

DíAZ, A.; GERVáS, P. Dynamic user modeling in a system for personalization of web contents. In: Current Topics in Artificial Intelligence. Current Topics in Artificial Intelligence. [S.I.]: Springer Berlin Heidelberg, 2004. (Lecture Notes in Computer Science, v. 3040), p. 281-290.

DEY, A. K. Understanding and using context. Personal Ubiquitous Comput., London, UK, UK, Springer-Verlag, v. 5, n. 1, p. 4-7, jan. 2001. 4 p. DOI: 10.1007/s007790170019.

DEY, A. K.; ABOWD, G. D. Towards a better understanding of context and contextawareness. Proceedings of the 1st international symposium on Handheld and Ubiquitous Computing. p. 304-307, 1999.

DJENIDI, H. et al. Generic multimedia multimodal agents paradigms and their dynamic reconfiguration at the architectural level. EURASIP J. Appl. Signal Process., New York, NY, United States, Hindawi Publishing Corp., v. 2004, p. 1688-1707, jan. 2004. 20 p. DOI: 10.1155/S1110865704402212.

DOUCE, C.; PORCH, W.; COOPER, M. Adapting e-learning and learning services for people with disabilities. 2010.

DOURISH, P.; BELL, G. "Resistance is futile": reading science fiction alongside ubiquitous computing. Personal and Ubiquitous Computing, Springer-Verlag, p. 1-10, 2013.

DRUMEA, A.; POPESCU, C. Finite state machines and their applications in software for industrial control. Electronics Technology: Meeting the Challenges of Electronics Technology Progress, 2004. 27th International Spring Seminar on. v. 1, p. 25-29, 2004. 
DUMAS, B.; LALANNE, D.; OVIATT, S. Human machine interaction. In: . Berlin, Heidelberg: Springer-Verlag, 2009. cap. Multimodal Interfaces: A Survey of Principles, Models and Frameworks, p. 3-26.

EMMERICH, W. Software engineering and middleware: a roadmap. Proceedings of the Conference on the Future of Software Engineering. p. 117-129, 2000.

FACEBOOK INC. Facebook Accessibility. Disponível Online em: https://www.facebook. com/accessibility. Acessado em: 03/09/2015.

FERBER, J.; GUTKNECHT, O. A meta-model for the analysis and design of organizations in multi-agent systems. Multi Agent Systems, 1998. Proceedings. International Conference on. p. 128-135, Jul 1998. DOI: 10.1109/ICMAS.1998.699041.

FISCHER, G. User modeling in human-computer interaction. User Modeling and UserAdapted Interaction, Kluwer Academic Publishers, v. 11, n. 1-2, p. 65-86, 2001. DOI: 10.1023/A:1011145532042.

FRIEDEWALD, M.; COSTA, O. Science and Technology Roadmapping: Ambient Intelligence in Everyday Life (AmI@Life). [S.I.]: Fraunhofer Institut für Systemtechnik und Innovationsforschung, 2003.

GARLAN, D.; MONROE, R.; WILE, D. Acme: an architecture description interchange language. Proceedings of the 1997 Conference of the Centre for Advanced Studies on Collaborative Research. p. 7-, 1997.

GENESERETH, M. R.; KETCHPEL, S. P. Software agents. Commun. ACM, v. 37, n. 7, p. 48-53, 1994.

GOOGLE INC. Google Accessibility. Disponível Online em: https://www.google.com/ accessibility/index.html. Acessado em: 03/03/2014.

SECRETARIA DOS DIREITOS DA PESSOA COM DEFICIÊNCIA. Site Oficial. Disponível Online em: http://www.pessoacomdeficiencia.sp.gov.br/. Acessado em : $11 / 11 / 2015$.

GRAçA, D. M.; GUERREIRO, T.; JORGE, J. A. Easyhouse: a multimodal domotic system for the tetraplegic. Interacção 2008 - Terceira Conferência Nacional em Interacção Pessoa-Máquina. v. 2008, October 2008.

HAKKENS,D. Phoneblocks. Site Oficial. Disponível Online em: https://phonebloks. com/. Acessado em: 01/11/2013. 
HARA, N.; NAKA, T.; HARADA, E. T. How can we make it appliances easy for older adults?: usability studies of electronic program guide system. In: Human-Computer Interaction. Human-Computer Interaction. [S.I.: s.n.], 2009. p. 369-388.

HAYKIN, S. Neural Networks: A Comprehensive Foundation. 2nd. ed. Upper Saddle River, NJ, USA: Prentice Hall PTR, 1998.

HEIM, S. The Resonant Interface: HCI Foundations for Interaction Design. Boston, MA, USA: Addison-Wesley Longman Publishing Co., Inc., 2007.

HINA, M. D. et al. A multi-agent based multimodal system adaptive to the user's interaction context. InTech, 2011. DOI: 10.5772/14692.

HOLLAND, J. H.; MILLER, J. H. Artificial adaptive agents in economic theory. The American Economic Review, American Economic Association, v. 81, n. 2, p. pp. 365-370, 1991.

HONG, J.-y.; SUH, E.-h.; KIM, S.-J. Context-aware systems: a literature review and classification. Expert Systems with Applications, Tarrytown, NY, USA, Pergamon Press, Inc., v. 36, n. 4, p. 8509-8522, maio 2009. 14 p. DOI: 10.1016/j.eswa.2008.10.071.

(IBGE), I. B. de Geografia e(Ed.). Censo Demográfico 2010: Características gerais da população, religião e pessoas com deficiência. [S.I.]: Instituto Brasileiro de Geografia e Estatística, 2010.

INTERNATIONAL CONFERENCE ON COMPUTERS HELPING PEOPLE WITH SPECIAL NEEDS. Site Oficial. Disponível Online em: http://www.icchp.org/. Acessado em : 03/09/2015.

INREDIS. Site Oficial. Disponível Online em: http://www.inredis.es/. Acessado em: 03/03/2014.

International Business Machine, IBM. IBM Training Manual. [S.I.: s.n.], 1991.

IWAI, M. K.; NETO, J. J. Introdução às Gramáticas Adaptativas. [S.I.]: Departamento de Engenharia de Computação e Sistemas Digitais, 2001. (Boletim Técnico).

JAIMES, A.; SEBE, N. Multimodal human-computer interaction: a survey. Computer Vision and Image Understanding, v. 108, n. 1-2, p. 116 - 134, 2007. DOI: http://dx.doi.org/10.1016/j.cviu.2006.10.019. Special Issue on Vision for Human-Computer Interaction.

JAMESON, A. Adaptive interfaces and agents. Human-Computer Interaction: Design Issues, Solutions, and Applications, CRC Press, v. 105, 2009. 
JANARTHANAM, S.; LEMON, O. Adaptive generation in dialogue systems using dynamic user modeling. Computational Linguistics, MIT Press, v. 40, n. 4, p. 883-920, 2014.

JUN, K.; SUNG, M.; CHOI, B. Steering behavior model of visitor npcs in virtual exhibition. In: Advances in Artificial Reality and Tele-Existence. Advances in Artificial Reality and Tele-Existence. [S.I.]: Springer, 2006. p. 113-121.

JUNIOR, P. T. A.; FILGUEIRAS, L. V. L. User modeling with personas. Proceedings of the 2005 Latin American conference on Human-computer interaction. p. 277-282, 2005.

KARPOV, A.; RONZHIN, A. Icando: low cost multimodal interface for hand disabled people. Journal on Multimodal User Interfaces, Springer-Verlag, v. 1, p. 21-29, 2007. DOI: 10.1007/BF02910056.

KARPOV, A. et al. Multimodal system for hands-free pc control. Proceedings of 13th European Signal Processing Conference EUSIPCO-2005. v. 1, p. 213-216, 2005.

KIM, J.-H.; HONG, K.-S. Improved multi-modal recognition interface for intelligent hci based on speech and the kssl recognition. Speaker and Language Recognition Workshop, 2006. IEEE Odyssey 2006: The. p. 1-6, June. DOI: 10.1109/ODYSSEY.2006.248108.

KOGUT, P.; CLEMENTS, P. Features of architecture description languages. In Proceedings of the Eighth International Workshop on Software Specification and Design. $p$. 16-25, 1994.

KRUPITZER, C. et al. A survey on engineering approaches for self-adaptive systems. Pervasive and Mobile Computing, v. 17, Part B, p. 184 - 206, 2015. DOI: http://dx.doi.org/10.1016/j.pmcj.2014.09.009 10 years of Pervasive Computing' In Honor of Chatschik Bisdikian.

LANE, N. et al. A survey of mobile phone sensing. Communications Magazine, IEEE, v. 48, n. 9, p. 140-150, Sept 2010. DOI: 10.1109/MCOM.2010.5560598.

LEBLOIS, A.(Ed.). World Summit on the Information Society (WSIS). [S.I.]: The Global Initiative for Inclusive Information and Communications Technologies, UNESCO, 2013.

LECKY-THOMPSON, G. W. Al and Artificial Life in Video Games. 1. ed. Rockland, MA, USA: Charles River Media, Inc., 2008. 125-128 p.

LEE, H.; CHOI, Y. S.; KIM, Y.-J. An adaptive user interface based on spatiotemporal structure learning. Communications Magazine, IEEE, IEEE, v. 49, n. 6, p. 118-124, 2011.

LIEBERHERR, K. Adaptive object-oriented software the demeter method. PWS Boston, 1996. 
LóPEZ-JAQUERO, V.; MONTERO, F.; GONZáLEZ, P. Ab-hci: an interface multi-agent system to support human-centred computing. IET software, IET, v. 3, n. 1, p. 14-25, 2009.

LUCK, M.; MCBURNEY, P.; PREIST, C. Agent technology: enabling next generation computing (a roadmap for agent based computing). [S.I.]: AgentLink/University of Southampton, 2003.

MACíAS-ESCRIVá, F. D. et al. Self-adaptive systems: a survey of current approaches, research challenges and applications. Expert Systems with Applications, v. 40, n. 18, p. 7267 - 7279, 2013. DOI: http://dx.doi.org/10.1016/j.eswa.2013.07.033.

MALINOWSKY, C.; NYGaRD, L.; KOTTORP, A. Psychometric evaluation of a new assessment of the ability to manage technology in everyday life. Scandinavian Journal of Occupational Therapy, v. 18, n. 1, p. 26-35, 2011. DOI: 10.3109/11038120903420606. PMID: 20001642.

MALLOUK, W.; CLUA, E. An object-oriented approach for hierarchical state machines. Proceedings of the SBGames conference in Computing. p. 8-10, 2006.

MATHEUS, C. J. Position paper: using ontology-based rules for situation awareness and information fusion. Rule Languages for Interoperability. 2005.

MCTEAR, M. User modelling for adaptive computer systems: a survey of recent developments. Artificial Intelligence Review, Kluwer Academic Publishers, v. 7, n. 3-4, p. 157184, 1993. DOI: $10.1007 /$ BF00849553.

MEDVIDOVIC, N.; TAYLOR, R. N. A classification and comparison framework for software architecture description languages. Software Engineering, IEEE Transactions on, IEEE, v. 26, n. 1, p. $70-93,2000$.

MICROSOFT CORPORATION. Microsoft Accessibility: Technology for Everyone. Site Oficial. Disponível Online em: http://www.microsoft.com/enable/default.aspx. Acessado em: 03/03/2014.

MIT ASSISTIVE TECHNOLOGY CLUB. Site Oficial. Disponível Online em: http://assistivetech.mit.edu/assistivetech/website/index.html. Acessado em : 03/09/2015.

MYNATT, E.; EDWARDS, W. K. The Mercator Environment: A Nonvisual Interface to $X$ Windows and Unix Workstations. [S.I.: s.n.], 1992.

NATIONS, I. T. U. Declaration of Principles. [S.I.]: United Nations, 2003. (World Summit on The Information Society - WSIS). 
NATIONS, U.(Ed.). The Universal Declaration of Human Rights. [S.I.]: United Nations, 1948.

NATIONS, U.(Ed.). Convention on the Rights of Persons with Disabilities. [S.I.]: United Nations, 2006.

NETO, J. J. Adaptive automata for context-dependent languages. SIGPLAN Not., New York, NY, USA, ACM, v. 29, n. 9, p. 115-124, set. 1994. 10 p. DOI: 10.1145/185009.185033.

NETO, J. J. Adaptative rule-driven devices - general formulation anda case study. In CIAA'2001 Sixth International Conference on Implementation and Application of Automata. p. 234-250, 2001.

NETO, J. J. Um levantamento da evolução da adaptatividade e da tecnologia adaptativa. IEEE Latin America Transactions, IEEE, v. 5, n. 7, p. 496-505, November 2007.

NETO, J. J.; ALMEIDA, J. J. R.; SANTOS, J. M. Novaes dos. Synchronized statecharts for reactive systems. In Proceedings of the IASTED International Conference on Applied Modelling and Simulation. p. 246-251, 1998.

NIELSEN, J. Usability Engineering. San Francisco, CA, USA: Morgan Kaufmann Publishers Inc., 1993.

NUANCE COMMUNICATIONS. Site Oficial. Disponível Online em: http://www.nuance. com/index.htm. Acessado em: 03/04/2014.

NWANA, H. S. Software agents: an overview. The knowledge engineering review, Cambridge Univ Press, v. 11, n. 03, p. 205-244, 1996.

OLIVEIRA, F. et al. The haptic deictic system-hds: bringing blind students to mainstream classrooms. Haptics, IEEE Transactions on, v. 5, n. 2, p. 172-183, April-June. DOI: 10.1109/TOH.2011.35

ORGANIZATION, W. H. International Classification of Functioning, Disability, and Health: Children \& Youth Version: ICF-CY. [S.I.]: World Health Organization, 2007.

PAOLINO, L. et al. Dynamic user modeling for personalized advertisement delivery on mobile devices. In: Information Systems: Modeling, Development, and Integration. Information Systems: Modeling, Development, and Integration. [S.I.]: Springer Berlin Heidelberg, 2009. (Lecture Notes in Business Information Processing, v. 20), p. 508-513.

PAPAZOGLOU, M. Service-oriented computing: concepts, characteristics and directions. Web Information Systems Engineering, 2003. WISE 2003. Proceedings of the Fourth International Conference on. p. 3-12, Dec 2003. DOI: 10.1109/WISE.2003.1254461. 
PEDRAZZI, T. Um ambiente de desenvolvimento baseado em tabelas de decisão adaptativas. 2007. Dissertação (Mestrado) — Universidade de São Paulo, Escola Politécnica, Departamento de Engenharia de Computação e Sistemas Digitais.

PEREZ, G.; AMORES, G.; MANCHON, P. A multimodal architecture for home control by disabled users. p. 134-137, Dec. DOI: 10.1109/SLT.2006.326836.

PERSSON, M. Adaptive Middleware for Self-Configurable Embedded Real-Time Systems : Experiences from the DySCAS Project and Remaining Challenges. [S.I.]: KTH, 2009. xv, 76 p. (Trita-MMK, 2009:22).

PFLüCKER, O.; NETO, J. J. Gama-nw: un enfoque reutilizable para un metalenguaje y un metacompilador. Memórias de la XXXIII Conferencia Latinoamericana en Informática. 2007.

PINSDORF, U. Travelling actors multimodal interaction with mobile agents. 10th International Conference on Software, Telecommunications \& Computer Networks (SoftCOM 2002). University of Split, R. Boskovica, HR-21000 Split, Croatia: Faculty of Electrical Engineering, Mechanical Engineering and Naval Architecture. p. 355-360, 2002.

POUS, M.; CECCARONI, L. Multimodal interaction in distributed and ubiquitous computing. Internet and Web Applications and Services (ICIW), 2010 Fifth International Conference on. p. 457-462, May 2010. DOI: 10.1109/ICIW.2010.75.

POUS, M. et al. Enhancing accessibility: mobile to atm case study. Consumer Communications and Networking Conference (CCNC), 2012 IEEE. p. 404-408, Jan. DOI: 10.1109/CCNC.2012.6181024.

RAJKUMAR, N.; VINOD, V. Integrated educational information systems for disabled schools via a service bus using soa. Indian Journal of Science and Technology, v. 8, n. 13, 2015.

RAMIREZ, R. et al. A genetic rule-based model of expressive performance for jazz saxophone. Computer Music Journal, The MIT Press, v. 32, n. 1, p. pp. 38-50, 2008.

RAMOS, M. V. M.; NETO, J. J.; VEJA, Í. S. Linguagens Formais: teoria, modelagem e implementação. [S.I.]: Bookman, 2009.

RANGANATHAN, A.; CAMPBELL, R. H. A middleware for context-aware agents in ubiquitous computing environments. Proceedings of the ACM/IFIP/USENIX 2003 International Conference on Middleware. p. 143-161, 2003.

REINSBERG, H. Buzzfeed: Lefties Are Not Happy About The Apple Watch Lefty-ism!. Disponível Online em: http://www.buzzfeed.com/hillaryreinsberg/ 
lefties-are-not-happy-about-the-apple-watch\#17ovxap Acessado em: 09/09/2014.

REHABILITATION ENGINEERING AND ASSISTIVE TECHNOLOGY SOCIETY OF NORTH AMERICA. Site Oficial. Disponível Online em: http://www.resna.org/. Acessado em : 03/09/2015.

RICHTER, K.; ENGE, M. Multi-modal framework to support users with special needs in interaction with public information systems. In: Human-Computer Interaction with Mobile Devices and Services. Human-Computer Interaction with Mobile Devices and Services. [S.I.]: Springer Berlin Heidelberg, 2003. (Lecture Notes in Computer Science, v. 2795), p. $286-301$.

RICHTER, K.; HELLENSCHMIDT, M. Interacting with the ambience: multimodal interaction and ambient intelligence. W3C Workshop on Multimodal Interaction, v. 19, p. 20, 2004.

ROCHE, E.; SCHABES, Y. Finite-state language processing. [S.I.]: MIT press, 1997.

SADJADI, S. M. A Survey of Adaptive Middleware. [S.I.: s.n.], 2003.

SADRI, F. Ambient intelligence: a survey. ACM Comput. Surv., New York, NY, USA, ACM, v. 43, n. 4, p. 36:1-36:66, out. 2011. 66 p. DOI: 10.1145/1978802.1978815.

SARJOUGHIAN, H. S.; CELLIER, F. E. Discrete event modeling and simulation technologies: a tapestry of systems and Al-based theories and methodologies. [S.I.]: Springer Science \& Business Media, 2013. 99-102 p.

SAVIDIS, A.; STEPHANIDIS, C.; STERGIOU, A. Generic containers for metaphor fusion in non-visual interaction: the hawk interface toolkit. Proceedings of the Interfaces 1997 Conference. p. 194-196, 1997.

SCHLOERB, D. W. et al. Blindaid: virtual environment system for self-reliant trip planning and orientation and mobility training. Haptics Symposium, 2010 IEEE. p. 363-370, March. DOI: 10.1109/HAPTIC.2010.5444631

SCHMIDT, A.; BEIGL, M.; GELLERSEN, H.-W. There is more to context than location. Computers and Graphics, v. 23, n. 6, p. 893 - 901, 1999. DOI: http://dx.doi.org/10.1016/S0097-8493(99)00120-X.

SCHMIDT, D. C. Middleware for real-time and embedded systems. Commun. ACM, New York, NY, USA, ACM, v. 45, n. 6, p. 43-48, jun. 2002. 6 p. DOI: 10.1145/508448.508472. 
SECRETARIA NACIONAL DE PROMOÇÃO DOS DIREITOS DA PESSOA COM DEFICIÊNCIA. Site Oficial. Disponível Online em: http://www.pessoacomdeficiencia.gov.br/ app/. Acessado em : 03/03/2015.

SMEDA, A.; KHAMMACI, T.; OUSSALAH, M. Meta architecting: toward a new generation of architecture description languages. Journal of Computer Science, Science Publications, v. 1 , n. 4 , p. $454-460,2005$. DOI: $10.3844 /$ jcssp.2005.454.460.

STAV, E. et al. Development and evaluation of soa-based \{aal\} services in real-life environments: a case study and lessons learned. International Journal of Medical Informatics, v. 82, n. 11, p. e269 - e293, 2013. DOI: http://dx.doi.org/10.1016/j.ijmedinf.2011.03.007.

STEPHANIDIS, C.; EMILIANI, P. L. 'Connecting' to the information society: a european perspective. Technology and Disability, IOS Press, v. 10, n. 1, p. 21-44, January 1999.

STEPHANIDIS, C.; EMILIANI, P. L. Universal access to information society technologies: opportunities for people with disabilities. In: Computers Helping People with Special Needs. Computers Helping People with Special Needs. [S.I.]: Springer Berlin Heidelberg, 2002. (Lecture Notes in Computer Science, v. 2398), p. 8-10.

STEPHANIDIS, C. et al. Supporting interface adaptation: the avanti web-browser. IN PROC. OF THE 3RD ERCIM WORKSHOP ON USER INTERFACES FOR ALL. p. 3-4, 1997.

STEPHANIDIS, C. et al. Adaptable and adaptive user interfaces for disabled users in the avanti project. Proceedings of the 5th International Conference on Intelligence and Services in Networks: Technology for Ubiquitous Telecom Services. p. 153-166, 1998.

STEPHANIDIS, C.; SAVIDIS, A. Universal access in the information society: methods, tools, and interaction technologies. Universal Access in the Information Society, SpringerVerlag, v. 1, n. 1, p. 40-55, 2001. DOI: 10.1007/s102090100008.

SZYPERSKI, C. Component Software: Beyond Object-Oriented Programming. 2nd. ed. Boston, MA, USA: Addison-Wesley Longman Publishing Co., Inc., 2002.

TALEBIFARD, P.; LEUNG, V. C. A data fusion approach to context-aware service delivery in heterogeneous network environments. Procedia Computer Science, v. 5, n. 0, p. $312-$ 319, 2011.

TCHEMRA, A. H. Aplicação da tecnologia adaptativa em sistemas de tomada de decisão. IEEE America Latina, IEEE Computer Society Press, v. 5, n. 7, p. 552-556, November 2007. 
TONINELLI, A. et al. Rule-based and ontology-based policies: toward a hybrid approach to control agents in pervasive environments. Semantic Web and Policy Workshop. p. 42-54, 2005.

TURUNEN, M. et al. Accessible speech-based and multimodal media center interface for users with physical disabilities. Proceedings of the Second international conference on Development of Multimodal Interfaces: active Listening and Synchrony. p. 66-79, 2010.

VANDERHEIDEN, G.; TREVIRANUS, J. Universal access in human-computer interaction. design for all and einclusion. In: UNIVERSAL access in human-computer interaction. design for all and einclusion. [S.I.]: Springer Berlin Heidelberg, 2011. (Lecture Notes in Computer Science, v. 6765), cap. Creating a Global Public Inclusive Infrastructure, p. 517-526.

VANTHIENEN, J.; DRIES, E. Developments in decision tables: evolution, applications and a proposed standard. DTEW Research Report 9227, 1992.

VELSEN, L. et al. User-centered evaluation of adaptive and adaptable systems: a literature review. The Knowledge Engineering Review, v. 23, p. 261-281, 9 2008. 21 p. DOI: $10.1017 /$ S0269888908001379.

VERSTOCKT, S. et al. Assistive smartphone for people with special needs: the personal social assistant. Human System Interactions, 2009. HSI '09. 2nd Conference on. p. 331-337, May. DOI: 10.1109/HSI.2009.5091001.

WANG, A. J. A.; QIAN, K. Component-oriented programming. [S.I.]: John Wiley \& Sons, 2005.

WARDEN, J. Finite State Machine in Game Development. Disponível Online em:http://jessewarden.com/2012/07/finite-state-machines-in-game-development.html.

Acessado em: 03/03/2015.

WEARABLE COMPUTING ORGANIZATION. Definition of Wearable Computing. Disponível Online em: http://wearcomp.org/wearcompdef.html. Acessado em: 03/08/2014.

WEI, L.; HU, H. Teechnical Report CES-510: Towards Multimodal Human-Machine Interface for Hands-free Control: A survey. [S.I.: s.n.], 2011.

WEISER, M. The computer for the 21st century. SIGMOBILE Mob. Comput. Commun. Rev., New York, NY, USA, ACM, v. 3, n. 3, p. 3-11, jul. 1999. 9 p. DOI: $10.1145 / 329124.329126$.

WELD, D. S. et al. Automatically personalizing user interfaces. Proceedings of the 18th International Joint Conference on Artificial Intelligence. p. 1613-1619, 2003. 
WOOLDRIDGE, M. Agent-based software engineering. IEE Proceedings-software, IET, v. 144, n. 1, p. $26-37,1997$.

World Health Organization; World Bank. World report on disability. World Health Organization, 2011.

WORLD WIDE WEB CONSORTIUM (W3C). XML Tutorial. Disponível Online em: http: //www.w3schools.com/xml/xml_whatis.asp. Acessado em: 06/04/2015.

XIAO-QIN, L. et al. A rule-based ontology for context-aware computing. Biomedical Engineering and Informatics, 2009. BMEl '09. 2nd International Conference on. p. 1-4, Oct 2009 .

YU, W.; KANGAS, K.; BREWSTER, S. Web-based haptic applications for blind people to create virtual graphs. Haptic Interfaces for Virtual Environment and Teleoperator Systems, 2003. HAPTICS 2003. Proceedings. 11th Symposium on. p. 318-325, March. DOI: 10.1109/HAPTIC.2003.1191301.

ZHONG, X.; FU, H.; JIANG, Y. Coupling ontology with rule-based theorem proving for knowledge representation and reasoning. In: Database Theory and Application, BioScience and Bio-Technology. Database Theory and Application, Bio-Science and Bio-Technology. [S.I.]: Springer Berlin Heidelberg, 2010. (Communications in Computer and Information Science, v. 118), p. 110-119. 
152

\section{Apêndice A - Mapa Conceitual da Revisão da Literatura}

A finalidade deste Anexo é fazer uma apresentação gráfica das áreas relacionadas e dos conceitos pesquisados como parte da revisão da literatura a maneira de expor a natureza interdis-

ciplinar do assunto deste trabalho e fornecer uma visão macroscópica, porém organizada, do aporte de cada uma para o desenvolvimento do projeto.

A continuação são apresentados são apresentados os mapas conceituais que refletem a revisão da literatura. A elaboração das figuras a seguir foi feita com a ferramenta MindMup. 
Figura 39 - Principais conceitos pesquisados na revisão da literatura

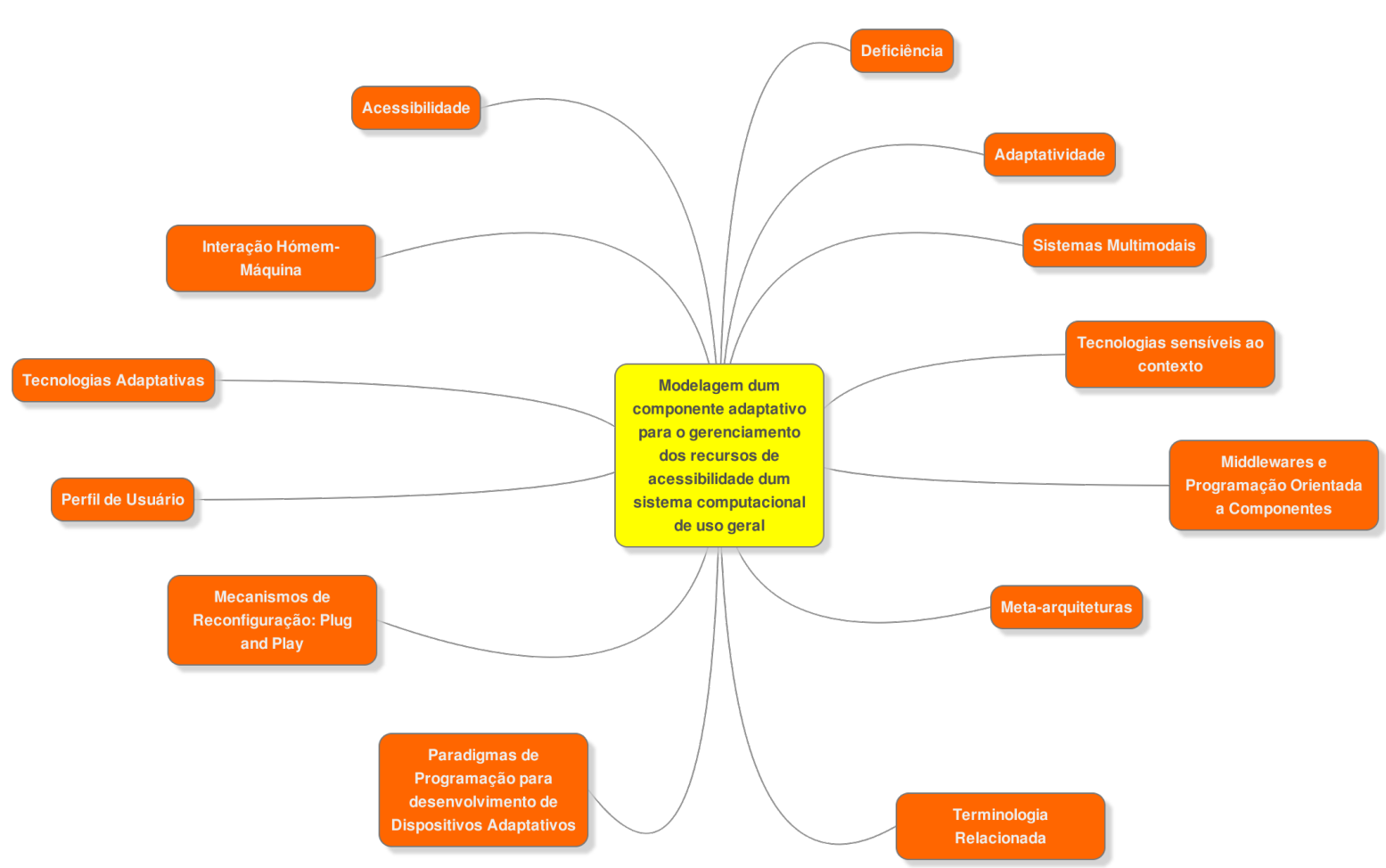

Fonte: Autora 
Figura 40 - Detalhe da revisão feita ao respeito de Acessibilidade

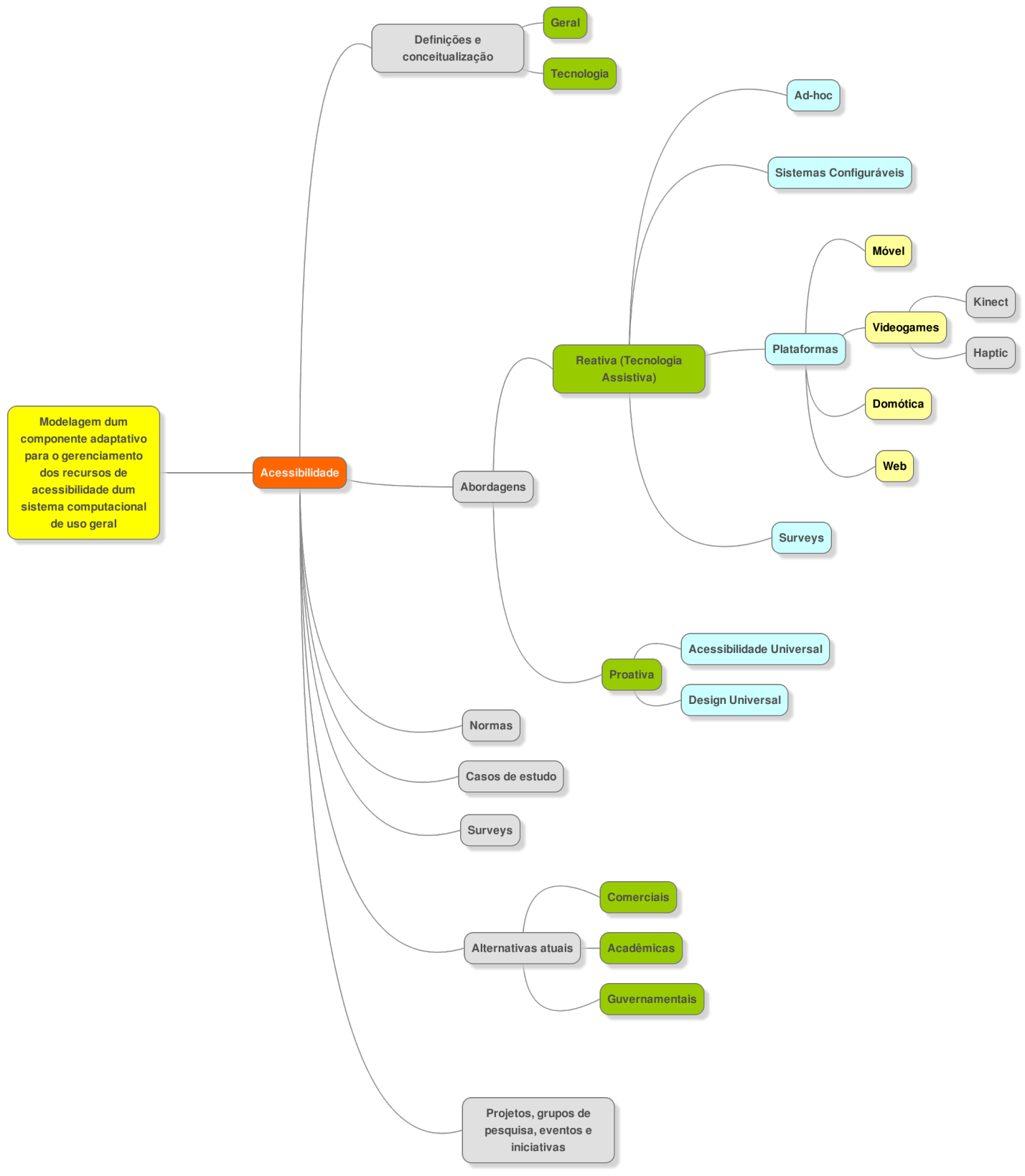

Fonte: Autora 
Figura 41 - Detalhe da revisão feita ao respeito de Adaptatividade

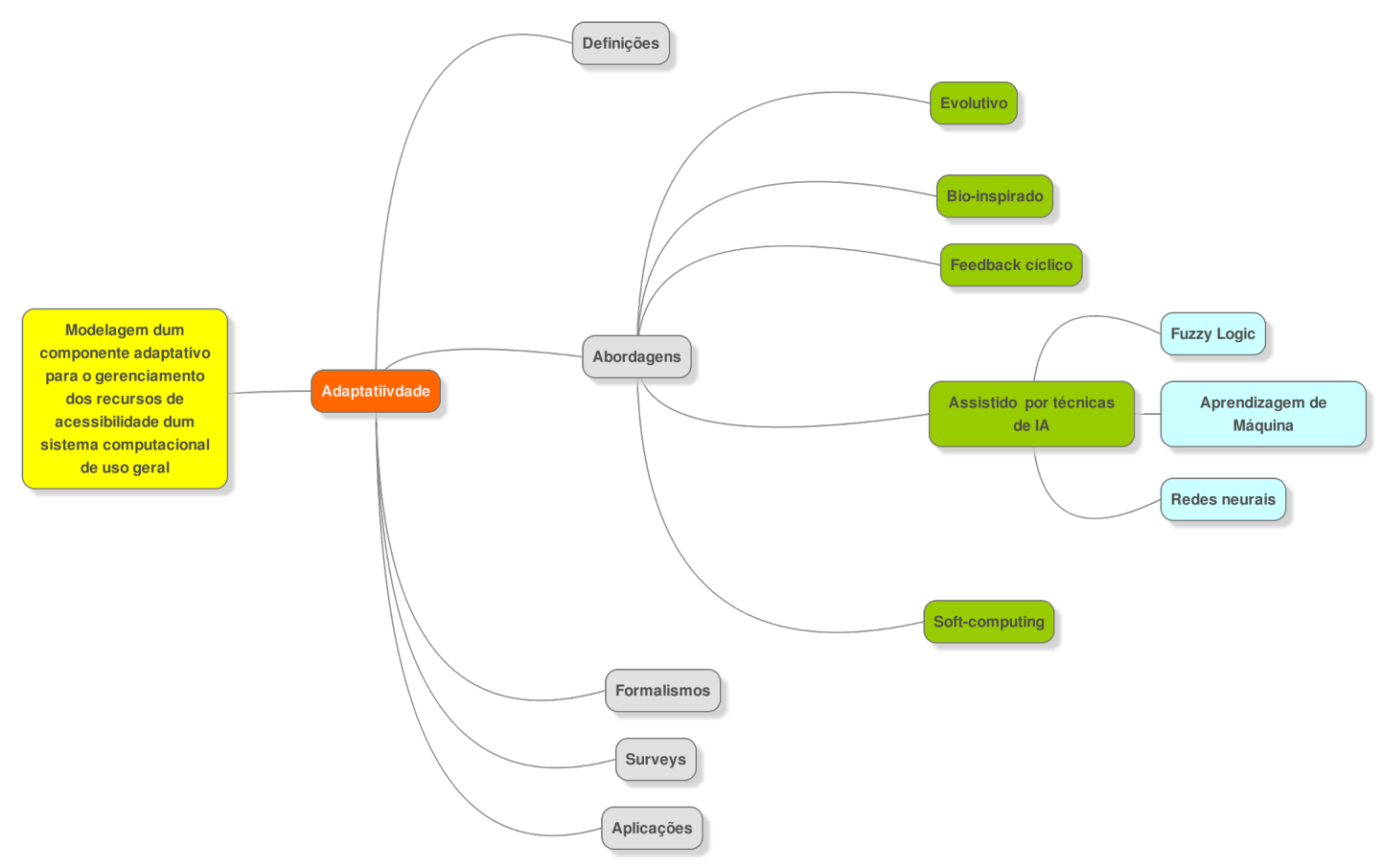

Fonte: Autora 


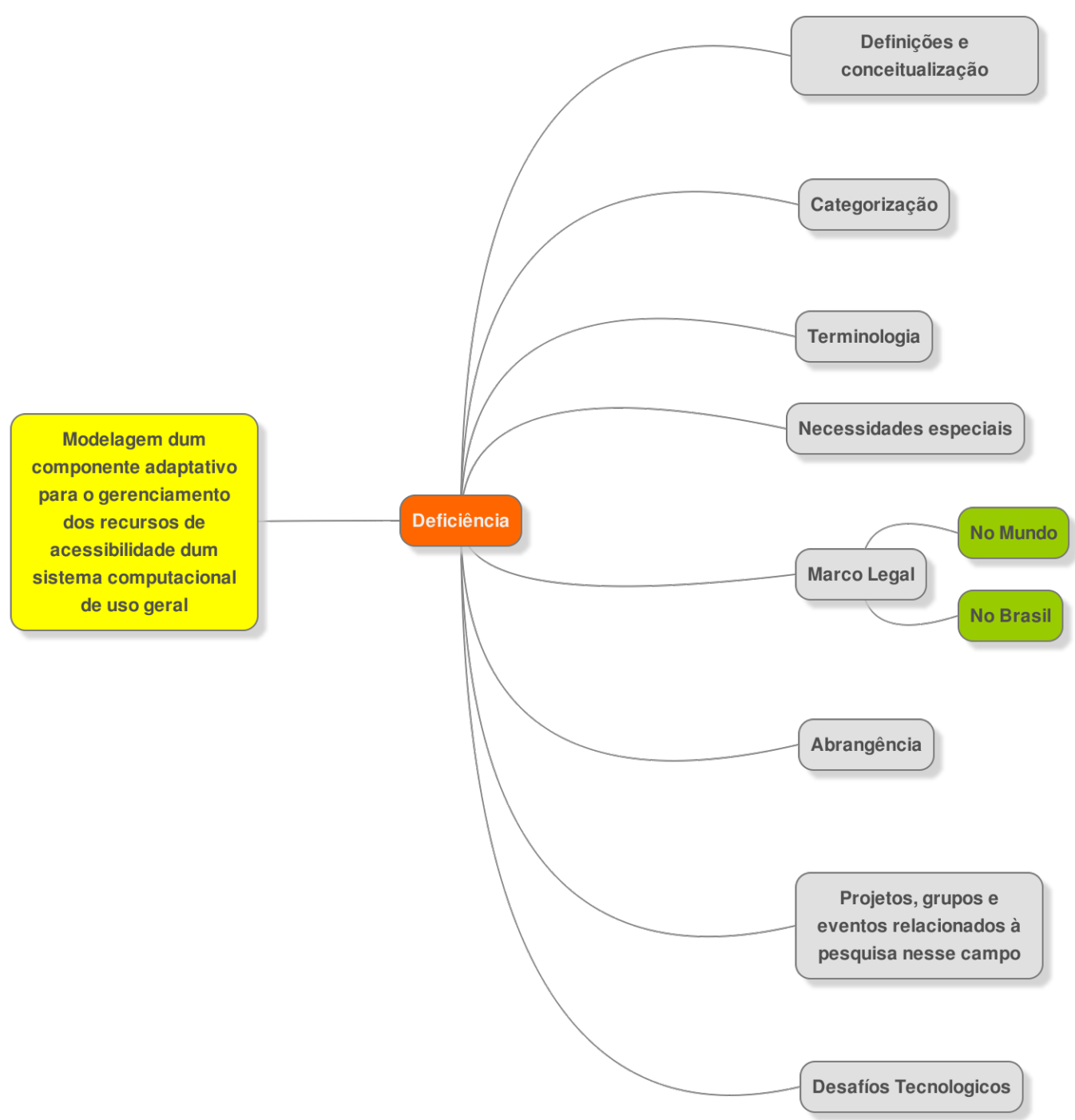

Fonte: Autora 
Figura 43 - Detalhe da revisão feita ao respeito de Interação Hómem-Máquina

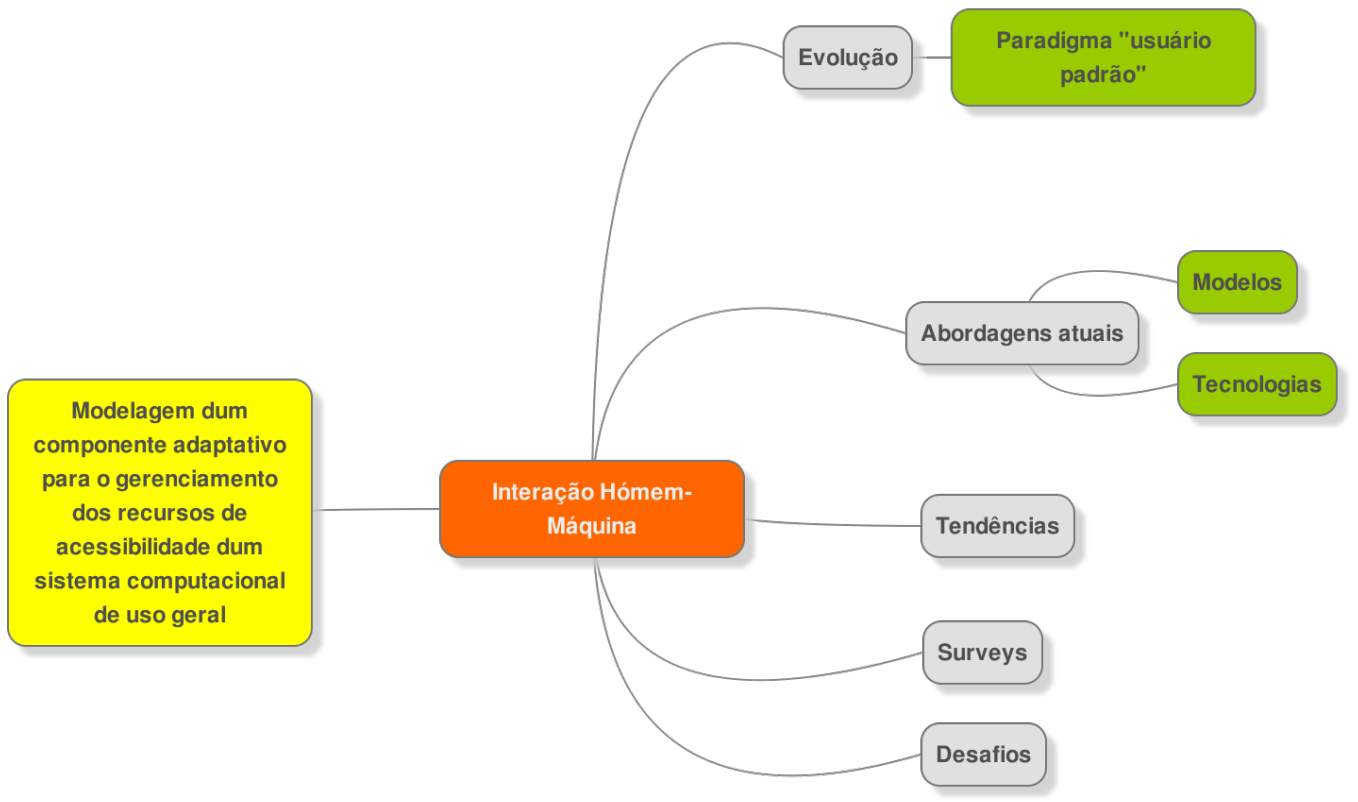

Fonte: Autora 


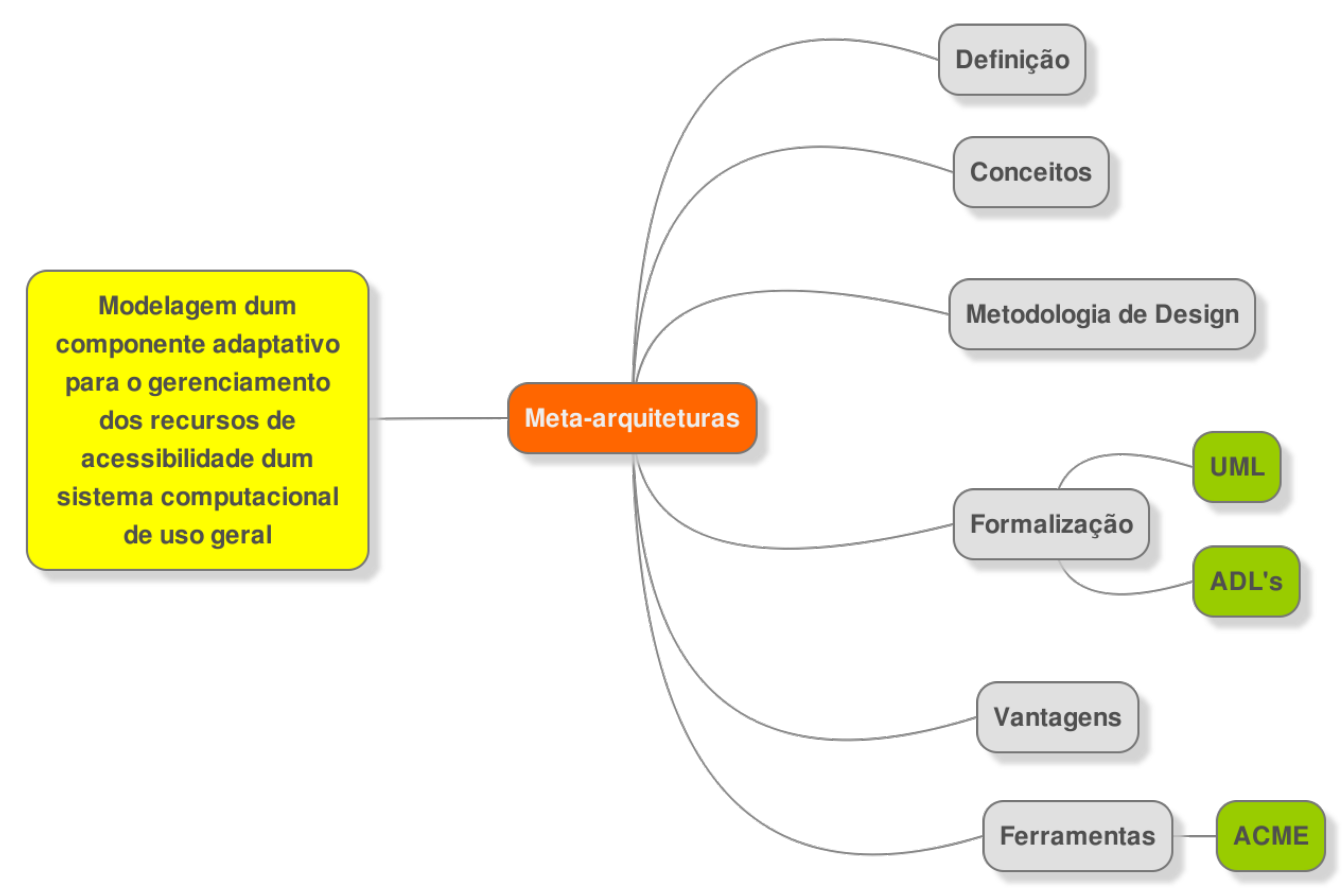

Fonte: Autora 
Figura 45 - Detalhe da revisão feita ao respeito do desenvolvimento de Middlewares sob o paradigma de Programação orientada a componentes

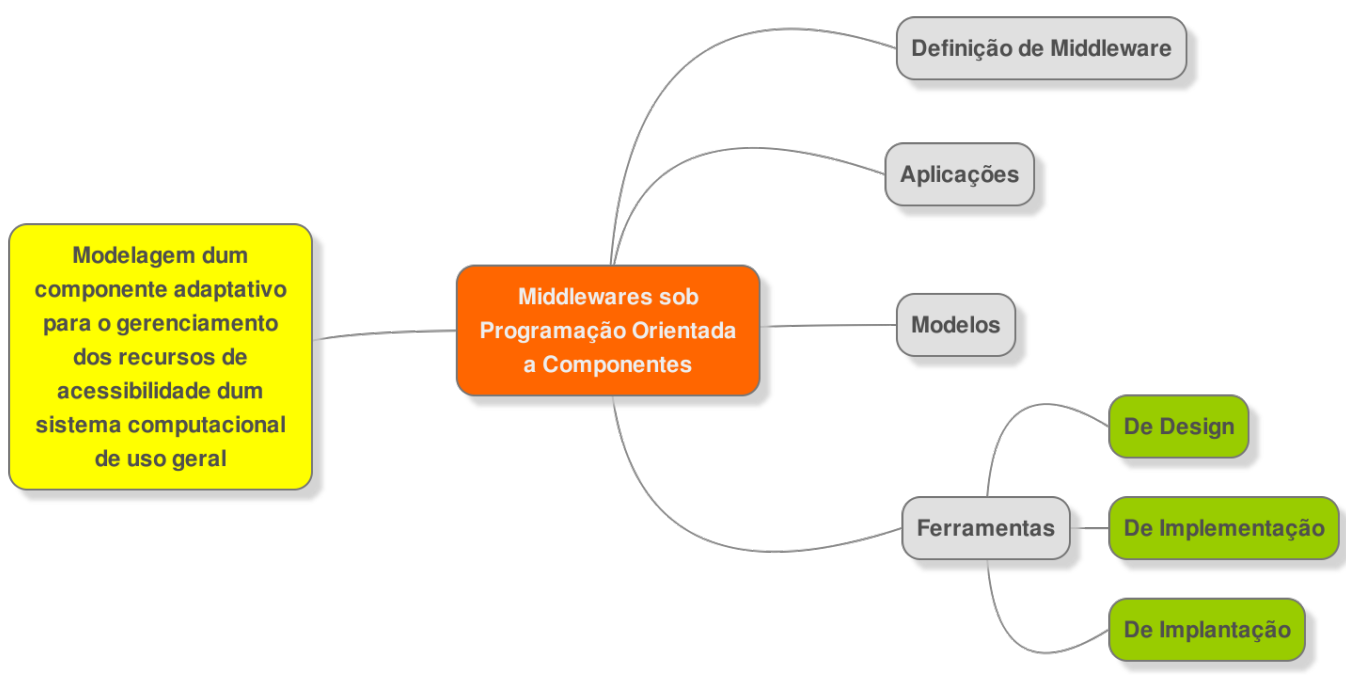

Fonte: Autora 


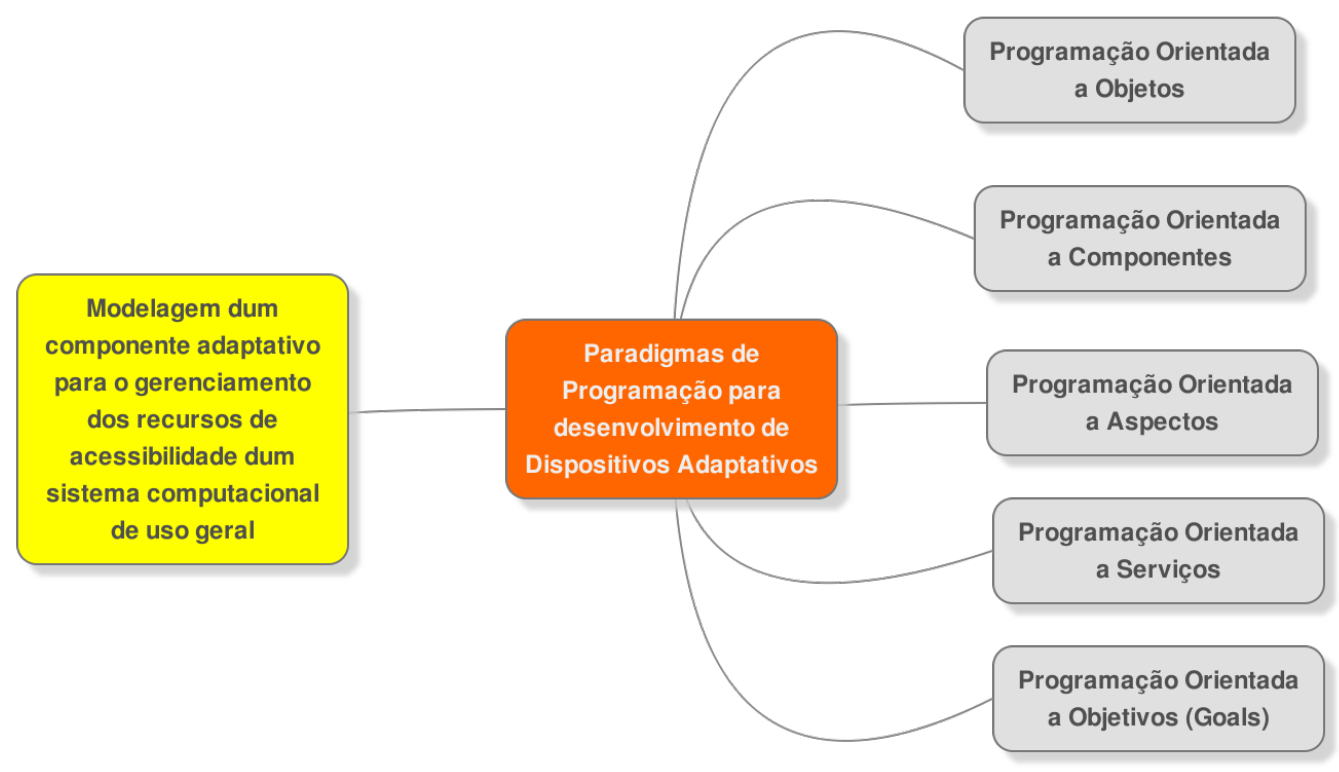

Fonte: Autora 
Figura 47 - Detalhe da revisão feita ao respeito aos Perfis de Usuário

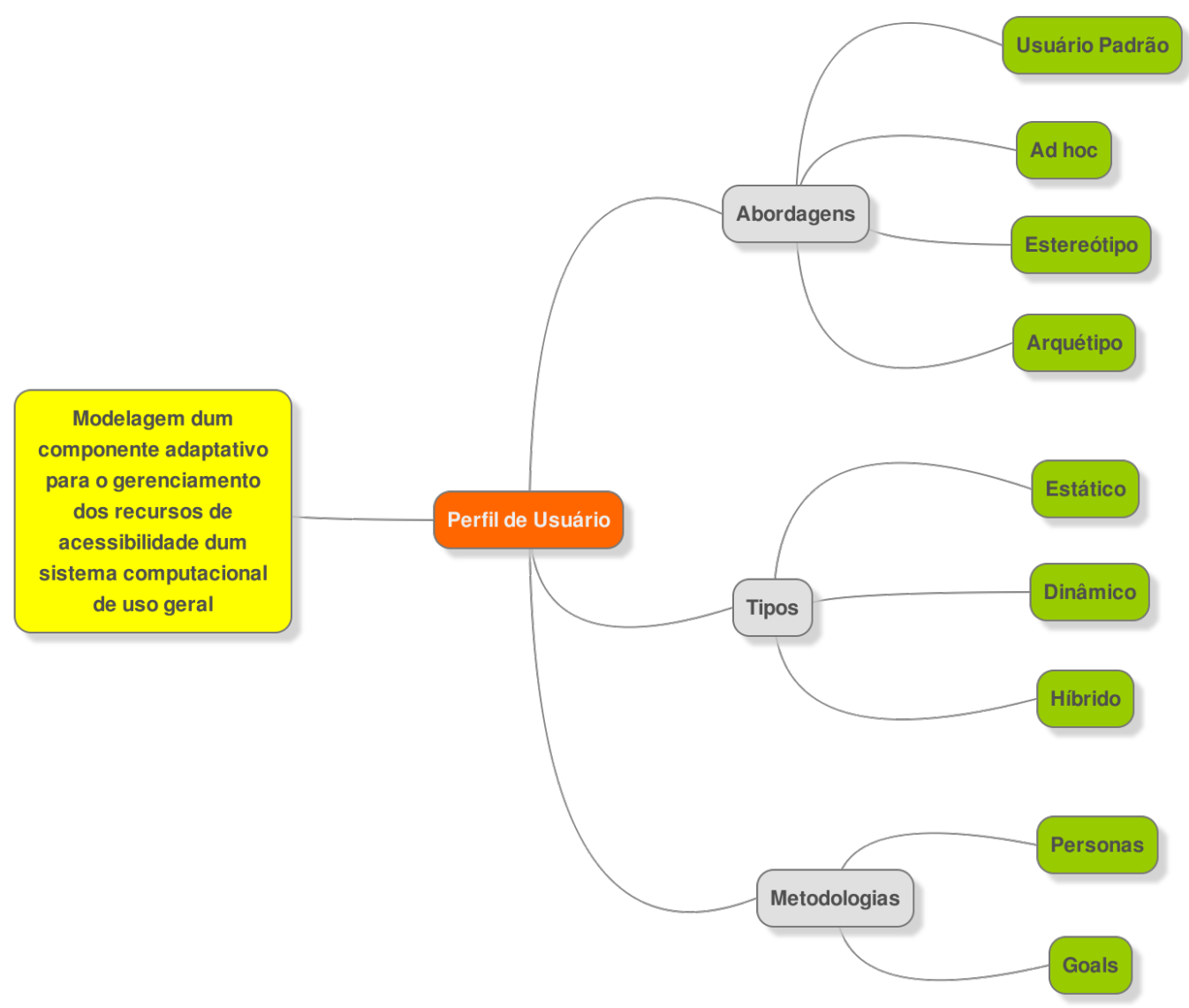

Fonte: Autora 


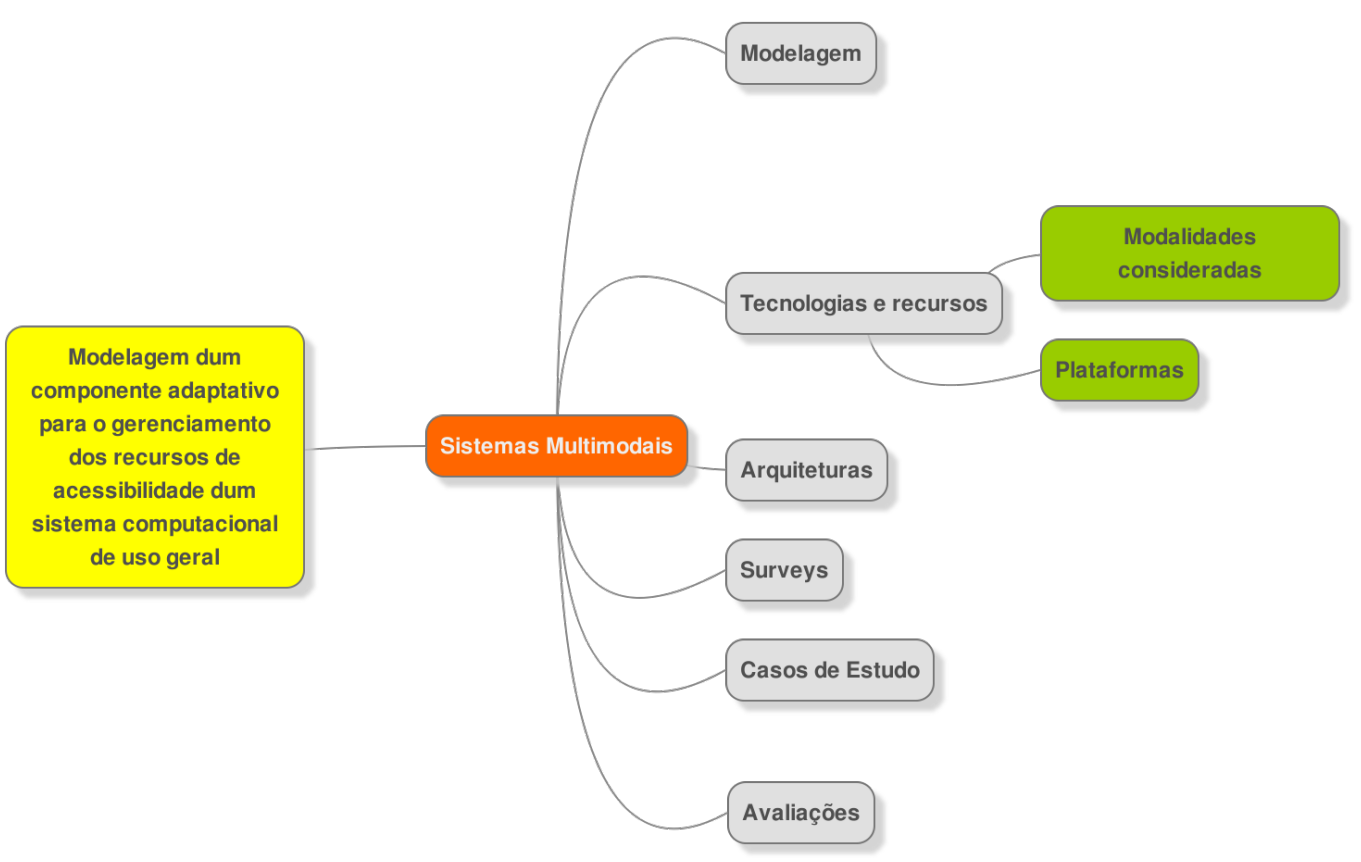

Fonte: Autora 
Figura 49 - Detalhe da revisão feita ao respeito do mecanismo de reconfiguração Plug-and-Play

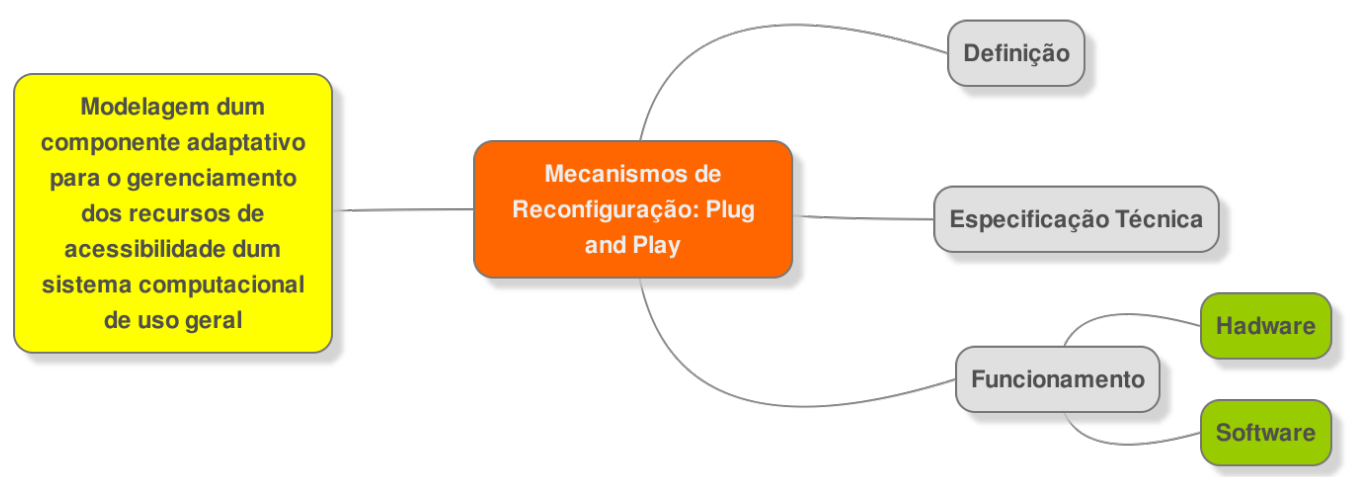

Fonte: Autora 


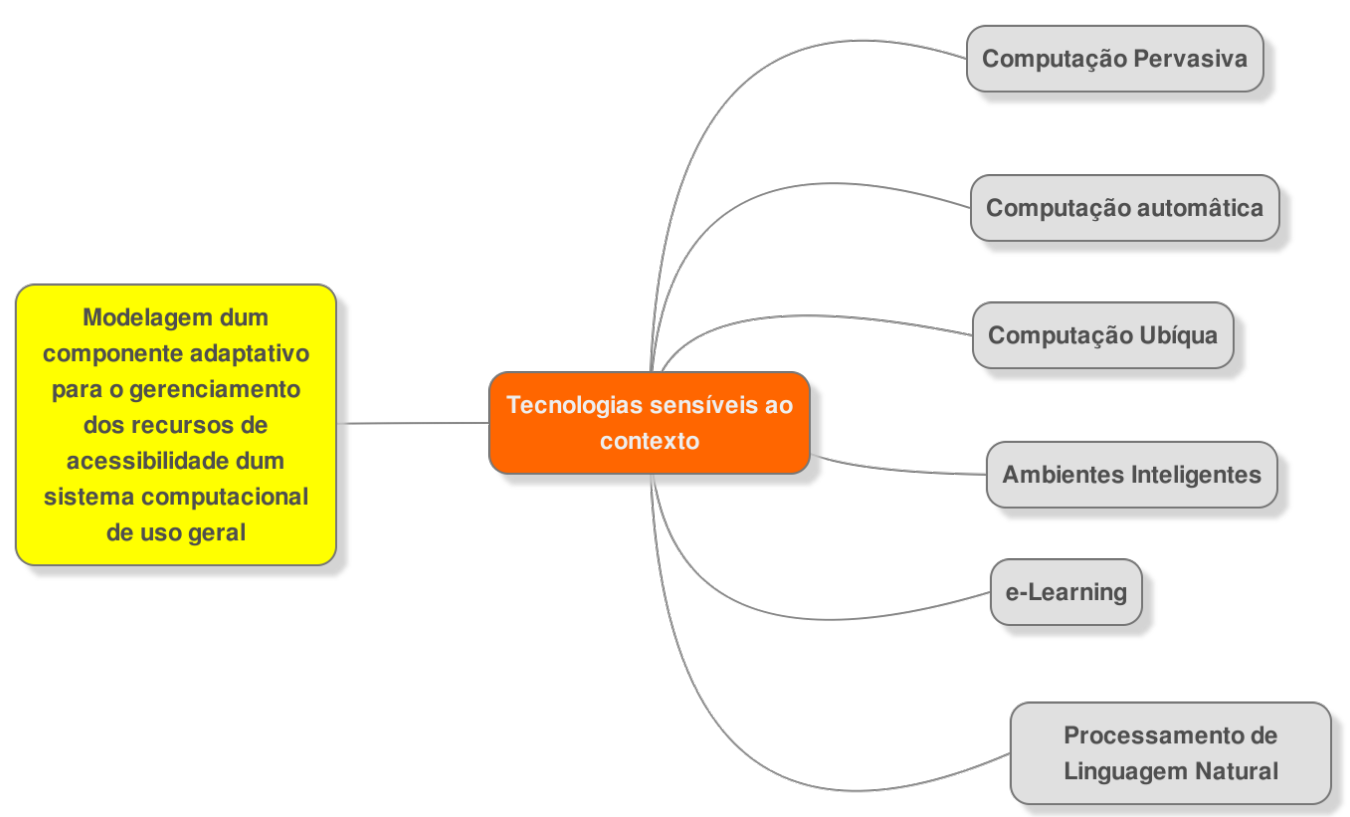

Fonte: Autora 
Figura 51 - Detalhe da revisão feita ao respeito das Tecnologias Adaptativas

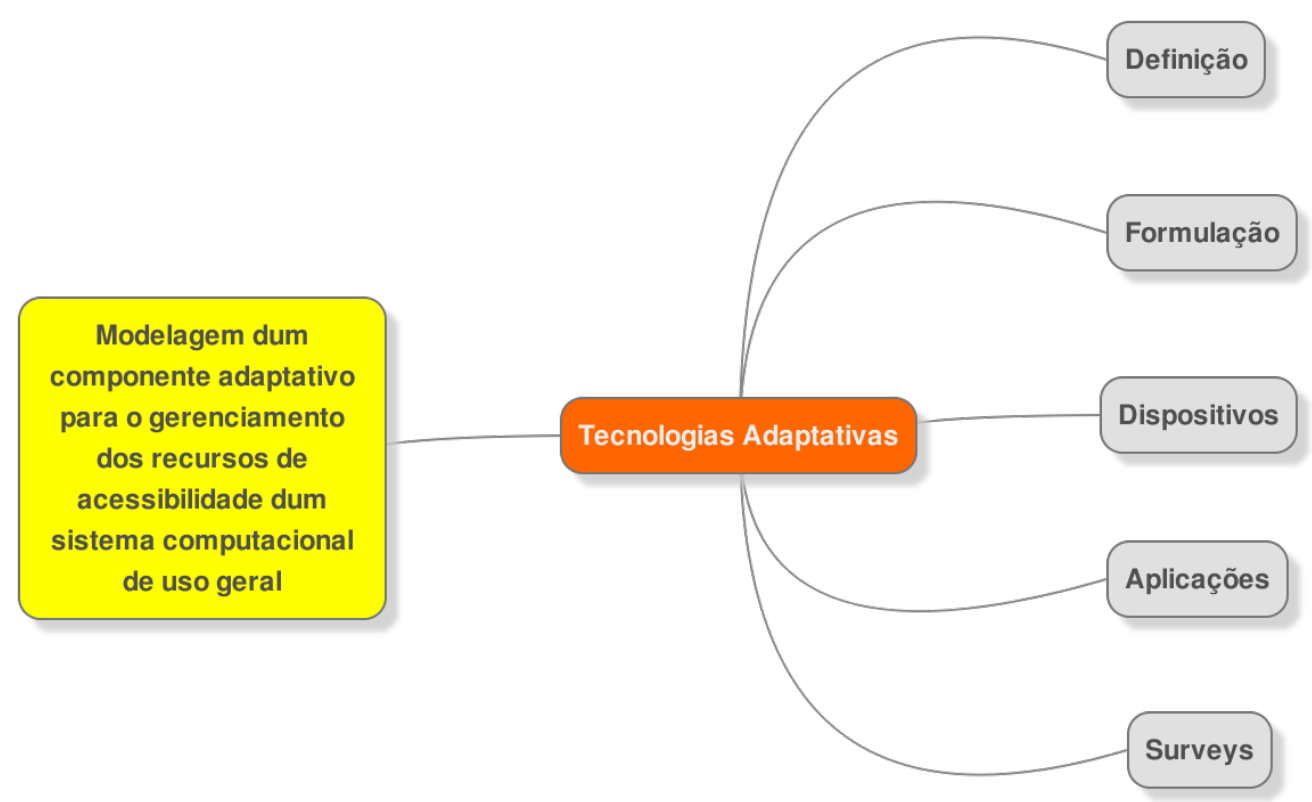

Fonte: Autora 


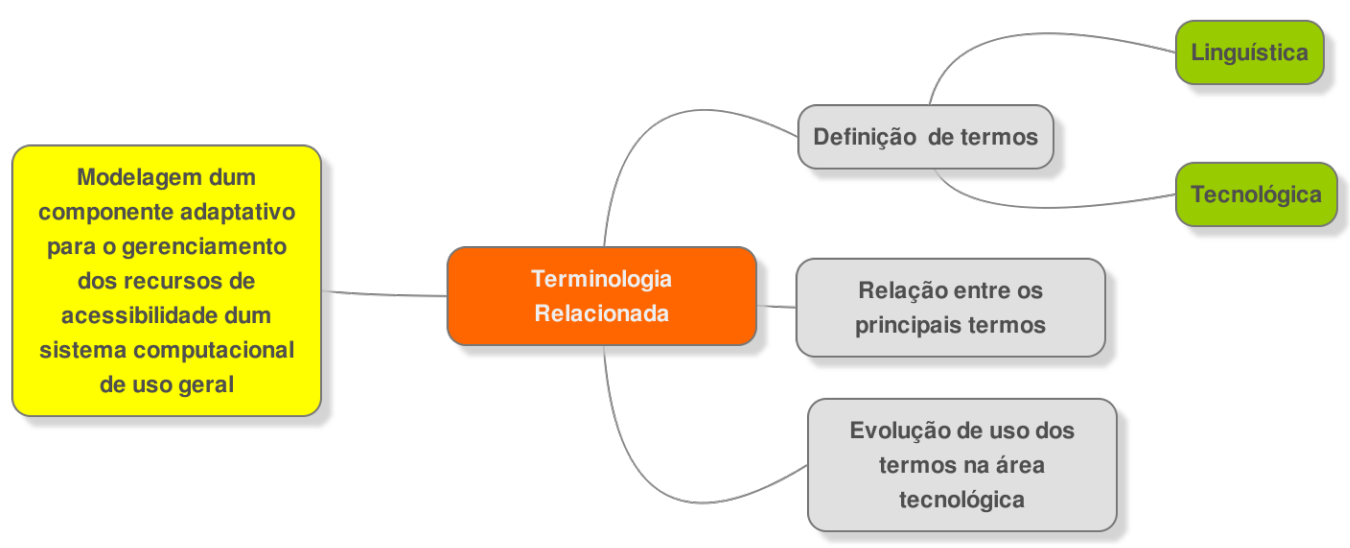

Fonte: Autora 


\section{Apêndice B - Personalização, Adaptabilidade e Adaptatividade}

A finalidade deste Anexo é fazer uma revisão das definições na literatura para os conceitos de personalização, adaptabilidade e adaptatividade a maneira de entender os seus pontos em comum assim como as principais diferenças entre eles com o objetivo de utilizar adequadamente cada um deles no contexto correspondente.

\section{DEFINIÇÕES}

Dentro da literatura relacionada ao área de Interação Humano-Computador existe uma grande quantidade de referências aos três termos que são objeto deste documento: personalização, adaptabilidade e adaptatividade. Não entanto as definições destes termos não são exclusivas desta área, muito pelo contrário, parte da dificuldade na construção de definições comuns é a abrangência de áreas do conhecimento que elaboraram suas próprias definições. Assim, desde as ciências da natureza até as engenharias, existem definições tanto gerais quanto especializadas para os três conceitos. Partiremos, então, desde a definição mais geral até chegar na área tecnológica.

\section{Personalização ou Personalization}

O dicionário Aurélio da Língua Portuguesa define "personalização"como o ato ou efeito de personalizar, que a sua vez é definido como: tornar pessoal, dar caráter original a um objeto fabricado em série, e adaptar às preferências do usuário. Já o dicionário Merriam-Webster, de Língua Inglesa, define "customize" como: mudar alguma coisa com a finalidade de ela ficar mais ajustada às necessidades ou requerimentos de uma pessoa, empresa, entre outros. $\mathrm{O}$ Collins, um outro conhecido dicionário de Língua Inglesa define "customize" como: mudar a aparência ou características de alguma coisa para ajustar-a aos seus gostos ou necessidades. Para este trabalho vamos definir de maneira geral, a personalização como o ato de mudar as características padrões de alguma coisa de acordo com as preferências ou necessidades do usuário. A personalização nasce como a necessidade de um tarefa, atividade, ferramenta, em geral um objeto, de considerar diferentes características dentro do seu ambiente de execução para se desempenhar de uma maneira adequada e atingir o objetivo para o qual foi criado. Assim, a personalização está definida de maneira básica como a aplicação de mudanças dentro de uma entidade padrão, para tornar-a adequada aos requerimentos de uma pessoa. Alguns exemplos simples e cotidianos de personalização são: fazer a bainha da calça, fazer um furo a mais no cinto, adoçar o café ao gosto, entre outros. Já na sociedade da informação na que vivemos é 
bastante fácil encontrar dentro do nosso entorno diferentes exemplos de personalização, alguns deles podem ser:

- Criar diferentes contas de usuário, cada um deles com permissões diferentes.

- A própria configuração dos telefones celulares.

- A implantação dos produtos tipo ERP dentro duma empresa.

- A configuração dos clientes de correio eletrónico.

Esses exemplos apresentam atividades de personalização de diferente nível e complexidade, mas que estão já sedimentadas como atividades regulares em seus contextos correspondentes, seja no uso de tecnologias no nível pessoal ou no nível de empresa.

\section{Adaptabilidade ou Adaptability}

O dicionário Aurélio define "adaptabilidade"como a qualidade ou capacidade do que é adaptável, e a sua vez define adaptável como alguma entidade que pode ser mudada, em alguma das suas caraterísticas, com a finalidade de ajusta-a para uma nova situação. Assim, uma entidade que possui adaptabilidade admite a possibilidade de aplicar de mudanças nas suas características padrões. Em inglês esta capacidade também têm recebido o nome de customizability.

\section{Adaptatividade ou Adaptativity}

O dicionáio Collins define "adaptivity"como a capacidade que possui alguma coisa para conseguir efetuar uma mudança a fim de se adequar a uma nova situação. Esta palavra também expressa um estado, condição, um grado ou medida de dita capacidade. Assim, uma entidade adaptativa não só tem a capacidade de aplicar mudanças nas suas características e, de fato efetua ditas mudanças, mas também é ela mesma que decide realizar essas ações.

\section{CORRELAÇÕES E PRINCIPAIS DIFERENCIAS}

Na área tecnológica existe, como mencionado em Lee, Choi e Kim (2011)), McTear (1993). a principal diferença está na origem das mudanças, assim se elas foram decisão do usuário e aplicadas no sistema trata-se de um sistema adaptável. Se pelo contrário, a origem das mudanças parte do próprio sistema então se diz que dito sistema é adaptativo. 
Uma outra diferença sutil, porém muito interessante, é a presença ou não da capacidade denominada em inglês como context-aware. Para o caso de um sistema computacional Byun e Cheverst (2001) define que context-aware é a necessidade do sistema de levar em conta diferentes parâmetros para reconhecer o ambiente de execução de dito sistema e efetuar as mudanças correspondentes na sua própria estrutura. Assim, exemplos de ditos parâmetros são: a locação de uso, a coleção de recursos próximos (pessoas, hosts, dispositivos acessíveis), assim como também as mudanças desses parâmetros ao longo do tempo. Dada esta definição é intuitivo reconhecer a necessidade deste tipo de comportamento no caso dos sistemas adaptativos. Não entanto, já não é uma exigência num sistema adaptável, pois não é ele quem deverá fazer a toma de decisões ao respeito das mudanças a serem aplicadas, o quando elas serão aplicadas.

Um resumo muito ilustrativo é dado em Fischer (2001) e apresentado na Figura 53

Figura 53 - Comparação entre características dos termos adaptável e adaptativo

\begin{tabular}{lll}
\hline & Adaptive & Adaptable \\
\hline Definition & $\begin{array}{l}\text { dynamic adaptation by the system itself to } \\
\text { current task and current user }\end{array}$ & $\begin{array}{l}\text { user changes (with substantial system } \\
\text { support) the functionality of the system }\end{array}$ \\
Knowledge & $\begin{array}{l}\text { contained in the system; projected in dif- } \\
\text { ferent ways }\end{array}$ & knowledge is extended \\
Strengths & $\begin{array}{l}\text { little (or no) effort by the user; no special } \\
\text { knowledge of the user is required }\end{array}$ & $\begin{array}{l}\text { user is in control; user knows her/his task } \\
\text { best; system knowledge will fit better; } \\
\text { success model exists }\end{array}$ \\
Weaknesses & $\begin{array}{l}\text { user has difficulty developing a coherent } \\
\text { model of the system; loss of control; few (if } \\
\text { any) success models exist (except humans) }\end{array}$ & $\begin{array}{l}\text { systems become incompatible; user must do } \\
\text { substantial work; complexity is increased } \\
\text { (user needs to learn the adaptation } \\
\text { component) }\end{array}$ \\
$\begin{array}{l}\text { Mechanisms } \\
\text { Required }\end{array}$ & $\begin{array}{l}\text { models of users, tasks, and dialogs; } \\
\text { knowledge base of goals and plans; powerful } \\
\text { matching capabilities; incremental update } \\
\text { of models }\end{array}$ & $\begin{array}{l}\text { layered architecture; domain models and } \\
\text { domain-orientation; "back-talk" from the } \\
\text { system; design rationale }\end{array}$ \\
$\begin{array}{l}\text { Application } \\
\text { Domains }\end{array}$ & $\begin{array}{l}\text { active help systems, critiquing systems, } \\
\text { differential descriptions, user interface } \\
\text { customization, information retrieval }\end{array}$ & $\begin{array}{l}\text { information retrieval, end-user } \\
\text { modifiability, tailorability, filtering, design } \\
\text { in use }\end{array}$ \\
\hline
\end{tabular}

Fonte: (FISCHER, 2001)

Já o conceito de personalization em inglês, serve para fazer referência para a capacidade dum sistema de admitir a aplicação de mudanças nas suas configurações como resposta às necessidades ou requerimentos do usuário Lee, Choi e Kim (2011), mas não indica se ditas mudanças são deitas por decisão do usuário ou por ele mesmo. Dessa maneira este termo é considerado um termo guarda-chuva para indicar quaisquer dos casos. 
Assim a Figura54 apresenta a relação entre esses três termos e a proposta de comunicar-os.

Figura 54 - Relação entre Personalização, Adaptabilidade e Adaptatividade

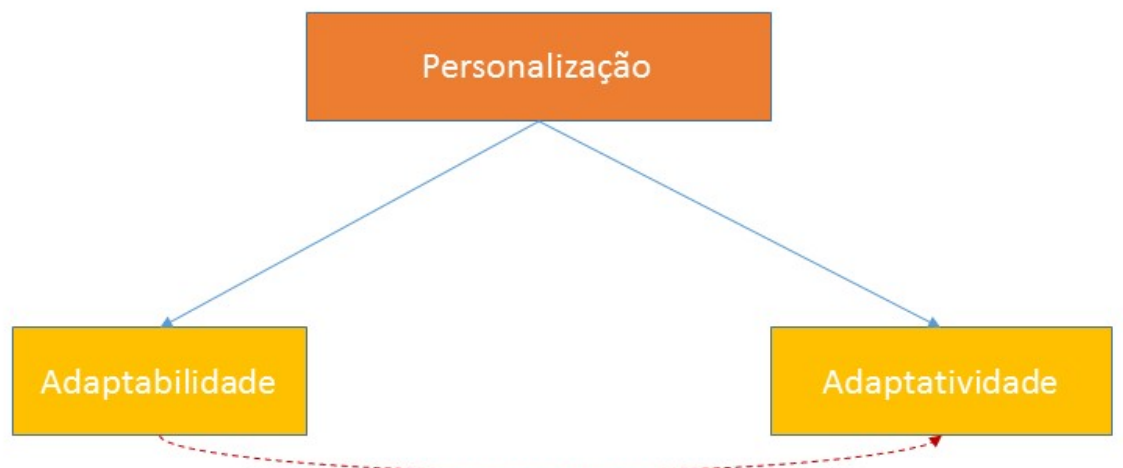

Fonte: Autora

Um fator importante a ser notado em relação a esses termos é a entidade responsável pela tomada de decisão sobre quais mudanças serão aplicadas no sistema em questão. No caso de "customização", o responsável pela decisão é o usuário do sistema, é ele que define ou indica, através de algum mecanismo, quais são as necessidades a serem cobertas. No caso de adaptabilidade, ela não afirma de maneira explícita a fonte da qual são obtidas as mudanças, ela só evidencia a capacidade do sistema de aplicar reconfigurações como consequência das mudanças no ambiente de execução do sistema. No caso de personalização, o termo indica que o usuário é a fonte da qual o sistema obtêm as mudanças a serem aplicadas, mas admite que tanto o usuário quanto o próprio sistema pode ser o responsável pela tomada de decisão. Finalmente, a adaptatividade indica de maneira explícita que o agente responsável da tomada de decisão e da execução das mudanças é o próprio sistema, mas afirma também que dita capacidade só é possível se o sistema possuir a capacidade de reconfiguração, quer dizer, adaptabilidade.

Assim é possível falar de "customização"e personalização concretizadas pela adaptabilidade, mas é conceptualmente impossível falar de "customização"concretizada por adaptatividade. 


\section{APLICAÇÃO DOS CONCEITOS DENTRO DA ÁREA TECNOLÓGICA}

Para declarar um sistema como adaptativo é preciso verificar que: (i) ele admite mudanças, (ii)que as decisões sobre quais mudanças aplicar e quando aplica-as estão sob domínio do mesmo sistema, (iii)e que esse sistema define um contexto de ação e é context-aware em dito contexto.

Já em um tom mais rigoroso em VELSEN et al. (2008) é estabelecido que um sistema adaptável utiliza dados de entrada explícitos para ajustar suas saídas, enquanto um sistema adaptativo ajusta suas saídas utilizando inferências implícitas com base na interação com o usuário.

Assim mesmo, alguns autores, como em McTear (1993), indicam que fornecer ambas as abordagens, adaptável e adaptativa, poderia permitir guiar ao usuário na participação dentro do processo de personalização do sistema de maneira ativa mas não direta.

\section{DEFINIÇÕES E TERMINOLOGIAS CORRELATAS}

Nesta seção são apresentados os termos frequentemente usados na literatura para descrever entidades que possuem comportamentos que admitem mudanças dinâmicas.

\section{Reconfigurável, autoconfigurável, y configuração dinâmica}

O termo "sistema reconfigurável"é amplamente conhecido na área de design de componentes de hardware, especificamente FPGAs (Field Programable Gates Array), pelo qual a maioria dos resultados das pesquisas com esse termo estão relacionados com trabalhos nas áreas de arquitetura de computadores e aplicativos de software especializados no aproveitamento das capacidades de hardware para melhorar o desempenho no cômputo de alguns tipos de informações.

O termo "reconfiguração dinâmica"se refere à reconfiguração de algum dispositivo em tempo de execução, mas que não necessariamente com suporte de software, o próprio usuário pode realizar dita mudança.

O termo autoconfiguração só implica a capacidade de um sistema de realizar de maneira autónoma as mudanças correpondentes com alguma regra de execução. 
172

\section{Auto-ajustável, auto-modificável, de alteração dinâmica}

A computação auto-ajustável se refere ao modelo computacional no qual os cômputos se ajustam a qualquer mudança externa em seus dados automaticamente com a finalidade de fornecer uma melhora no desempenho das tarefas a serem executadas. Por outro lado, os termos "de alteração dinâmica"e "auto modificável"estão mais relacionados com a característica dum programa de efetuar alterações no seu próprio código. Algumas das linguagens de programação que permitem a escrita deste tipo de código são chamadas linguagens dinâmicas.

\section{Sistemas auto-adaptativos}

O termo sistemas auto-adaptativos, ou Self-adaptive System(SaS), se refere aos sistemas computacionais que são autónomos na decisão e aplicação de mudanças nas suas próprias configurações com a finalidade de desempenhar de maneira bem-sucedida a tarefa para a qual foi desenvolvido, superando as possíveis dificuldades introduzidas no ambiente de execução. Este termo é relativamente recente e corresponde especificamente à área de Engenharia de Software. 


\section{Apêndice C - O Mecanismo PnP}

O mecanismo Plug-and-Play (conectar e brincar) é definido dentro da documentação oficial no site da Microsoft como:

"Um suporte de hardware e software que permite a um sistema de computador reconheça e se adapte às mudanças nas configurações de hardware com pouca ou nenhuma intervenção do usuário. O usuário pode incorporar e remover dispositivos num sistema de computador sem ter que fazer configurações manuais incomodas ou confusas, e sem ter que possuir conhecimento dos complexos dispositivos de hardware."

Assim o mecanismo Plug-and-Play, em adiante textitPnP, fornece o suporte necessário para a adaptação no nível de recursos de hardware de um sistema de computador durante sua própria execução.

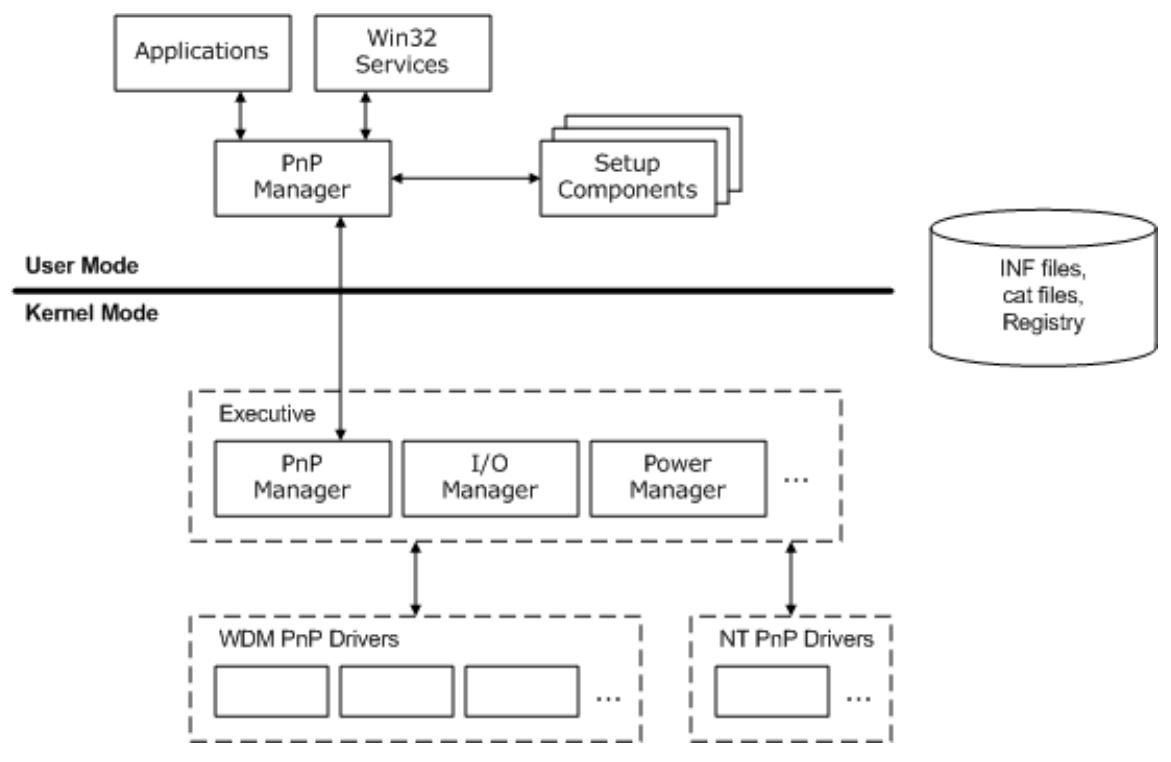

\section{INCORPORAÇÃO DE UM NOVO RECURSO PNP}

Durante a incorporação de um novo elemento hardware que suporta o mecanismo $\mathrm{PnP}$ são executadas as seguintes ações:

1. O usuário insere um dispositivo periférico dentro do sistema através de alguma porta de hardware.

2. O sistema, especificamente o Bus Driver para a comporta onde foi inserido o dispositivo, reconhece a existência de um novo componente hardware. 
174

3. O Function Driver correspondente ao bus [da comporta] onde foi incorporado o dispositivo notifica ao PnP Manager que ocorreu uma mudança nos dispositivos relacionados com ele.

4. O PnP Manager consulta os Bus Drivers associados à comporta para obter a lista dos dispositivos correntes presentes no sistema.

Para atingir esse objetivo o PnP Manager envia uma IRP (I/O Request Packet) para o topo da pilha de dispositivos que o Bus tem associada. De acordo com a documentação e o Protocolo Padrão do PnP, cada um dos Device Drivers na pilha trata a IRP (se for pertinente) e depois propagar a IRP para o próximo Device Driver da pilha.

5. Em resposta cada Device Driver devolve um PDO (Peripheral Device Object) correspondente com o dispositivo que suporta. Neste momento é assignado para cada dispositivo uma enumeração que permite sua identificação no sistema.

6. O PnP Manager faz uma comparação entre a informação recuperado dos drivers e a árvore de dispositivos armazenada para o bus no sistema. Logo, ele incorpora os nós correspondentes aos novos dispositivos no sistema e remove aqueles que foram retirados.

7. O PnP Manager colhe as informações sobre os novos dispositivos e começa configura-os. Para efetuar a coleta das informações o PnP Manager envia um conjunto de IRP's para a pilha de dispositivos associados ao bus. Logo, o PnP Manager armazena ditas informações no registro, sob a subkey <instancelD>, se ela não estiver criada ele cría a estrutura correspondente dentro do registro.

As informações que o $\operatorname{PnP}$ Manager armazena são:

- DeviceDesc: obtida da IRP_MN_QUERY_DEVICE_TEXT

- Location: obtida da IRP_MN_QUERY_DEVICE_TEXT

- Capabilities: as bandeiras da IRP_MN_QUERY_CAPABILITIES

- UINumber: obtida da IRP_MN_QUERY_CAPABILITIES

- HardwarelD: obtida da IRP_MN_QUERY_ID

- CompatibleIDs: obtida da IRP_MN_QUERY_ID

- ContainerID: obtida de IRP_MN_QUERY_ID

- LogConf $\backslash$ BootConfig: obtida da IRP_MN_QUERY_RESOURCES

- LogConf BasicConfigVector: obtida da IRP_MN_QUERY_RESOURCE_REQUIREMENTS 
8. Neste estágio o PnP Manager é capaz de procurar e carregar o Function Driver e os Filter Drivers correspondentes para cada um dos dispositivos. Para isso o PnP Manager no Kernel-mode coordena com o PnP Manager no User-mode e os componentes que assitem o sistema operacional nas tarefas de configuração desde o User-mode para encontrar os drivers correspondentes com o dispositivo corrente. As seguintes ações são executadas com esse fim:

- O PnP Manager no Kernel-mode registra uma nova instância na fila de eventos a serem processados pelo PnP Manager no User-mode identificando o dispositivo que precisa ser instalado.

- o PnP Manager no User-mode solicita o ingresso no sistema de um usuário com privilégios para fazer as mudanças necessárias.

- Os componentes que assistem ao sistema operacional nas suas configurações procuram pelos drivers correspondentes com o Vendor ID ou com algum dos CompatibleID registrados para o dispositivo.

9. Os componentes de configuração nUser-mode guiam o PnP Manager no Kernel-mode para carregar os Filter Drivers (se tiver) e o Function Driver do dispositivo. Assim, primeiro são carregados os Lower-Filter Drivers, se existirem para o dispositivo, depois será carregado o Function Driver, e finalmente os Upper-Filter Driver, se existir algum. Se o driver para o dispositivo não foi carregado previamente no sistema (por exemplo, em alguma outra ocasião quando o dispositivo foi conectado) o $P n P$ Manager chama à rotina DriverEntry e carrega o driver que faz falta. Além disso o PnP Manager inicializa o o dispositivo chamando a rotina AddDevice para criar o FDO(Functional Device Object).

10. O PnP Manager assigna recursos ao dispositivo, já identificado e registrado no sistema. Primeiro, ele envia uma IRP para obter a lista de recursos requeridos pelo dispositivo. Depois, ele assigna os recursos do sistema de acordo tanto com os requerimentos do dispositivo como com os recursos disponíveis no instante corrente no sistema.

11. O PnP Manager inicializa o dispositivo

12. Para finalizar o processo de incorporação de um novo dispositivo no sistema o PnP Manager envia mais três IRP:

- IRP_MN_QUERY_CAPABILITIES

- IRP_MN_QUERY_PNP_DEVICE_STATE

- IRP_MN_QUERY_DEVICE_RELATIONS 


\section{Apêndice D - Exemplo do arquivo XML relacionado ao Componente de interação com o Usuário}

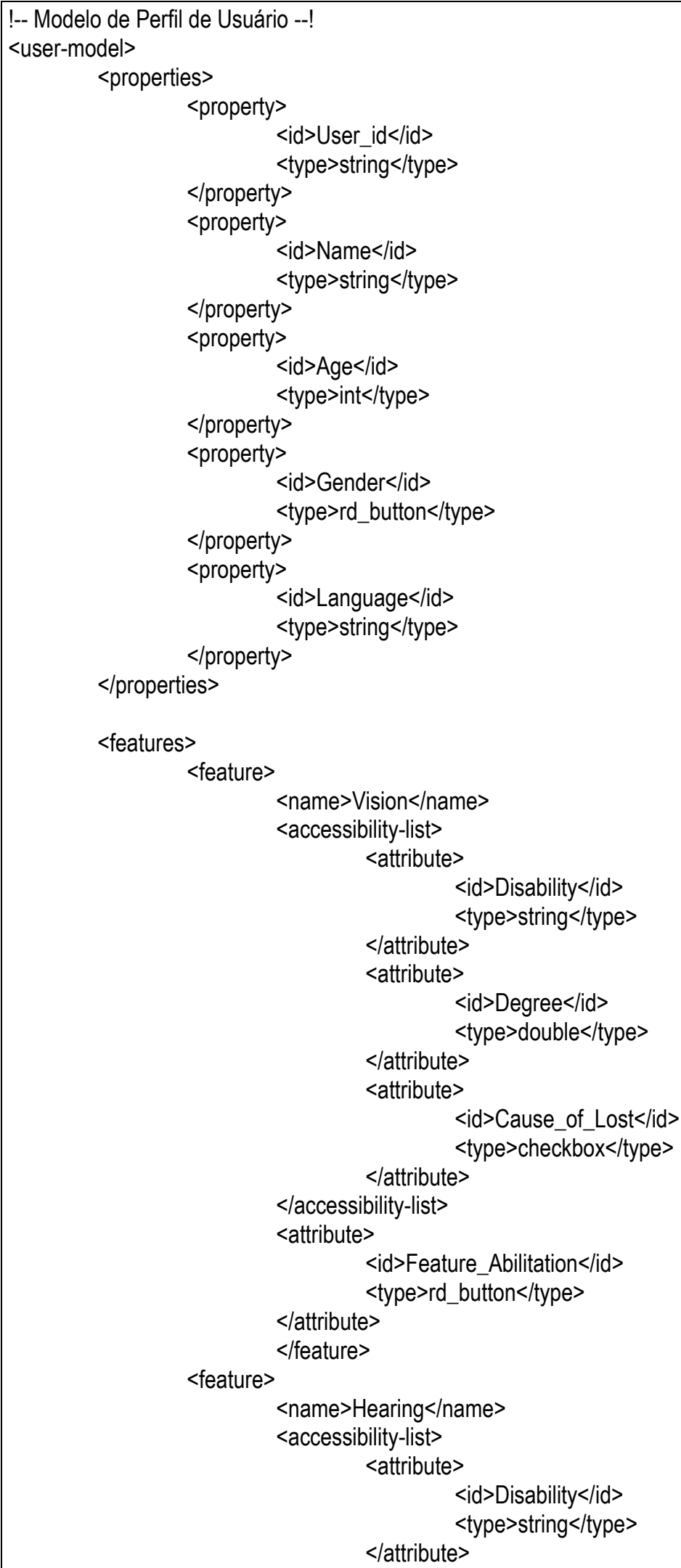


177

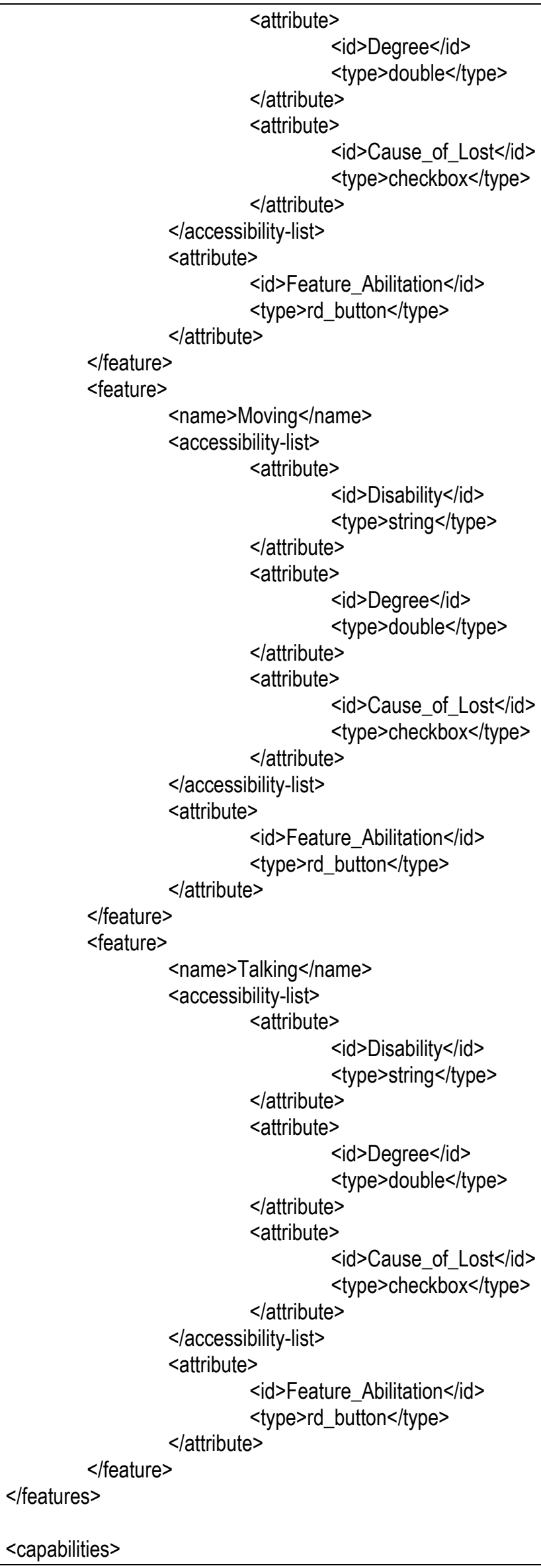




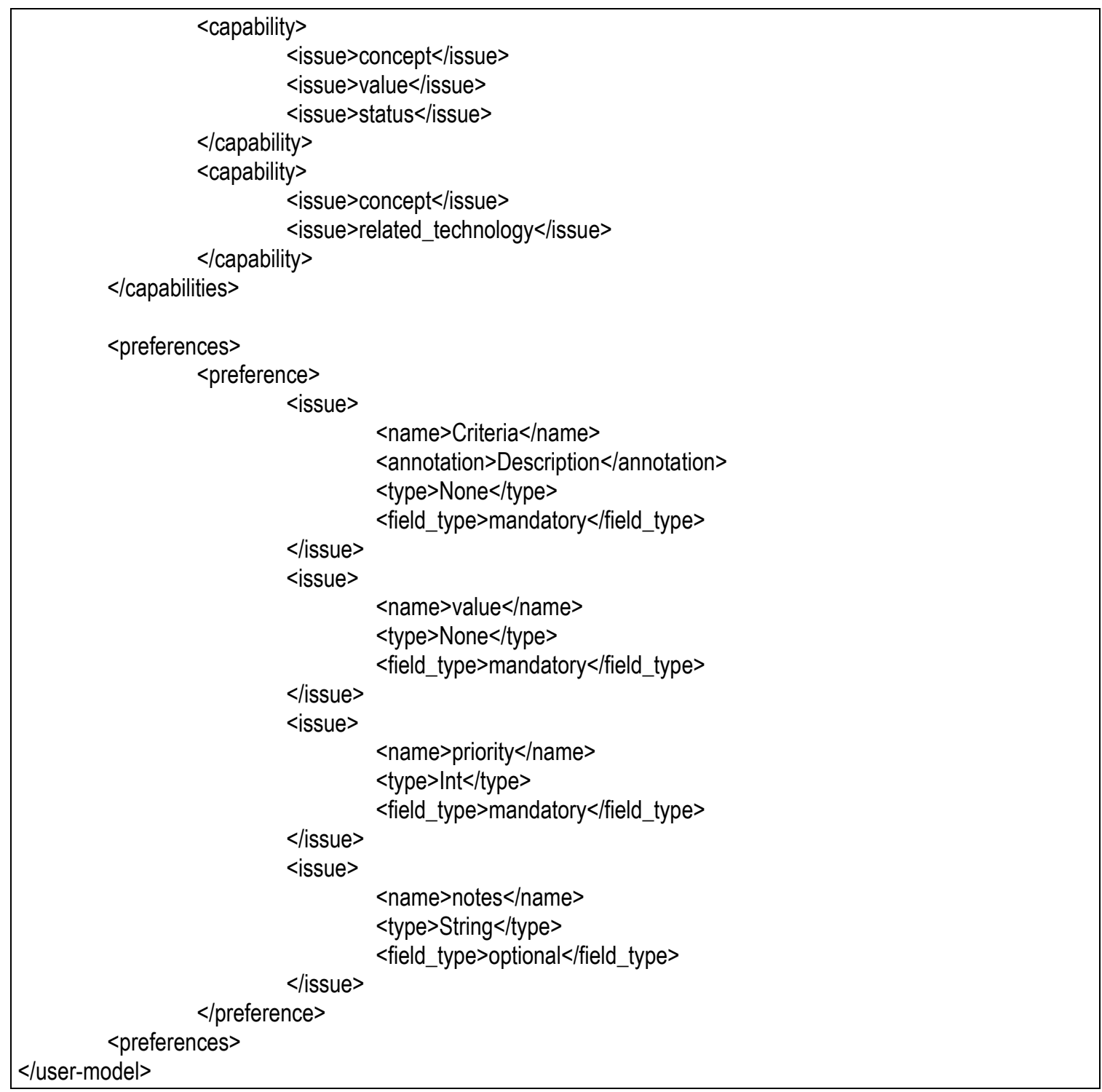


Apêndice $E$ - Exemplo dos arquivos XML relacionados ao Componente de interação com o Sistema Operacional 


\section{Apêndice E - Exemplo do arquivo XML relacionado ao Componente de interação com o Sistema Operacional}

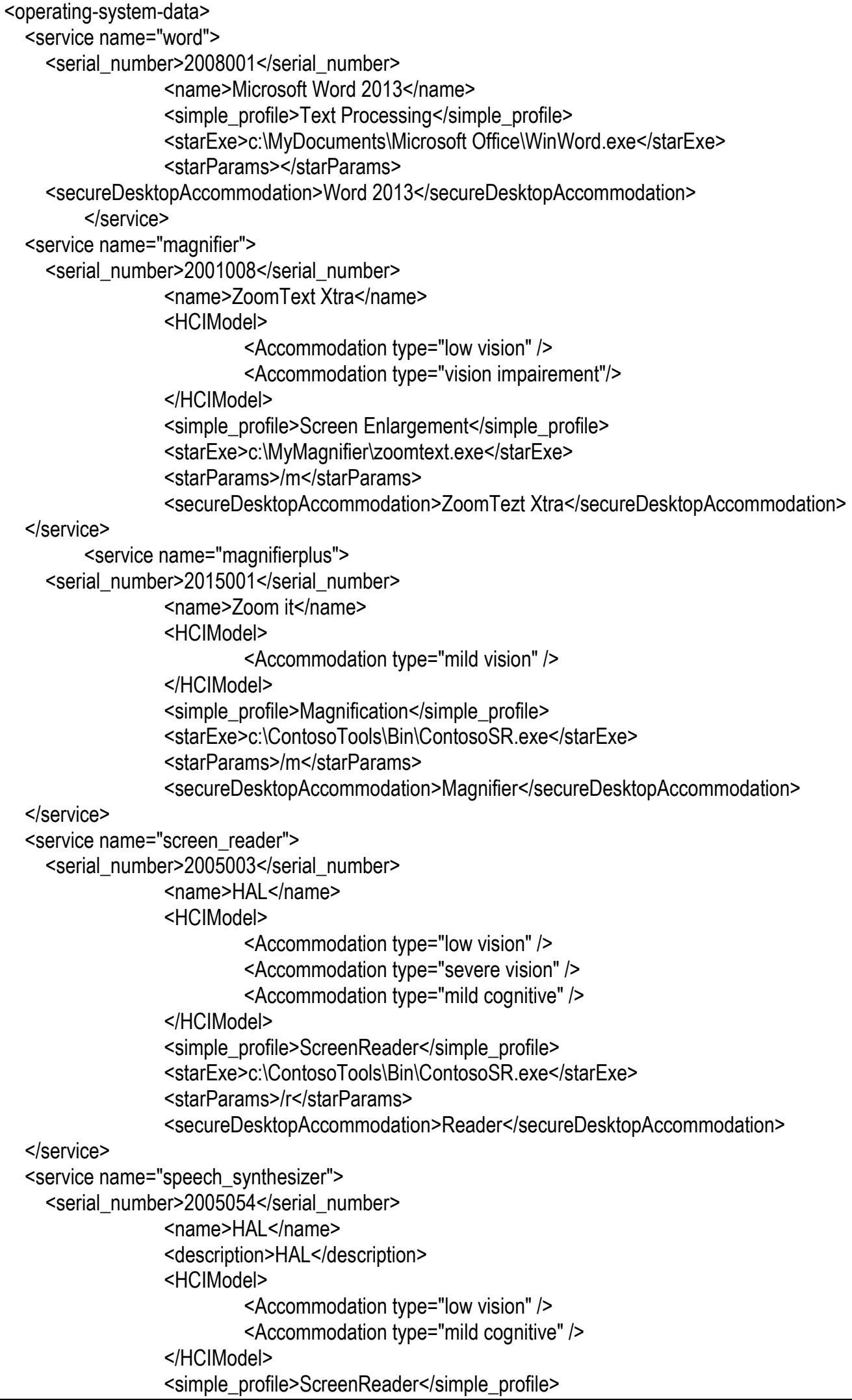


<starExe>c:IContosoTools|Bin|ContosoSR.exe</starExe>

$<$ starParams $>/$ n $</$ starParams $>$

$<$ service $>$

<secureDesktopAccommodation>Narrator</secureDesktopAccommodation>

$</$ operating-system-data $>$ 


\section{Apêndice E - Exemplo do arquivo XML relacionado ao Componente de interação com o Ambiente de Execução}

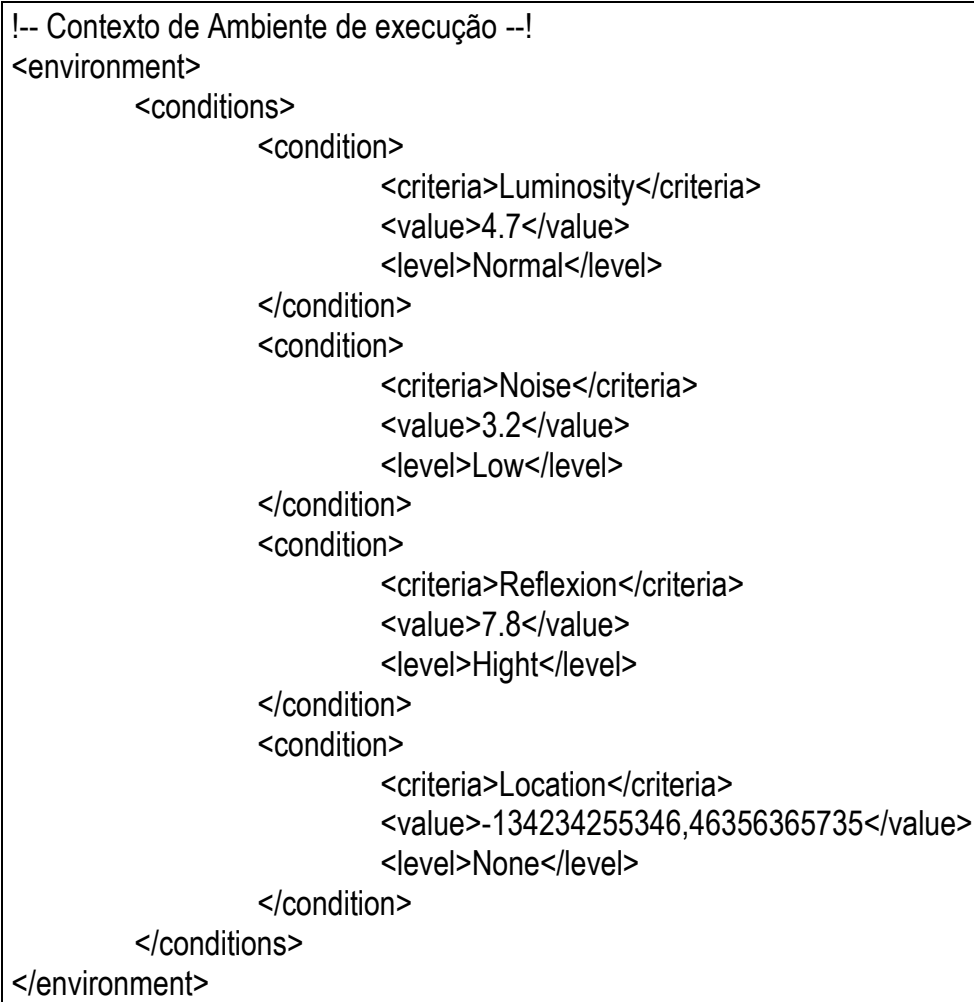

